\title{
AEROSOL SAMPLING STRATEGY: Effect of Particle Transfer to Sampler Covers and Estimation of Conversion Factors between the United States and German Methods for Quartz sampling
}

\author{
Godwin Akpevwe Erekaife
}

West Virginia University, gerekaif@mix.wvu.edu

Follow this and additional works at: https://researchrepository.wvu.edu/etd

Part of the Epidemiology Commons, and the Occupational Health and Industrial Hygiene Commons

\author{
Recommended Citation \\ Erekaife, Godwin Akpevwe, "AEROSOL SAMPLING STRATEGY: Effect of Particle Transfer to Sampler \\ Covers and Estimation of Conversion Factors between the United States and German Methods for Quartz \\ sampling" (2021). Graduate Theses, Dissertations, and Problem Reports. 10226. \\ https://researchrepository.wvu.edu/etd/10226
}

This Dissertation is protected by copyright and/or related rights. It has been brought to you by the The Research Repository @ WVU with permission from the rights-holder(s). You are free to use this Dissertation in any way that is permitted by the copyright and related rights legislation that applies to your use. For other uses you must obtain permission from the rights-holder(s) directly, unless additional rights are indicated by a Creative Commons license in the record and/ or on the work itself. This Dissertation has been accepted for inclusion in WVU Graduate Theses, Dissertations, and Problem Reports collection by an authorized administrator of The Research Repository @ WVU. For more information, please contact researchrepository@mail.wvu.edu. 


\title{
AEROSOL SAMPLING STRATEGY: Effect of Particle Transfer to Sampler Covers and Estimation of Conversion Factors between the United States and German Methods for Quartz sampling
}

\section{GODWIN A. EREKAIFE}

\author{
Dissertation submitted to the \\ Statler College of Engineering and Mineral Resources \\ at West Virginia University \\ in partial fulfillment of the requirements for the degree of \\ Doctor of Philosophy in

\section{OCCUPATIONAL SAFETY AND HEALTH} \\ Dr. Jeremy Gouzd, Ph.D., Chair \\ Dr. Eun Gyung (Emily) Lee, Ph.D. \\ Dr. Gary Winn, Ph.D. \\ Dr. Michael McCawley, Ph.D. \\ Dr. Michael Kashon, Ph.D. \\ Dr. Warren Myers, Ph.D.
}

Department of Industrial and Management Systems Engineering

Morgantown, West Virginia

2021

Keywords: quartz, aerosols, dust samplers, particle migration, XRD, IR, IFA, dose estimation, aerosol chamber, spiked samples

Copyright 2021 Godwin Erekaife 


\section{ABSTRACT \\ AEROSOL SAMPLING STRATEGY: Effect of Particle Transfer to Sampler Covers and Estimation of Conversion Factors between the United States and German Methods for Quartz sampling}

\section{GODWIN A. EREKAIFE}

In many countries, communities of experts, including industrial hygienists, have developed unique sampling strategies to determine workers' exposure to aerosolized particles (e.g., metals, wood dust etc.). However, using different sampling and analytical methods for the same chemical often results in different exposure levels for a similar exposure group (SEG). The exposure discrepancies among different countries that are caused by using different measurement strategies are not always systematically defined. Therefore, this study investigates aerosol sampling strategies in two parts: 1) the potential for particle loss to the sampler covers during sample transportation to improve sampling methodology and prevent underestimation of mass concentrations (Chapter 2) and 2) determining the relationship between exposure measurements of respirable crystalline silica (RCS) using the U.S. measurement strategy (NIOSH method) and the German strategy (IFA method), and to develop a conversion factor (or equation) to adjust for differences (Chapter 3 ). Below is a result summary of the investigation.

Effects of particle transfer to the covers of aerosol samplers during transportation: Wood dust samples were collected in a sanding chamber using four different samplers: closedface cassettes (CFC), CFC with Accu-CAP'M inserts, disposable inhalable samplers (DIS), and Institute of Occupational Medicine (IOM). Welding fumes were collected in a walk-in chamber using the same samplers, with Solu-Sert ${ }^{\text {tm }}$ replacing Accu-CAP. The samples were divided into two groups, with one group transported by air and the other by land. They were returned in the same manner and analyzed gravimetrically for wood dust and chemically for welding fumes. For wood dust, IOM showed a significantly higher percentage of particles transferred to the covers compared with the other samplers regardless of the transportation mode, while other samplers 
did not. For the welding fumes samples, most samples showed nondetectable amounts of the analyte on the covers. Overall, this study confirms that particle transfer to sampler covers during transport highly depends upon the transportation mode, particle size ranges, and the sampler type for wood dust, whereas particle transfer seems minimal for welding fumes. Although the findings of this study are based on two materials and limited sample sizes, occupational professionals should account for this transfer when handling and analyzing samples in practice.

\section{Estimation of conversion factors between the United States and German methods for} quartz sampling: This study compared the sampling and analytical methods of each country to determine RCS exposures in three ways: 1) spiked sample analysis, to verify the differences between both countries' analytical methods, 2) environmental chamber study, where side-byside samples were collected under environmentally controlled conditions to determine the differences of samplers along with the analytical difference, and 3) field study, to determine the impact of uncontrolled environmental conditions and unknown workplace characteristics on the results by each method. Overall, differences between the two country's methods were observed and the calculated conversion factor was 0.71 when converting RCS concentrations from GK2.69 to FSP-10 cyclones using infrared spectroscopy (IR). The findings of this study will fill the knowledge gap associated with exposure discrepancies between two countries that are caused by using different measurement strategies. Most importantly, by using the outputs of this study, larger databases can be created from several smaller repositories of existing data and can be exploited to determine long-term exposure trends and evaluate exposure control methods. Finally, the application of the findings would not be limited to just these two countries but can extend to other countries that have adopted either NIOSH or IFA methods. 


\section{Contents}

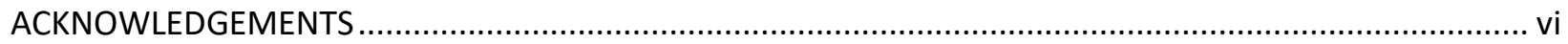

LIST OF PUBLICATION AND CONFERENCE PRESENTATIONS ........................................................... viii

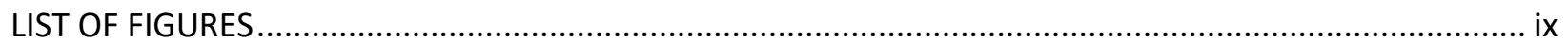

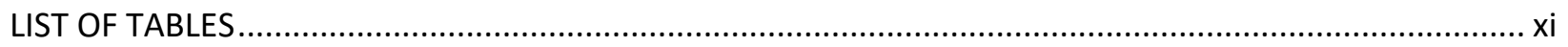

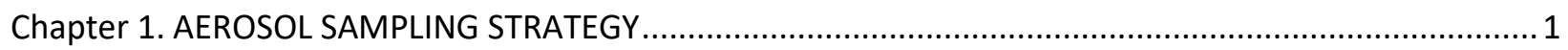

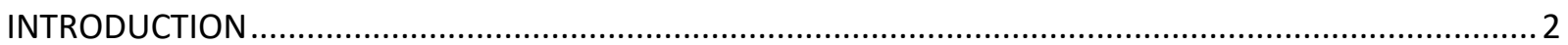

Chapter 2. AEROSOL SAMPLING STRATEGY I: EFFECT OF PARTICLE TRANSFER TO SAMPLER COVERS

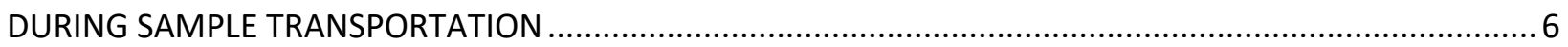

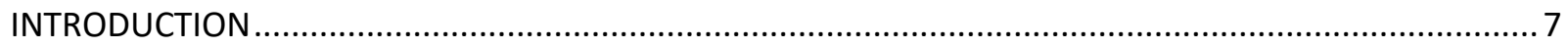

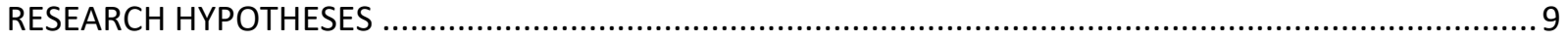

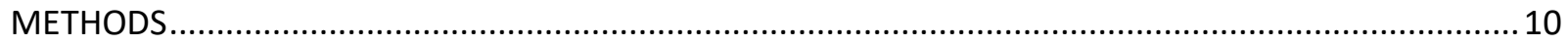

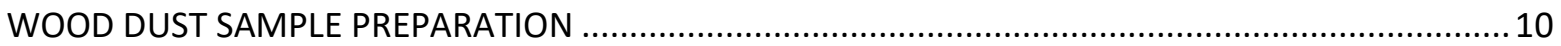

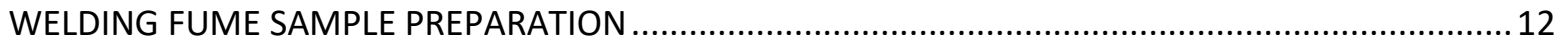

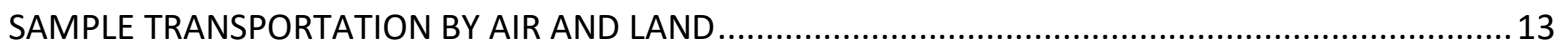

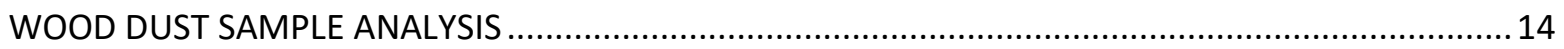

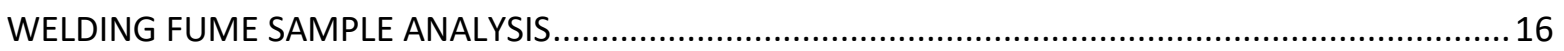

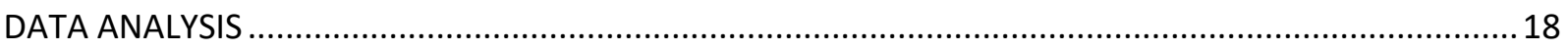

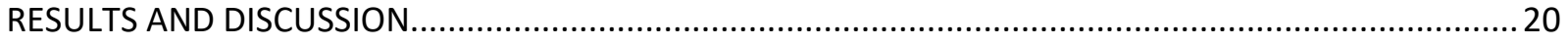

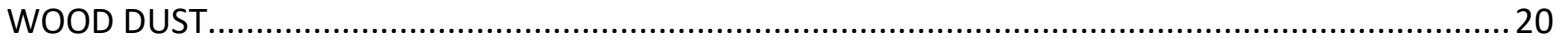

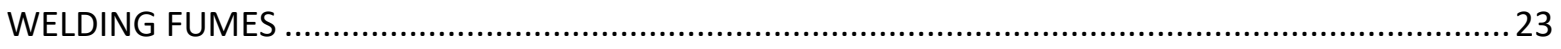

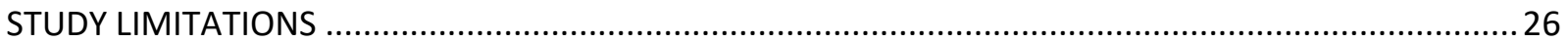

Chapter 3. AEROSOL SAMPLING STRATEGY II: ESTIMATION OF CONVERSION FACTORS BETWEEN THE UNITED STATES AND GERMAN METHODS FOR QUARTZ SAMPLING .................................................27

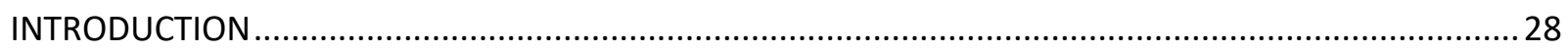

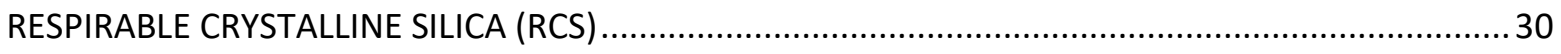

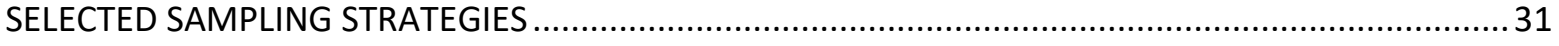

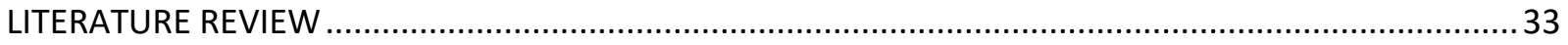

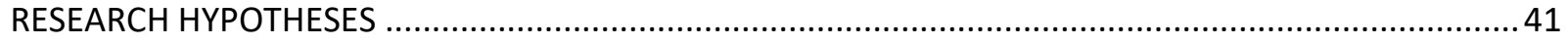

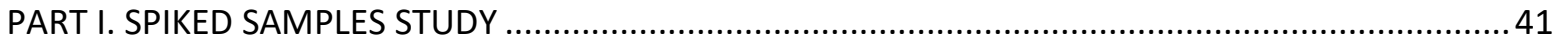

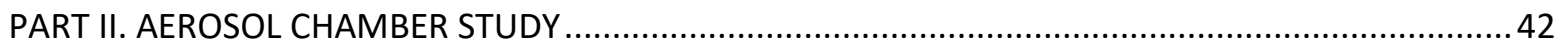




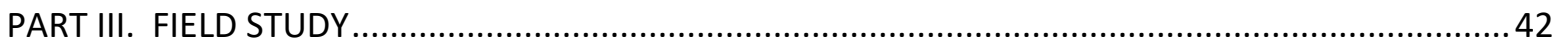

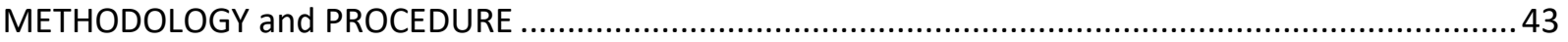

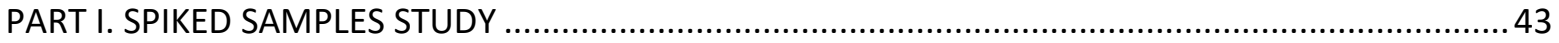

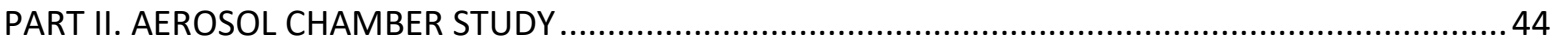

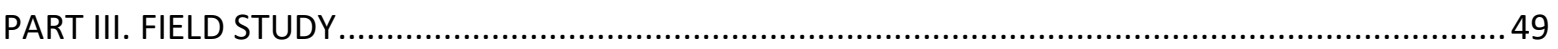

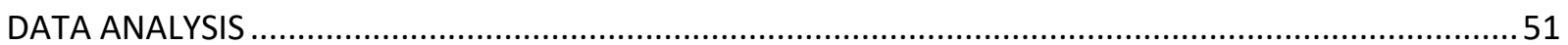

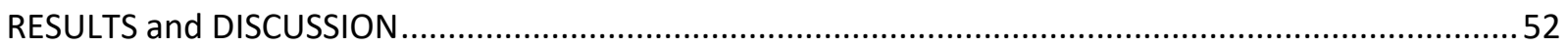

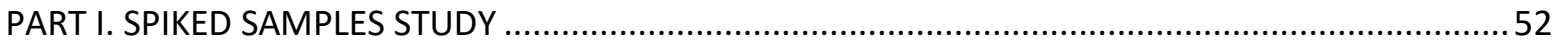

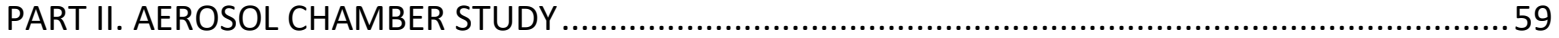

A NOTE ON SIZE -SELECTIVE COLLECTION EFFICIENCY OF RESPIRABLE SAMPLERS.............................75

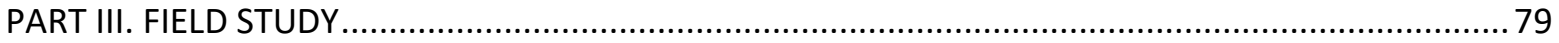

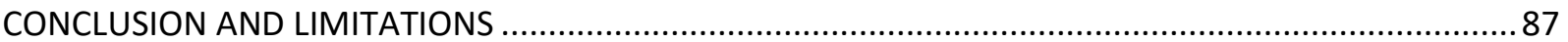

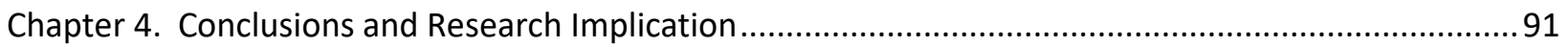

AEROSOL SAMPLING STRATEGY I: Effect of Particle Transfer to Sampler Covers during Sample Transportation

AEROSOL SAMPLING STRATEGY II: Estimation of Conversion factors between US and German

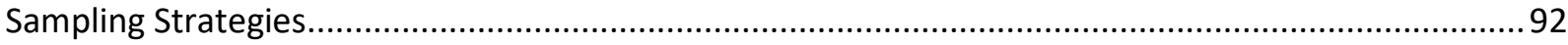

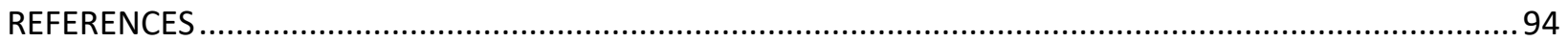

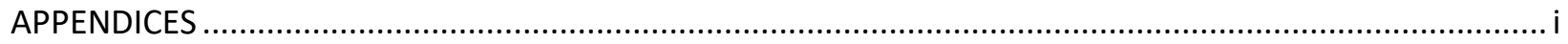

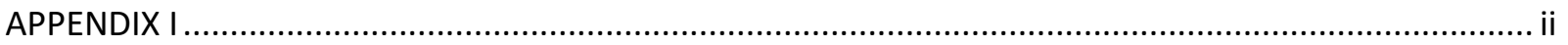

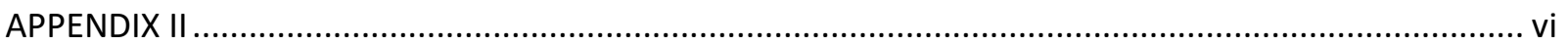

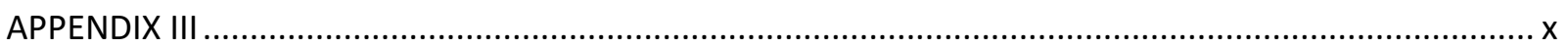

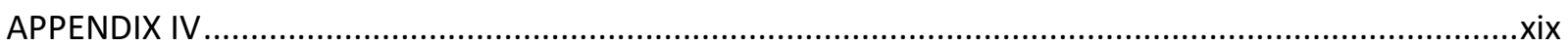

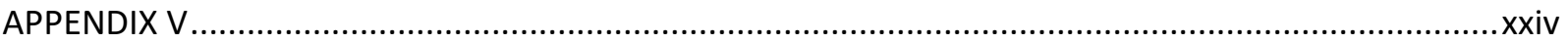

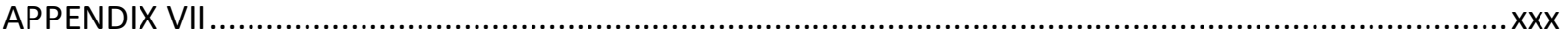




\section{ACKNOWLEDGEMENTS}

I will start by thanking the people who were here before I even started thinking about doing a doctoral dissertation. These are my personal and most important relationships, my Mom and Dad, and all of my brothers and sisters, who offered assistance in ways they're unaware of, even when they didn't know what I was doing- Juliette, Tega, Ochuko, Arho, BKO,

\section{Mega, TJ and Sunshine.}

I would also like to thank my committee for their special connection to this project in varying ways. Dr. Winn brought me into the program and has been there from the beginning. He was my original chair. I hope I wasn't the one that drove him into retirement. I like to think he was going to do it anyways. Dr. Gouzd took over chairmanship under quite unusual circumstances and could not have been more gracious with the advice and assistance he gave to me. Dr. Myers was also kind enough to step into the committee and has been generous with both research and career advice, as has Dr. Kashon, so has not only helped with my statistical analysis but his calm demeanor was also quite settling.

Sometimes people in my position will say of their committee members "I couldn't have written this dissertation without you". While that's a very gracious expression of gratitude, we mostly understand it to be quite hyperbolic. However, it is literally true in my case for both Dr. McCawley and Dr. Lee. Dr. McCawley introduced me to the site where I took my field samples. It was the best possible place to sample. They were welcoming and open with lots of volunteer employees willing to participate in sampling. I also got paid for the work when I probably would have done it for free. I like to think Dr. McCawley's relationship with them had something to do with that.

And of course, Dr. Lee has been the backbone and engine for this enterprise. She's taught me almost everything I know about research and most of the practical non-theoretical things I know about IH. She has literally read every single word in this 150-page document, and for your feedback, guidance, encouragement and overall goodwill, I thank you very much. 
There are also those whose help has been immeasurable but don't fit easily into any of the above categories. Rachel Hamm, my beautiful and wonderful girlfriend. Your love and support were beyond what I had the right to expect. From the other side of the world, HaeDong Park and Juwoon, researchers from Korea that taught me practical laboratory techniques that saved me an enormous amount of time in the lab. Dr. Jennifer Ripley, who I believe is now the boss I've had the longest. You not only taught me how to manage myself in front of a classroom of student, but your career advice meant more that you probably realized. Of course, Ron, Dianne, Chad, Andrea, Edward, you're not just honorable mentions, you are honorable people.

And finally, to all the good people that were patient and kind enough to put on a sampler for 6 hours of your already unbearably hot shift. I realize it was not a pleasant 6 hours. You didn't do it for money or fame, but for a variety of reasons, not the least of which was to help a pesky graduate student. Please know that your endurance and cooperation has pushed the IH field forward, however imperceptible that forward progress may look from our current vantage point. 


\section{LIST OF PUBLICATION AND CONFERENCE PRESENTATIONS}

\section{PUBLICATION:}

1. Godwin Erekaife, Hae Dong Park, Michael L. Kashon, William P. Chisholm \& Eun Gyung Lee (2021): Investigation of particle transfer to sampler covers during the transportation of samples, Journal of Occupational and Environmental Hygiene, DOI:

10.1080/15459624.2021.1926467 Pages 295-304

To link to this article: https://doi.org/10.1080/15459624.2021.1926467

\section{CONFERENCE PRESENTATIONS:}

1. International Occupational Hygiene Association (IOHA) 2021, 11-15 September 2021| Daegu, Korea (Virtual)

a. Effect of Particle Transfer to Sampler Covers on Mass Concentrations of Airborne Particles during the Transportation of Samples

i. Nominated for Abstract Award

b. Comparison of Sampling Strategy between the United States and Germany for Measuring Respirable Crystalline Silica

2. American Industrial Hygiene Conference \& Exposition (AlHce) 2021, May 24-26, 2021| Dallas, Texas (Virtual)

a. Developing Conversion Factors between the United States \& Germany Sampling Methodologies for Measuring Respirable Crystalline Silica

i. First Place: Best in Show Awards

ii. First Place Student Poster Award: AlHA Leadership and Management Committee (Volunteer Group)

3. American Industrial Hygiene Conference \& Exposition (AlHce) 2020, June 1-3, 2020 | Atlanta, Georgia (Virtual)

a. INVESTIGATION OF DUST MIGRATION CAUSED FROM THE TRANSPORTATION OF SAMPLES

i. First Place: AlHA Aerosol Technology Committee (Volunteer Group)

4. Great Minds in Stem (GMiS) 2021, October 11-22, 2021| Virtual

a. Respirable Crystalline Silica: Developing Conversion Factors Between the United States \& German Sampling Strategy 


\section{LIST OF FIGURES}

Figure 2. 1. Four commercially available samplers for wood dust and welding fumes. A: AccuCAP $^{\mathrm{TM}}$ (or Solu -Sert ${ }^{\mathrm{TM}}$ ), B: Disposable inhalable sampler (DIS), C: Institute of Occupational Medicine (IOM), and D: Closed-face cassettes (CFC). 11

Figure 2. 2. Sampling and Analytical Procedure. Wood Dust and Welding Fumes samples collected, transported and analyzed. 15

Figure 2. 3. Wood Dust particle transfer for IOM sampler after air transport...... 20

Figure 2. 4. Percentage of mass loadings on the sampler covers. Data with less than LOD treated with the LOD/V2. 23

Figure 2. 5. Percentage of mass loadings on the sampler covers with the corresponding total mass loadings.

Figure 3. 1. Aerosol Test Chamber. Seven sets of side-by-side samplers were placed to collet aerosolized particles (Arizona Road Dust and MIN-U-SIL ${ }^{\circledR} 10$ ) generated via a fluidized bed aerosol generator. 44

Figure 3. 2. Cyclones Samplers used for the study. 45

Figure 3. 3. Sample collection and distribution of samples to each lab..... 48

Figure 3. 4. Sampler placement on a volunteer employee

Figure 3. 5. Near Field area sampling stations at the Silo House (Left) and Pressure Casting (Right)

Figure 3. 6. Summaries for the spiked samples analyzed by the US and German labs (Mass level in $\mu \mathrm{g}: 20,50,100,250$, and 500) Each box plot represents the minimum, 25th, 50th (median), 75th percentiles, and maximum (" $\mathrm{x}$ " is mean and dots are individual data points). 54 Figure 3. 7. Comparison of analytical methods (NIOSH 7602 vs. NIOSH 7500; IFA 213-582 vs. NIOSH 7500; and IFA 213-582 vs. NIOSH 7602) with NIST Spiked Samples. Analyzed by A) US (NC) lab and B) German (IFA) labs (only IFA 213-582 vs. NIOSH 7602). 55

Figure 3. 8. Comparison of quartz masses between both US (NC) and German (IFA) labs......... 56 Figure 3. 9. Respirable mass concentrations of ARD analyzed by the US (NC) and German (IFA) labs. 60 
Figure 3. 10. RCS concentrations of ARD analyzed by the US (NC) and German (IFA) labs. 61

Figure 3. 11. Ratio of RCS (Quartz) concentrations to the corresponding respirable mass concentrations (ARD) 63

Figure 3. 12. Figure 3. 12. Comparison of different sampling and analytical methods (NIOSH 7602 vs. NIOSH 7500; IFA 213-582 vs. NIOSH 7500; and IFA 213-582 vs. NIOSH 7602) with ARD data. Analyzed by A) US (NC) lab and B) German (IFA) labs. 64

Figure 3. 13. Comparison of RCS concentrations between the US (NC) lab and the German (IFA) lab.

Figure 3. 14. Respirable mass concentrations of MIN-U-SIL ${ }^{\circledR} 10$ analyzed by the US (NC) and German (IFA) labs.

Figure 3. 15. RCS concentrations of $\mathrm{MIN}-\mathrm{U}-\mathrm{SIL}^{\circledR} 10$ analyzed by the US (NC) and German (IFA) labs.

Figure 3. 16. Ratio of RCS (Quartz) to the corresponding respirable mass concentrations (RCS/RMC)

Figure 3. 17. Comparison of different sampling and analytical methods (NIOSH 7602 vs. NIOSH 7500; IFA 213-582 vs. NIOSH 7500; and IFA 213-582 vs. NIOSH 7602) with MIN-U-SIL ${ }^{\circledR} 10$ data. Analyzed by A) US (NC) lab and B) German (IFA) labs. 72

Figure 3. 18. Comparison of RCS concentrations between the US (NC) lab and the German (IFA) lab. 72

Figure 3. 19. Bias (\%) when using ARD and MIN-U-SIL ${ }^{\circledR} 10$ as an estimate of alveolar. 77 Figure 3. 20. Ratio of RCS concentrations to the corresponding respirable mass concentrations (personal samples). 81

Figure 3. 21. Comparison of RCS concentrations between methods: a) FSP-10 FS vs. GK2.69 FS, b) FSP-10 1stS vs. FSP-10 2ndS c) FSP-10 1stS vs. GK2.69 FS d) FSP-10 2ndS vs. GK2.69 FS....... 82 Figure 3. 22. Comparison of RCS concentrations between methods: NIOSH Method $7602 \mathrm{v}$. NIOSH Method 7500; IFA 213-582 v. NIOSH 7500; and IFA 213-582 v. NIOSH 7602................. 84 Figure 3. 23. Comparison of RCS concentrations for combined personal and area exposures ... 85 


\section{LIST OF TABLES}

Table 2. 1. Overall Research Hypothesis......

Table 2. 2 Summary of total mass sampled, and percentage transferred to sampler cover by

transportation method (Wood Dust). 21

Table 2. 3. Summary of particle mass sampled and transferred to the sampler covers (Cu) ...... 24

Table 2. 4. Summary of particle mass sampled and transferred to the sampler covers (Mn) ..... 24

Table 3. 1. Summary of RCS Sampling and Analytical Methods.... 32

Table 3. 2. Converting Chinese 'Total Dust' Measurements to Respirable Concentrations in Metal Mines and Pottery Industries. 34

Table 3. 3. Converting Total Dust to Respirable Crystalline Silica Exposures for Chinese Pottery Workers and Iron/Copper, Tin, and Tungsten Miners 35

Table 3. 4. Converting Historical Dust Measurements to Modern Dust Measurements in

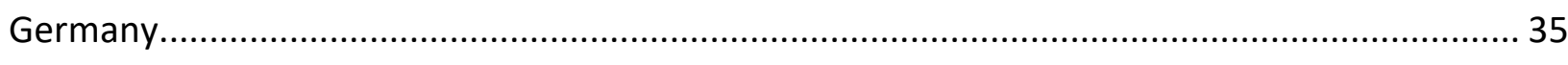

Table 3. 5. Converting Chinese total dust to respirable dust concentrations ........................... 37

Table 3. 6. Conversion factors for Field Sampling of Bitumen between the US and German

Methods 38

Table 3. 7. Comparison of German and French methods to determine a conversion formula for bitumen fumes. 40

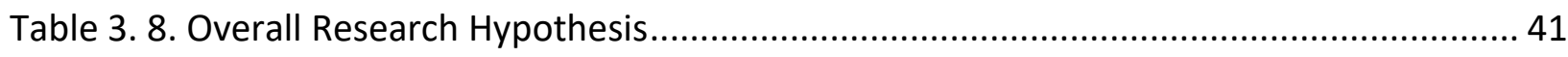

Table 3. 9. Spiked samples prepared for RCS analyses ..................................................... 43

Table 3. 10. Aerosol samples generated from the exposure chamber .................................. 47

Table 3. 11. Results of Spiked Samples using three analytical methods (US NC lab) .................. 52

Table 3. 12. Results of Spiked Samples using two analytical methods (German IFA lab) ........... 53

Table 3. 13. Statistical Summary of the NIST Spiked Samples ................................................ 58

Table 3. 14. Summary of RMC concentrations at each target level (ARD) ..............................6 62

Table 3. 15. Summary of RCS concentrations for each target respirable mass concentration

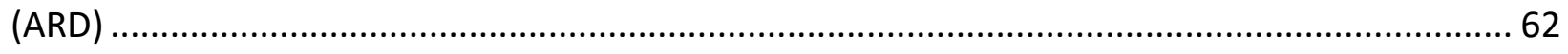

Table 3. 16. Summary of RMC concentrations at each target level (MIN-U-SIL $\left.{ }^{\circledR} 10\right)$..................69 
Table 3. 17. Summary of RCS concentrations for each target RMC (MIN-U-SIL $\left.{ }^{\circledR} 10\right)$................. 69

Table 3. 18. Summary of the Aerosol Chamber Study results .............................................. 74

Table 3. 19. Summary of respirable mass concentrations for the personal exposures $(\mathrm{mg} / \mathrm{m} 3) 80$

Table 3. 20. Summary of RCS concentrations for the personal exposures $(\mathrm{mg} / \mathrm{m} 3)$................ 80

Table 3. 21. Summary of respirable mass and RCS concentrations (Area exposure).................. 83

Table 3. 22. Summary of the Combined Personal and Area exposures (full-shift exposures)..... 85

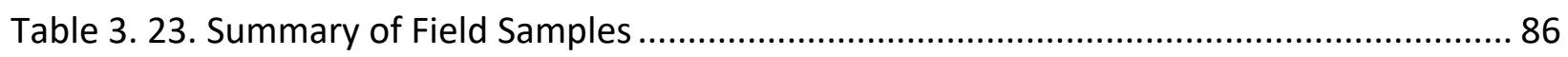

Table 3. 24. Summary of Results from the Spiked Sample Analysis, Aerosol Chamber Study, and

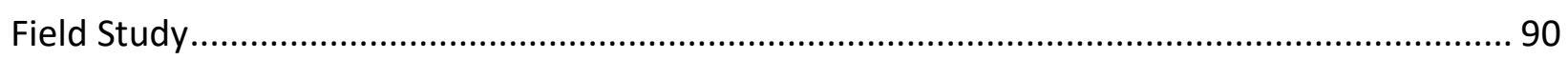




\section{Chapter 1. AEROSOL SAMPLING STRATEGY}




\section{INTRODUCTION}

Industrial hygiene sampling activities are performed as a necessary part of safety and health programs to identify potential health hazards, evaluate exposure levels, and recommend proper control measures (e.g., engineering control, administrative control, personal protective equipment). The quality of exposure data derived from sampling activities can be affected by various factors, such as performance and effectiveness of sampling instruments used, the analytical methods, sample handling, sampling environment, etc. In the past, many investigators have focused on these metrics with the goal of maximizing accuracy when determining exposure levels of occupational chemical agents. As a result of these efforts, sampling and analytical methods have been modified over time to accommodate advances in technology with regards to sampler design and efficiency, advances in knowledge of scientific principles that lead to more precise analyses of samples, etc. When these exposures are accurately quantified, recommendations made to prevent workers' exposure to potential health hazards are more effective.

In the United States, two federal government agencies-Occupational Safety and Health Administration (OSHA) and National Institute for Occupational Safety and Health (NIOSH)-and one volunteer scientific committee, ASTM International (formerly known as the American Society for Testing and Materials) develop sampling and analytical methods for known chemical agents to provide standard methods in determining exposure levels. Similarly, other countries also develop their own sampling and analytical methods, and often different sampling and analytical methods for the same chemical are utilized. Using different sampling and analytical methods for the same chemical often results in different exposure levels for a similar exposure group (SEG). For example, the 10-mm nylon cyclone is widely used in the United States while the FSP-BIA cyclone is used in Germany to measure respirable crystalline silica (RCS) exposures in workplaces. When operating in a wind tunnel, the FSP-BIA cyclone collected $63 \%$ to $73 \%$ more respirable dust than the 10-mm nylon cyclone (Yang et al., 2016). The exposure discrepancies among different countries that are caused by using different measurement strategies have not all been systematically defined. 
There is also a matter of data generation through aerosol sampling. Many exposure databases have been developed by different countries and used as a source of data for epidemiologic studies to determine associations between occupational agents and health effects that inform risk assessment. Those exposure databases include: IMIS (Integrated Management Information System), MEGA (Messdaten zur Exposition gegenüber Gefahrstoffen am Arbeitsplatz), OEDB (Occupational exposure database), IMA-DMP (Industrial Minerals Association-Dust Monitoring Program), WOODEX (wood dust exposure), CAREX (carcinogen exposure) developed by the US, Germany, experts from the EU member states, respectively. However, epidemiologists often find it difficult to compare the effect estimates of the exposure-response relationship (i.e., effect per unit of exposure) obtained from different population data sources or different countries. This is, in part, due to quantitative differences in exposure data resulting from different measurement strategies. As a result, a direct comparison of exposure estimates between two data sources or different countries could be misleading without the use of conversion factors. At any rate, combining data derived from different sources for epidemiological research is desirable because doing so would increase the statistical power of the study by increasing the data points available, leading to a better understanding of the risk assessment and a better basis for decision making.

Furthermore, action can be taken to modify occupational exposure limits (OELs) based on the scientific evidence derived from a compilation of numerous short- and long-term epidemiological studies (Karvonen et al. 1986), if the studies reveal that the old limits are insufficient in protecting workers from the hazard of interest. Admittedly, the difficulty in implementing this has been well documented (Deveau et al. 2015). While many factors complicate the issue of setting and establishing OELs, exposure-response data from occupationally active populations are one of the many considerations in the process (Dotson et al. 2015) and there is growing evidence to suggest that the use of these exposure data derived through exposure sampling can contribute to more reliable and scientifically based OELs (Wheeler et al. 2015; Dahmann et al. 2007).

Currently, the United States and Germany are the two biggest sources of data for numerous chemical agents, although the level of details on the exposure-related variables 
differ. In addition, U.S. and German measurement strategies have been widely accepted by other countries but the relationship between exposure measurements collected using the U.S. measurement strategies and the German strategies has not been evaluated.

Therefore, this study investigated aerosol sampling strategies in two parts: 1) the potential for particle loss to the sampler covers during sample transportation, to improve sampling methodology and prevent underestimation of mass concentrations and 2) determining the relationship between RCS exposure measurements using the U.S. measurement strategy (NIOSH method) and the German strategy (IFA method), and to develop conversion factors (or equations) to adjust for differences.

In Chapter 2, “Aerosol Sampling Strategy I: Effect of Particle Transfer to Sampler Covers during Sample Transportation", a laboratory study was conducted to investigate the effect of particle transfer to sampler covers during the transportation of samples. Aerosolized particles of wood dust and welding fumes were generated in exposure chambers, collected using 4 different commercially available samplers. The samples of each aerosol were divided into two groups, with one group transported by air and the other by land and returned in the same manner. The sampler covers were then analyzed for any aerosol particles that may have deposited on them during transportation resulting in sample loss from the filter media. The results of this study would give occupational professionals, who routinely collect and analyze samples at different locations, an awareness of the potential for particle loss during transportation. Furthermore, if the same trend is observed by other comparable studies, then there is reason to adjust the sampling methods to ensure that unaccounted particles on the sampler covers do not lead to an underestimation of the calculated mass concentrations.

In Chapter 3, "Aerosol Sampling Strategy II: Estimation of Conversion Factors between the United States and German Methods for Quartz sampling", the relationship between exposure measurements in evaluating respirable crystalline silica (RCS) using the U.S. measurement strategy (NIOSH method) and the German strategy (IFA method) was determined and conversion factors were generated. RCS was chosen for its ubiquity in industry and its welldocumented threat to occupational health. Comparisons between each country's sampling and 
analytical methods were done in three ways: 1) spiked sample analysis, to verify the differences between two countries' analytical methods, 2) an aerosol chamber study, where side-by-side samples were collected under environmentally controlled conditions, to determine the differences in the samplers along with the analytical differences, and 3) a field study, to determine the impact of uncontrolled environmental conditions and unknown workplace characteristics on the exposure results by each method.

The findings of this research will address some previously unexplored but important gaps in a fundamental aspect of the field of industrial hygiene: aerosol sampling. It will help to influence sampling methodology of some aerosols and help to bridge the gap associated with exposure discrepancies between US and German measurement strategies. Finally, as was earlier mentioned, research epidemiologists would directly benefit from this new knowledge by applying the outputs to their studies to generate large datasets by combining exposure measurement data from different sources. 
Chapter 2. AEROSOL SAMPLING STRATEGY I: EFFECT OF PARTICLE TRANSFER TO SAMPLER COVERS DURING SAMPLE TRANSPORTATION 


\section{INTRODUCTION}

Time-weighted average mass concentrations of airborne particles are determined by sample collection using size-selective samplers, such as inhalable or respirable samplers, depending on the purpose of sampling. The collected samples are often transported to a laboratory for analysis, at a facility other than the collection site.

Several researchers have addressed the concerns of particle concentration being underestimated because of particle deposition to the sampler's internal walls during sample collection. Puskar et al. (1991), for example, found that only $22 \%$ of the pharmaceutical dust sampled was collected on the filters with $78 \%$ settling on different parts of the sampler cassette body. Other studies have reported on the proportion of metal components deposited to the internal walls when samples were collected using two commonly used samplers, the 37-mm closed-face cassette (CFC) and the Institute of Occupational Medicine (IOM) inhalable sampler. The median mass percentages of wall deposit measured from various work environments ranged from $5-53 \%$ for the CFC sampler and 3-19\% for the IOM sampler for metal components including copper ( $\mathrm{Cu}$ ), lead, zinc, hexavalent chromium, iron, aluminum, tin, and beryllium (Ceballos et al. 2015; Demange et al. 1990; Harper et al. 2005, 2006; Harper and Demange 2007; Harper and Pacolay 2006; Hetland and Thomassen 1993; Lee et al. 2019; OSHA 2006). These findings indicate that sample analysis of the filter only should not be considered representative for worker exposure and might substantially underestimate worker exposure.

To address these concerns, there has been a steady evolution of sampling and analytical practices. The Occupational Safety and Health Administration (OSHA), for example, requires wiping the sampler's internal walls when evaluating metal components (Hendricks et al. 2009; OSHA 2008). The National Institute for Occupational Safety and Health (NIOSH) also recommends wiping internal walls when analyzing metal components (e.g., NIOSH Method 7302) and using an internal capsule to limit wall deposits during sampling (NIOSH 2020). For example, Accu-CAP (SKC Inc., Eighty-Four, PA) or Gravi-Sert (Zefon International, Ocala, FL) can be used for gravimetric analysis by capturing the entire sample collected into the sampler. In addition, Solu-Sert (Zefon International) and Solu-CAP (SKC Inc.) can be used for the analysis of 
airborne metals because the filter medium, a mixed cellulose ester (MCE) filter attached to a cellulose dome, can undergo complete dissolution for wet chemistry and thus account for all particles deposited on its walls.

Nevertheless, little attention has been given to particle deposits that could potentially transfer to the covers of samplers. This is highly likely to occur during sample handling and transportation as particles could bounce and transfer to the cover. From literature search (e.g., Google, PubMed), only one study was found by Lee et al. (2019) reporting particle transfer to disposable inhalable aerosol sampler (DIAS; customized prototype and not commercially available) and IOM covers. As of this writing, no previous studies have been conducted that investigate particle transfer to sampler covers. This particle transfer, if not adequately accounted for, would create the same concerns with underestimation as do unaccounted particles on internal sampler surfaces.

This study investigated particle transfer to the covers of aerosol samplers caused by two transportation modes (air and land). Two occupational agents (wood dust and welding fumes) and four types of samplers were used, focusing on potential losses to the sampler covers, not to the internal walls. As these losses can be easily neglected in analytical procedures, the findings of this study would provide a basis to review current common practices in the industrial hygiene community. 


\section{RESEARCH HYPOTHESES}

For this study, the overall research question of interest is:

"Does the transportation of aerosol samples cause particle transfer to the sampler covers?

The question will be explored using two transportation modes and two occupational agents. The overall null and alternative hypotheses are:

Table 2. 1. Overall Research Hypothesis

$\boldsymbol{H}_{\mathbf{0}}$ : There is no particle transfer of aerosol samples to the sampler cover after transportation.

$\boldsymbol{H}_{\boldsymbol{a}}: \quad$ There is particle transfer of aerosol samples to the sampler cover after transportation.

Intermediate hypotheses are as follows.

Wood Dust (WD) and welding fumes (WF) samples will be collected will 4 commercial dust samplers and shipped by air and land freight. Afterwards, the sampler covers will be analyzed for particle deposition.

\section{Comparison of Air and Land Transport for Wood Dust samples}

$\mathrm{H}_{\mathrm{o}}$ : There are no statistical differences in particle transfer of wood dust samples to the sampler covers between air and land transport. $\boldsymbol{\mu}_{\text {Air Transport }}=\boldsymbol{\mu}_{\text {Land Transport }}$ $\mathrm{H}_{\mathrm{a}}$ : There are statistical differences in particle transfer of wood dust samples to the sampler covers between air and land transport. $\boldsymbol{\mu}_{\text {Air Transport }} \neq \boldsymbol{\mu}_{\text {Land Transport }}$

\section{Comparison of Air and Land Transport for Welding Fumes samples}

$\mathrm{H}_{\mathrm{o}}$ : There are no statistical differences in particle transfer of welding fumes samples to the sampler covers between air and land transport. $\boldsymbol{\mu}_{\text {Air } \text { Transport }}=\boldsymbol{\mu}_{\text {Land Transport }}$

$\mathrm{H}_{\mathrm{a}}$ : There are statistical differences in particle transfer of welding fumes samples to the sampler covers between air and land transport. $\mu_{\text {Air Transport }} \neq \mu_{\text {Land Transport }}$ 


\section{METHODS}

\section{WOOD DUST SAMPLE PREPARATION}

Four samplers were used to collect airborne wood dust from an automated sanding chamber where a sander (Model 97181; Central Machinery, Camarillo, CA) equipped with zirconium aluminum oxide sandpaper (P120-grit; Norton, Saint-Gobain Abrasives, Inc., Worcester, MA) performed sanding action on a wooden log. Lee et al. (2020) provides a detailed description of the sanding chamber. The following samplers were used: Accu-CAP insert in a 37-mm two-piece cassette (part number [PN]: 225-8516GLA; SKC Inc., Eighty-Four, PA); 25-mm disposable inhalable sampler (DIS) with a polyvinylchloride (PVC) filter capsule (PN: PVPV-DIS5010; Zefon International, Ocala, FL); 25-mm IOM sampler (PN: 225-79A; SKC Inc.); and 37-mm CFC (PN: 225-2250; SKC Inc.) (Figure 1).

All samplers, except for the Accu-CAP, were loaded with a 5-mm pore sized PVC filter. The Accu-CAP insert consisted of a PVC filter (5-mm pore size) attached to a PVC capsule and placed as a whole inside a 37-mm cassette. Wood dust samples were collected at a nominal flowrate of 2 L/min using personal sampling pumps (AirChek XR5000; SKC Inc.) for all samplers. Sampling flowrates were checked before and after sampling with a mass flowmeter (Model 4143; TSI Inc., Shoreview, MN) to ensure the flowrate variation stayed within $\pm 5 \%$. Based on the stipulated range of mass loadings in NIOSH Method 0501, four mass levels of wood dust (0.5 $\mathrm{mg}, 1 \mathrm{mg}, 2 \mathrm{mg}$, and $3.5 \mathrm{mg}$ ) were generated by running all samplers at the same flowrate and adjusting the sample duration. For each run, one type of sampler was used, and a total of 128 samples (32 per sampler type) were collected.

Two preliminary studies were conducted to determine the optimum locations of samplers in the chamber and to measure the particle size distributions using an aerodynamic particle sizer (Model 3321; TSI Inc., Shoreview, MN) with a measurable size range of 0.5-20 $\mu \mathrm{m}$. The preliminary runs exhibited the same shapes of particle size distributions by mass, showing two modes with peak concentrations at about $3 \mu \mathrm{m}$ and $13.8 \mu \mathrm{m}$. Their magnitudes were also similar. 


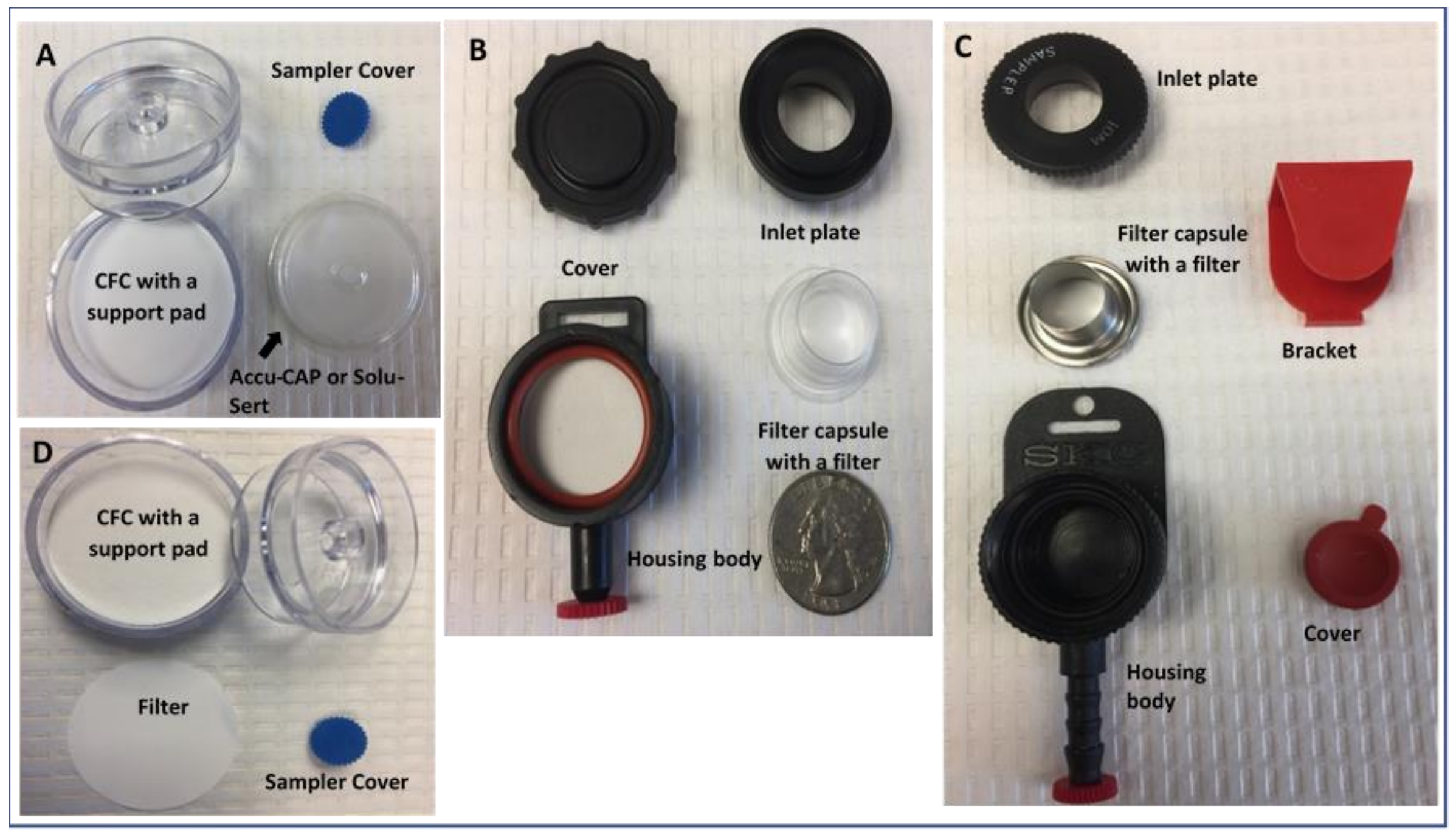

Figure 2. 1. Four commercially available samplers for wood dust and welding fumes. A: Accu-CAP'M (or Solu -Sert ${ }^{\mathrm{TM}}$ ), B: Disposable inhalable sampler (DIS), C: Institute of Occupational Medicine (IOM), and D: Closed-face cassettes (CFC). 
Because the same test conditions and wooden log were used for all runs, the particle size distributions by mass were assumed to be uniform, and thus no additional particle size distributions were measured. Prior to the sample collection, all sampling media (the filter for CFC, the insert for Accu-CAP, and the filter capsule with filters for IOM and DIS) and the corresponding sampler covers were equilibrated in an environmentally controlled weighing room (temperature at $20 \pm 2 \mathrm{C}$ and relative humidity of $50 \pm 5 \%$ ) for $48 \mathrm{hrs}$. Laboratory personnel measured pre-weights by using a microbalance (Model AG245; Mettler-Toledo LLC, Columbus, $\mathrm{OH}$ ) with a $0.01 \mathrm{mg}$ sensitivity. For each sampler type, six field blank samples (sampling media and sampler covers) were weighed in the same manner.

\section{WELDING FUME SAMPLE PREPARATION}

Welding fumes were generated through the welding action of a robotic welder built in a walk-in chamber. In this study, the welding fumes were sampled in a replicated manner using the same operating and environmental conditions as described in Cena et al. (2016). The wire feeder connected to the robotic arm was fitted with mild steel wire (ER70S-3; Lincoln Electric, Cleveland, $\mathrm{OH}$ ) that operated at $762 \mathrm{~cm} / \mathrm{min}$ with $0.17-0.22 \% \mathrm{Cu}$ and $1.42-1.60 \% \mathrm{Mn}$. The welding machine was operated at 25 volts and 220 amperes with $95 \%$ argon and $2 \%$ carbon dioxide shielding gas at $1.13 \mathrm{~m}^{3} / \mathrm{hr}$. Cena et al. (2016) collected samples at $30 \mathrm{~cm}$ and $120 \mathrm{~cm}$ away from the fume generation source, and reported that regardless of the sampler's locations, the particle size distributions by number were similar over time, showing a single mode with a peak at about $200 \mathrm{~nm}$, except when welding-in-progress at $30 \mathrm{~cm}$ away from the arc, which showed a secondary mode between $15 \mathrm{~nm}$ and $50 \mathrm{~nm}$. The particle size distributions by mass were also similar, showing the mass median aerodynamic diameter at $0.3 \mathrm{~mm}$ at $30 \mathrm{~cm}$ and $0.35 \mathrm{~mm}$ at $200 \mathrm{~cm}$ away from the source over different time intervals. Because the test conditions were replicated, the particle size distributions by number and by mass were assumed to be the same as those reported by Cena et al., and no additional particle size distributions were measured. 
Welding fumes were collected using the same sampler types except for replacing AccuCAP with Solu-Sert (PN: CLCL-C3750; Zefon International, Ocala, FL). Also, instead of PVC filters, all samplers were loaded with MCE filters with a 0.8- $\mathrm{mm}$ pore size for analyzing metal components, according to the modified NIOSH Method 7303 (see modification below).

All samplers were run at $2 \mathrm{~L} / \mathrm{min}$ with flowrate variations less than $5 \%$. For each run, three sets of the four sampler types were placed in the welding chamber, and 11 runs were conducted for a total of 132 collected samples. For each sampler type, six field blanks (sampling media and sampler covers) were prepared.

\section{SAMPLE TRANSPORTATION BY AIR AND LAND}

All sample collections and handlings were performed by a senior industrial hygienist with good laboratory practices. Before and during the sample collections, all sampler covers were kept in the weighing room to minimize cross-contamination. After the sample collection, the samples were taken to the weighing room for packing.

After sampling, wood dust samples (128 samples plus six field blanks per sampler type) were divided evenly into two groups for either air or land transportation. For welding fume samples, samples with an odd number of runs (72 samples $=4$ samplers per set $\mathrm{x} 3$ sets per run $x 6$ runs) were transported by land, while samples with an even number of runs (60 samples $=4$ samplers per set $\times 3$ sets per run $\times 5$ runs) were transported by air; for each transportation method, three field blanks per sampler type were included. For the samples of CFC and CFC with Accu-CAP (or Solu-Sert) inserts, the sampler covers were placed tightly on both inlet and outlet orifices of the samplers without removing the filters or inserts.

Similarly, for DIS samples, the sampler covers and outlet plugs were secured on the samplers without removing the capsules from the housing body (Figure 1). For IOM samples, each filter capsule with its filter was removed from the housing body, covered with the corresponding sampler cover, and secured with the supplied bracket. All samples of each group were placed upright in a cardboard box. Antistatic packing peanuts were used to secure the 
samples during transport, and a sticker, which said "fragile," was placed on each box. Both land and air transport boxes were prepared identically.

The air transportation sample box was shipped to Ocala, Florida from Morgantown, West Virginia, using the following chain of custody: a courier service picked up the box from the Morgantown facility and drove it to the local airport (about $126 \mathrm{~km}$ ) where it was flown about $1,500 \mathrm{~km}$ to Ocala. The box was then driven to the receiving facility from the Ocala airport (about $3 \mathrm{~km}$ ). It was returned to Morgantown in the same manner. The land transportation sample box was driven in a personal vehicle for $965 \mathrm{~km}$ on paved interstate highway roads with minimal turns (i.e., less vibration compared with unpaved roads), and with an elevation change of approximately $245 \mathrm{~m}$ for the entire trip. During land transportation, the sample box was not unloaded or reloaded into the vehicle.

\section{WOOD DUST SAMPLE ANALYSIS}

All returned samples along with field blanks were stabilized for $48 \mathrm{hr}$ in the same weighing room used for the pre-weighing of sampling media and sampler covers. Then, the same laboratory personnel who performed the pre-weighing conducted the post-weighing analysis using the same microbalance to minimize variations between users and balances. In addition, six media blanks were used to determine the limit of detection (LOD) for each sampler type. The LODs of the sampling media and covers for each sampler type were calculated at three times the standard deviation for differences between pre- and post-weighing of the six media blanks and covers. The estimated LODs for the sampling media and covers were 0.04930 $\mathrm{mg}$ and $0.03912 \mathrm{mg}$ for Accu-CAP; $0.06481 \mathrm{mg}$ and $0.05254 \mathrm{mg}$ for DIS; $0.07823 \mathrm{mg}$ and $0.05167 \mathrm{mg}$ for IOM; and $0.05899 \mathrm{mg}$ and $0.03507 \mathrm{mg}$ for CFC, respectively. 

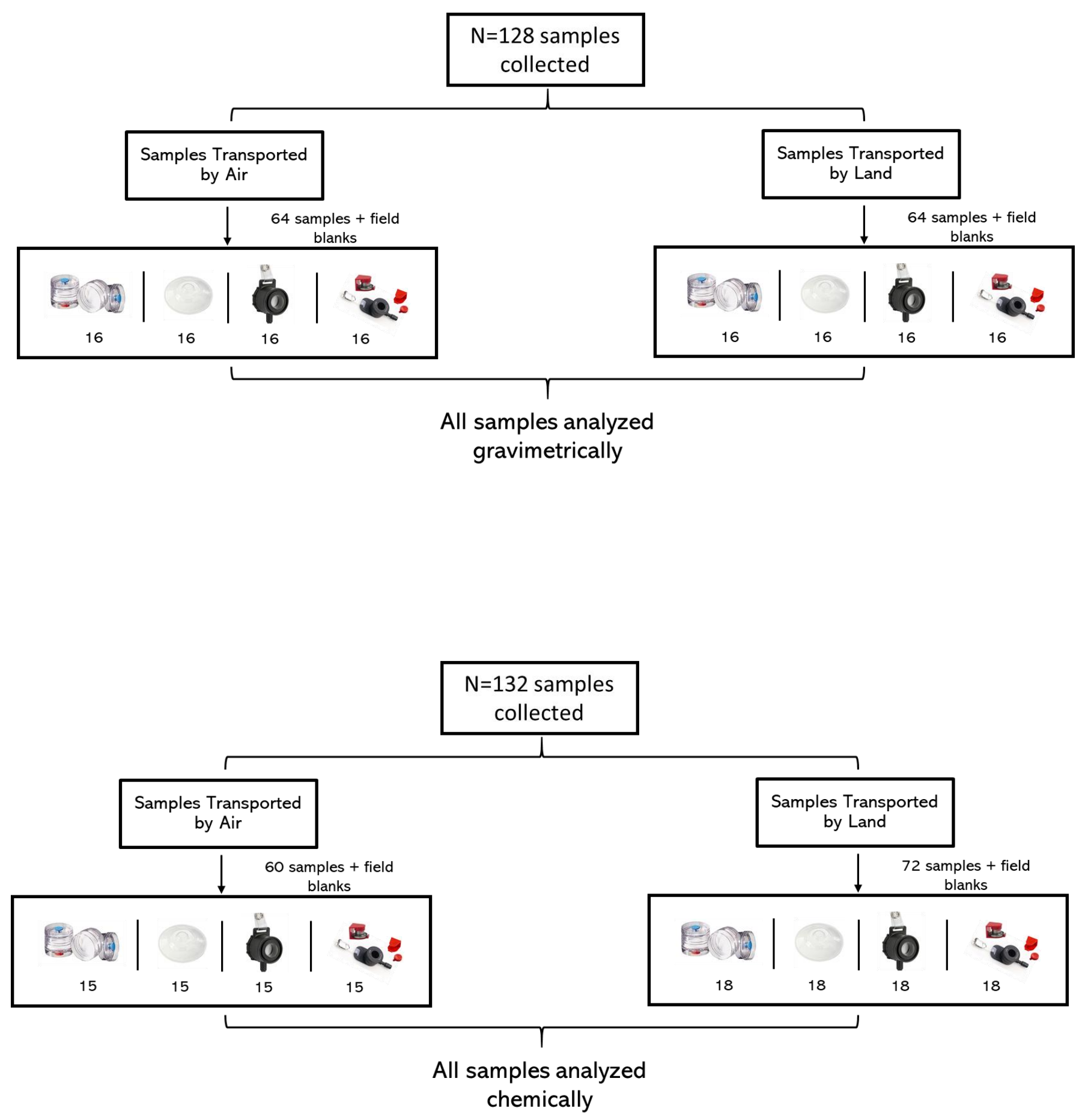

Figure 2. 2. Sampling and Analytical Procedure. Wood Dust and Welding Fumes samples collected, transported and analyzed. 


\section{WELDING FUME SAMPLE ANALYSIS}

For the IOM and CFC samples, each sample was prepared in three steps. First, the filter medium was carefully removed from the sampler and placed in a $50-\mathrm{mL}$ reaction tube. Next, the internal walls of the sampler were wiped twice with a quartered $25-\mathrm{mm}$ MCE filter soaked with isopropyl alcohol and then placed in a second tube.

Last, the sampler cover was wiped with a fresh wipe in the same manner and placed in a third tube. Although Hendricks et al. (2009) demonstrated that a single wipe of the internal walls was sufficient to extract most metal components, the second wipe was performed to ensure that almost all metals deposited to the internal walls and covers were removed.

For the Solu-Sert and DIS samples, the first and third steps just described were performed; however, in the first step, each Solu-Sert insert and filter capsule with its filter for DIS was placed in a tube. In addition, six field blank samples were treated in the same manner as the samples. The prepared samples were analyzed to determine the amount of $\mathrm{Cu}$ and $\mathrm{Mn}$ using inductively coupled plasma-mass spectrometry (ICP-MS; Perkin Elmer 300 D, Waltham, MA) following the NIOSH Method 7303 with some modifications. To dissolve each filter sample placed in a tube, nitric acid $(3 \mathrm{~mL})$, hydrochloric acid $(1 \mathrm{~mL})$, and water $(2 \mathrm{~mL})$ were added to the tube and then left for $30 \mathrm{~min}$ at room temperature.

The tube was then placed in a water bath and warmed to 85-95 C for $1 \mathrm{hr}$. After cooling at room temperature, water was added to bring the volume to $40 \mathrm{~mL}$. The wipe samples were treated in the same manner with reduced volumes of acids $(0.75 \mathrm{~mL}$ nitric acid and $0.25 \mathrm{~mL}$ hydrochloric acid) and water $(0.5 \mathrm{~mL})$. Water was also added later to the sample to a final volume of $10 \mathrm{~mL}$. Aliquots of sample solutions were diluted with water to a nominal $1 \%$ total acid concentration and analyzed by ICP-MS. The concentration of $\mathrm{Cu}$ and $\mathrm{Mn}$ in sample solution was determined by comparison to standard solutions made by diluting concentrated standard solutions (10 ppm, Multi-element, two standards: SPEX CertiPrep Inc., Metuchen, NJ) with an acid mixture of $0.75 \%$ nitric acid and $0.25 \%$ hydrochloric acid. The LODs for these experiments were $0.076 \mathrm{mg}$ for $\mathrm{Cu}$ and $0.144 \mathrm{mg}$ for $\mathrm{Mn}$. 
All field blank samples (including the sampling media and wiped samples of internal walls and sampler covers) resulted in non-detectable amounts of $\mathrm{Cu}$ and $\mathrm{Mn}$ except for the sampling media for $\mathrm{Cu}$. For $\mathrm{Cu}$, the average mass of sampling media for Solu-Sert, DIS, IOM, and CFC was $0.45 \mu \mathrm{g}, 0.34 \mu \mathrm{g}, 0.42 \mu \mathrm{g}$, and $0.25 \mu \mathrm{g}$ for land transportation, respectively, and 0.38 $\mu \mathrm{g}, 0.35 \mu \mathrm{g}, 0.43 \mu \mathrm{g}$, and $0.27 \mu \mathrm{g}$ for air transportation, respectively. 


\section{DATA ANALYSIS}

For the samples of wood dust and welding fumes, the mass (i.e., dust mass for wood dust and $\mathrm{Cu} / \mathrm{Mn}$ mass for welding fumes) on a sampling medium and sampler cover were adjusted by the corresponding field blank samples. Then, the proportion of dust or metal components that transferred to the sampler cover was calculated by dividing the mass on the cover by the total mass. The total mass was determined by adding the mass of dust or metal components on the sampling medium-i.e., on the insert for Accu-CAP or Solu-Sert, the filter capsule with its filter for DIS, the filter capsule with its filter for IOM (wood dust only), the filter plus wiped sample of internal walls for IOM and CFC (metal components only), and the filter for CFC (wood dust only) - plus the mass of dust or metal components that transferred to the sampler cover.

For the wood dust samples, 11 negative values between pre- and post-weight of sampler covers were excluded. For the IOM samples, two extreme total masses (197 mg and $511 \mathrm{mg}$ ) were observed, while the total mass of the remaining IOM samples ranged $0.4-14 \mathrm{mg}$ (Table 1). During the weighing analysis, we observed no indication of large, agglomerated particles on the sampling media that could cause such extreme values. Although the sources of the errors were unclear, both data points were removed from the further data analysis. For the dust mass loaded on the sampler covers that resulted in less than LOD, the mass was replaced with the LOD divided by the square root of 2 (Hornung and Reed, 1990).

Statistical analyses were conducted to determine the differences of the percentage of dust loading on the sampler cover between the modes of transportation and among different sampler types using a two-way analysis of variance with JMP software (SAS Institute, Cary, NC) Data were log transformed prior to the analysis to meet the assumption of the model. Post-hoc comparisons were carried out using Fisher's least significant difference. Differences with a pvalue of $<0.05$ were considered statistically significant.

Of the 132 welding fume samples, three samples (two land-transported and one airtransported) were excluded because of sampling pump malfunctions. In addition, two landtransported samples were excluded because of mishandling of samples during the ICP-MS 
sample preparation. Finally, 11 land samples and seven air samples showed negative values of Cu when the mass of sampling filter was adjusted by the mass of field blanks and thus excluded from data analysis.

As shown in Tables 2 and 3, the majority of samples showed mass on the sampler covers less than LOD for $\mathrm{Cu}$ and $\mathrm{Mn}$. Thus, no statistical analysis was done and only the masses on the covers greater than LOD were used to calculate the proportion of an analyte transferred to the cover. 


\section{RESULTS AND DISCUSSION}

\section{WOOD DUST}

Table 1 presents a summary of the number of samples and the percentages of particle transfer to the sampler covers during the sample transportation. Note that 11 negative values between pre- and post-weight of sampler covers or sampling media and two outliers were removed. As a result, the number of samples for each sampler type ranged from 10 to 16 for the land-transported samples and from 13 to 15 for the air-transported samples. Unlike other samples, CFC samples transported by land had the highest number of samples showing less than LOD on the sampler covers (11 out of 16 samples).

Regardless of the transportation mode, IOM samples showed a wider variation compared to the other sampler types. The median percentage of mass transfer to the sampler covers for IOM was considerably higher than that for the other sampler types (15\% for the landand $64 \%$ for the air-transported samples; $p$-value $<0.001)$, while no differences were observed among the other three sampler types (Table 1). Figure 2 shows a photograph of the wood dust transfer to one IOM sampler cover used for air transport during the study. The remaining samplers showed the median percentage of dust transfer to the covers less than or close to $10 \%$.

Both IOM and CFC air samples showed higher percentages of dust transfer than the land samples $(p$-values $=$

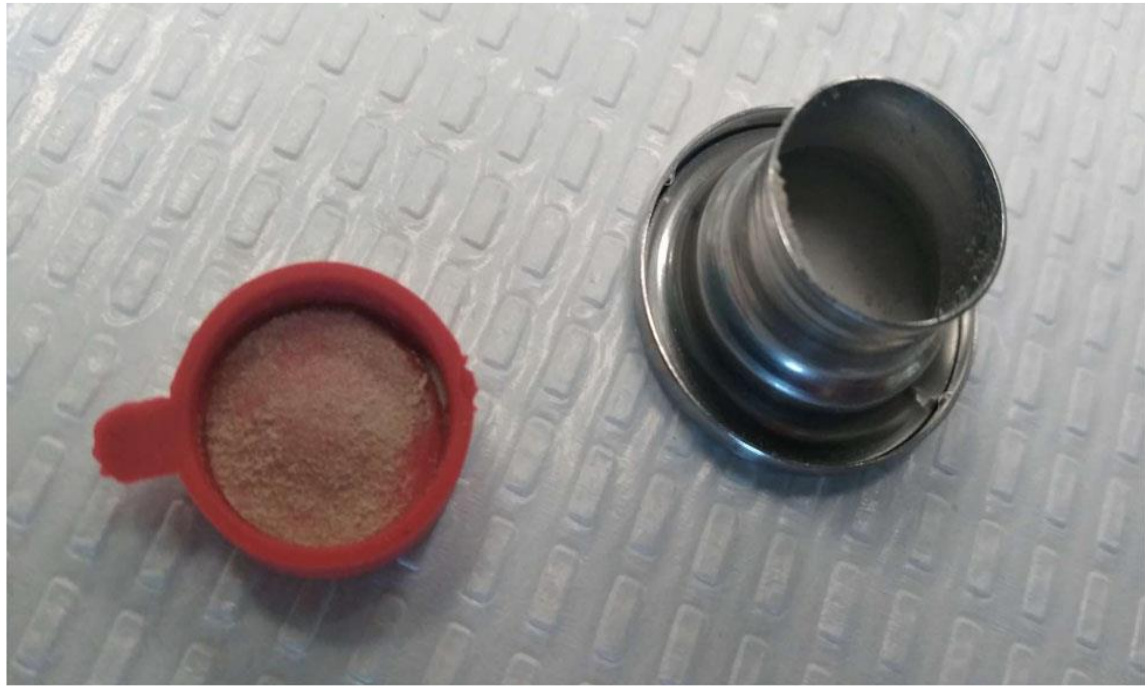

Figure 2. 3. Wood Dust particle transfer for IOM sampler after air transport. 0.0005 for IOM and 0.0027 for CFC). However, the Accu-CAP and DIS samples demonstrated no statistical differences between the air and land transports. As shown in Figure 3, no trend 
between the percentage of dust mass loadings on the sampler covers and total dust mass loadings was observed.

Several investigators have reported that wood dust mass is highly influenced by particles $>10 \mu \mathrm{m}$, although the reported mass median aerodynamic diameters (MMAD) would be different depending on the industry types and tasks (Harper et al. 2004; Hinds 1988; Pisaniello et al. 1991; Whitehead et al. 1981). For example, Whitehead et al. (1981) collected wood dust samples using cascade impactors during sanding of various wood material types at furniture and plywood manufacturing companies. They reported that particles $>22.5 \mu \mathrm{m}$ contributed to about $65 \%-86 \%$ of total mass concentrations for 14 of 15 samples. Pisaniello et al. (1991) reported an average MMAD of $18.7 \mu \mathrm{m}$ for hardwood dust and $19.6 \mu \mathrm{m}$ for softwood dust from sanding works. This study revealed two peaks at $3 \mu \mathrm{m}$ and $13.8 \mu \mathrm{m}$, which are smaller diameters than those reported by Whitehead et al. and Pisaniello et al. It is expected that more particles would transfer to the sampler covers during shipping if particle size larger than those in this study were collected.

Table 2. 2 Summary of total mass sampled, and percentage transferred to sampler cover by transportation method (Wood Dust)

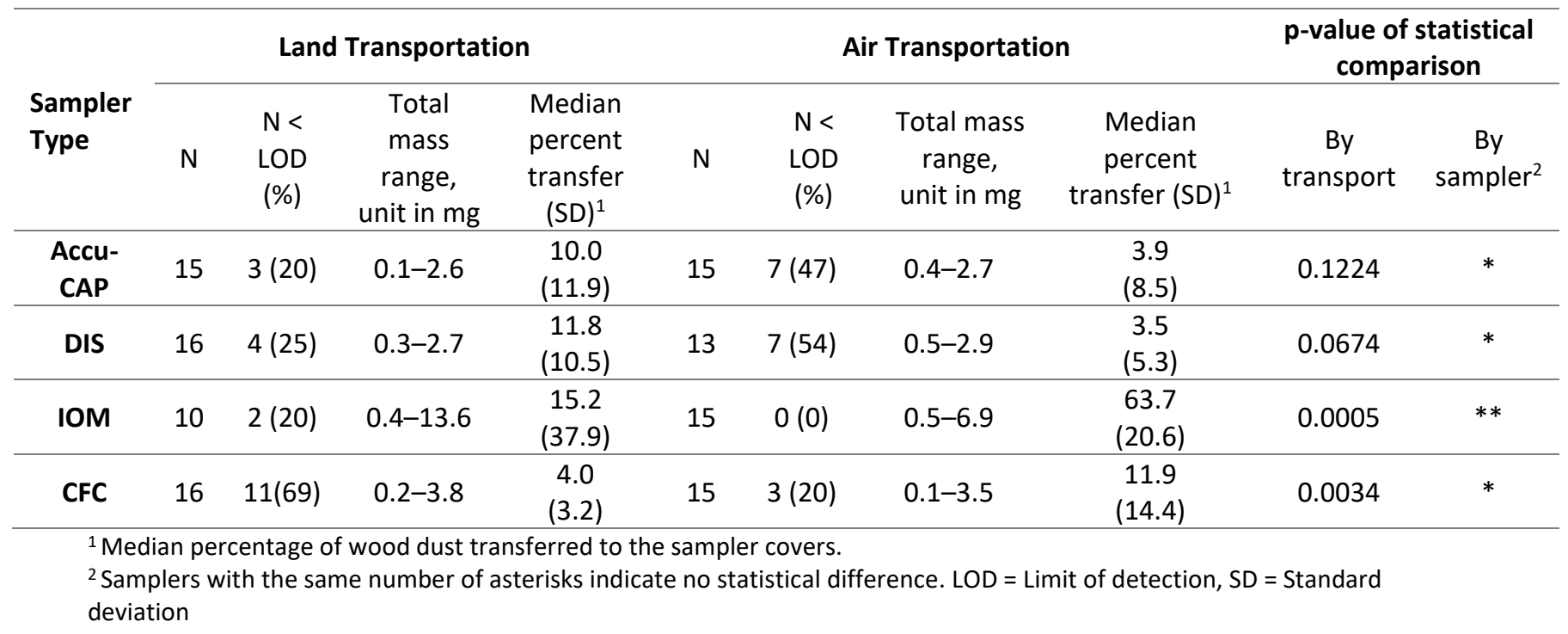


The findings of this study demonstrate that the mode of transportation and sampler type can result in dust transfer to the sampler covers, affecting subsequent weighing analyses and leading to an underestimation of mass concentrations. Interestingly, as shown in Figure 1, identical sampler covers were used for Accu-CAP and CFC, and the statistical test showed no difference between these two samplers (see the comparison results by sampler type in Table 1).

On the other hand, when a comparison was made between air and land transportation, CFC showed a significant difference ( $p$-value $=0.0034)$, while Accu-CAP showed no difference $(p$-value $=0.1224)$. Probably, various factors such as differences in material handling, sampler packing, and travel distances were involved in causing such differences.

Unfortunately, the scope of this study did not allow for investigating the impact of each factors influence. Special caution should be given to the IOM sampler because of its wider inlet diameter. IOM samplers showed a considerably higher percentage of dust transfer to their covers compared to the other samplers. Interestingly, DIS samplers, having the same inlet diameter as the IOM sampler, did not exhibit the same pattern. The difference might be caused from the nonconductive plastic body of the $25-\mathrm{mm}$ DIS sampler, which is more likely to attract dust particles that stick to its capsule, while the conductive metal body of the IOM sampler doesn't behave in the same manner. It should be noted that IOM has two versions of filter capsules-conductive stainless steel and nonconductive plastic capsules. Typically, the former is recommended for the chemical and weighing analyses, while the latter is suggested for the chemical analysis. 

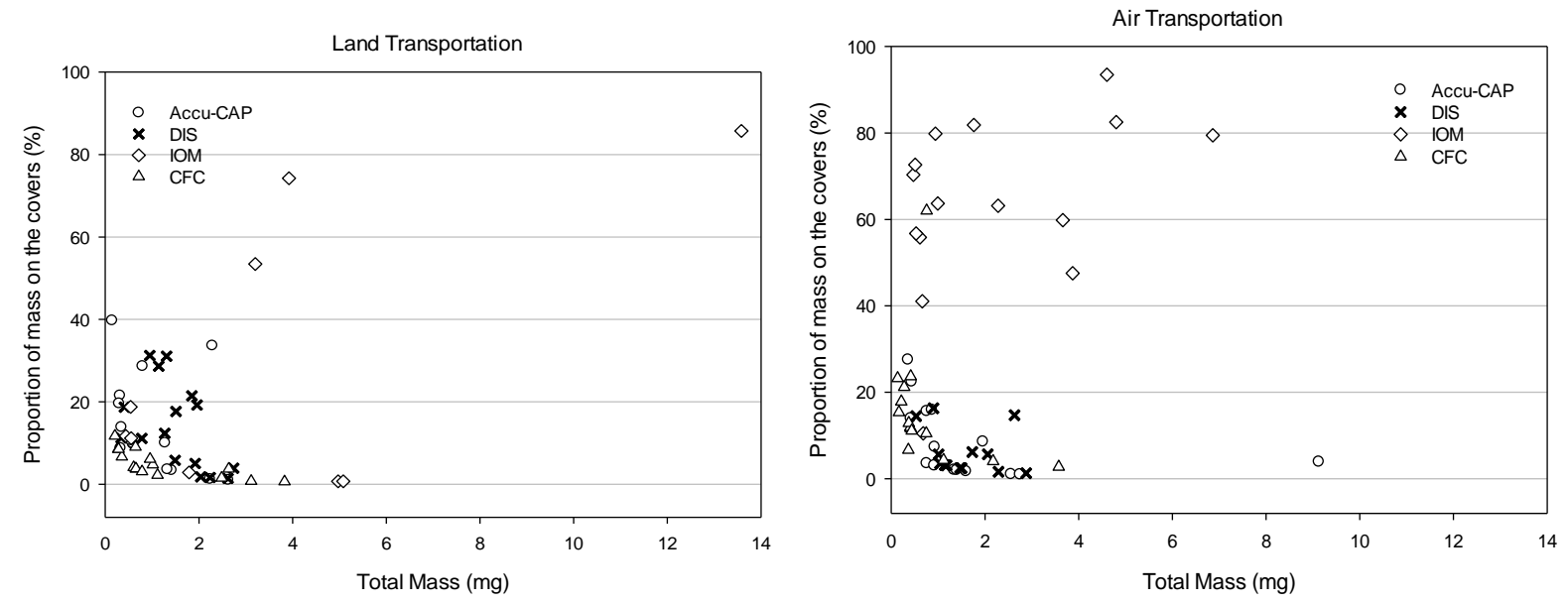

Figure 2. 4. Percentage of mass loadings on the sampler covers. Data with less than LOD treated with the LOD/V2.

The IOM manufacturer made weighing the sampler cover as part of the pre-weight assembly "optional" depending on the size of dust being measured. However, the findings in this study suggest that ignoring the sampler cover could potentially result in underestimation of mass concentrations.

\section{WELDING FUMES}

Summaries of particle mass sampled and transferred to the sampler covers are listed in Table 2 for $\mathrm{Cu}$ and Table 3 for $\mathrm{Mn}$. As expected from the type of welding wire, greater masses were observed from Mn compared with Cu. Overall, the majority of samples had nondetectable amounts of the analyte on the sampler covers for all sampler types (33-79\% of samples for $\mathrm{Cu}$ and $43-94 \%$ of samples for $\mathrm{Mn}$ ). Figure 4 shows the percentage of mass loadings on the covers for those having mass greater than LOD. For the Cu samples, the DIS sampler seemed to demonstrate a higher percentage of mass on the covers compared to the other sampler types. The $\mathrm{Mn}$ results show the percentage of transfer to the covers at less than $4.5 \%$ regardless of the transportation modes and sampler types. Also, no trend-such as a positive or negative correlation between the total mass and the percentage of mass loadings on the covers-was observed (Figure 4). 
Table 2. 3. Summary of particle mass sampled and transferred to the sampler covers (Cu)

\begin{tabular}{|c|c|c|c|c|c|c|c|c|}
\hline \multirow[b]{2}{*}{$\begin{array}{l}\text { Sampler } \\
\text { Type }\end{array}$} & \multicolumn{4}{|c|}{ Land Transportation } & \multicolumn{4}{|c|}{ Air Transportation } \\
\hline & $\mathrm{N}$ & $\begin{array}{c}\mathrm{N}<\mathrm{LOD} \\
(\%)\end{array}$ & $\begin{array}{c}\text { Total mass } \\
\text { range, unit in } \\
\mu \mathrm{g}\end{array}$ & $\begin{array}{c}\% \text { transfer to } \\
\text { the cover }\end{array}$ & $\mathrm{N}$ & $\mathrm{N}<\operatorname{LOD}(\%)$ & $\begin{array}{c}\text { Total mass } \\
\text { range, unit in } \\
\mu \mathrm{g}\end{array}$ & $\begin{array}{c}\% \text { transfer } \\
\text { to the } \\
\text { cover }^{1}\end{array}$ \\
\hline $\begin{array}{l}\text { Solu- } \\
\text { Sert }\end{array}$ & 15 & $11(73)$ & $0.2-19$ & $1.1-11.2$ & 14 & $7(50)$ & $1.0-20$ & $1.3-19.3$ \\
\hline DIS & 14 & $11(79)$ & $0.3-14$ & $0.9-30.8$ & 15 & $7(47)$ & $0.1-12$ & $0.2-33.3$ \\
\hline IOM & 13 & $10(77)$ & $0.7-16$ & $5.1-12.6$ & 12 & $4(33)$ & $0.8-20$ & $0.9-8.7$ \\
\hline CFC & 15 & $11(73)$ & $0.3-14$ & $0.7-4.7$ & 11 & $6(55)$ & $0.6-16$ & $0.4-12.0$ \\
\hline
\end{tabular}

${ }^{1}$ Range of Cu transfer to the sampler covers for those having mass on the cover greater than LOD. LOD = Limit of detection

Table 2. 4. Summary of particle mass sampled and transferred to the sampler covers (Mn)

\begin{tabular}{|c|c|c|c|c|c|c|c|c|}
\hline \multirow[b]{2}{*}{$\begin{array}{c}\text { Sampler } \\
\text { Type }\end{array}$} & \multicolumn{4}{|c|}{ Land Transportation } & \multicolumn{4}{|c|}{ Air Transportation } \\
\hline & $\mathrm{N}$ & $\mathrm{N}<\mathrm{LOD}(\%)$ & $\begin{array}{c}\text { Total mass } \\
\text { range, unit in } \\
\mu \mathrm{g}\end{array}$ & $\begin{array}{c}\% \text { transfer } \\
\text { to the } \\
\text { cover }^{1}\end{array}$ & $\mathrm{~N}$ & $\mathrm{~N}<\mathrm{LOD}(\%)$ & $\begin{array}{c}\text { Total mass } \\
\text { range, unit } \\
\text { in } \mu g\end{array}$ & $\begin{array}{c}\% \text { transfer } \\
\text { to the } \\
\text { cover }^{1}\end{array}$ \\
\hline $\begin{array}{c}\text { Solu- } \\
\text { Sert }\end{array}$ & 17 & $12(71)$ & 7.4-156 & $0.1-1.7$ & 15 & $12(80)$ & $0.4-165$ & $0.3-2.4$ \\
\hline DIS & 16 & $15(94)$ & $7.2-161$ & 1.4 & 15 & $14(93)$ & $6.8-153$ & 1.6 \\
\hline IOM & 17 & $13(76)$ & $1.9-202$ & $0.3-4.4$ & 14 & $6(43)$ & $1.5-109$ & $0.2-1.3$ \\
\hline CFC & 18 & $15(83)$ & $7.5-160$ & $0.2-3.9$ & 15 & $10(67)$ & $4.1-153$ & $0.2-3.5$ \\
\hline
\end{tabular}

${ }^{1}$ Range of $\mathrm{Mn}$ transfer to the sampler covers for those having mass on the cover greater than LOD. LOD = Limit of detection

Lee et al. (2019) reported that for samples collected at an electro refinery worksite, 7.4\% of Cu particles transferred to the sampler covers during transport for IOM samplers and $6.4 \%$ for a customized prototype of DIAS (not commercially available). In this study, given the information in Tables 2 and 3, as well as in Figure 4, the results show that the particle transfer to the covers might not be a major issue because the majority of samples showed nondetectable amounts of metals on the sampler covers. The particle size distributions by mass in this study showed peak concentrations between $0.3 \mu \mathrm{m}$ and $0.35 \mu \mathrm{m}$. Unfortunately, Lee et al. (2019) did not report the particle size distributions by mass or number and thus, it would be difficult to explain the differences between two studies. 
Compared with the wood dust results, welding fumes resulted in smaller percentages of particle transfer to the covers during shipping. This is probably due to the different processes from which the particles are generated. The aerosolized particles from the welding process condensate and coagulate at ambient temperatures, forming agglomerates of nanoparticles and spheres (0.5 - $4 \mu \mathrm{m})$ from the welding spatter (Cena et al., 2016). In this study, the mechanical sanding process produced larger particles than the hot wire welding process, leading to more particle transfer to the sampler covers.
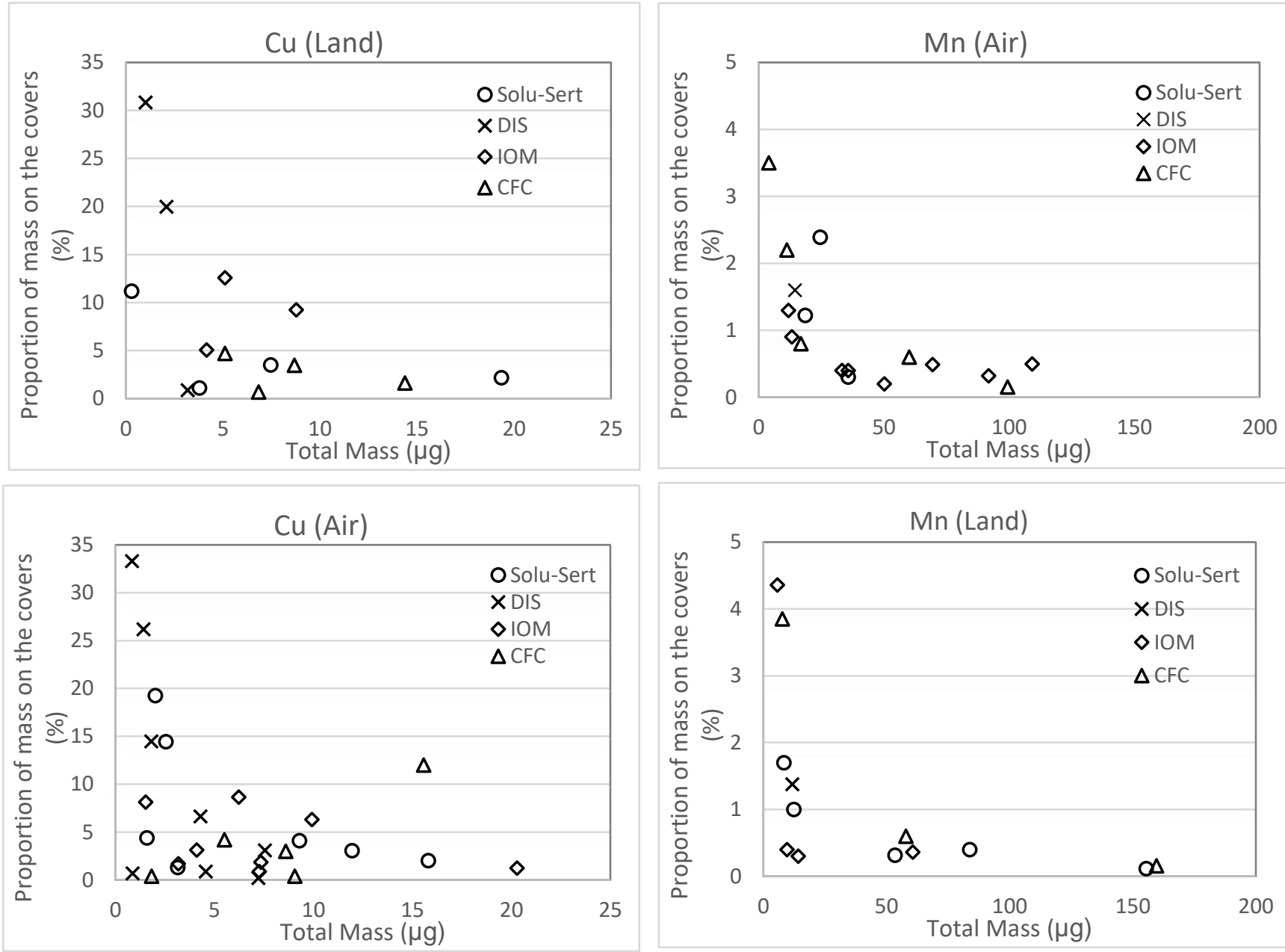

Figure 2. 5. Percentage of mass loadings on the sampler covers with the corresponding total mass loadings.

Overall, no strong conclusions can be made about the effect of transportation on Cu or Mn particle transfer to the sampler covers because of the limited sample sizes above the LOD 
for both analytes. For a similar reason, no conclusion can be made among different sampler types.

\section{STUDY LIMITATIONS}

This study is limited to the unique transportation conditions used. For example, the proportion of particles transferred to the sampler covers could be considerably different if collected samples were shipped on different road conditions (e.g., paved vs. unpaved), traveling distances (e.g., 2-hr driving vs. 6-hr driving), and/or environmental factors (e.g., vibration). The material handlers' characteristics could be another important factor. In practice, conditions of sample handling can be highly variable, which might lead to completely different results.

In this study, the air transportation sample box made a round trip, combining both air and ground transport, while in practice, only a one-way trip would be utilized. Thus, the associated material handling (e.g., loading and unloading of the sample box) between transport vehicles was likely doubled. Although we placed a "fragile" sticker on the box, this doubled amount of handling might provide more opportunity for more particles to move to the covers than during a one-way trip. Unfortunately, determining all the variability in the material handling could not be done in this study because that is beyond our capacity, and thus we cannot estimate which factor is more effective between the transportation method and the material handling. Similarly, the land transportation box traveled only on paved roads. Other environmental factors (e.g., unpaved road, car vibration) could affect the particle transfer to the covers but again, these factors were not investigated in this study.

The present study is limited to only two materials and one task per material. In addition, the sample sizes, especially for welding fumes, might not be large enough to draw firm conclusions. Additional studies considering other factors such as different particle size distributions, material types (e.g., hard wood vs. soft wood), material characteristics (e.g., different static electricity properties), tasks (e.g., cutting vs. sanding), and sufficient sample sizes would be necessary. 
Chapter 3. AEROSOL SAMPLING STRATEGY II: ESTIMATION OF CONVERSION FACTORS BETWEEN THE UNITED STATES AND GERMAN METHODS FOR QUARTZ SAMPLING 


\section{INTRODUCTION}

In epidemiology, a study design that generates quantitative estimates of the exposureresponse relationship between a specific exposure and risk of disease is desirable for risk assessment (Soutar et al., 2000), and is thus recommended as the preferred approach (given adequate breadth \& depth of available data) (EPA, 1996; CCCF, 1991). Specifically, epidemiological studies, including those that utilize cohort or case-control design demonstrating a progressive increase in health risk to the suspected agent in relation to increases in quantitative exposures are useful for risk assessment. In practice, few exposureresponse studies have been conducted compared to descriptive studies and case registries because of the lack of detailed exposure information (Soutar et al., 2000). Additionally, epidemiologists often have difficulty merging different studies together in meta-analyses because of the quantitative differences in exposures due to different measurement strategies (Birk et al., 2010; Guldner et al., 2011). Due to this limitation, risk assessments are often restricted to exposure data collected using one sampling methodology and thus, very likely limited to the country of which the methodology originated.

Yet, the emerging findings of adverse health effects based on accurate risk assessments calls for developing large hazard exposure datasets. However, for practical reasons, it would be very difficult to generate sufficient exposure data by performing one or even a few industrial hygiene sampling campaigns to satisfy the needs of a large scale or long-term epidemiological study. It would be more practical to generate large data sets by combining data from different sources, or databases dedicated to accumulating information on a variety of workplace hazards.

Currently, various occupational exposure databases are available in the world. The United States (US) Occupational Safety and Health Administration (OSHA) manages the Integrated Management Information System (IMIS) (Stewart and Rice, 1990); Germany's Institute for Occupational Safety (IFA) manages measurement data relating to workplace exposure to hazardous substances (MEGA) databases, containing more than 3.4 million datapoints (IFA, 2018); experts from the European Union member states generated databases for wood dust (WOODEX database), CAREX for carcinogen exposure (Kauppinen et al., 2006), 
France manages COLCHIC and SCOLA databases, including 670 chemicals. Other exposure databases include NIOSH Health Hazard Evaluation (HHE) reports (NIOSH 2021), OEDB (Occupational exposure database) for respirable crystalline silica (Beaudry et al., 2013), and IMA-DMP (Industrial Minerals Association-Dust Monitoring Program) for respirable dust and quartz (Zilaout et al., 2017).

However, combining data from different sources without determining the similarities and differences can lead to inaccurate results in conducting risk assessments. For example, Yang et al. (2016) sampled respirable dust using pairs of 10-mm nylon cyclone (common US sampler) and FSP-BIA (common German sampler) in a wind tunnel and reported that the German samples collected $63 \%$ to $73 \%$ more respirable dust than the US samples.

As of this writing, the US and Germany constitute the two biggest sources of occupational exposure data (including officially known databases such as IMIS and MEGA mentioned above, and reports such as NIOSH HHE reports), although the level of detail about variables related to exposure levels differ. Furthermore, US measurement strategies have been widely accepted by other countries (Zilaout et al., 2017). So, exposure data sources using NIOSH measurement strategies not only affect risk assessment activities in the US, but also in countries around the world that adopt those methods. Thus, from the perspective of the epidemiologist, if a knowledge gap associated with exposure discrepancies between two countries (or among many countries) caused by different measurement strategies can be filled, larger datasets combined from different sources could be used, leading to more accurate risk assessment than depending solely on one data source.

Therefore, the purpose of this study is to determine the relationship between exposure measurements using the US and German measurement strategies, and to develop conversion factors (or equations), as necessary. This study is limited to respirable crystalline silica (RCS). Three known sampling methodologies for RCS were utilized-NIOSH Method 7602, NIOSH Method 7500, and IFA 213-582 Method. 


\section{RESPIRABLE CRYSTALLINE SILICA (RCS)}

The ubiquity of respirable crystalline silica in industrial applications has made it the subject of extensive research for many decades. In its many different forms, it is a commonly used material in industries of ceramics, foundry, glass making, pottery making, metallurgy, construction etc. Work processes like stone cutting, sawing, sanding, polishing, grinding, drilling, abrasive blasting, hydraulic fracturing or even cleaning (in the form of sweeping) generates aerosolized RCS, with particles as small as 10 microns $(\mu \mathrm{m})$ or less becoming airborne. RCS is also known to be a human carcinogen classified as group 1 carcinogen by the International Agency for Research on Cancer and causes other health conditions like silicosis, lung cancer, chronic obstructive pulmonary disease and kidney disease (DOL, 2017).

About 2.3 million people are exposed to RCS occupationally according to data from the US OSHA. Although the incidence of silicosis has generally decreased due to the use of effective control measures, OSHA has acknowledged an increase in silica exposures in new industries such as hydraulic fracturing and countertop manufacturing (DOL, 2017). The number of silicosis deaths by the National Occupational Research Agenda (NORA) industrial sector between 1990 and 1999 was 386 (43.8\%) in manufacturing, 203 (23\%) in mining, 118 (13.4\%) in construction, and $174(19.8 \%)$ in the remaining sectors (NIOSH, 2008).

Although the number of deaths from silicosis decreased from 1,965 in 1968 to 101 in 2010, the number of hospitalizations did not decline between 1993 and 2011 due to the long latency period required to develop silicosis (Filios et al., 2015). Nevertheless, from 2011 to 2013, 12 people younger than 45 years old had silicosis as a cause or contributor to death, probably because exposure levels of silica are higher for these young adults than in older individuals (NIOSH Science Blog., 2015). Schleiff et al. (2016) stated that the Bureau of Labor Statistics consistently undercounts silicosis during surveillance and expected between 3,600 and 7,300 new cases of silicosis per year. Such a high number of new cases indicates that the occurrence of silicosis has not been completely prevented, even with current regulatory standards. Hnizdo and Vallyathan (2003) reported that exposure to silica causes additional 
forms of non-malignant lung disease indicating that the actual burden of silica induced NMRD is greater than that indicated by silicosis data alone.

\section{SELECTED SAMPLING STRATEGIES}

Three known sampling and analytical methods - NIOSH Methods 7602 and 7500 (US methods) and IFA 213-582 (German method)-were selected and the summary of each method is listed in Table 3.1. Both NIOSH 7602 and IFA 213-582 methods use similar sample preparation procedures - the quartz content collected on a filter is homogenized with $\mathrm{KBr}$ in a crucible and formed into pellets - to be analyzed by Fourier transform infrared spectroscopy (IR). The difference between both methods is that while IFA 213-582 recommends annealing the crucible contents for 1.5 hours at $550{ }^{\circ} \mathrm{C}, \mathrm{NIOSH} 7602$ calls for a 2 -hour ashing at $600{ }^{\circ} \mathrm{C}$. The absorption spectrum of quartz for IFA 213-582 is evaluated in the range of wavelengths $798 \mathrm{~cm}^{-1}$ and 779 $\mathrm{cm}^{-1}$, while NIOSH 7602 scans absorbance between $400 \mathrm{~cm}^{-1}$ and $1000 \mathrm{~cm}^{-1}$.

NIOSH 7500 analyzes samples using X-ray diffraction (XRD), where a filter, loaded with quartz, is folded and transferred into a sample crucible. The filter is then washed and rinsed in series with hydrochloric acid rinse solution, deionized water, and isopropyl alcohol (IPA). Unlike the IR methods, a higher ashing temperature is utilized: $800^{\circ} \mathrm{C}$ for 2 hours in a muffle furnace, after which the crucible sides are rinsed down with about $2 \mathrm{~mL}$ of IPA and sonicated. The quartz contents are then transferred to a silver membrane filter, and subsequently to a sample plate to be placed in the automated sample changer for analysis by XRD. In addition, different samplers (e.g., GK2.69 for both NIOSH methods and FSP-10 for the IFA 213-582 method) were used to collect aerosolized particles. 
Table 3. 1. Summary of RCS Sampling and Analytical Methods

\begin{tabular}{|c|c|c|c|}
\hline Analytical Method & IFA 213-582 (Germany) & NIOSH 7602 (US) & NIOSH 7500 (US) \\
\hline Method Published & 2013 & 2017 & 2003 \\
\hline Analyte & Crystalline $\mathrm{SiO}_{2}$ & Crystalline $\mathrm{SiO}_{2}$ & Crystalline $\mathrm{SiO}_{2}$ \\
\hline Chemical Principle & Infrared spectroscopy (IR) & Infrared spectroscopy (IR) & X-ray powder diffraction (XRD) \\
\hline Measures & $\begin{array}{l}\text { Absorbance between } \\
798 \mathrm{~cm}^{-1} \text { and } 779 \mathrm{~cm}^{-1}\end{array}$ & $\begin{array}{l}\text { Absorbance between } \\
400 \mathrm{~cm}^{-1} \text { and } 1000 \mathrm{~cm}^{-1}\end{array}$ & $\begin{array}{l}\text { Optimize for intensity; } 1^{\circ} \text { slit } \\
\text { Slow step scan, } 0.02^{\circ} / 10 \mathrm{sec} \\
\text { Integrated intensity w. background } \\
\text { subtraction }\end{array}$ \\
\hline Sampler & FSP-10 Cyclone & Respirable Cyclone & $\begin{array}{l}\text { 10-mm nylon, Higgins Dewell }(H D) \text {, or } \\
\text { Aluminum Cyclone }(A C)^{1}\end{array}$ \\
\hline Media & Nitrocellulose (NC) filter ( $8 \mu \mathrm{m}$ pore size) & Polyvinyl chloride (PVC) filter (5 $\mu \mathrm{m}$ pore size) & $\begin{array}{c}\text { PVC filter } \\
(5 \mu \mathrm{m} \text { pore size })\end{array}$ \\
\hline Flowrate & $10 \mathrm{~L} / \mathrm{min}$ & $\begin{array}{l}\sim 2 \text { to } \sim 4 \mathrm{~L} / \mathrm{min} \text {, } \\
\text { specific to the cyclone }\end{array}$ & $\begin{array}{c}\text { Nylon cyclone: } 1.7 \mathrm{~L} / \mathrm{min} ; \\
\text { HD cyclone: } 2.2 \mathrm{~L} / \mathrm{min} ; \mathrm{AC}: 2.5 \mathrm{~L} / \mathrm{min}\end{array}$ \\
\hline Collection time & $2 \mathrm{~h}$ & Not specified full shift (6-8 hrs) & Not specified full shift (6-8 hrs) \\
\hline Collection volume & $1.2 \mathrm{~m}^{3}(1200 \mathrm{~L})$ & $400 \mathrm{~L}-1000 \mathrm{~L}$ (total dust < $4 \mathrm{mg}$ ) & $400 \mathrm{~L}-1000 \mathrm{~L}$ (total dust < $4 \mathrm{mg}$ ) \\
\hline RCS Range & Not specified & 10 to $>160 \mu \mathrm{g}$ & 0.02 to $2 \mathrm{mg}$ \\
\hline Precision & Not specified & $<0.15$ at $30 \mu \mathrm{g}$ per sample & 0.08 at 0.05 to $0.2 \mathrm{mg}$ per sample \\
\hline Estimated RCS LOD & $0.008 \mathrm{mg} / \mathrm{m}^{3}$ & $5 \mu \mathrm{g}$ & $0.005 \mathrm{mg} \mathrm{SiO}_{2}$ per sample \\
\hline Estimated LOQ & $\begin{array}{c}\text { absolute: } \sim 0.03 \mathrm{mg} \text {. } \\
\text { relative: } 0.0013 \text { to } 0.13 \mathrm{mg} / \mathrm{m}^{3} \text { (for } 2 \mathrm{~h} \\
\text { sampling) \& } \\
0.0003 \text { and } 0.031 \mathrm{mg} / \mathrm{m}^{3} \text { (for } 8 \mathrm{~h} \text { sampling) }\end{array}$ & Not specified & Not specified \\
\hline
\end{tabular}




\section{LITERATURE REVIEW}

Gao et al. (2000) explored the dose-response relationship for developing epidemiological data investigating a variety of diseases like lung cancer and silicosis in workers within the metal mining (iron/copper, tin, and tungsten) and pottery industries. The study was a collaboration of the NIOSH and Tongji Medical University. Two different sampling methodologies were compared: the Chinese and US dust sampling methods. The Chinese method recommends data collection for 15 minutes during operations and compares the data to a given maximum allowable concentration (MAC) standard using traditional Chinese total dust samplers (Model FC-2, Wuhan Analytical Instrument Company, Wuhan, China) running at a flowrate of 25 liters per minute (LPM). The US method for this study used 2 sampler types-a 10-mm nylon cyclone running at 1.7 LPM and a multi-stage 'cassette' impactor running at 2.01 LPM for the eight-hour time-weighted average (TWA) sampling period. One hundred side-byside area samples were collected using the 3 sampler types over a 12-month period in 29 locations in China including tungsten mines, copper mines, tin mines, and pottery factories. Both the 10-mm cyclone and the cassette impactor measured the respirable mass gravimetrically. Dust concentrations were then calculated using the ratio of the respirable dust mass to the sampled air volume. The regression analysis yielded a slope of 0.223 for the $10-\mathrm{mm}$ nylon cyclone and 0.274 for the impactor. Because the slopes of both samplers were not statistically different, a weighted average of the two slope estimates were calculated and yielded a pooled mean conversion factor of 0.25 with a $95 \%$ confidence interval $(\mathrm{Cl})$ of \pm 0.04 for all the job titles and industries included in the study (See Table 3.2). No statistical differences were found among the different job titles (crusher, driller, loader etc.) within each industry. Applying the above conversion factor to the previously collected total dust measurements, it was determined that workers in China have historically been in compliance with the American Conference of Governmental Industrial Hygienists (ACGIH) guide for respirable dust. 
Table 3. 2. Converting Chinese 'Total Dust' Measurements to Respirable Concentrations in Metal Mines and Pottery Industries

\begin{tabular}{|c|c|c|c|c|}
\hline Country & Sampler & Industry & Conversion & $\begin{array}{l}\text { Conversion } \\
\text { Factor (CF) }\end{array}$ \\
\hline US & 10 mm Nylon Cyclone & \multirow{3}{*}{$\begin{array}{c}\text { Metal Mining } \\
\text { (iron/copper, tin, } \\
\text { tungsten) Pottery }\end{array}$} & \multirow{3}{*}{$\begin{array}{l}\text { Total Dust to } \\
\text { respirable Dust }\end{array}$} & \multirow{3}{*}{$0.25 \pm 0.04^{1}$} \\
\hline US & $\begin{array}{l}\text { Multi-stage cassette } \\
\text { impactor }\end{array}$ & & & \\
\hline CHINA & $\begin{array}{l}\text { Chinese Dust Sampler } \\
\text { (FC-2) }\end{array}$ & & & \\
\hline
\end{tabular}

${ }_{1}^{1}$ Pooled mean conversion factor from the conversion factors between the 10-mm nylon cyclone and FC-2 (0.223) and between the impactor and FC-2 (0.274)

Zhuang et al. (2000) conducted a similar investigation with the same retrospective dust monitoring data derived from the historical industrial hygiene records. The purpose of the study was to standardize the Chinese total dust data with published RCS exposure data using dust from the pottery and mining industry. Side-by-side area samples were taken during normal work operation using the 10-mm nylon cyclone (NIOSH) operating at 1.7 LPM for full shifts and the Chinese dust sampler (FC-2). As was mentioned above, Chinese sampling methodology requires sampling during the task of interest at a flowrate of 25 LPM for about 15-20 minutes. Bulk samples were collected for particle size analysis of the crystalline silica content. Historical dust measurement data typically did not analyze particle size for crystalline silica, but the bulk data collected did, which served as a useful baseline comparison. The study reported conversion factors (from the total dust to RCS concentrations) of 0.014 for iron/copper mines, 0.036 for pottery factories, 0.043 for tin mines, and 0.086 for tungsten mines and showed that mean conversion factors were significantly different among facilities within the iron/copper industry and within the pottery industry (See Table 3.3). Based on the application of these conversion factors, the investigators concluded that the average RCS concentrations for iron/copper mines and pottery factories have remain relatively constant, but tungsten mines concentrations have seen a steady decline, possibly due to the introduction of dust suppression and control systems. 
Table 3. 3. Converting Total Dust to Respirable Crystalline Silica Exposures for Chinese Pottery Workers and Iron/Copper, Tin, and Tungsten Miners

\begin{tabular}{ccccc}
\hline Country & Sampler & Conversion & Industry & Conversion Factor (CF) \\
\hline \multirow{2}{*}{ US } & $\begin{array}{c}\text { 10-mm } \\
\text { Nylon }\end{array}$ & & & \\
& Cyclone & Total Dust to & Metal Mining & 0.014 for the iron/copper mines; \\
Respirable & $\begin{array}{c}\text { (iron/copper, tin, } \\
\text { tungsten) Pottery }\end{array}$ & $\begin{array}{c}0.036 \text { for the pottery factories; } 0.0429 \\
\text { for the tin mines; } 0.086 \text { for the } \\
\text { CHINA }\end{array}$ & $\begin{array}{c}\text { Chinese } \\
\text { Dust }\end{array}$ & $\begin{array}{c}\text { Crystalline Silica } \\
\text { tungsten mines }\end{array}$ \\
& $\begin{array}{c}\text { Sampler } \\
\text { (FC-2) }\end{array}$ & & & \\
\hline
\end{tabular}

Guldner et al. (2011) performed side-by-side dust sampling using German dust samplers used pre and post 1970's. Because no standardized methods existed before 1971, dust sampling data were based on the specific methodology and sampler used. After 1971 to date, approved and standardized methods have been used to measure dust across various industries, but no direct comparisons could be made within the data produced pre and post 1971 . The Double cone shapes sampling unit (DC) and Gravikon WL 10/40 were inhalable and respirable dust samplers used between 1955 and 1975 running at a flowrate of $20 \mathrm{~m}^{3} / \mathrm{h}$. Afterwards the VC $25 \mathrm{~F}$ sampler running at $22.5 \mathrm{~m}^{3} / \mathrm{h}$ was developed to sample respirable dust. Side-by-side area samples were taken using all 3 samplers in a porcelain facility and in a wind tunnel. A sampling device factors (conversion factors) were calculated by divided results of VC 25 F by DC and Gravikon WL 10/40 samplers, and accounting for both the sampling procedure and the analytical process, a conversion factor of 1.5 was suggested (See Table 3.4).

Table 3. 4. Converting Historical Dust Measurements to Modern Dust Measurements in Germany

\begin{tabular}{|c|c|c|c|c|}
\hline Country & Sampler & Conversion & Industry & $\begin{array}{l}\text { Conversion } \\
\text { Factor (CF) }\end{array}$ \\
\hline Germany (pre-1970) & $\begin{array}{l}\text { Double cone shapes } \\
\text { sampling unit (DC) }\end{array}$ & \multirow{3}{*}{$\begin{array}{l}\text { Historical Dust to } \\
\text { Modern Dust } \\
\text { Measurements }\end{array}$} & \multirow{3}{*}{$\begin{array}{l}\text { Porcelain/Wind } \\
\text { Tunnel }\end{array}$} & \multirow{3}{*}{1.5} \\
\hline Germany (pre-1970) & Gravikon WL 10/40 & & & \\
\hline Germany (post-1970) & VC $25 \mathrm{~F}$ & & & \\
\hline
\end{tabular}


Chen et al. (2005) work with cohorts from Chinese tin and tungsten mine workers as well as pottery workers illustrates how the use of conversion factors can be used to merge results from different industrial hygiene studies for epidemiology research. The objective of the study was to compare the risk of silicosis among cohorts of silica dust-exposed Chinese tin miners, tungsten miners, and pottery workers and to assess whether different types of silica dust exposed workers to silicosis to a greater or lesser degree. The cohort was composed of workers from 20 factories. Data for the study was assessed in terms of cumulative total dust (CTD) and gathered from industrial hygiene records compiled in the almost 4 decades from 1950 to 1986 . The cumulative total dust was then converted to cumulative respirable dust (CRD) and then converted to cumulative respirable silica dust (CRSD). Conversion factors from Zhuang et al. (2000) and its companion study (Gao et al. 2000) were used to calculate final conversion factors for converting Chinese total dust to US respirable silica and those were: 0.031 for potteries, 0.039 for tin mines, and 0.050 for tungsten mines. They then applied these factors to a cohort study including 4,028 tin miners, 14,427 tungsten miners, and 4,547 pottery workers who had similar onset of employment and duration of follow-up. The results indicated that the highest percentage of subjects with silicosis were found especially among tin and tungsten miners and pottery workers registered the lowest percentage. Chen et al. study illustrates the usefulness of conversion factors or equations for retrospective studies, where factors can be applied to already existing data, but it also shows the potential for use in prospective studies, where the factors can be applied to data after sampling is conducted in one country and interconverted to get reliable results for another.

Yang et al. (2012) compared the Chinese total dust sampler (CT) with both the US 10mm nylon cyclone (AR) and the German FSP-BIA sampler (GR) with the objective of obtaining conversion factors for recalculating respirable dust from total dust. Two sets of conversion factors were derived: AR to CT and GR to CT. Area samples were collected from 15 factories across several industries. The Chinese dust sampler, which ran at a flowrate of 25 LPM for 15 minutes, sampled 3 times during a shift, while the other two samplers-10-mm nylon cyclone operating at 1.7 LPM and FSP-BIA sampler running at 2.0 LPM-sampled for 2-6 hours. In addition, the same experiment was conducted under more controlled conditions in a wind 
tunnel ( $1 \mathrm{~m} / \mathrm{s}$ ) for comparative analysis. The three samplers were placed on a stand inside the tunnel about $20 \mathrm{~m}$ from the aerosol emission source generating a mixture of quartz flour (Millisil W6 ${ }^{\circledR}$, DIN 4226) with a medium grain size (D50\%) of $40 \mu \mathrm{m}$ as tested powder and washed quartz sand as carrier. All collected samples were analyzed gravimetrically. Conversion factors of AR/CT were 0.38 for tungsten mines, 0.19 for copper/iron mines, 0.65 for tin mines, and 0.20 for the pottery industry, while the factors for GR/CT were 0.69 for tungsten, 0.37 for copper/iron, and 0.52 for pottery factories (See Table 3.5). The average conversion factors reported for the $1989-90$ sampling in the same industries were 0.45 for GR/CT and 0.29 for $A R / C T$. Notably, the GR/CT ratio is much larger than the AR/CT ratio. The AR/CT ratio was similar to 0.25 reported by Gao et al. (2000) mentioned earlier, but unlike Gao et al., Yang et al. reported that $A R / C T$ ratios were significantly different among industries. Both the field study and wind tunnel results indicate that the German FSP-BIA sampler gave respirable measurements higher that the US 10-mm nylon cyclone.

Table 3. 5. Converting Chinese total dust to respirable dust concentrations

\begin{tabular}{|c|c|c|c|c|c|}
\hline Country & Sampler & Conversion & Industry & Conversior & Factor (CF) \\
\hline US & $\begin{array}{l}10 \text { mm Nylon } \\
\text { Cyclone (AR) }\end{array}$ & \multirow{3}{*}{$\begin{array}{l}\text { Chinese total } \\
\text { dust to } \\
\text { respirable dust } \\
\text { concentrations }\end{array}$} & \multirow{3}{*}{$\begin{array}{c}\text { Metal Mining } \\
\text { (iron/copper, } \\
\text { tin, tungsten); } \\
\text { Pottery }\end{array}$} & \multirow{3}{*}{$\begin{array}{l}\frac{\mathrm{AR} / \mathrm{CT}(0.29)^{1}}{0.38 \text { for the }} \\
\text { tungsten mines } \\
0.19 \text { for the } \\
\text { copper/Iron } \\
0.65 \text { for the tin } \\
\text { mines } \\
0.20 \text { for the } \\
\text { pottery industry }\end{array}$} & \multirow{3}{*}{$\begin{array}{c}\text { GR/CT }(0.45)^{1} \\
0.69 \text { for the } \\
\text { tungsten mines } \\
0.37 \text { for the } \\
\text { Copper/Iron } \\
0.52 \text { for the } \\
\text { pottery } \\
\text { Industry }\end{array}$} \\
\hline GERMANY & FSP-BIA (GR) & & & & \\
\hline CHINA & $\begin{array}{c}\text { Chinese Dust } \\
\text { Sampler, FC-2 } \\
\text { (CT) }\end{array}$ & & & & \\
\hline
\end{tabular}

${ }^{1}$ Conversion factors of exposure measurements collected during the period of 1989-1990

Dahmann et al. (2008) reviewed exposure assessment issues unique to the evaluation of RCS for use in epidemiological studies. The report focused on reviewing different methods and equipment used to measure silica from respirable dust along with the effectiveness of these methods and conversion factors developed between the historical dust data and the data useful for more recent times. It addressed the need for a job-exposure matrix (JEM) 
development due to a lack of historical data and how quantification of methodological uncertainties can lead to recommendations for best practices in exposure assessments. The findings of that report indicate a need for additional studies using side-by-side measurement strategies to reduce this uncertainty.

Similar research works were done for other chemical agents. Kriech et al. (2010) conducted a field study of bitumen exposures in paving and roofing worksites across Europe and the US. Personal samples were collected using the German PGP-GGP with a XAD-2 resin cartridge system sampler and US closed face cassette (CFC) sampler during a variety of industrial processes with both samplers mounted on the left and right shoulder of the workers. Two comparisons were made between 1) aerosol values analyzed using the German IFA Method 6305 and benzene soluble fraction (BSF) values analyzed with the US NIOSH Method 5042; and 2) (aerosol + vapor) using the IFA method 6305 and the total organic matter (TOM) data reported from the Heritage method. Regression analysis was run with 35 of the 55 samples collected that had values over the limit of detection (LOD) to compare the aerosol data with the total particulate matter $\left(\right.$ TPM) yielded the relationship: $Y_{(T P M)}=1.01 \times($ aerosol) with an $r^{2}$ value of 0.83 . BSF, the organic part of the TPM, was also compared to the aerosol data and the regression equation for the relation was $Y_{(B S F)}=0.60 *$ (aerosol) with a $r^{2}$ value of 0.88 . An additional analysis with 13 pairs of roofing samples was used to compare the TOM data with the aerosol + vapor data. The conversion equation derived was $Y_{(\text {(Tом })}=0.74 *$ (aerosol + vapor) $\left(r^{2}=0.91\right)$.

Table 3. 6. Conversion factors for Field Sampling of Bitumen between the US and German Methods

\begin{tabular}{|c|c|c|c|c|}
\hline Country & Sampler & Conversion & Industry & Conversion Factor (CF) \\
\hline US (NIOSH) & $\begin{array}{l}\text { Closed-face filter } \\
\text { cassette with PTFE }\end{array}$ & $\begin{array}{c}\text { Converting } \\
\text { German (IFA) to } \\
\text { US (NIOSH) }\end{array}$ & Paving and & $\begin{aligned} U_{\text {TPM }} & =1.01 \times I F A_{\text {aerosol }} \\
U_{\text {BSF }} & =0.60 \times I_{\text {IFA }} A_{\text {aerosol }}\end{aligned}$ \\
\hline Germany (IFA) & $\begin{array}{l}\text { PGP-GGP system } \\
\text { with glass fiber } \\
\text { filter }\end{array}$ & $\begin{array}{l}\text { Methods for } \\
\text { Bitumen } \\
\text { Exposures }\end{array}$ & worksites & $\begin{array}{c}\text { US }_{\text {TOM }}=0.74 * \text { IFA }_{\text {(aerosol }+} \\
\text { vapor) }\end{array}$ \\
\hline
\end{tabular}


In 2018, Sutter et al. conducted another Bitumen study comparing the sampling strategies between Germany (IFA) and France (INRS) in a lab setting and using field area samples. The objective was to develop conversion factors, which can be used to increase the data points available for bitumen studies, thereby increasing the statistical power. Both the IFA and INRS methods of sampling bitumen are similar in principle but differ in sampler types, solvent used to extract bitumen, and specific method of analysis (see below for details). The IFA strategy uses an inhalable dust-gas-sampling system comprising an inhalable particle sampler running at 3.5 LPM. It includes a glass-fiber depth filter for particle collection, and a 10-g XAD-2 amberlite resin cartridge $(0.5-0.9 \mathrm{~mm})$ to adsorb organic vapors. The INRS strategy samples bitumen with a 37-mm polystyrene cassette containing a Polytetrafluoroethylene (PTFE) membrane filter and an XAD-2 amberlite sorbent tube connected in a series sampling at 1 LPM. Also, the analytical method recommended by IFA utilizes extraction in $10 \mathrm{ml}$ of tetrachloroethylene $\left(\mathrm{C}_{2} \mathrm{Cl}_{4}\right)$ for a minimum of 16 hours and any elements present will be detected by infrared absorption; but Frances' INRS methods extract substrates in $n$-heptane ( $n$ $\mathrm{C}_{7} \mathrm{H}_{16}$ ) and the extracts are analyzed by gas chromatography and flame ionization detector (GCFID).

The study was conducted both in a controlled lab chamber generating bitumen and on French and German road construction sites. Side-by-side samplers used in both countries were placed inside an exposure chamber generating bitumen fumes with concentrations ranging from 0.01 to $9.36 \mathrm{mg} / \mathrm{m}^{3}$. In the field test, 6 sets of side-by-side area samplers were placed on a construction road site close to an emission source and sampled for 2 hours along with 2 other samplers used for field blanks. This was repeated 3 times during the shift. Sampling was conducted during a wintertime in France and a Fall in Germany. Results from both the chamber and field tests indicate that the German strategy sampled quantifiably higher concentrations of bitumen than the French. Based on the results a conversion equation with a $95 \% \mathrm{Cl}$ was determined as $C_{\text {IFA }}=1.76 * C_{\text {INRS }} \pm 0.39\left(r^{2}=0.99\right)$. (Table 3.7) 
Table 3. 7. Comparison of German and French methods to determine a conversion formula for bitumen fumes

\begin{tabular}{ccccc}
\hline Country & Sampler & Conversion & Industry & $\begin{array}{c}\text { Conversion } \\
\text { Factor (CF) }\end{array}$ \\
\hline \multirow{2}{*}{ FRANCE } & $\begin{array}{c}\text { 37-mm polystyrene cassette w. } \\
\text { (PTFE) filter \& XAD-2 amberlite } \\
\text { sorbent tube }\end{array}$ & $\begin{array}{c}\text { French to } \\
\text { German Bitumen } \\
\text { concentrations }\end{array}$ & $\begin{array}{c}\text { Load paving } \\
\text { sites }\end{array}$ & $\begin{array}{c}\mathrm{C}_{\text {IFA }}=1.76^{*} \mathrm{C}_{\text {INRS }} \\
\pm 0.39\end{array}$ \\
\hline \multirow{2}{*}{ GERMANY } & $\begin{array}{l}\text { Inhalable Dust-Gas Sampler } \\
\text { W. glass-fiber depth filter \& 10-g } \\
\text { XAD-2 amberlite resin cartridge }\end{array}$ & & \\
& & & \\
\hline
\end{tabular}

As far as we are aware, no study has been conducted to investigate the relationship between exposure measurements of RCS using the current US and German measurement strategies. Since NIOSH sampling and analytical methods are widely accepted in other countries (Zilaout et al., 2017) and Germany maintains one of largest exposure datasets (i.e., MEGA database), it is necessary to determine the exposure relationship between those two countries. 


\section{RESEARCH HYPOTHESES}

For this study, the overall research question of interest is: "Is there any relationship between the US (NIOSH) and German (IFA) sampling methodologies for respirable crystalline silica?"

The question was explored using spiked samples and exposure data collected from an environmentally controlled chamber and a worksite. The overall null and alternative hypotheses are:

Table 3. 8. Overall Research Hypothesis

$\boldsymbol{H}_{\mathbf{0}}: \quad$ There are no statistical differences in RCS concentrations between the US sampling strategy (NIOSH) and the German sampling strategy (IFA)

$\boldsymbol{H}_{\boldsymbol{a}}: \quad$ There are statistical differences in RCS concentrations between the US sampling strategy (NIOSH) and the German sampling strategy (IFA)

\section{PART I. SPIKED SAMPLES STUDY}

Spiked samples were analyzed by both German lab (IFA) and NIOSH contract lab (NC) using each analytical method to determine the variability between the analytical methods and between the labs. To determine the difference between the analytical methods, three comparisons were made- NIOSH 7602 vs. IFA 213-582, NIOSH 7500 vs. IFA 213-582, and NIOSH 7602 vs. NIOSH 7500. The variability between the labs was also determined by comparing the results of both countries for each method. Below is an example of the hypothesis test for differences in quartz masses between the NIOSH 7602 (IR) method and the IFA 213-582 (IR) method.

$\mathrm{H}_{\mathrm{o}}$ : There are no statistical differences in quartz masses $(\mu \mathrm{g})$ between the NIOSH 7602 (IR) method and the IFA 213-582 (IR) method for the NIST RCS reference samples.

\section{$\mu_{\text {NIOSH } 7602}=\mu_{\text {IFA 213-582 }}$}

$\mathrm{H}_{\mathrm{a}}$ : There are statistical differences in quartz masses $(\mu \mathrm{g})$ between the NIOSH 7602 (IR) method and the IFA 213-582 (IR) method for the NIST RCS reference samples.

$\mu_{N I O S H} 7602 \neq \mu_{I F A 213-582}$ 


\section{PART II. AEROSOL CHAMBER STUDY}

Samples from an environmentally controlled chamber were analyzed by both German (IFA) and US (NC) labs using each analytical method to determine the level of variability between the (sampler + analytical methods). The variability between the labs was also determined by comparing the results of both countries for each method. For this phase, the same comparisons done with the spiked sample results were conducted. Below is an example of the hypothesis test for differences in RCS concentrations between the NIOSH 7602 (IR) and the IFA 213-582 (IR) method.

$\mathrm{H}_{0}$ : There are no statistical differences in RCS concentrations between the NIOSH 7602 (IR) method and the IFA 213-582 (IR) method. $\mu_{G K 2.69 \text { (N.7602) }}=\mu_{F S P-10 \text { (IFA 213-582) }}$ $\mathrm{H}_{\mathrm{a}}$ : There are statistical differences in RCS concentrations between the NIOSH 7602 (IR) method and the IFA 213-582 (IR) method. $\mu_{G K 2.69(N .7602)} \neq \mu_{F S P-10(I F A ~ 213-582)}$

\section{PART III. FIELD STUDY}

The major factors causing the variation of RCS concentrations between two country's methods from a field study include different sampler types, different analytical methods, and human/environmental conditions. For the field study, samples from the US samplers (GK2.69) were analyzed by the US (NC) lab and samples from the German samplers (FSP-10) were analyzed by the German (IFA) lab. Thus, no comparison of RCS concentrations between labs was conducted. Below is an example of the hypothesis test for differences in RCS concentrations between the NIOSH 7602 (IR) and the IFA 213-582 (IR) method.

$\mathrm{H}_{0}$ : There is no statistical difference in RCS concentrations between the NIOSH 7602 (IR) method and the IFA 213-582 (IR) method. $\boldsymbol{\mu}_{G K 2.69 \text { (N.7602) }}=\boldsymbol{\mu}_{F S P-10 \text { (IFA 213-582) }}$ $\mathrm{H}_{\mathrm{a}}$ : There is a statistical difference in RCS concentrations between the NIOSH 7602 (IR) method and the IFA 213-582 (IR) method. $\mu_{G K 2.69(N .7602)} \neq \mu_{F S P-10}$ (IFA 213-582)

For all hypotheses, a p-value of 0.05 was used to detect the difference. For a detailed list of all hypotheses tested in this study, see Appendix II. 


\section{METHODOLOGY and PROCEDURE}

This study compared the sampling and analytical methods between the US (NC) and Germany (IFA) by determining RCS mass or concentrations in three parts:

1) spiked samples study, to verify differences in the analytical methods within and between both labs,

2) aerosol chamber study, where side-by-side samples were collected under environmentally controlled conditions to determine differences in mass concentration due to (different samplers + analytical methods), within and between both labs, and

3) field study to determine the impact of uncontrolled environmental conditions in addition to those from different sampling and analytical methods.

\section{PART I. SPIKED SAMPLES STUDY}

Certified reference materials (CRM), SRM 2950a respirable alpha quartz on filter media, were purchased from the National Institute of Standards and Technology (NIST) and sent to the US (NC) lab and Germany (IFA) lab for the quartz analysis. A set of SRM 2950a included 70 filters, 35 blank filters plus 35 filters of pre-determined levels of nominal mass of alpha quartz $(5,10,20,50,100,250$, and $500 \mu \mathrm{g})$, at 5 filters per level. Thus, a total of 126 spiked samples plus blank filters were used for this part of the study (126 filters $=(5$ filters +1 blank $) /$ mass $\times 7$ masses $x 3$ analytical methods). The US (NC) lab analyzed the spiked samples with each of 3 analytical methods, but the German (IFA) lab utilized 2 methods (NIOSH 7602 and IFA 213-582 methods) (Table 3.9).

Table 3. 9. Spiked samples prepared for RCS analyses

\begin{tabular}{cccc}
\hline $\begin{array}{c}\text { Analytical Method } \\
\text { Lab }\end{array}$ & IFA 213-582 method & NIOSH Method 7602 & NIOSH Method 7500 \\
\hline \# of mass levels & $7(5,10,20,50$, & US (NC) & US (NC) \\
$(\mu \mathrm{g})$ & $100,250,500)$ & $7(5,10,20,50$, & $7(5,10,20,50$, \\
\hline \# Filters/mass & 5 & $100,250,500)$ & $100,250,500)$ \\
\hline Blank filter/mass & 1 & 1 & 5 \\
\hline Chemical Principle & IR & IR & XRD \\
\hline
\end{tabular}




\section{PART II. AEROSOL CHAMBER STUDY}

The chamber study was conducted inside an environmentally controlled chamber built in the Office of Mine Safety Health Research/NIOSH, Pittsburgh, PA, USA. The chamber, hexagonally shaped, is approximately $2.4 \mathrm{~m}$ high with an inside effective diameter of $1.2 \mathrm{~m}$ and a test section volume of $1.8 \mathrm{~m}^{3}$ (Figure 3.1). Within the chamber sits a rotating table, capable of a 360 을 rotion at speeds ranging from $0.25 \mathrm{rpm}$ to $2.1 \mathrm{rpm}$. The overall flow rate into the chamber ranges from 80 to 300 LPM. In a previous study (Marple and Rubow, 1983), the chamber had been tested for spatial uniformity and temporal stability and shown to be within \pm $3 \%$ when testing with monodisperse liquid particles (particle diameter $=2.5,10$, and $15 \mu \mathrm{m}$ ) and $\pm 5 \%$ when testing with polydisperse dust particles (coal dust and ARD).
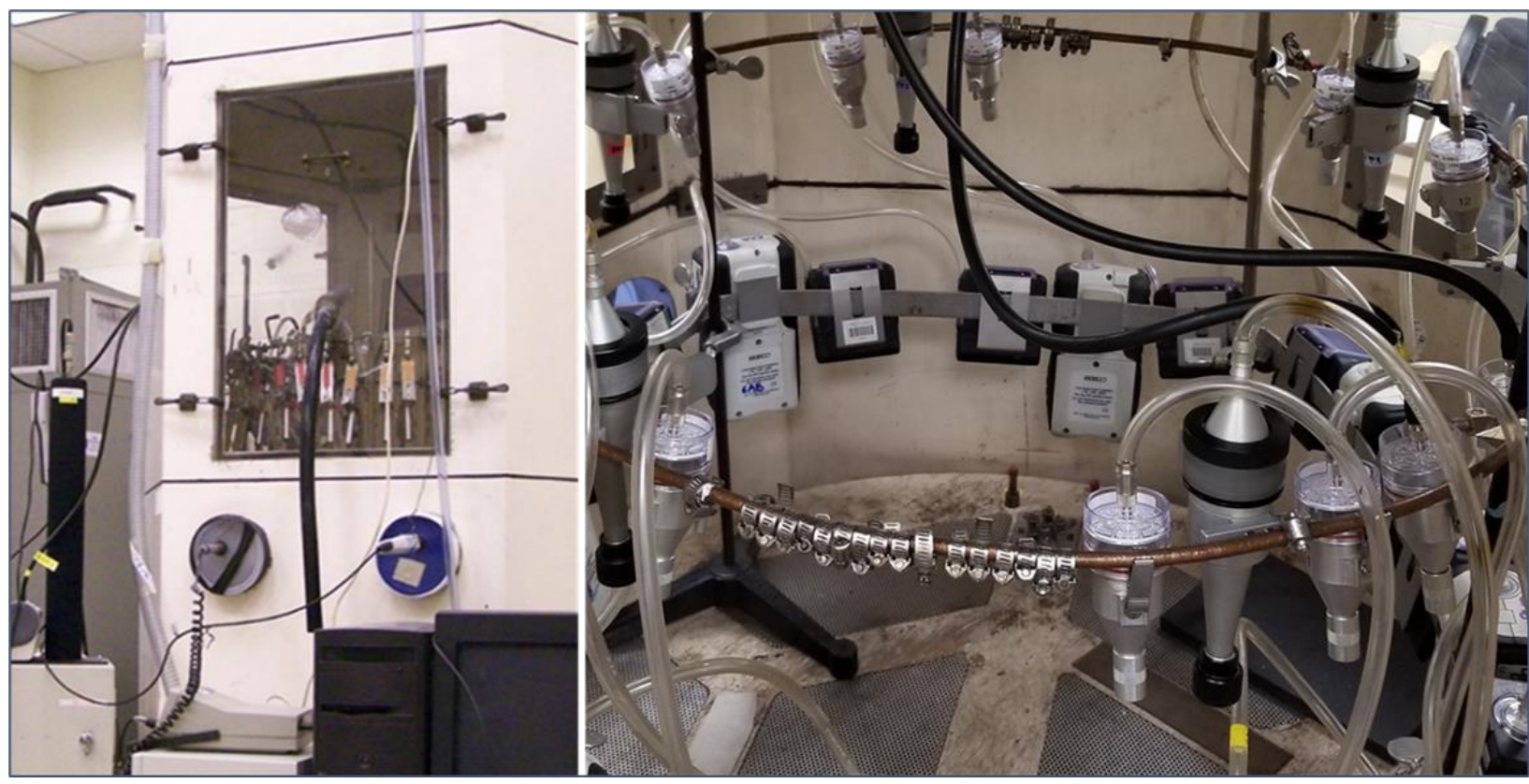

Figure 3. 1. Aerosol Test Chamber. Seven sets of side-by-side samplers were placed to collet aerosolized particles (Arizona Road Dust and MIN-U-SIL ${ }^{\circledR} 10$ ) generated via a fluidized bed aerosol generator.

For this study, GK2.69 cyclones, loaded with PVC filters (5- $\mu \mathrm{m}$ pore size), were used to represent the US sampler and the collected samples were analyzed according to NIOSH Methods 7602 (IR) and 7500 (XRD) for the US sampling and analytical methods (Figure 3.2). For 
the German method, samples were collected with FSP-10 cyclones, loaded with nitrocellulose filters ( $8 \mu \mathrm{m}$ pore size), and analyzed using IFA 213-582 (IR) method.

The GK2.69 and FSP-10 samplers were run at 4.2 LPM and 10 LPM, respectively. Prior to collecting samples, a preliminary test was performed to determine the number of sampler sets (two GK2.69 and one FSP-10 sampler per set) that could be placed in the chamber per testing condition. As a result, it was decided to place 7 sets of samplers per testing condition. The samples from GK2.69 samplers had an average concentration of $3.78 \mathrm{mg} / \mathrm{m}^{3}$ with a relative
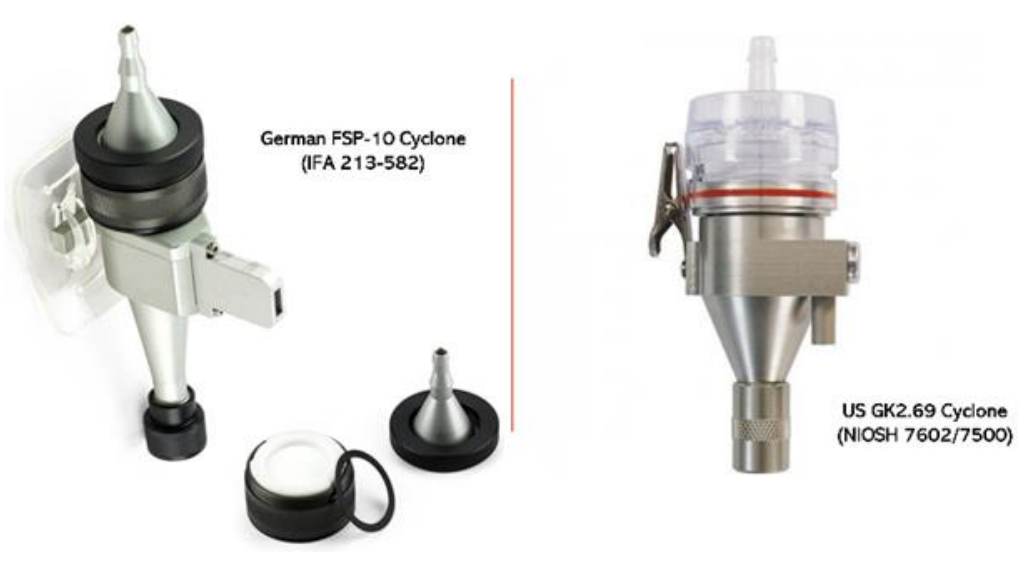
standard deviation (RSD) of 3.25\% and FSP-10 samples had an average concentration of 4.75 $\mathrm{mg} / \mathrm{m}^{3}$ with a RSD of $0.96 \%$. The preliminary test results are available in Appendix III. Then, a standard operating procedure (SOP) including step-by-step procedures for the sample collection was developed to ensure the consistency of the experimental procedures (Appendix III).

The test aerosols used were Arizona Road Dust (ARD) containing about 70\% RCS (mass median aerodynamic diameter $(M M A D)=4.27 \mu \mathrm{m})$ and $\mathrm{MIN}-\mathrm{U}-\mathrm{SIL}{ }^{\circledR} 10$ containing at least 98.6\% RCS with $97 \%$ of the silica particles having an equivalent spherical diameter $<10 \mu \mathrm{m}$ (median size of $2.66 \mu \mathrm{m}$ ). The test aerosols were generated via a fluidized bed aerosol generator. In the chamber, four different levels of the respirable dust concentrations $(0.8,1.3,5$ and $8 \mathrm{mg} / \mathrm{m}^{3}$ ) were targeted. These concentrations were chosen based on a range of results from Lee et al. (2016) study at construction and silica sand production worksites, where respirable dust concentration of RCS ranged from 0.085 to $7.45 \mathrm{mg} / \mathrm{m}^{3}$ with a corresponding quartz mass concentration of 14.8 to $4062 \mu \mathrm{g} / \mathrm{m}^{3}$. The target concentrations in the chamber were monitored with a Thermo TEOM (model 1400, Thermo Fisher Scientific, Franklin, MA). In addition, an Aerodynamic Particle Sizer ${ }^{\circledR}$ (APS) spectrometer (model 3321, TSI Inc.) was used to monitor the size distributions of mass and number concentrations of airborne particles in the 
chamber. When a target mass concentration was reached, the sampling pumps (AirChek XR5000 for GK2.69; Leland Legacy PN:100-3002 for FSP-10; SKC Inc.) attached to the samplers were turned on. The sampling time for this activity was 1 hour per testing condition.

A total of 168 samples per test aerosol (4 concentration levels $x 7$ sets of samples $x 2$ labs $\times 3$ samplers per set $=168$ ) were collected (Table 3.10). Prior to the sample collection, the PVC and nitrocellulose filters were equilibrated in an environmentally controlled weighing room (temperature at $20 \pm 3^{\circ} \mathrm{C}$ and relative humidity of $50 \pm 5 \%$ ) for 24 hours. Pre- and post-weights were then taken using a calibrated 5-figure balance (Model AG245; Mettler-Toledo LLC, Columbus, $\mathrm{OH}$ ) to obtain the masses.

After post-weighing the filters, they were secured in 37-mm two-piece CFCs and boxed for shipment to the labs. Each set was sent to the US (NC) and German (IFA) lab for analysis, where the samples were analyzed using the 3 analytical methods prescribed for the samplesGK2.69 samples analyzed according to NIOSH 7602 and 7500 methods and FSP-10 samples analyzed according to IFA 213-582 method (Table 3.10 and Figure 3.3).

Demange et al. (2002) investigated metal deposits on the internal walls of sampling cassettes and reported that during transportation, about $1.8 \%$ of the sampled mass of barium and $7.9 \%$ of the sampled mass of iron were deposited on the cassette walls. Stacey et al. (2013) also compared the weight of dust on 12 samples after transporting to Italy and South Africa from the UK and reported no significant differences before and after transport (i.e., slopes close to 1). The weights of two other sets of 12 samples used for a round robin study in Belgium were analyzed after transport and showed very similar slopes ranging from 0.98 to 1 (all $r^{2}=0.99$ ). Erekaife et al. (2021) demonstrated that CFC samplers incur no significant particle losses during transport of wood dust samples, which the particle sizes are often larger than those tested in this study. Thus, in the present study, the test aerosols, ARD (MMAD = 4.27 $\mu \mathrm{m})$ and MIN-U$\mathrm{SIL}^{\circledR} 10(\mathrm{MMAD}=2.66 \mu \mathrm{m})$ with a similar diameter, were expected to produce a similar result (i.e., expecting no effect of particle losses during transporting samples from the US to Germany). 
Table 3. 10. Aerosol samples generated from the exposure chamber

\begin{tabular}{|c|c|c|c|}
\hline Analytical Methods & IFA 213-582 method & NIOSH Method 7602 & NIOSH Method 7500 \\
\hline $\begin{array}{c}\text { Number of } \\
\text { concentration levels } \\
\left(\mathrm{mg} / \mathrm{m}^{3}\right)\end{array}$ & $\begin{array}{c}4 \\
(0.8,1.3,5 \text { and } 8)\end{array}$ & $\begin{array}{c}4 \\
(0.8,1.3,5 \text { and } 8)\end{array}$ & $\begin{array}{c}4 \\
(0.8,1.3,5 \text { and } 8)\end{array}$ \\
\hline Sample sets & 7 & 7 & 7 \\
\hline Chemical Principle & $\begin{array}{l}\text { Infrared spectroscopy } \\
\text { (IR) }\end{array}$ & $\begin{array}{l}\text { Infrared spectroscopy } \\
\text { (IR) }\end{array}$ & X-ray Diffraction (XRD) \\
\hline Aerosols sampled & $\begin{array}{c}\text { Arizona road dust (ARD) } \\
\& \text { MIN-U-SIL }{ }^{\circledR} 10\end{array}$ & $\begin{array}{l}\text { Arizona road dust (ARD) } \\
\text { and } \mathrm{MIN}-\mathrm{U}-\mathrm{SIL}^{\circledR} 10\end{array}$ & $\begin{array}{c}\text { Arizona road dust (ARD) } \\
\& M I N-U-S I{ }^{\circledR} 10\end{array}$ \\
\hline $\begin{array}{l}\text { Total number of } \\
\text { samples per test } \\
\text { aerosol }\end{array}$ & 56 & 56 & 56 \\
\hline
\end{tabular}




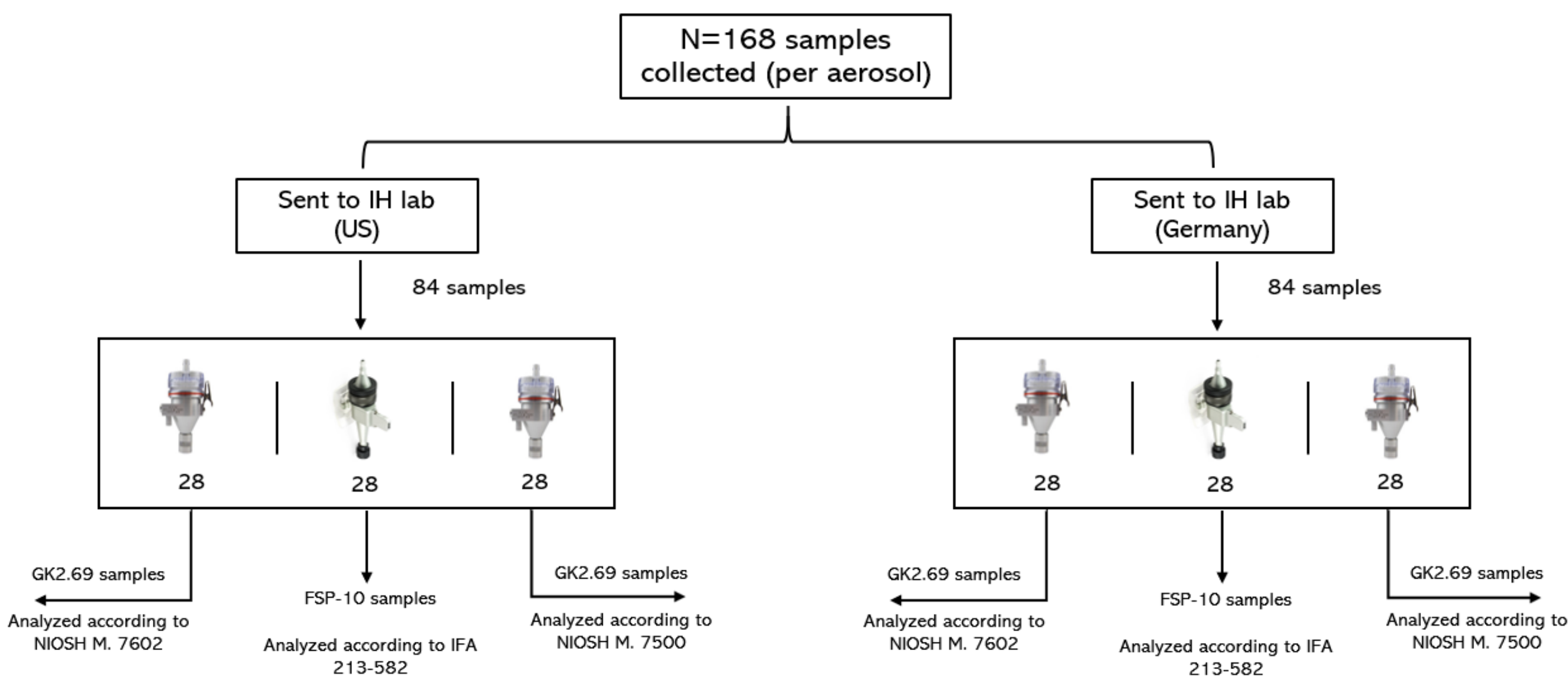

Figure 3. 3. Sample collection and distribution of samples to each lab 


\section{PART III. FIELD STUDY}

Field samples were collected in a ceramic manufacturing (pottery) where dinnerware and other ceramic items are made from different types of clay. The facility was approximately 1,200 feet long $\times 300$ feet wide with an average temperature of $92^{\circ} \mathrm{F}$ and $51 \%$ humidity. Sampling occurred in the months of July and August 2019.

Eleven different job tasks were subject to exposure monitoring: Glost Processing, Waredressing, Casting, Stripping, SKK Operator, Silo House Operator, Glaze Making, Slip House Operator, Pressure Casting, PC RAM Finishing, and Plaster Machine Operator (Appendix V gives brief descriptions of each job task). Before visiting the company, ethical approval was obtained from the NIOSH Institutional Review Board (IRB). Prior to sampling, consent forms were obtained from employees, who participated in the study voluntarily, along with permission for photo documentation.

Personal exposures were obtained by attaching both samplers (GK 2.69 and FSP-10) to the worker's breathing zone, typically on the worker's lapel or shoulder (Figure 3.4). The sampler placement (either on left or on right side) was randomly chosen to minimize any influence of sampler position. Typically, NIOSH recommends sampling for at least 6 to 8 hours to determine a time-weighted average (TWA) exposure reflected in a shift, while IFA recommends sampling for 2 hours (by personal communication). However, to ensure sufficient dust deposition on the filters above the limit of detection (LOD), the sampling times for FSP-10 samplers were adjusted in most cases for the collection of personal samples, ranging from 2 to 4 hours.

Area exposures were collected in the near- and far-field

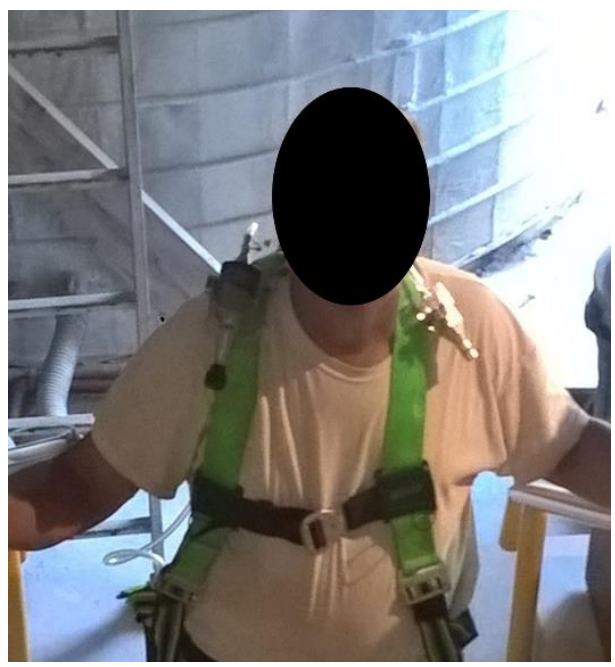

Figure 3. 4. Sampler placement on a volunteer employee from each emission source. Near field samples were generally within 3 feet of the emission source (i.e., the employee) and the far field were generally 3-6 feet further away. These near and far field samples were used to compare how RCS concentrations changed as the dust migrated away from the emission source. For each area sampling location, a basket containing 
four GK2.69 cyclones and two FSP-10 samplers was placed (Figure 3.5). A total of 255 samples including 52 blank samples, 95 personal samples and 100 area samples were collected.

Similar to the chamber study, prior to the sample collection, PVC filters ( $5 \mu \mathrm{m}$ pore size) and nitrocellulose filters ( $8 \mu \mathrm{m}$ pore size) used for the GK2.69 and FSP-10 samplers, respectively, were equilibrated in an environmentally controlled weighing room (temperature at $20 \pm 3^{\circ} \mathrm{C}$ and relative humidity of $50 \pm 5 \%$ ) for 24 hours. Pre- and post-weights were then measured using a calibrated 5-figure balance to obtain respirable mass concentrations (RMC). After post-weighing, the filters loaded with dust were secured in 37-mm two-piece CFCs (for the GK2.69 samples) and plastic cassette holders (for the FSP-10 samples) and boxed for shipment to each lab for the analyses. The GK2.69 samples were analyzed with NIOSH 7602 (IR; personal and area samples) and NIOSH 7500 (XRD; area samples only) at the US (NC) lab, while the FSP-10 samples were sent to the German (IFA) lab for analysis using IFA 213-582 (IR).
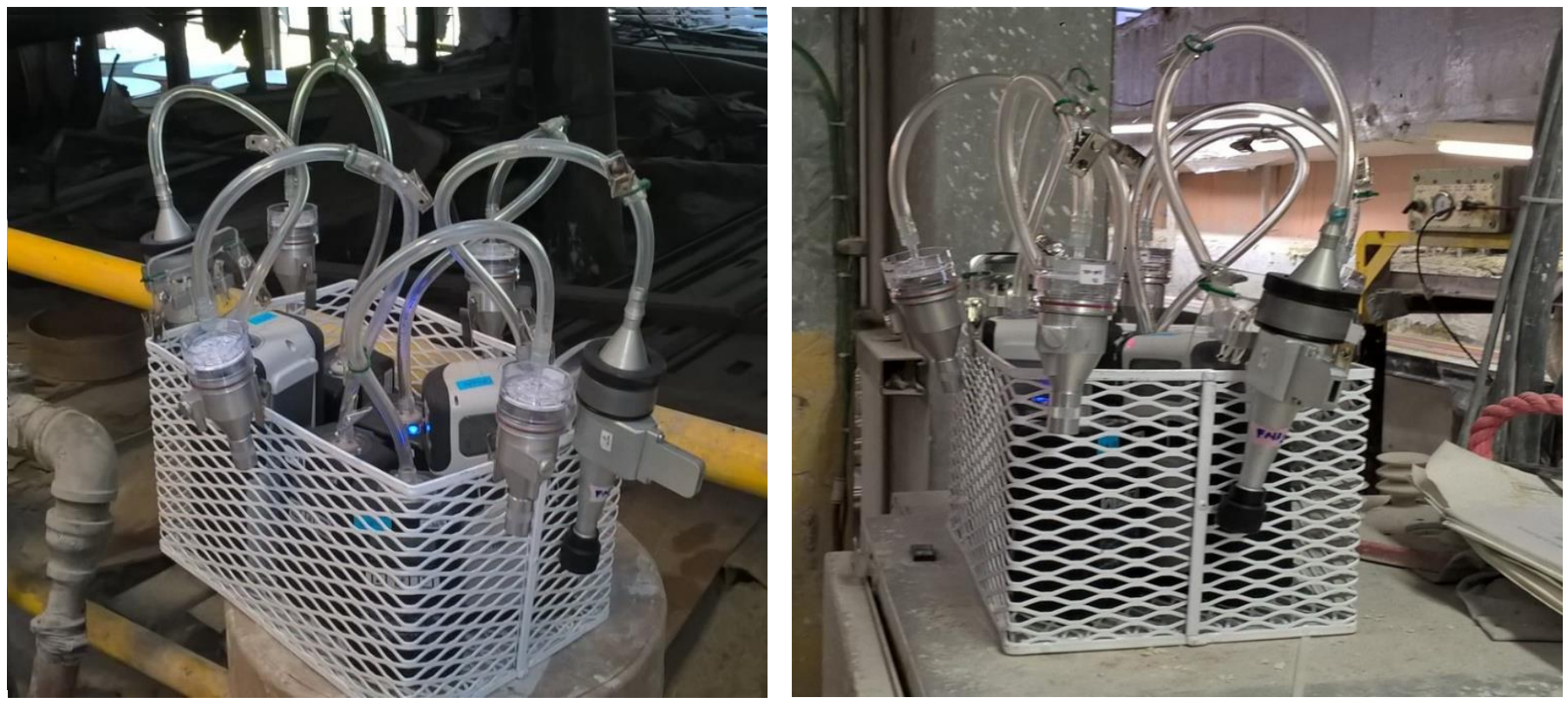

Figure 3. 5. Near Field area sampling stations at the Silo House (Left) and Pressure Casting (Right). 
DATA ANALYSIS

Statistical analyses were conducted to determine the differences between the results of the different methods using a mixed-model two-way analysis of variance with JMP software (SAS Institute, Cary, NC). Sample pair was included in the model as a random variable. For the samples collected from the chamber study and a workplace, analyses were performed on matched pairs of different samplers after calculation of both the RMC and RCS concentrations. In some results, values below the LOD were imputed using the LOD/sqrt 2 (Hornung and Reed, 1990). The data underwent a log transformation prior to analysis tested to ensure that all relevant statistical assumptions were met. These assumptions were tested by analysis of the residuals and qq-plots demonstrating normally distributed residuals with no heterogeneous variance. Pairwise comparisons were generated using Fisher's least significance difference tests. All differences were considered significant at $p<0.05$. In addition, regression analyses were conducted as follows:

- Spiked Samples and aerosol chamber study: Several regression lines were generated to compare different methods- NIOSH 7602 vs. IFA 213-582, NIOSH 7500 vs. IFA 213-582, and NIOSH 7602 vs. NIOSH 7500-in each lab, where possible and each lab's performance for each method. For the spiked samples, all reference filters except for a nominal mass of 5 ug were used ( $n=150$ samples). For the chamber study, a total of 670 samples were utilized.

- Field Study: For the personal samples, 31 out of 55 pairs (only IR methods by both countries) was used for the regression analyses. Among 35 area sample pairs, 31 pairs were used for the regression analyses. Then, the combined data of personal and area samples were analyzed in the same manner.

For the spiked samples and samples generated from all the sampling sessions during the test chamber (ARD and $\mathrm{MIN}-\mathrm{U}-\mathrm{SIL}^{\circledR} 10$ ) and field study, no quantifiable quartz material was detected in the blank samples, so no blank adjustments were necessary. 


\section{RESULTS and DISCUSSION}

\section{PART I. SPIKED SAMPLES STUDY}

The overall means for the spiked sample results are displayed in Tables 3.11 and 3.12. Among 7 nominal masses $(5,10,20,50,100,250$, and $500 \mathrm{ug})$, the filters with nominal mass of $5 \mu \mathrm{g}$ were excluded because all masses reported by both labs were less than the LOD for IFA 213-582 and NIOSH 7602 methods. Also, filters with a nominal mass of $10 \mu \mathrm{g}$ (analyzed in the US (NC) lab) were excluded because all, but the filters analyzed according to NIOSH 7500 (XRD) were less than LOD.

The LODs of the IR instruments as reported by both labs were $10 \mu \mathrm{g}$ and $5 \mu \mathrm{g}$ for the US (NC) and German (IFA) labs, respectively and $5 \mu \mathrm{g}$ for the XRD instrument. Only the US (NC) lab analyzed the samples using NIOSH 7500 (XRD). Overall, NIOSH 7500 (XRD) method showed higher quartz masses compared to the other two methods, regardless of mass levels, while both IR methods showed similar results (Figure 3.6).

The ratios of the lab mass over target mass (lab mass/spiked mass) were $0.86,0.88$, and 1.13 for the IFA 213-582 (IR), NIOSH 7602 (IR), and NIOSH 7500 (XRD), respectively for the samples analyzed by the US (NC) lab. For the German (IFA) lab, the mass ratio for the IFA 213582 (IR) and NIOSH 7602 (IR) methods were 0.78 and 0.80, respectively. The coefficient of variation (CV) ranged from $3 \%$ to $23 \%$ for all samples analyzed by the US (NC) regardless of the analytical methods. On the other hand, the samples with target masses of $20 \mu \mathrm{g}$ and $50 \mu \mathrm{g}$ analyzed by the German (IFA) lab showed CVs greater than $20 \%$ (range from $3 \%$ to $34 \%$ ) regardless of the methods.

Table 3. 11. Results of Spiked Samples using three analytical methods (US NC lab)

\begin{tabular}{cccccccc}
\hline \multirow{2}{*}{$\begin{array}{c}\text { Nominal } \\
\text { Mass, } \mu \mathrm{Ng}\end{array}$} & $\mathrm{N}^{1}$ & \multicolumn{7}{c}{ IFA 213-582 (IR) } & NIOSH 7602 (IR) & \multicolumn{2}{c}{ NIOSH 7500 (XRD) } \\
\cline { 3 - 8 } & & Mean & CV & Mean & CV & Mean & CV \\
\hline $10^{2}$ & & - & - & - & - & 12.20 & 0.05 \\
\hline 20 & 5 & 14.34 & 0.09 & 15 & 0.23 & 21.52 & 0.06 \\
\hline 50 & 5 & 44.9 & 0.11 & 41.5 & 0.08 & 58.7 & 0.03 \\
\hline 100 & 5 & 90.04 & 0.11 & 94.88 & 0.11 & 109.02 & 0.09 \\
\hline 250 & 5 & 214.4 & 0.09 & 229.2 & 0.09 & 275.2 & 0.05 \\
\hline 500 & 5 & 467.2 & 0.11 & 469.6 & 0.03 & 594.6 & 0.07 \\
\hline
\end{tabular}


Table 3. 12. Results of Spiked Samples using two analytical methods (German IFA lab)

\begin{tabular}{|c|c|c|c|c|c|}
\hline \multirow{3}{*}{$\begin{array}{l}\text { Nominal } \\
\text { Mass, } \mu g\end{array}$} & \multirow{3}{*}{$N^{1}$} & \multicolumn{4}{|c|}{ Mass of samples, $\mu \mathrm{g}$ (German lab) } \\
\hline & & \multicolumn{2}{|c|}{ IFA 213-582 (IR) } & \multicolumn{2}{|c|}{ NIOSH 7602 (IR) } \\
\hline & & Mean & CV & Mean & $\mathrm{CV}$ \\
\hline 10 & 5 & 6.73 & 0.08 & 7.62 & 0.13 \\
\hline 20 & 5 & 11.70 & 0.31 & 12.86 & 0.34 \\
\hline 50 & 5 & 36.96 & 0.24 & 36.87 & 0.25 \\
\hline 100 & 5 & 86.53 & 0.09 & 86.36 & 0.10 \\
\hline 250 & 5 & 235.95 & 0.09 & 230.35 & 0.07 \\
\hline 500 & 5 & 437.35 & 0.03 & 425.98 & 0.03 \\
\hline
\end{tabular}


US Lab: NIOSH_XRD $\square$ US Lab: NIOSH_IR $\square$ US Lab: IFA_IR $\square$ German Lab: NIOSH_IR $\square$ German Lab: IFA_IR

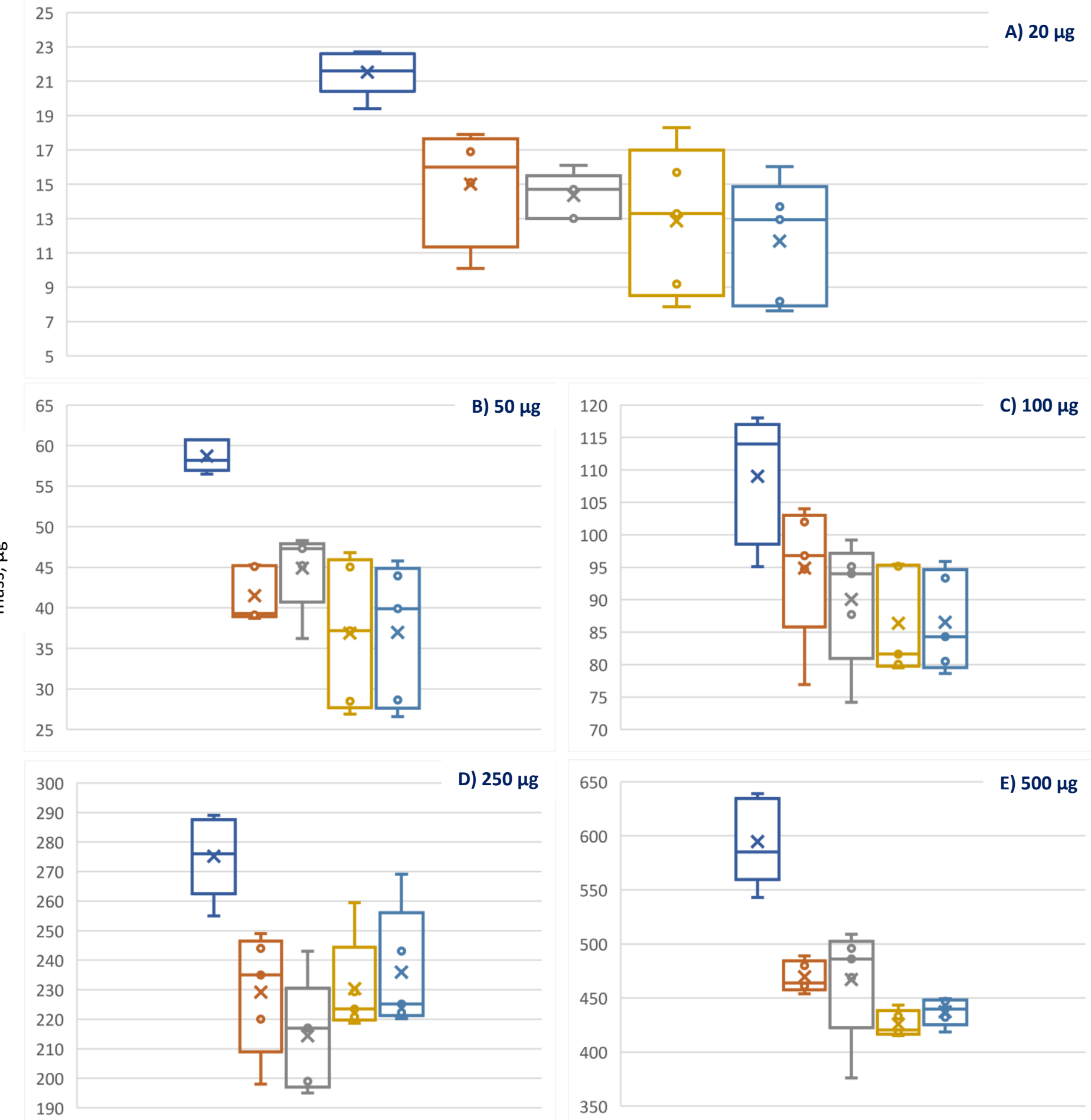

Figure 3. 6. Summaries for the spiked samples analyzed by the US and German labs (Mass level in $\mu \mathrm{g}: 20,50,100,250$, and 500) Each box plot represents the minimum, 25th, 50th (median), 75th percentiles, and maximum (" $x$ " is mean and dots are individual data points). 


\section{Within Lab Comparisons}

For the spiked samples analyzed according to the NIOSH 7602 and IFA 213-582 methods, no statistical differences were observed across all mass levels (20 to $500 \mu \mathrm{g}$ ) regardless of labs ( $p$-value: 0.0511 for the German (IFA) lab and 0.7280 for the US (NC) lab). As mentioned above, NIOSH 7500 showed significantly higher mass than the other two methods (all p-values $<0.0001$ ) for the samples analyzed by the US (NC) lab.

Regression lines for samples analyzed by the US (NC) and German (IFA) labs are shown in Figure 3.7. These plots show the differences in quartz mass within each analytical lab. In Figure 3.7A, the regression lines for the US (NC) lab samples are displayed. The slope between NIOSH 7602 and NIOSH 7500 is 1.26 (adj. $\left.r^{2}=0.75\right)$, indicating a moderate correlation between the two methods. The relationship between NIOSH 7500 and IFA 213-582 yielded a slope of 1.27 (adj. $\left.r^{2}=0.75\right)$ and $1.02\left(\operatorname{adj} . r^{2}=0.75\right)$ for the NIOSH 7602 and IFA 213-582. A similar regression line was plotted for samples analyzed by the German (IFA) lab (See Figure 3.6B). The slope of the line for that relationship is 0.98 with an adj. $r^{2}$ of 0.80 .
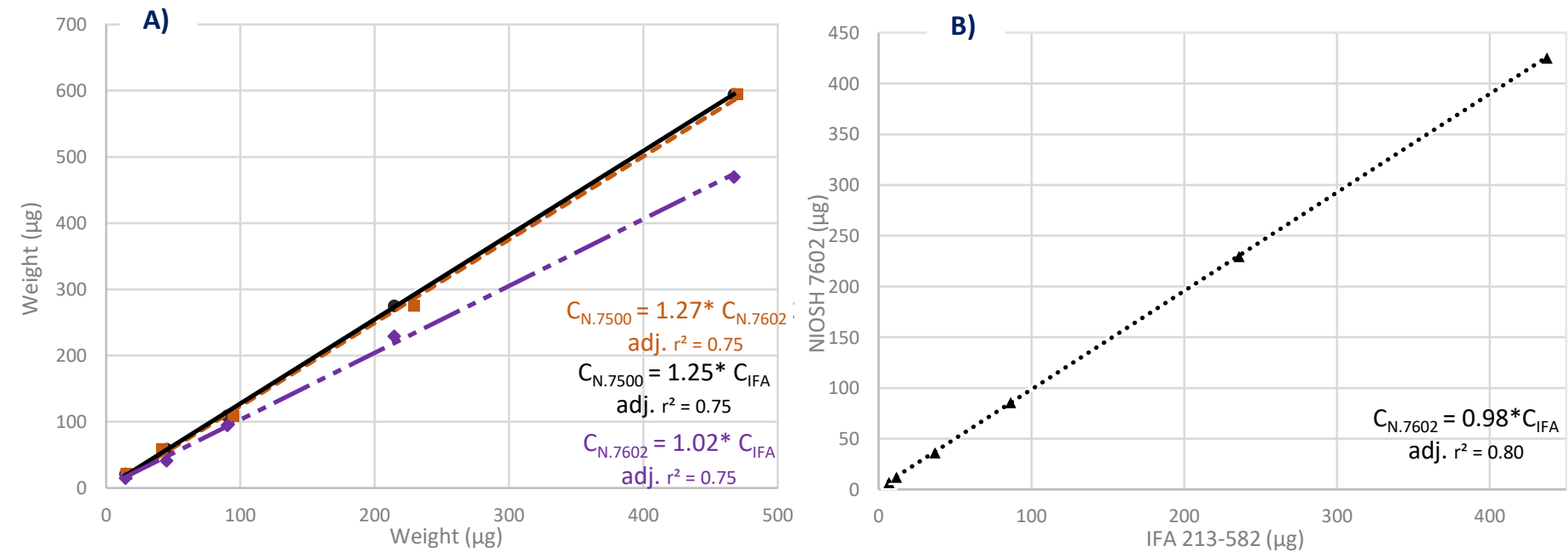

Figure 3. 7. Comparison of analytical methods (NIOSH 7602 vs. NIOSH 7500; IFA 213-582 vs. NIOSH 7500; and IFA 213-582 vs. NIOSH 7602) with NIST Spiked Samples. Analyzed by A) US (NC) lab and B) German (IFA) labs (only IFA 213-582 vs. NIOSH 7602). 


\section{Between Lab Comparisons}

Additional analysis was conducted to determine how well each lab adhered to the prescribed analytical methods i.e., each lab quantified the mass levels using each of the analytical methods and comparisons were made to determine similarities in results. For the samples analyzed using the IFA 213-582 method, statistical differences were observed between both labs across all mass levels $(p=0.0171)$. However, for the samples analyzed according to NIOSH 7602, no statistical difference was observed between both labs ( $p=0.1775)$. Nevertheless, the slopes from regression analyses were similar for both methods, $0.96\left(\right.$ adj. $r^{2}=$ 0.75 ) for the IFA $213-582$ method and 0.93 (adj. $\left.r^{2}=0.75\right)$ for the NIOSH 7602 method (Figure 3.8). The similarities in these results indicate that although there are slight differences in the IR analytical methods between both countries (e.g., time, temperature, and absorbance range), these differences in this case, affected the overall sensitivity for determining quartz content in different labs. Since no samples were analyzed using the NIOSH 7500 (XRD) method from the German (IFA) lab, no lab comparison was made for this method.

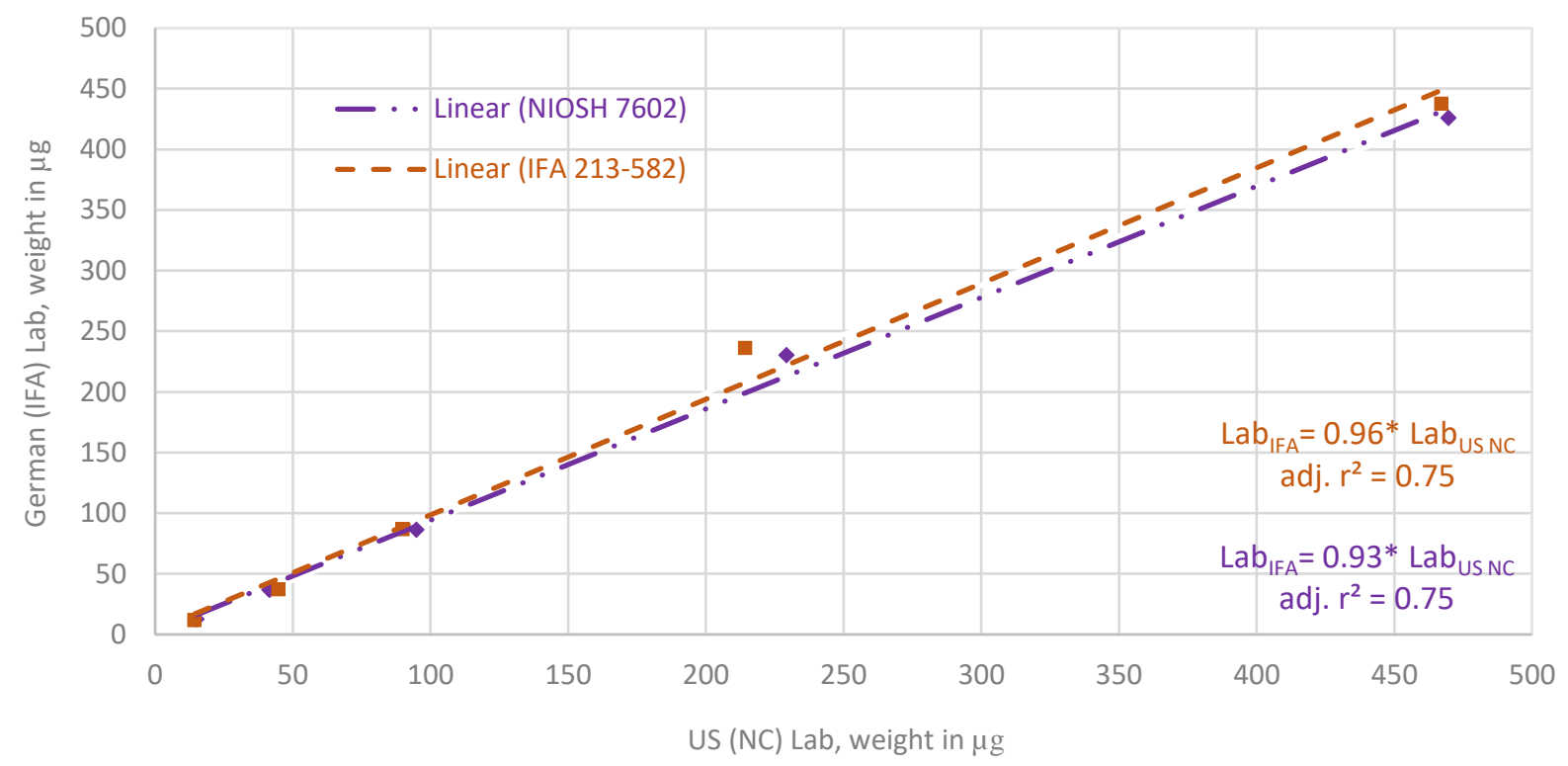

Figure 3. 8. Comparison of quartz masses between both US (NC) and German (IFA) labs. 


\section{Summary}

A summary of the spiked sample results is displayed in Table 3.13. Harper et al. (2016), in his assessment of Proficiency Analytical Testing (PAT) samples (> $40 \mu \mathrm{g}$ ) between 2003 and 2013, reported no differences between labs analyzing samples using XRD or IR methods. In this study, although a statistically significant difference was observed for the IFA 213582 method (IR) between the US (NC) lab and the German (IFA) lab, the slop between two labs was close to 1. For the NIOSH 7602 method, both labs did not show a significant difference. Harper et al. also noted an increase in the relative standard deviation (RSD) for filters with lower mass loadings analyzed with both methods. In this study, the same pattern was observed for the samples with target masses of 20 ug and 50 ug analyzed by the German (IFA) lab; the CVs for those target masses were considerably higher (> 20\%) than other target masses (Table 3.12).

Samples analyzed according to NIOSH 7500 (XRD) resulted in higher masses than those analyzed using both IR methods (NIOSH 7602 and IFA 213-582), although those samples (NIOSH 7500) were only analyzed by the US (NC) lab. Previous investigations comparing these two methods have not shown consistent results. Stacey et al. (2003) compared RSDs of samples analyzed using the two methods, MDHS 37 (IR method) and MDHS $51 / 2$ (XRD method). Aerosolized dust (A9950 Sikron F-600 dust with $\alpha$-quartz content of $96.3 \pm 1.4 \%$ and mass median diameter $=2.6 \mu \mathrm{m}$ ) in a chamber was sampled with a 'multi-port' sampler. No significant differences were reported between both methods when just the pure $\alpha$-quartz dust masses were analyzed. A slope of $0.97\left(r^{2}=0.97\right)$ was reported from the regression equation. However, when limited aerosol samples were collected from the cutting of concrete slab and the sample was contaminated with non-amorphous dust, and analyzed with using both methods, the XRD performed better (i.e., lower RSD) than the IR method, showing statistically significant difference. The authors reported that this might be likely due to the reduced background noise caused by the filter when other non-amorphous dusts are also present. Ichikawa et al. (2021) also reported no differences between XRD and FT-IR direct-on-filter analyses using pure $\alpha$-quartz standards, but saw significant differences between both methods when field samples of quartz from various industries (road construction, tunneling, coal mining, kitchen benchtop, manufacturing etc.) were analyzed, reporting IR concentration results were 
$9 \%$ higher than XRD results due to the interference of silicates absorbing around peaks of 800 $\mathrm{cm}^{-1}$, where many Si-O bonds appear, a common issue with IR analysis. However, the XRD methods was reported to be more robust due to less interference. Additionally, Lee et al. (2012) reported no statistically significant differences in quartz percent when comparing the two methods (NIOSH 7602 (IR) and 7500 (XRD)) with coal dust samples collected using high and low flowrate samplers in an exposure chamber. The average quartz content (SD) from the IR and XRD analyses were $7.2 \pm 1.7 \%$ and $8.6 \pm 5.6 \%$, respectively.

Table 3. 13. Statistical Summary of the NIST Spiked Samples

\begin{tabular}{|c|c|c|c|c|c|c|}
\hline $\begin{array}{l}\text { Analysis } \\
\text { by }\end{array}$ & Analytical Method & $\mathbf{N}$ & $\begin{array}{c}\text { Total mass range, } \\
\text { unit in } \mathrm{mg}\end{array}$ & $\begin{array}{l}\text { Samples }< \\
\text { LOD }\end{array}$ & p-value & Slope \\
\hline \multirow{6}{*}{$\begin{array}{l}\text { NIOSH } \\
\text { contract lab }\end{array}$} & NIOSH 7602 (y) & 30 & $10.1-489$ & 6 & \multirow{2}{*}{0.7280} & \multirow{2}{*}{1.02} \\
\hline & IFA 213-583 (x) & 30 & $13-509$ & 5 & & \\
\hline & NIOSH 7500 (y) & 30 & $6.71-639$ & 4 & \multirow{2}{*}{$<0.0001$} & \multirow{2}{*}{1.25} \\
\hline & IFA 213-583 (x) & 30 & $13-509$ & 6 & & \\
\hline & NIOSH $7602(x)$ & 30 & $10.1-489$ & 5 & \multirow{2}{*}{$<0.0001$} & \multirow{2}{*}{1.27} \\
\hline & NIOSH 7500 (y) & 30 & $6.71-639$ & 4 & & \\
\hline \multirow{2}{*}{ IFA lab } & NIOSH 7602 (y) & 30 & $6.27-443$ & 1 & \multirow{2}{*}{0.0511} & \multirow{2}{*}{0.98} \\
\hline & IFA 213-583 (x) & 30 & $6.27-449$ & 1 & & \\
\hline \multirow{4}{*}{$\begin{array}{l}\text { Difference } \\
\text { between } \\
\text { labs }\end{array}$} & US: NIOSH 7602 (x) & 30 & $10.1-489$ & 6 & \multirow{2}{*}{0.1775} & \multirow{2}{*}{0.96} \\
\hline & German: NIOSH 7602 (y) & 30 & $6.27-443$ & 1 & & \\
\hline & US: IFA 213-583 (x) & 30 & $13-509$ & 5 & \multirow{2}{*}{0.0171} & \multirow{2}{*}{0.93} \\
\hline & German: IFA 213-583 (y) & 30 & $6.27-449$ & 1 & & \\
\hline
\end{tabular}

Abbreviation: $\mathrm{N}=$ number of samples; $\mathrm{LOD}=$ Limit of detection 
PART II. AEROSOL CHAMBER STUDY

ARIZONA ROAD DUST (ARD)

For the four target respirable mass concentrations (RMC), the CV at each RMC level ranged from $1 \%$ to $20 \%$ (average $C V=6 \%$ ) for samples sent to the NIOSH contract lab and from $2 \%$ to $14 \%$ (average $C V=4 \%$ ) for samples sent to the IFA lab, indicating that a comparable set of samples were sent to both labs for the sample analysis (Table 3.14). As shown in Figure 3.9, overall, FSP-10 samples collected higher RMCs than GK2.69 samples across all target levels. This pattern has been confirmed by previous studies. (Lee et al., 2011; Stacey et al., 2013).

Table 3.15 provides the overall RCS data analyzed in both labs for each RMC level. Generally, CVs for the FSP-10 samples are higher than those of the GK2.69 samples. Stacey et al. (2013) suggested that the higher flow rate of the FSP-10 samplers might add to the variability of results, contributing to a higher CV. Additionally, FSP-10 samplers require more handling to retrieve the filters from its casing within the sampler, while the filter compartment in the GK2.69 samplers are more accessible. Figure 3.10 shows RCS concentrations analyzed by both labs. The FSP-10 samples analyzed by the US (NC) lab resulted in the lowest RCS concentrations. As shown in Figure 3.11, the ratios of RCS concentrations to RMCs (RCS/RMC) were similar, ranging from $18 \%$ to $29 \%$ for both labs and all methods except for samples analyzed by the US (NC) lab using IFA 213-582; the ratio of RCS/RMC ranged 3-9\% (mean =6\%) for the IFA method (IR). Both the spiked samples results reported earlier, and the chamber study results presented here were analyzed by the same labs in the US and Germany about 6 months apart. It seems that some errors occurred during the sample analyses using IFA 213-582 by the US (NC) lab. One possible explanation would be a misinterpretation of the method. However, since the spiked samples were unaffected, it is unlikely that this error was caused from the interpretation of the method. Another explanation might be that the samples were analyzed by a different analyst from the one who conducted the sample analyses of the spiked samples. And of course, human error in the analysis is another unfortunate but probable reason. At any rate, because the results of the IFA 213-583 samples seemed artificially low, any 
analysis conducted with them could not be viewed as reliable. Thus, FSP-10 samples analyzed by the US (NC) lab were excluded from further analyses.

It is known that the RCS content of ARD is close to $70 \%$ according to the manufacturer. However, in this study, neither lab detected RCS levels close to 70\%. In contrast, Stacey et al. (2013), in his international study of RCS measurements by XRD, using the same test aerosol (medium grade ARD with $70 \%$ RCS) reported RCS/RMC ratios greater than 0.90 for the GK2.69 samples and 0.82 for the FSP-10 samples and noted that the analytical method used does not significantly affect this ratio. Again, here it is not clear how this happened in this study.

US Lab: GK2.69 samples

German Lab: GK2.69 samples
US Lab: GK2.69 samples German Lab: GK2.69 samples
US Lab: FSP-10 samples

German Lab: FSP-10 samples
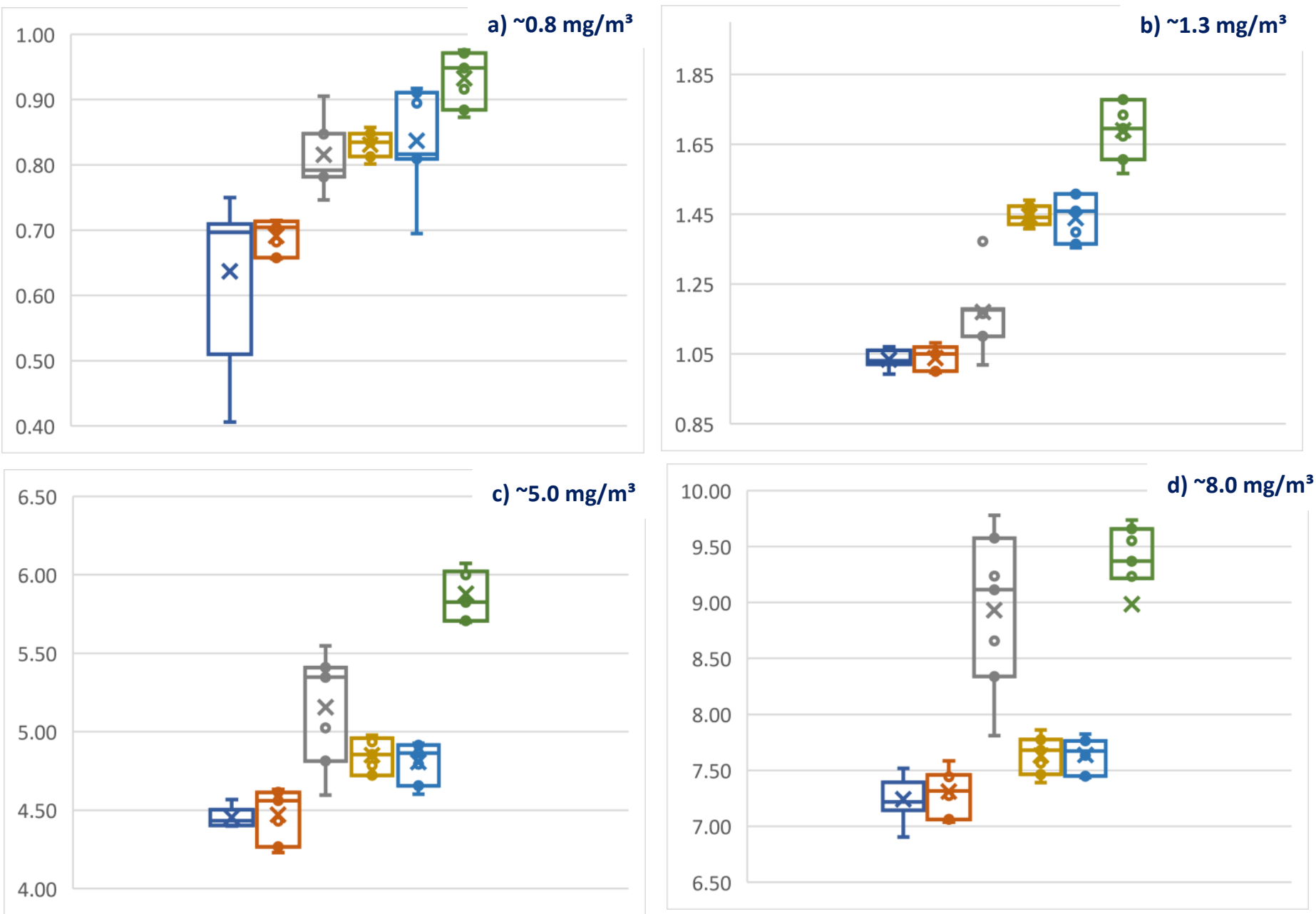

Figure 3. 9. Respirable mass concentrations of ARD analyzed by the US (NC) and German (IFA) labs. 
$\square$ US lab: GK2.69 (XRD) $\square$ US Lab: GK_IR $\square$

\section{a) $\sim 0.8 \mathrm{mg} / \mathrm{m}^{3}$}

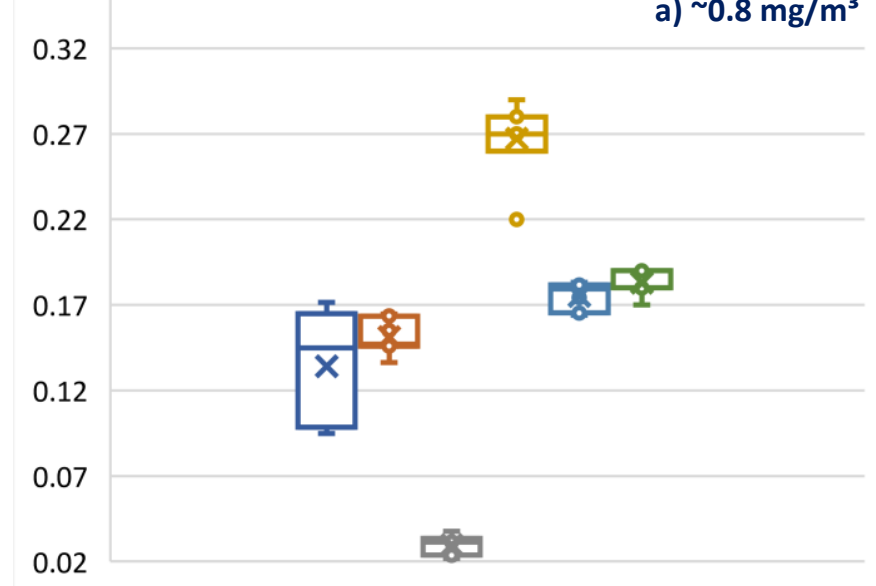

है

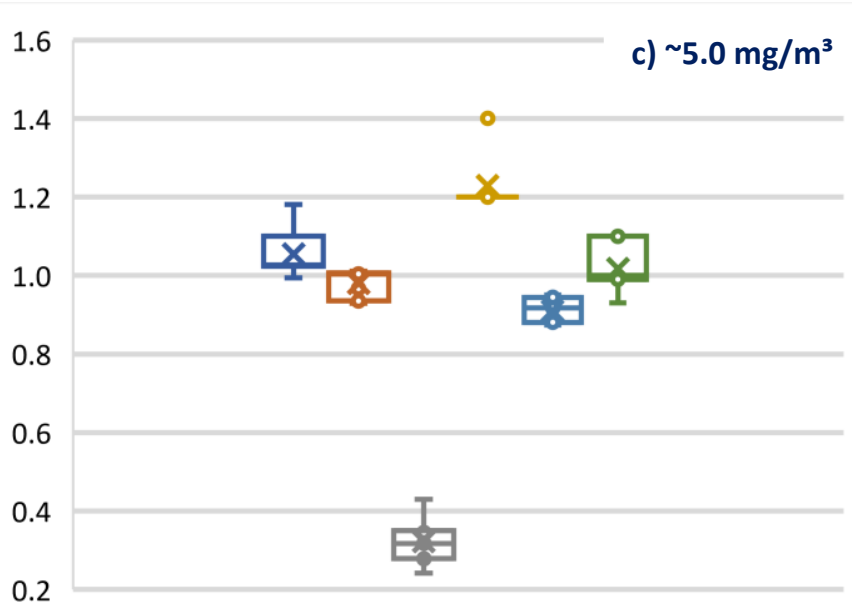

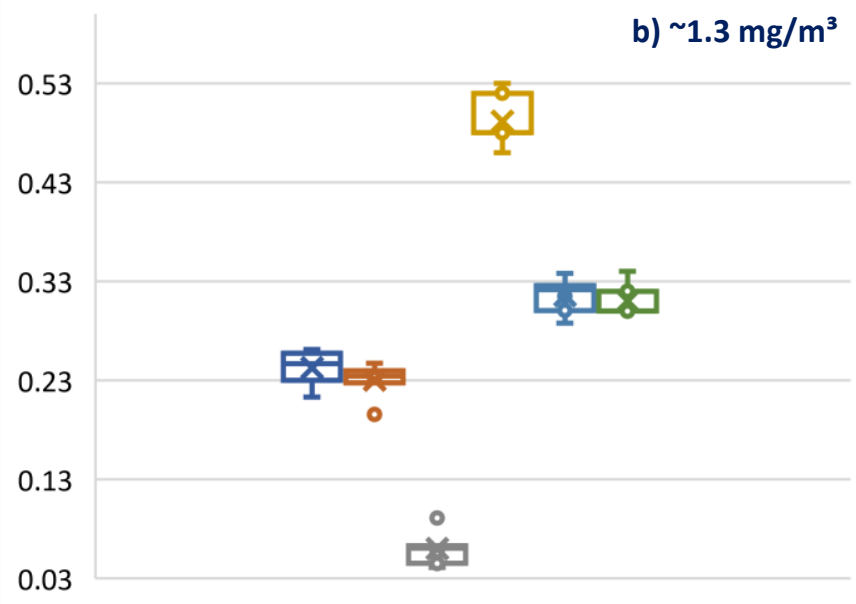

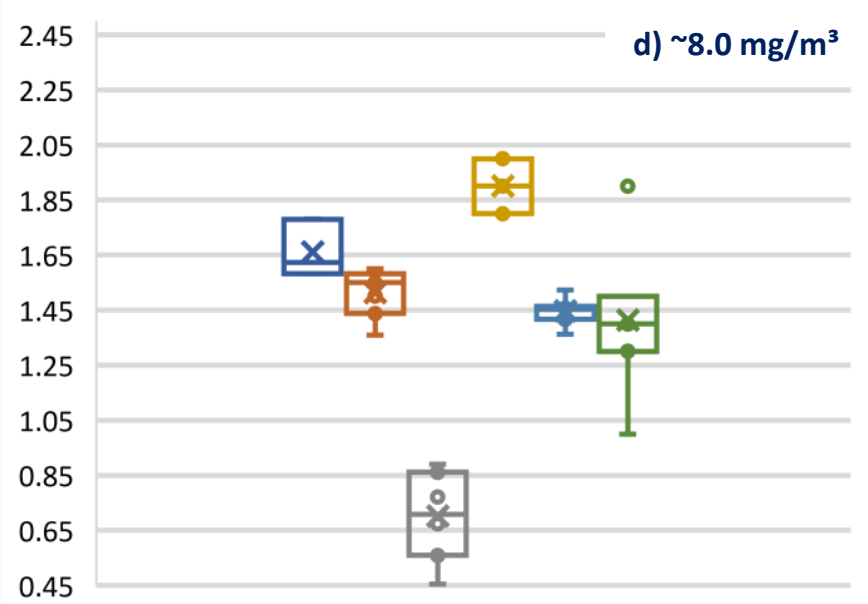

Figure 3. 10. RCS concentrations of ARD analyzed by the US (NC) and German (IFA) labs. 
Table 3. 14. Summary of RMC concentrations at each target level (ARD)

\begin{tabular}{|c|c|c|c|c|c|c|c|}
\hline \multirow{2}{*}{\multicolumn{2}{|c|}{$\begin{array}{c}\text { Target RMC } \\
\left(\mathrm{mg} / \mathrm{m}^{3}\right)\end{array}$}} & \multicolumn{3}{|c|}{ US Lab } & \multicolumn{3}{|c|}{ IFA Lab } \\
\hline & & GK2.69 & GK2.69 & FSP-10 & GK2.69 & GK2.69 & FSP-10 \\
\hline \multirow{4}{*}{$\sim 0.8$} & Mean & 0.64 & 0.69 & 0.82 & 0.83 & 0.84 & 0.93 \\
\hline & Median & 0.70 & 0.70 & 0.79 & 0.83 & 0.82 & 0.95 \\
\hline & $\mathrm{CV}$ & 0.20 & 0.04 & 0.07 & 0.02 & 0.09 & 0.04 \\
\hline & Min - Max & $0.41-0.75$ & $0.66-0.71$ & $0.75-0.91$ & $0.80-0.86$ & $0.69-0.92$ & $0.87-0.98$ \\
\hline \multirow{4}{*}{$\sim 1.3$} & Mean & 1.03 & 1.04 & 1.17 & 1.44 & 1.44 & 1.69 \\
\hline & Median & 1.03 & 1.05 & 1.18 & 1.44 & 1.46 & 1.7 \\
\hline & $\mathrm{CV}$ & 0.03 & 0.03 & 0.09 & 0.02 & 0.05 & 0.05 \\
\hline & Min-Max & $0.99-1.07$ & $1.00-1.08$ & $1.02-1.37$ & $1.41-1.49$ & $1.35-1.51$ & $1.57-1.78$ \\
\hline \multirow{4}{*}{$\sim 5.0$} & Mean & 4.45 & 4.47 & 5.16 & 4.85 & 4.81 & 5.88 \\
\hline & Median & 4.43 & 4.56 & 5.35 & 4.85 & 4.86 & 5.83 \\
\hline & CV & 0.01 & 0.04 & 0.07 & 0.02 & 0.03 & 0.03 \\
\hline & Min - Max & $4.40-4.57$ & $4.23-4.63$ & $4.60-5.55$ & $4.72-4.98$ & $4.60-4.93$ & $5.70-6.07$ \\
\hline \multirow{4}{*}{$\sim 8.0$} & Mean & 7.24 & 7.31 & 8.93 & 7.63 & 7.64 & 8.98 \\
\hline & Median & 7.22 & 7.32 & 9.11 & 7.68 & 7.67 & 9.37 \\
\hline & CV & 0.03 & 0.03 & 0.08 & 0.02 & 0.02 & 0.14 \\
\hline & Min - Max & $6.90-7.52$ & $7.04-7.59$ & $7.81-9.78$ & $7.39-7.86$ & $7.44-7.82$ & $6.12-9.74$ \\
\hline
\end{tabular}

Table 3. 15. Summary of RCS concentrations for each target respirable mass concentration (ARD)

\begin{tabular}{|c|c|c|c|c|c|c|c|}
\hline \multirow{2}{*}{\multicolumn{2}{|c|}{$\begin{array}{c}\text { Target RMC } \\
\left(\mathrm{mg} / \mathrm{m}^{3}\right)\end{array}$}} & \multicolumn{3}{|c|}{ US Lab } & \multicolumn{3}{|c|}{ IFA Lab } \\
\hline & & GK2.69 & $\begin{array}{c}\text { GK2.69 } \\
\text { (N 7602) }\end{array}$ & FSP-10 (IFA & GK2.69 & GK2.69 & FSP-10 (IFA \\
\hline \multirow{4}{*}{$\sim 0.8$} & Mean & 0.13 & 0.15 & 0.03 & 0.27 & 0.18 & 0.18 \\
\hline & Median & 0.15 & 0.15 & 0.03 & 0.27 & 0.18 & 0.18 \\
\hline & $\mathrm{CV}$ & 0.23 & 0.07 & 0.2 & 0.09 & 0.04 & 0.04 \\
\hline & Min - Max & $0.10-0.17$ & $0.14-0.17$ & $0.02-0.04$ & $0.22-0.29$ & $0.16-0.18$ & $0.17-0.19$ \\
\hline \multirow{4}{*}{$\sim 1.3$} & Mean & 0.24 & 0.23 & 0.06 & 0.49 & 0.32 & 0.31 \\
\hline & Median & 0.25 & 0.23 & 0.06 & 0.48 & 0.32 & 0.3 \\
\hline & $\mathrm{CV}$ & 0.07 & 0.07 & 0.27 & 0.05 & 0.05 & 0.05 \\
\hline & Min - Max & $0.21-0.26$ & $0.20-0.25$ & $0.04-0.09$ & $0.46-0.53$ & $0.29-0.34$ & $0.30-0.34$ \\
\hline \multirow{4}{*}{$\sim 5.0$} & Mean & 1.05 & 0.98 & 0.322 & 1.229 & 0.91 & 1.02 \\
\hline & Median & 1.03 & 1.004 & 0.318 & 1.2 & 0.917 & 1 \\
\hline & CV & 0.06 & 0.04 & 0.19 & 0.06 & 0.03 & 0.06 \\
\hline & Min - Max & $0.10-1.18$ & $0.93-1.01$ & $0.24-0.43$ & $1.20-1.40$ & $0.87-0.95$ & $0.93-1.10$ \\
\hline \multirow{4}{*}{$\sim 8.0$} & Mean & 1.66 & 1.51 & 0.70 & 1.9 & 1.45 & 1.41 \\
\hline & Median & 1.62 & 1.55 & 0.71 & 1.9 & 1.45 & 1.4 \\
\hline & $\mathrm{CV}$ & 0.05 & 0.06 & 0.22 & 0.04 & 0.03 & 0.19 \\
\hline & Min - Max & $1.58-1.78$ & $1.36-1.60$ & $0.46-0.89$ & $1.800-2.000$ & $1.36-1.52$ & $1.00-1.90$ \\
\hline
\end{tabular}




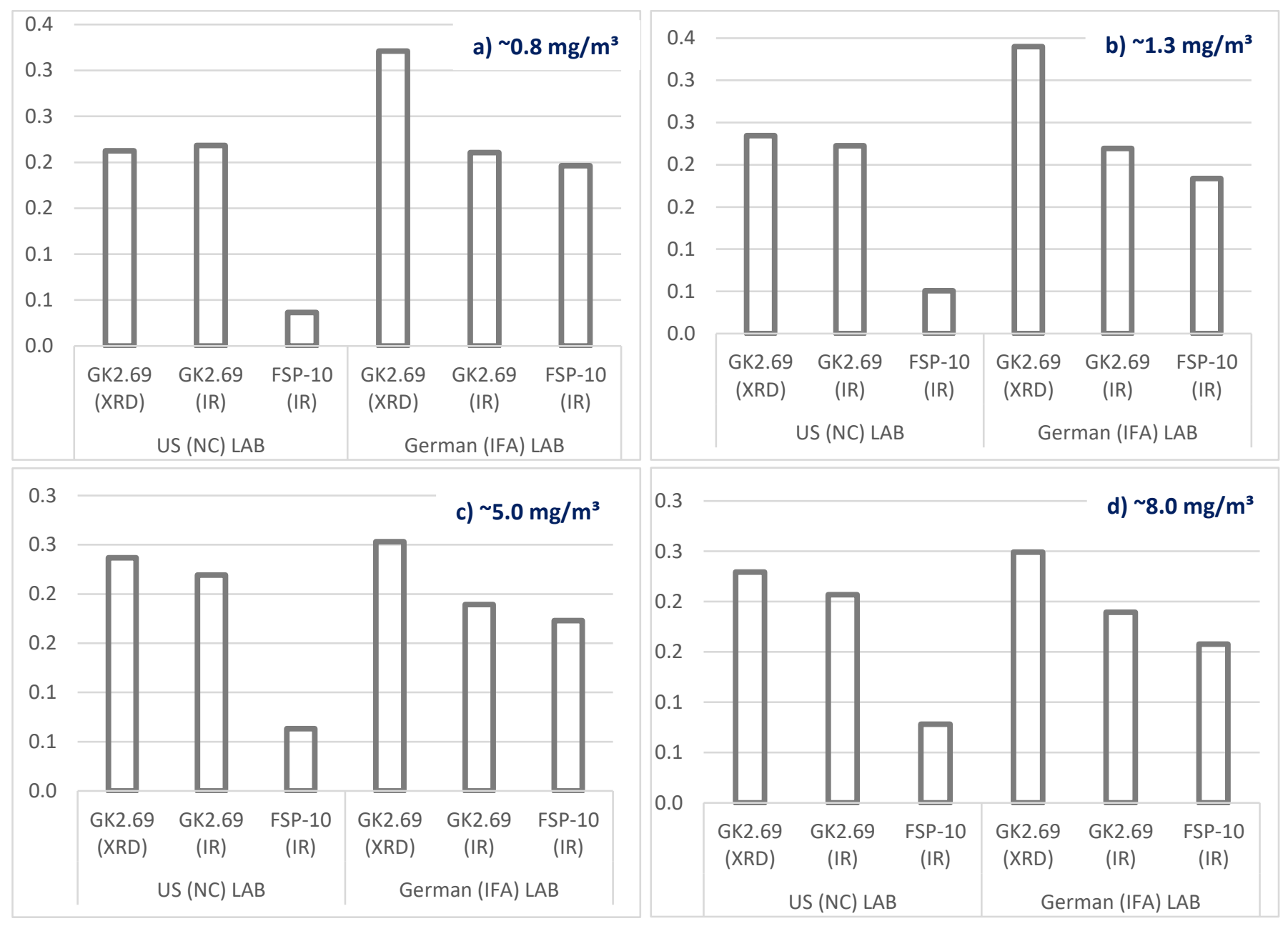

Figure 3. 11. Ratio of RCS (Quartz) concentrations to the corresponding respirable mass concentrations (ARD)

\section{Within Lab Comparisons}

\section{For samples analyzed by the US (NC) lab}

The RCS concentrations revealed no statistical differences between NIOSH 7500 (XRD) and NIOSH 7602 (IR) for the samples collected with GK2.69 cyclones. This trend has also been observed by several previous studies and discussed earlier (Lee et al., 2012; Stacey et al., 2003). Pickard et al. (1985) compared both NIOSH methods with samples collected from foundries, brick and tile works, and potteries and found no statistical differences except for the samples collected from potteries. Figure 3.12A shows the results of linear regression analysis between the two NIOSH methods. The slope between NIOSH 7500 and 7602 is 1.09 (adj. $r^{2}=0.66$ ), indicating a moderate correlation between the two methods. 


\section{For samples analyzed by the German (IFA) lab}

Overall, GK2.69 samples analyzed with NIOSH 7500 (XRD) in the German (IFA) lab showed the highest RCS concentration results among all analytical methods $(p<0.0001)$. As shown in Figure 3.12B, the NIOSH 7500 method generated 1.33 times higher RCS concentrations compared to the NIOSH 7602 method and 1.31 times higher than the IFA 213582 method. Previous studies have similarly reported masses of XRD samples greater than IR samples. Hart et al. (2018) compared RCS concentrations determined from XRD analysis and a field portable IR instrument with area samples collected from three metal/nonmetal mines (gold, copper, silver/lead/zinc). They reported higher XRD concentrations than IR concentrations with mean differences ranging from 4 to $133 \mu \mathrm{g} / \mathrm{m}^{3}$. However, the report identified several other minerals in the bulk samples that could potentially cause interference with the crystalline silica absorption band $\left(800 \mathrm{~cm}^{-1}\right)$ absorption band.

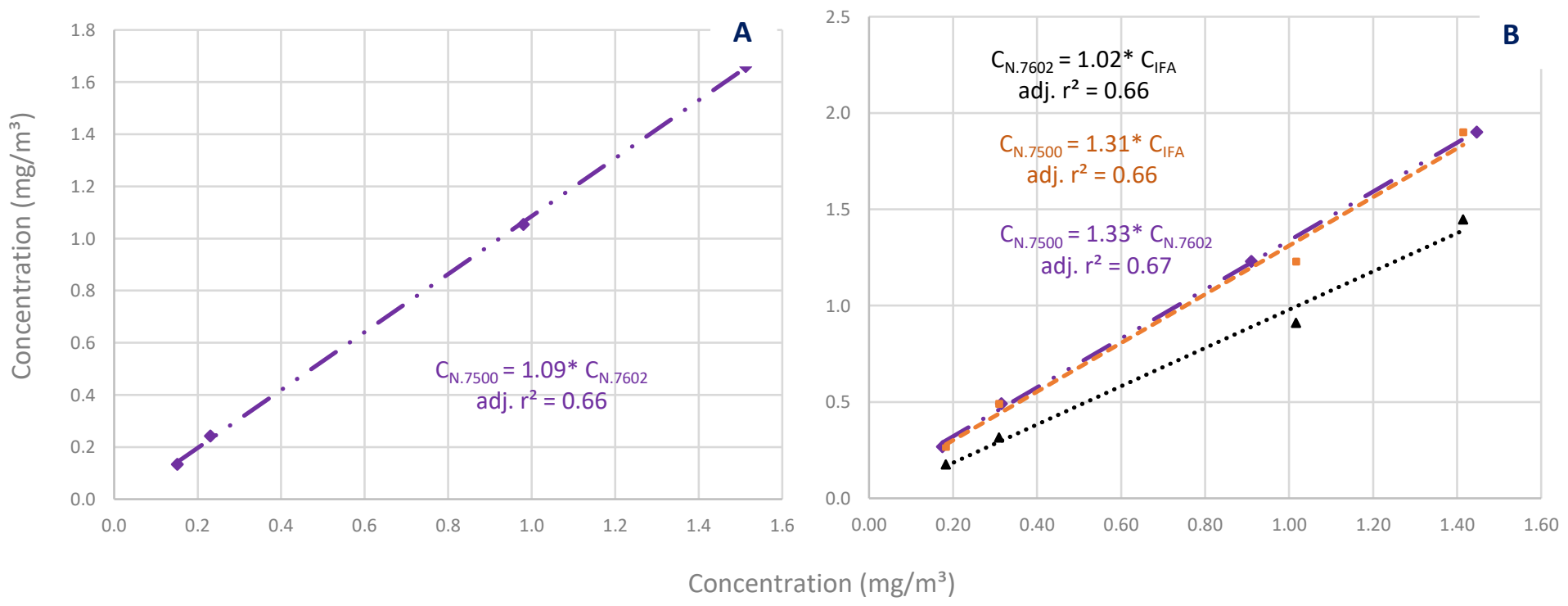

Figure 3. 12. Figure 3. 12. Comparison of different sampling and analytical methods (NIOSH 7602 vs. NIOSH 7500; IFA 213-582 vs. NIOSH 7500; and IFA 213-582 vs. NIOSH 7602) with ARD data. Analyzed by A) US (NC) lab and B) German (IFA) labs.

No statistical difference was observed between the NIOSH 7602 and IFA 213-582 methods $(p=0.2647)$. The slope between both IR methods, NIOSH 7602 and IFA 213-582, is $1.02\left(\operatorname{adj} . r^{2}=0.66\right)$ (Figure 3.12B). This agrees well with the results reported from the spiked 
samples analysis from both labs (1.02 (NC) and 0.98 (IFA)), also confirming the similarity of both IR methods.

\section{Between Lab Comparisons}

To determine how well each lab followed the prescribed analytical method, each lab's performance was compared for each method. Note that the comparison between both labs for the IFA 231-582 method was not conducted for the reasons mentioned earlier. For both NIOSH methods, RCS concentrations between the US (NC) lab and the German (IFA) lab showed statistically significant differences (all p values $<0.0001$ ). For the NIOSH 7602 (IR) and 7500 (XRD) methods, the slopes between the US (NC) lab and the German (IFA) lab were 0.95 (adj. $r^{2}$ $=0.66)$ and 1.17 (adj. $\left.r^{2}=0.66\right)$, respectively, as shown in Figure 3.13. Even though the statistical test results showed significant differences for both NIOSH methods, the slopes between the US (NC) lab and the IFA lab were close, implying a similarity in both results.

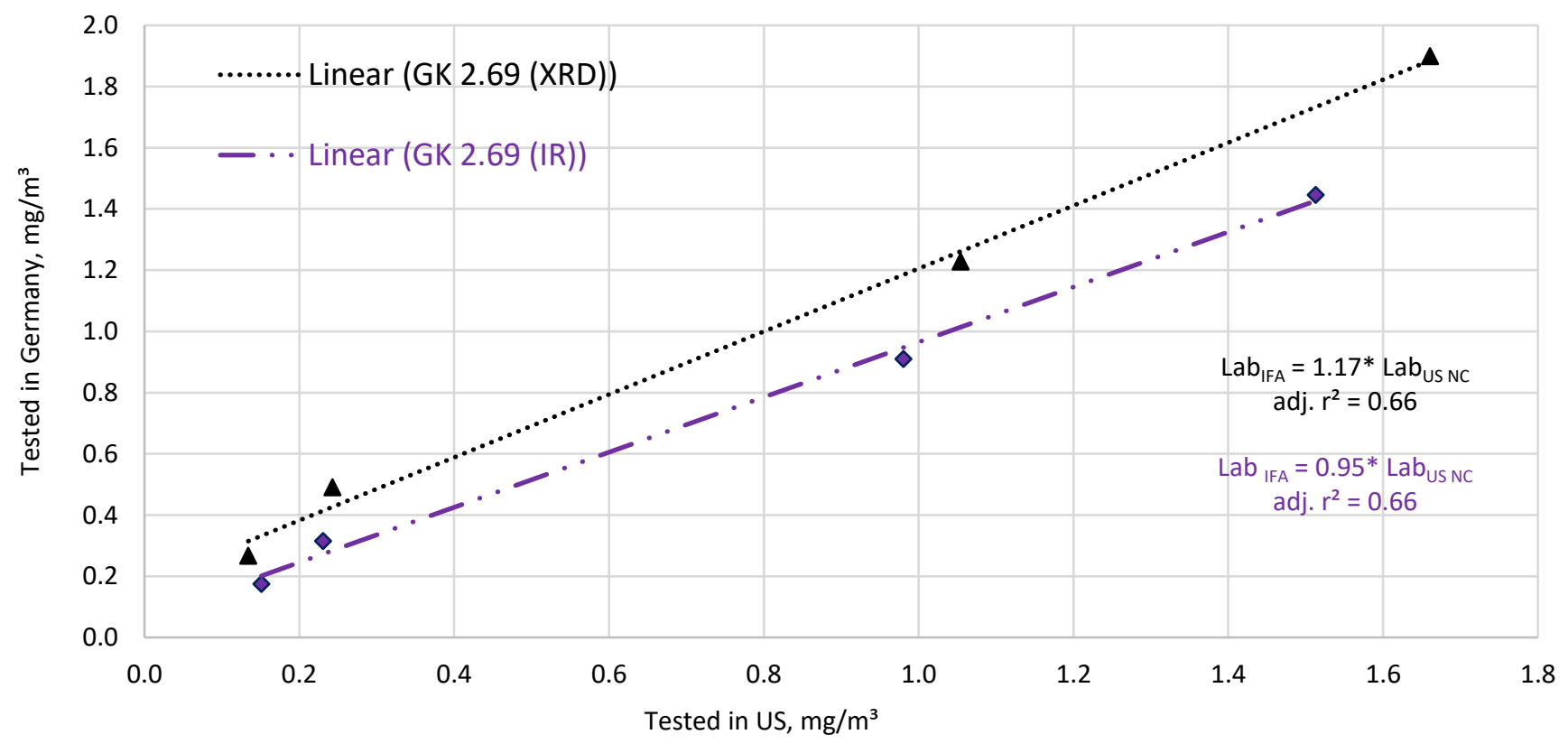

Figure 3. 13. Comparison of RCS concentrations between the US (NC) lab and the German (IFA) lab. 
MIN-U-SIL ${ }^{\circledR} 10$

The average CV for the four target RMCs $\left(0.8,1.8,5.9\right.$ and $\left.8.7 \mathrm{mg} / \mathrm{m}^{3}\right)$ was $6 \%$ (range $=$ $1-13 \%$ ) for the samples sent to the US (NC) lab and 8\% (range $=1-21 \%$ ) for the samples sent to the German (IFA) lab (Table 3.16). Overall, FSP-10 samplers collected more respirable dust of MIN-U-SIL ${ }^{\circledR} 10$ than GK2.69 samplers, similar to the results of ARD and the other studies mentioned earlier (Table 3.16 and Figure 3.14).

The results of RCS concentrations are reported in Table 3.17 and Figure 3.15. Like the ARD study, the CVs for the FSP-10 samples were generally higher than the GK2.69 samples. As shown in Figure 3.16, the RCS/RMC ratios from samples analyzed in the US (NC) lab ranged from 68 to 91\% (mean $=81 \%)$ for NIOSH 7500, 53 to 122\% (mean =100\%) for NIOSH 7602, and 8 to $36 \%$ (mean $=20 \%$ ) for IFA 213-582. Samples analyzed by the German (IFA) lab, the RCS percentages ranged from 97 to $110 \%($ mean $=106 \%)$ for NIOSH 7500, 71 to $99 \%($ mean $=85 \%)$ for NIOSH 7602, and 34 to 99\% (mean =77\%) for IFA 213-582. Unlike ARD, the percentages of RCS were much closer to that reported by the manufacturer for this quartz type $\left(\mathrm{SiO}_{2}-98.6 \%\right)$ except for the IFA 213-582 method analyzed by the US (NC) lab. Thus, for the FSP-10 samples analyzed by the US (NC) lab, no further analyses were conducted for the same reason described in the ARD section. Furthermore, the XRD results obtained for this chamber study are comparable to those obtained by Page (2003), who reported averages of 95.3 to $99 \%$ RCS, depending on the aerodynamic equivalent diameter.

Interestingly, results from the US (NC) lab showed that the analytical response for IR samples were more detectable for smaller particle sized aerosols (MIN-U-SIL $\left.{ }^{\circledR} 10\right)$. This trend has been observed and reported on by many other investigations (Esche et. al., 1999; Bello et al., 2002). However, the German (IFA) lab results showed higher concentrations for XRD samples, for the same sized particles. 
口 US Lab: GK2.69 samples

German Lab: GK2.69 samples
US Lab: GK2.69 samples

German Lab: GK2.69 samples
US Lab: FSP-10 samples

German Lab: FSP-10 samples
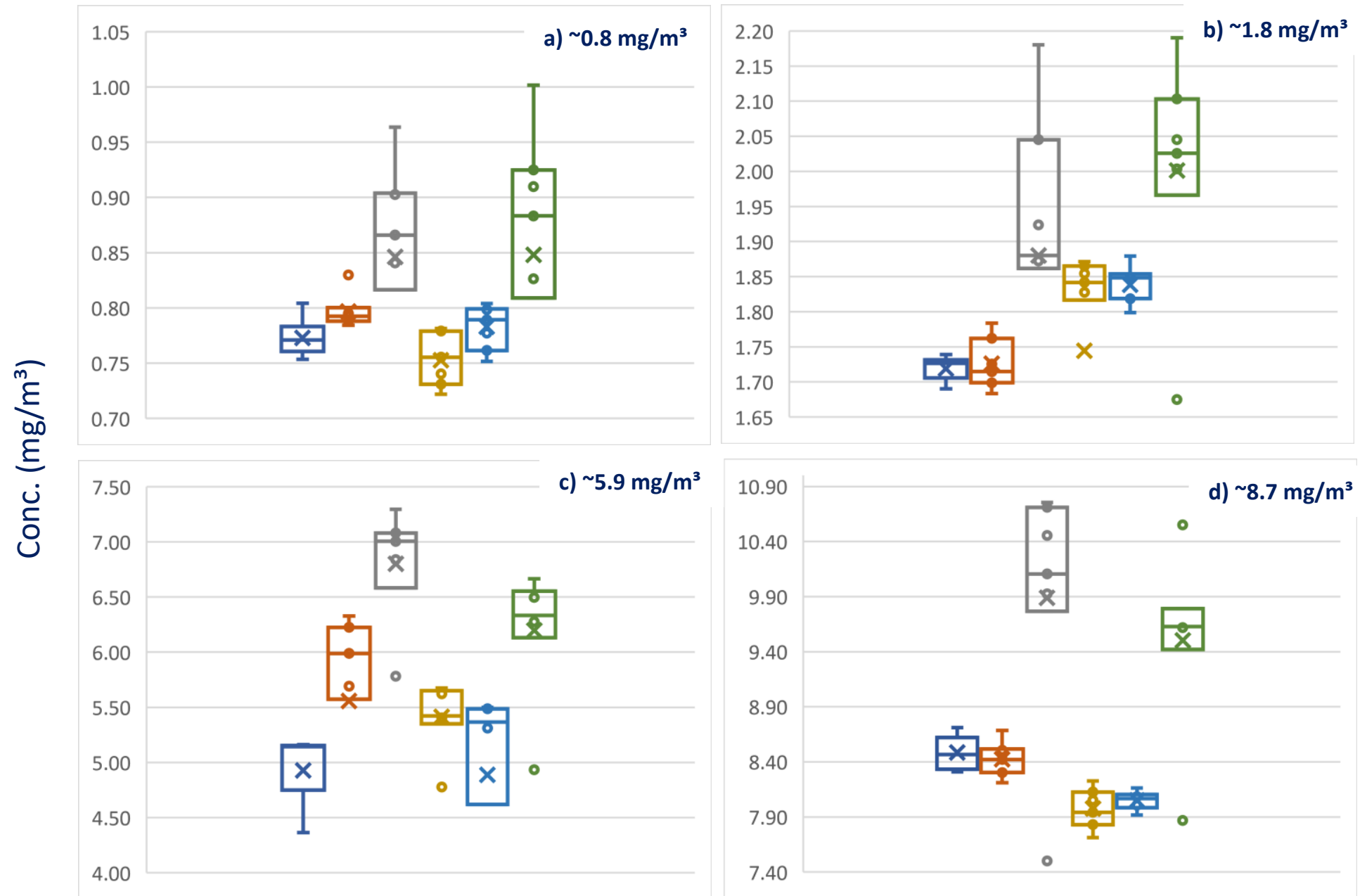

Figure 3. 14. Respirable mass concentrations of MIN-U-SIL ${ }^{\circledR} 10$ analyzed by the US (NC) and German (IFA) labs. 


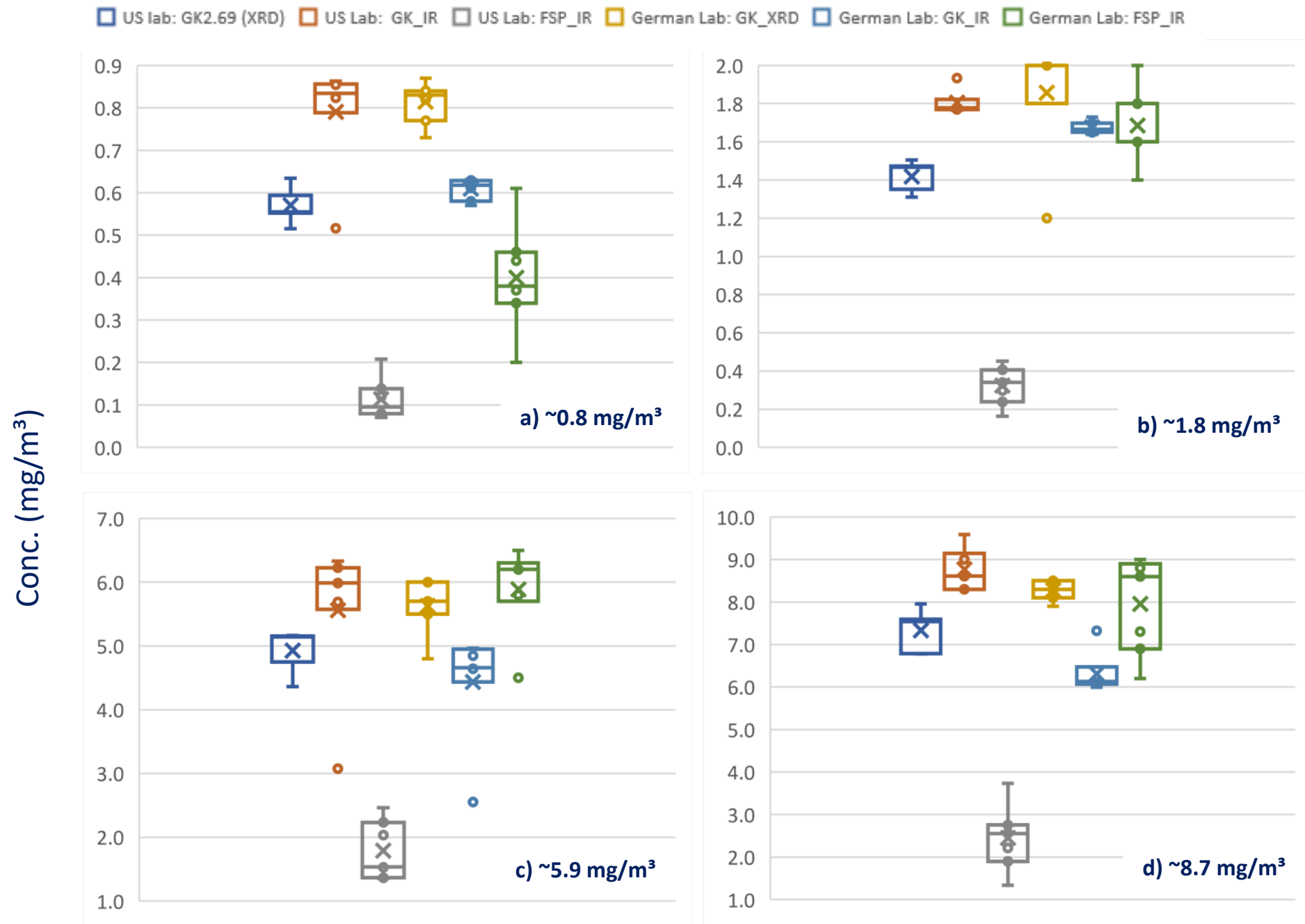

Figure 3. 15. RCS concentrations of MIN-U-SIL ${ }^{\circledR} 10$ analyzed by the US (NC) and German (IFA) labs. 
Table 3. 16. Summary of RMC concentrations at each target level (MIN-U-SIL ${ }^{\circledR} 10$ )

\begin{tabular}{|c|c|c|c|c|c|c|c|}
\hline & \multirow{2}{*}{$\begin{array}{c}\text { Target RMC } \\
(\mathrm{mg} / \mathrm{m} 3)\end{array}$} & \multicolumn{3}{|c|}{ US Lab } & \multicolumn{3}{|c|}{ IFA Lab } \\
\hline & & GK2.69 & GK2.69 & FSP-10 & GK2.69 & GK2.69 & FSP-10 \\
\hline \multirow{4}{*}{$\sim 0.8$} & Mean & 0.77 & 0.8 & 0.85 & 0.75 & 0.78 & 0.85 \\
\hline & Median & 0.77 & 0.79 & 0.87 & 0.76 & 0.79 & 0.88 \\
\hline & $\mathrm{CV}$ & 0.02 & 0.02 & 0.13 & 0.03 & 0.03 & 0.16 \\
\hline & Min-Max & $0.75-0.80$ & $0.78-0.83$ & $0.63-0.96$ & $0.72-0.78$ & $0.75-0.80$ & $0.58-1.00$ \\
\hline \multirow{4}{*}{$\sim 1.3$} & Mean & 1.72 & 1.73 & 1.88 & 1.75 & 1.84 & 2.00 \\
\hline & Median & 1.73 & 1.72 & 1.88 & 1.84 & 1.85 & 2.03 \\
\hline & CV (\%) & 0.01 & 0.02 & 0.13 & 0.2 & 0.02 & 0.08 \\
\hline & Min - Max & $1.69-1.74$ & $1.68-1.78$ & $1.39-2.18$ & $1.13-1.87$ & $1.80-1.88$ & $1.68-2.19$ \\
\hline \multirow{4}{*}{$\sim 5.0$} & Mean & 5.99 & 5.88 & 6.8 & 5.41 & 4.89 & 6.2 \\
\hline & Median & 6 & 5.79 & 7.01 & 5.42 & 5.37 & 6.33 \\
\hline & CV (\%) & 0.02 & 0.1 & 0.07 & 0.06 & 0.22 & 0.1 \\
\hline & Min - Max & $5.78-6.1$ & $4.9-6.9$ & $5.78-7.30$ & $4.78-5.67$ & $2.57-5.50$ & $4.93-6.66$ \\
\hline \multirow{4}{*}{$\sim 8.0$} & Mean & 8.49 & 8.42 & 9.89 & 7.98 & 8.05 & 9.5 \\
\hline & Median & 8.47 & 8.42 & 10.11 & 7.94 & 8.07 & 9.63 \\
\hline & CV (\%) & 0.02 & 0.02 & 0.11 & 0.02 & 0.01 & 0.09 \\
\hline & Min - Max & $8.31-8.71$ & $8.21-8.68$ & $7.50-10.76$ & $7.71-8.22$ & $7.91-8.16$ & $7.87-10.5$ \\
\hline
\end{tabular}

Table 3. 17. Summary of RCS concentrations for each target RMC (MIN-U-SIL $\left.{ }^{\circledR} 10\right)$

\begin{tabular}{|c|c|c|c|c|c|c|c|}
\hline \multirow{2}{*}{\multicolumn{2}{|c|}{$\begin{array}{c}\text { Target RMC } \\
\left(\mathrm{mg} / \mathrm{m}^{3}\right)\end{array}$}} & \multicolumn{3}{|c|}{ US Lab } & \multicolumn{3}{|c|}{ IFA Lab } \\
\hline & & GK2.69 & $\begin{array}{l}\text { GK2.69 } \\
\text { (N 7602) }\end{array}$ & $\begin{array}{r}\text { FSP-10 (IFA } \\
213-582)\end{array}$ & GK2.69 & $\begin{array}{l}\text { GK2.69 } \\
\text { (N 762) }\end{array}$ & $\begin{array}{r}\text { FSP-10 (IFA } \\
213-582)\end{array}$ \\
\hline \multirow{4}{*}{$\sim 0.8$} & Mean & 0.57 & 0.79 & 0.11 & 0.81 & 0.61 & 0.4 \\
\hline & Median & 0.56 & 0.83 & 0.1 & 0.83 & 0.62 & 0.38 \\
\hline & CV (\%) & 0.07 & 0.16 & 0.42 & 0.06 & 0.04 & 0.31 \\
\hline & Min - Max & $0.52-0.63$ & $0.52-0.86$ & $0.07-0.21$ & $0.73-0.87$ & $0.57-0.63$ & $0.2-0.61$ \\
\hline \multirow{4}{*}{$\sim 1.8$} & Mean & 1.42 & 1.81 & 0.32 & 1.86 & 1.68 & 1.69 \\
\hline & Median & 1.47 & 1.78 & 0.34 & 2.00 & 1.66 & 1.6 \\
\hline & $\mathrm{CV}$ & 0.05 & 0.03 & 0.31 & 0.16 & 0.02 & 0.12 \\
\hline & Min - Max & $1.31-1.51$ & $1.77-1.93$ & $0.16-0.45$ & $1.20-2.0$ & $1.64-1.73$ & $1.4-2$ \\
\hline \multirow{4}{*}{$\sim 5.9$} & Mean & 4.93 & 5.56 & 1.79 & 5.63 & 4.44 & 5.89 \\
\hline & Median & 5.14 & 5.99 & 1.53 & 5.7 & 4.66 & 6.2 \\
\hline & CV (\%) & 0.06 & 0.2 & 0.25 & 0.07 & 0.19 & 0.11 \\
\hline & Min - Max & $4.36-5.16$ & $3.08-6.32$ & $1.36-2.46$ & $4.8-6$ & $2.55-4.97$ & $4.5-6.5$ \\
\hline \multirow{4}{*}{$\sim 8.7$} & Mean & 7.34 & 8.77 & 2.45 & 8.29 & 6.31 & 7.96 \\
\hline & Median & 7.54 & 8.61 & 2.55 & 8.3 & 6.13 & 8.6 \\
\hline & CV (\%) & 0.06 & 0.06 & 0.31 & 0.03 & 0.08 & 0.14 \\
\hline & Min - Max & $6.78-7.95$ & $8.30-9.59$ & $1.34-3.73$ & $7.9-8.5$ & $5.99-7.32$ & $6.2-9$ \\
\hline
\end{tabular}



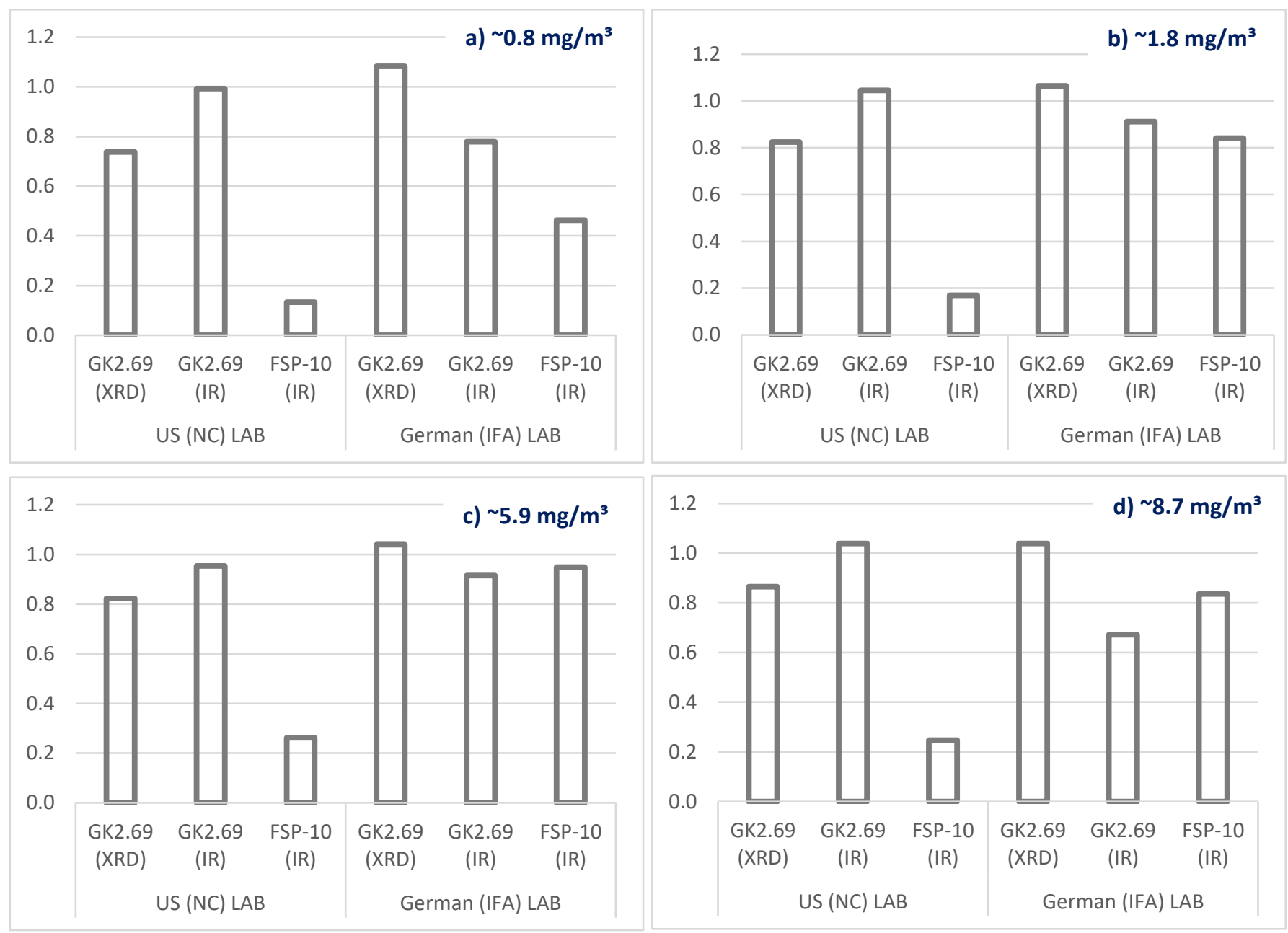

Figure 3. 16. Ratio of RCS (Quartz) to the corresponding respirable mass concentrations (RCS/RMC)

\section{Within Lab Comparisons}

For samples analyzed by the US (NC) lab

For samples analyzed according to the NIOSH 7500 and NIOSH 7602 methods, the RCS concentrations ranged from 0.52 to $7.95 \mathrm{mg} / \mathrm{m}^{3}$ and 0.52 to $9.59 \mathrm{mg} / \mathrm{m}^{3}$, respectively (Table 3.17). Unlike ARD (MMAD $=4.3 \mu \mathrm{m}$ ), a statistical difference was observed between RCS concentrations of NIOSH 7500 (XRD) and NIOSH 7602 (IR) for the samples collected with GK2.69 samplers $(p=0.0006)$. The average RCS percentages in the RMC collected in GK2.69 samples analyzed by NISOH 7500 and 7602 were $81 \%$ and $100 \%$ respectively. This is typical of smaller 
particle sized aerosol as the IR absorption is highest for particles in the 1-3 $\mu \mathrm{m}$ range (Esche et. al., 1999). The slope between NIOSH 7500 and 7602 is 0.85 (adj. $\left.r^{2}=0.66\right)$, indicating a moderate correlation between the two methods (Figure 3.17A).

\section{For samples analyzed by the German (IFA) lab}

For samples analyzed according to the NIOSH 7500 (XRD), NIOSH 7602 (IR) and IFA 213582 (IR) methods, the RCS concentrations ranged from 0.73 to $8.5 \mathrm{mg} / \mathrm{m}^{3}, 0.57$ to $7.32 \mathrm{mg} / \mathrm{m}^{3}$, and 0.20 to $9.0 \mathrm{mg} / \mathrm{m}^{3}$, respectively (Table 3.17). Overall, the RCS concentrations from the GK2.69 samples (NIOSH 7500) were statistically greater than those from all the other samplers ( $p<0.0001$ ). No statistical difference was observed between GK2.69 (NIOSH 7602) and FSP-10 (IFA 213-582) samples ( $p=0.7398$ ) (Figure 3.17B).

The average RCS percentages in the samples analyzed by the NIOSH 7500 (XRD), NIOSH 7602 (IR), and IFA 213-582 (IR) were 105\%, 84\%, and 77\%, respectively. Interestingly, XRD had higher RCS concentrations than the samples from both IR methods (NIOSH 7602 and IFA 213582), whereas in the US (NC) lab, the reverse trend was observed.

The slope for the relationship between both NIOSH methods, 7500 (XRD) and 7602 (IR), is 1.39 (adj. $\left.r^{2}=0.66\right)$, which agrees well with the slope from the ARD study (slope $=1.33$ ). For the other relationships, both IR methods (NIOSH 7602 and IFA 213-582), generated a slope of $0.73\left(\operatorname{adj} . r^{2}=0.66\right)$, and $1.02\left(\operatorname{adj} . r^{2}=0.66\right)$ for the relationship between IFA 213-582 and NIOSH 7500 (Figure 3.17B). 

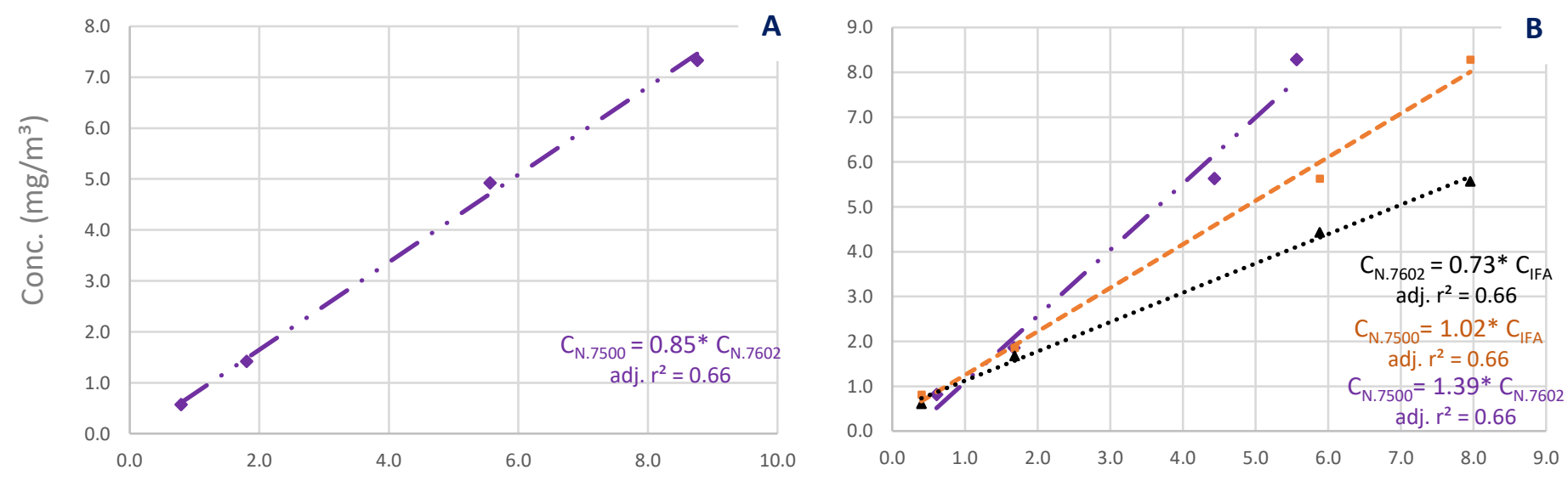

Conc. $\left(\mathrm{mg} / \mathrm{m}^{3}\right)$

Figure 3. 17. Comparison of different sampling and analytical methods (NIOSH 7602 vs. NIOSH 7500; IFA 213-582 vs. NIOSH 7500; and IFA 213-582 vs. NIOSH 7602) with MIN-U-SIL ${ }^{\circledR} 10$ data. Analyzed by A) US (NC) lab and B) German (IFA) labs.

\section{Between Lab Comparisons}

For the samples analyzed using the NIOSH 7602 (IR) method, a statistical difference was observed between the US (NC) lab and German (IFA) lab ( $p<0.0001$ ), with the US (NC) lab showing higher RCS concentrations than the German (IFA) lab. The regression line for this relationship yielded a slope of 0.69 (adj. $\mathrm{r}^{2}=0.99$ ). Samples analyzed according to NIOSH 7500 also show a statistical difference between both labs ( $p$ value $<0.0001$ ), with the German (IFA)

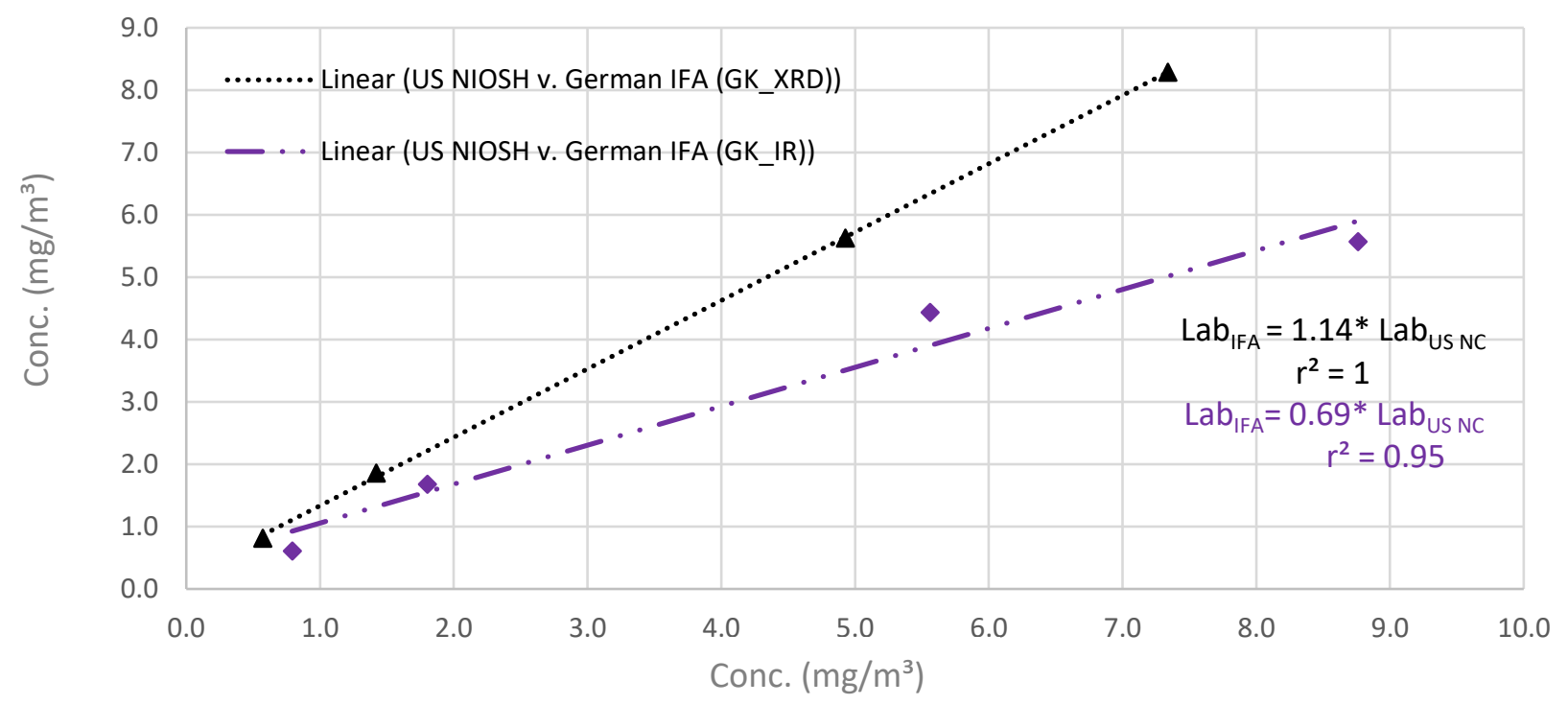

Figure 3. 18. Comparison of RCS concentrations between the US (NC) lab and the German (IFA) lab. 
lab having higher RCS concentration. For this method, a slope of $1.14\left(\mathrm{adj} . \mathrm{r}^{2}=1\right)$ was generated between the US (NC) lab and the German (IFA) lab (Figure 3.18).

\section{Summary}

The summary of the aerosol chamber study results for both testing materials, ARD and MIN-U-SIL ${ }^{\circledR} 10$, is displayed in Table 3.18. For the comparison between the NIOSH 7602 (IR) method and NIOSH 7500 (XRD) method, the slopes are greater than 1 for both testing materials (except for MIN-U-SIL ${ }^{\oplus} 10$ analyzed by the US (NC) lab), indicating that the XRD method generated higher concentrations than the IR method, although the magnitude of the slopes are different. For the other comparisons within each lab (i.e., NIOSH 7602 vs. IFA 213-582 and NIOSH 7500 vs. IFA 213-582), the sample results analyzed by the US (NC) lab were inconclusive because of potential errors occurring during the sample analyses using IFA 213-582 method. The comparison between the NIOSH 7500 and IFA 213-582 methods indicates that XRD method (NIOSH 7500) generated higher concentration than IFA 213-582 method (IR). On the other hand, the comparison between the NIOSH 7602 and IFA 213-582 methods showed different results depending on the testing materials; the NIOSH IR method generated slightly higher RCS concentrations than the IFA IR method for ARD with a slope of 1.02, while an opposite result was observed when testing with MIN-U-SIL ${ }^{\oplus} 10$ (slope $=0.73$ ). These differences might be caused from different particle sizes of testing materials. The particle MMADs are $4.27 \mathrm{um}$ for ARD and 2.66 um for MIN-U-SIL ${ }^{\circledR} 10$. The findings of this chamber study agree with findings that the size of different aerosols can affect the way it is detected by the analytical method.

Similarly, the comparison of both labs' performance for each method indicates that regardless of testing materials, both labs generated similar results with slopes close to $1 \mathrm{except}$ for the MIN-U-SIL ${ }^{\circledR} 10$ samples analyzed using NIOSH 7602 (IR) method. The difference in slopes between both IH labs for the methods confirm that more work is needed in standardizing lab analytical practices for research and compliance purposes. 
Table 3. 18. Summary of the Aerosol Chamber Study results

\begin{tabular}{|c|c|c|c|c|c|}
\hline \multirow[b]{2}{*}{ Analysis in } & \multirow[b]{2}{*}{ Method } & \multicolumn{2}{|c|}{ ARD } & \multicolumn{2}{|c|}{ MIN-U-SIL ${ }^{\circledR} 10$} \\
\hline & & Slopes & p-value & Slopes & p-value \\
\hline \multirow{6}{*}{ US (NC) lab } & NIOSH 7602 & \multirow{2}{*}{$N^{1}$} & \multirow{2}{*}{ NR } & \multirow{2}{*}{ NR } & \multirow{2}{*}{ NR } \\
\hline & IFA 213-583 & & & & \\
\hline & NIOSH 7500 & \multirow{2}{*}{ NR } & \multirow{2}{*}{ NR } & \multirow{2}{*}{ NR } & \multirow{2}{*}{ NR } \\
\hline & IFA 213-583 & & & & \\
\hline & NIOSH $7602(x)$ & \multirow{2}{*}{1.09} & \multirow{2}{*}{0.6429} & \multirow{2}{*}{0.85} & \multirow{2}{*}{0.0006} \\
\hline & NIOSH $7500(y)$ & & & & \\
\hline \multirow{6}{*}{ German (IFA) lab } & NIOSH 7602 (y) & \multirow{2}{*}{1.02} & \multirow{2}{*}{0.2647} & \multirow{2}{*}{0.73} & \multirow{2}{*}{0.7398} \\
\hline & IFA 213-583 (x) & & & & \\
\hline & NIOSH 7500 (y) & \multirow{2}{*}{1.31} & \multirow{2}{*}{$<0.0001$} & \multirow{2}{*}{1.02} & \multirow{2}{*}{$<0.0001$} \\
\hline & IFA 213-583 (x) & & & & \\
\hline & NIOSH $7602(x)$ & \multirow{2}{*}{1.33} & \multirow{2}{*}{$<0.0001$} & \multirow{2}{*}{1.39} & \multirow{2}{*}{$<0.0001$} \\
\hline & NIOSH 7500 (y) & & & & \\
\hline \multirow{6}{*}{$\begin{array}{l}\text { To determine the } \\
\text { difference } \\
\text { between labs }\end{array}$} & US: NIOSH 7602 (x) & \multirow{2}{*}{0.95} & \multirow{2}{*}{$<0.0001$} & \multirow{2}{*}{0.69} & \multirow{2}{*}{$<0.0001$} \\
\hline & German: NIOSH 7602 (y) & & & & \\
\hline & US: NIOSH 7500 (x) & \multirow{2}{*}{1.17} & $<00001$ & 114 & $<00001$ \\
\hline & German: NIOSH 7500 (y) & & 0.0001 & 1.14 & $<0.0001$ \\
\hline & US: IFA $213-583$ & & & & \\
\hline & German: IFA 213-583 & $\mathrm{NR}$ & NR & NR & $\mathrm{NR}$ \\
\hline
\end{tabular}




\section{A NOTE ON SIZE -SELECTIVE COLLECTION EFFICIENCY OF RESPIRABLE SAMPLERS}

Lee et al. (2010) discussed the need and utility of using high flow-rate samplers for sampling RCS, not just low flow samplers like the Higgins-Dewell and 10-mm nylon cyclone, which is used traditionally. However, the practicability of performing RCS sampling with either the GK2.69 or FSP-10 samplers is dependent on its sampling similarity to the well-established ISO/CEN/ACGIH/ASTM sampling convention for respirable dust. The implication of developing such a criterion is that samplers conforming to it can perform sampling that predicts size selective deposition to critical regions of the respiratory tract. Using monodisperse aerosols of ammonium fluorescein, Lee et al (2010) reported a 50\% cutoff size ( ${ }_{50} \mathrm{~d}_{\mathrm{ae}}$ ) for the GK2.69 and FSP-10 sampler at 4.1 and $4.8 \mu \mathrm{m}$, respectively compared to the $4 \mu \mathrm{m}$ measured with the international standard respirable convention. Sampling efficiencies for both samplers' approach zero more sharply as the particle size increases than the ISO/CEN/ACGIH/ASTM convention curve. Bias maps were generated for both samplers using the MMAD and GSD, and the positive bias reported indicate that both samplers overestimate the exposures to respirable particles compared to the convention curve. The efficiency curves generated from Lee et. al paper was used as a basis to determine similarities between the international standard respirable convention and the respirable dust efficiency of the FSP-10 samplers with both of the test aerosols used for this study (ARD with MMAD $=4.27 \mu \mathrm{m}$ and $\mathrm{MIN}-\mathrm{U}-\mathrm{SIL}{ }^{\circledR} \mathrm{MMAD}=2.66 \mu \mathrm{m}$ ), using the GK2.69 as a reference.

Previous investigators have raised concerns about usefulness of attributing health risk based on a samplers' ability to take penetration-based measurements, which is the basis of the ISO/CEN/ACGIH/ASTM sampling convention and most respirable dust sampler design, including the samplers used in this study. An employee working in a dusty environment will breathe in a given amount of aerosol particles along with each inhaled volume of air. The particle size of the aerosols will determine location of deposition along the respiratory tract and possible accumulation. This location will often the health consequence to the worker, which is of interest to the epidemiologist. Because epidemiological studies aim to track disease after the exposure, the connection between the exposure, or exposure results from aerosol sampling 
using size selective samplers (GK2.69 and FSP-10) and eventual health consequences must be established predictably. In theory, these size selective samplers are designed to estimate where in the respiratory tract particles would penetrate (exposure) and the implied assumption is that exposure measurements represent the dose (inhaled and deposited) to the respiratory tract. However, many available sampling devices don't have a collection efficiency curve that follows the shape of the corresponding lung deposition curve. In fact, Hewett (1991) reported that for many particle sizes, respirable samplers conforming to the ISO/CEN/ACGIH curve overestimated the dose to the lung, indicating that penetration to a region does not always equal deposition. Moreover, McCawley et al. (1993) demonstrated that not all penetrating particles deposit in the pulmonary regions of the respiratory tract. Thus, if there's a difference between the deposited particle (dose) and measured particle (exposure), relying on penetration-based measurements derived from traditional respirable samplers to predict an exposure-dose relationship may be inadequate or impractical for use in epidemiological research seeking to determine associations between occupational agents and health effects (Esmen et al., 2001).

Hewett (1991) conducted a study of collection efficiency based on theoretical particle size, and generated deposition curves based on a lung deposition prediction formula as described by Heyder et al. (1986). Numerical integrations were used to calculate the particle size distribution that a sampler following the ISO/CEN/ACGIH convention would collect, and bias was calculated as the percentage by which the sampler overestimates or underestimates the estimated deposited aerosol. Particles of geometric means (GM) $0.5,1,2.5,5,10,15$, and $20 \mu \mathrm{m}$ were used with geometric standard deviation (GSD) of 1.5, 2 and 3 for each GM. It was reported that the bias for respirable samplers varies significantly with lower particle sizes ( $<5$ $\mu \mathrm{m})$, but not as much for greater particle sizes $(>5 \mu \mathrm{m})$. Thus, for a distribution of particles with GM size $2.5 \mu \mathrm{m}$ and GSD $2.0 \mu \mathrm{m}$, a typical respirable sampler will overestimate the aerosol by approximately $109 \%$ per unit volume sampled, than will be deposited in the alveoli, per unit volume inhaled. The bias is inversely proportional to GM, but varies considerably with GSD, concluding that the alveolar deposition curve predicts greater deposition than does the ACGIH RF'M collection efficiency curve for larger diameters. 
A similar calculation was performed to calculate bias in the samples collected in the chamber study with both samplers. An excel spreadsheet was developed to calculation the integrations as described in Hewett (1991). An Aerodynamic Particle Sizer ${ }^{\circledR}$ (APS) spectrometer (model 3321, TSI Inc.) was used to monitor the size distributions of airborne particles in the chamber. Using the MMAD and SD from the APS for each level of RMCs, the alveolar dose bias was calculated. Figure 3.19 displays the comparison between the bias for both test aerosols.

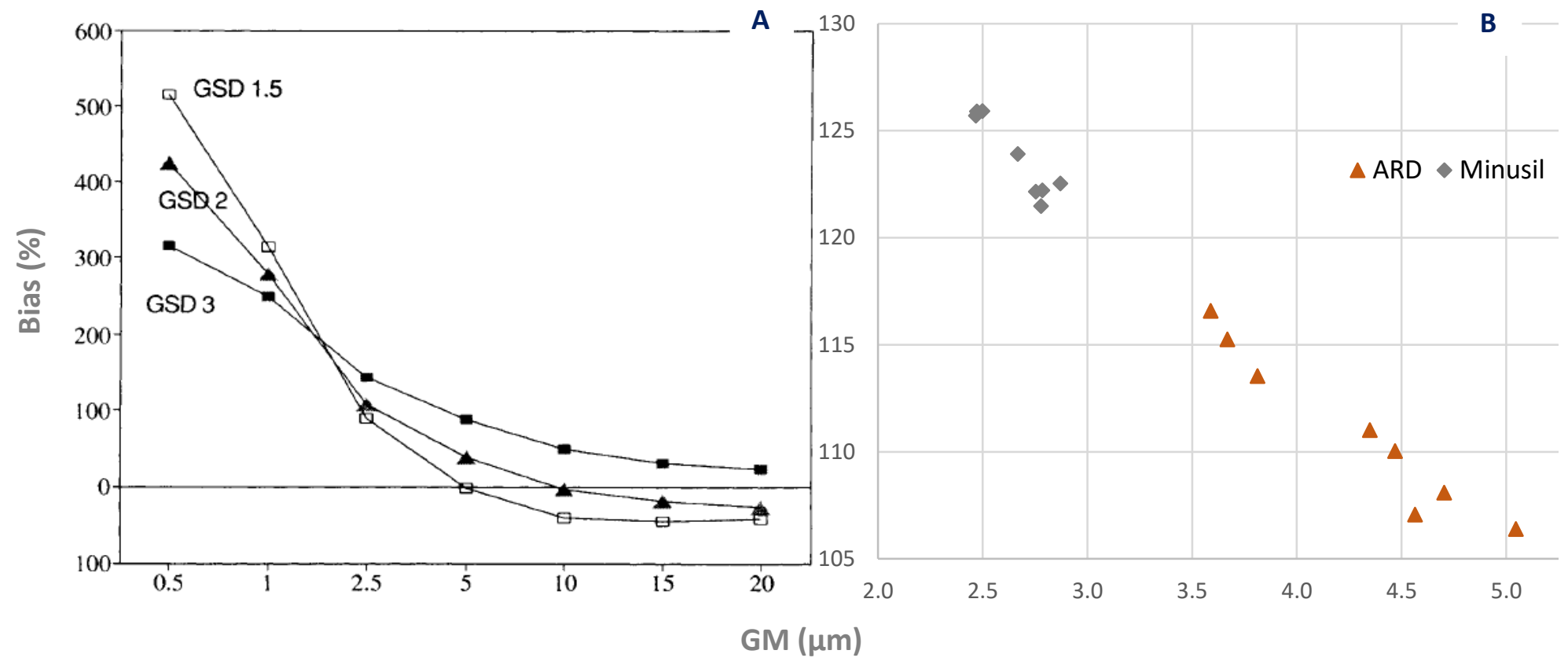

Figure 3. 19. Bias (\%) when using ARD and MIN-U-SIL ${ }^{\circledR} 10$ as an estimate of alveolar deposition for different particle size distributions. A) Graphical result from Hewett (1991); B) Results from aerosol test chamber data.

The bias for $\mathrm{MIN}-\mathrm{U}-\mathrm{SIL}{ }^{\circledR} 10$ particles $(\mathrm{MMAD}=2.66 \mu \mathrm{m})$ was higher than ARD particles (MMAD $=4.27)$. Similar trends were observed in this study compared to the Hewett (1991). For example, for particles with GM size $2.5 \mu \mathrm{m}$ and GSD $1.77 \mu \mathrm{m}$, the FSP-10 sampler bias was $126 \%$. It was not the primary scope of this research to evaluate different particle sized aerosols for the purpose of bias calculations. Thus, only 2 test aerosols (MIN-U-SIL ${ }^{\circledR} 10$ and ARD) were available for this assessment. However, the limited data points used in this calculation agree well with the results from Hewett that bias decreases with increasing GM. So, while this overestimation of deposition could be beneficial for risk assessment geared toward compliance 
purposes, it could have less than desirable results for epidemiological studies because it introduces additional variability into dose-response analysis that combines workers exposed to different particle size distributions (Hewett, 1991). That been said, from the viewpoint of an epidemiologist, for a reasonable range of particle sizes, neither the US GK2.69 nor German FSP10 sampler will give different estimates of the dose, even though the bias percentages differ both samplers. Other size selective sample like impactors that segregate particle sizes with more precision can generate a better estimate of dose along the different regions of the respiratory tract. 
PART III. FIELD STUDY

PERSONAL SAMPLING

Full-shift respirable mass concentrations ranged from 0.040 to $1.019 \mathrm{mg} / \mathrm{m}^{3}$ (CV = 1.2) for the GK2.69 samples and 0.025 to $1.445 \mathrm{mg} / \mathrm{m}^{3}$ (CV=1.0) for the FSP-10 samples (Table 3.19). For both samplers, the mean concentrations were similar, while the median concentration of the FSP-10 samples was about two times higher than that of the GK2.69 samples, indicating a left-skewed distribution of the GK2.69 samples. As stated in Methods section, two FSP-10 samples-first half and second half of a full-shift-were collected from each worker. Thus, the reported RMCs for the FSP-10 samples were the combined concentrations of the two samples. Statistical analyses indicated that RMC results from the GK2.69 samplers were statistically different (lower) from the FSP-10 samplers $(p=0.0001)$. Also, there were no statistical differences in RMCs between the first half of full-shift $\left(1^{\text {st }} \mathrm{S}\right)$ for the FSP-10 samples and the full shift (FS) for the FSP-10 samples, but the second half of full-shift results ( $2^{\text {nd }} S$ ) were statistically different from those of both FSP-10 FS and the FSP-10 $1^{\text {st }}$. The mean respirable mass concentrations (CV) for FSP-10 samplers were $0.314 \mathrm{mg} / \mathrm{m}^{3}(1.0)$ for the $1^{\text {st }} \mathrm{S}$ and $0.244 \mathrm{mg} / \mathrm{m}^{3}$ (1.3) for the $2^{\text {nd }} \mathrm{S}$.

A comparison of RCS concentrations between two methods-NIOSH 7602 (IR) and IFA 213-582 (IR) - was performed. The mean RCS concentration (CV) for GK2.69 samples was 0.023 $\mathrm{mg} / \mathrm{m}^{3}$ (1.8), while that of the FSP-10 samples was $0.033 \mathrm{mg} / \mathrm{m}^{3}$ (1.8) (Table 3.20). Ninety-four percent of GK2.69 samples were under the OSHA PEL of $0.05 \mathrm{mg} / \mathrm{m}^{3}$. The mean RCS concentration (CV) for the FSP-10 samples was $0.033 \mathrm{mg} / \mathrm{m}^{3}(1.8)$ for the $1^{\text {st }}$ and $0.030 \mathrm{mg} / \mathrm{m}^{3}$ (2.2) for the $2^{\text {nd }}$ S. Personal samples from the GK2.69 (NIOSH 7602) FS were statistically different from the FSP-10 FS samples ( $p=0.0016)$, and FSP-10 $1^{\text {st }}$ S samples also differed from its $2^{\text {nd }} S$ samples $(p=0.0110)$. 
Table 3. 19. Summary of respirable mass concentrations for the personal exposures $(\mathrm{mg} / \mathrm{m} 3)$

\begin{tabular}{ccccc}
\hline Sampler & GK2.69 FS & FSP-10 FS & FSP-10 $\mathbf{1}^{\text {st }} \mathbf{S}^{\mathbf{2}}$ & FSP-10 2 $^{\text {nd }} \mathbf{S}^{\mathbf{3}}$ \\
\hline Mean & 0.21 & 0.28 & 0.31 & 0.24 \\
\hline Median & 0.11 & 0.21 & 0.26 & 0.153 \\
\hline CV & 1.2 & 1.0 & 1.0 & 1.3 \\
\hline Min & 0.04 & 0.025 & 0.03 & 0.019 \\
\hline Max & 1.02 & 1.45 & 1.62 & 1.64 \\
\hline $\mathbf{N}$ & 31 & 31 & 31 & 31 \\
\hline
\end{tabular}

${ }^{1} \mathrm{FS}=$ Full-shift; ${ }^{2} 1 \mathrm{stS}=$ first half of the full-shift; ${ }^{3}{ }^{\text {nd }} \mathrm{S}=$ second half of the full-shift

Table 3. 20. Summary of RCS concentrations for the personal exposures $(\mathrm{mg} / \mathrm{m} 3)$

\begin{tabular}{ccccc}
\hline $\begin{array}{c}\text { Analytical } \\
\text { Method }\end{array}$ & $\begin{array}{c}\text { GK2.69 FS } \\
\text { (NIOSH 7602) }\end{array}$ & $\begin{array}{c}\text { FSP-10 FS } \\
\text { (IFA 213-582) }\end{array}$ & $\begin{array}{c}\text { FSP-10 1 } \text { 1 }^{\text {st }} \\
\text { (IFA 213-582) }\end{array}$ & $\begin{array}{c}\text { FSP-10 2 }^{\text {nd }} \text { S } \\
\text { (IFA 213-582) }\end{array}$ \\
\hline Mean & 0.023 & 0.033 & 0.033 & 0.03 \\
\hline Median & 0.008 & 0.018 & 0.018 & 0.01 \\
\hline CV & 1.8 & 1.8 & 1.8 & 2.2 \\
\hline Min & 0.007 & 0.006 & 0.006 & 0.005 \\
\hline Max & 0.184 & 0.271 & 0.33 & 0.34 \\
\hline N & $31(11)^{\mathrm{a}}$ & $31(8)^{\mathrm{a}}$ & $31(5)^{\mathrm{a}}$ & $31(10)^{\mathrm{a}}$ \\
\hline
\end{tabular}

${ }^{a}$ Number of samples showing concentrations < LOD.

Tables 3.19 and 3.20 show the overall comparison of RMC and RCS concentrations. Ratios of RCS/RMC were calculated for each sample pair and averaged about $10 \%$ for all comparisons, which was considerably lower than both average ratios from the results obtained in the chamber study, indicating the presence of low quartz content in the field aerosols (Figure 3.20). The pottery plant utilized clay, glaze and coloring powders with a range of silica content from $2 \%$ to $99 \%$ purity, depending on the formulation. Unfortunately, the percent of silica content matched with specific task was not obtained during the sampling. Thus, no further analysis was done. 


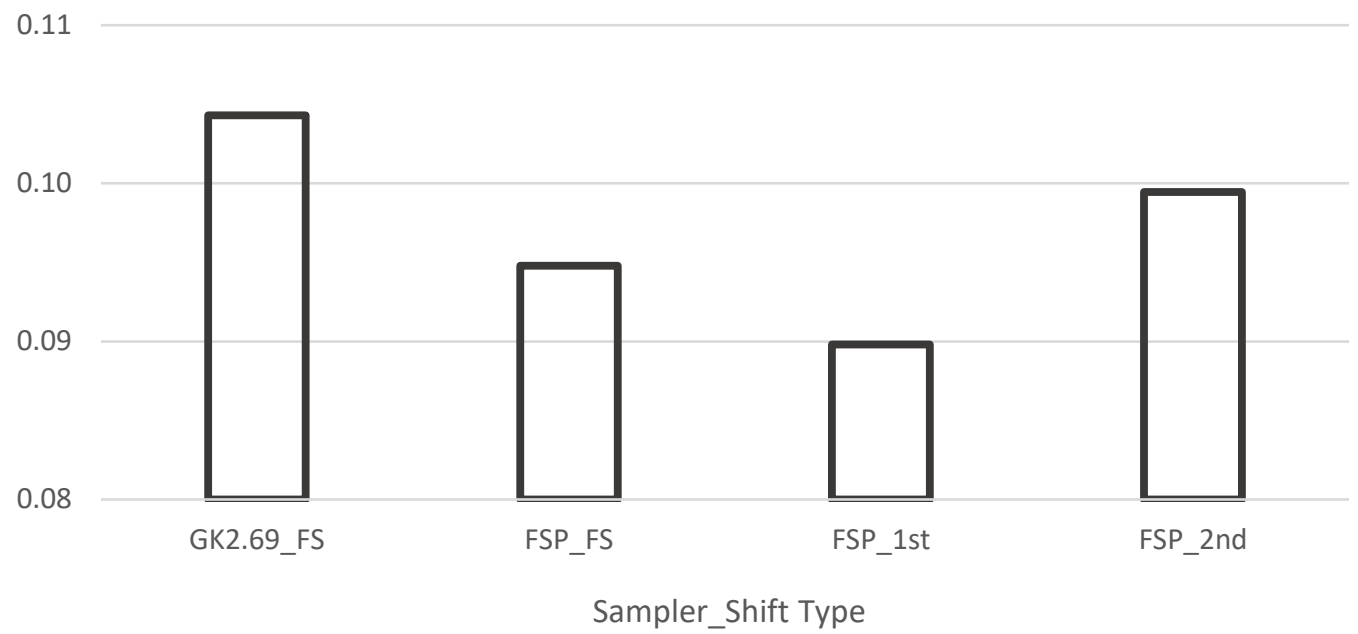

Figure 3. 20. Ratio of RCS concentrations to the corresponding respirable mass concentrations (personal samples)

The slope of the regression line for the RCS concentrations between FSP-10 FS (IFA 213582) and GK2.69 FS (NIOSH 7602) is 0.71 (adj. $\left.r^{2}=0.94\right)$ (Figure 3.21A). For the other comparisons, the calculated slopes are 0.64 (adj. $\left.r^{2}=0.81\right)$ between FSP-10 $1^{\text {st }}$ S and GK2.69 FS, 0.61 (adj. $r^{2}=0.81$ ) between FSP-10 $2^{\text {nd }}$ S and GK2.69 FS, and 0.77 (adj. $r^{2}=0.50$ ) between FSP$101^{\text {st }} S$ and $2^{\text {nd }} S$. It should be noted that most data points are clustered at the bottom of the graph indicating that the majority of RCS concentrations were low, with the exception of the 2 data points contained within the red highlighted box. Also, during sampling, it was observed that most of the dust generating tasks happened early in the shift (loading clay powder into the tank, mixing powdered colorings etc.). Thus, as expected, the first half of full-shift samples had higher respirable mass concentrations and RCSs than the $2^{\text {nd }}$ S samples (Figure 3.21B).

The results of this comparison clearly indicate that occupational professionals collecting exposure samples should be aware of differences in workers' exposure levels based on the sampling time and collect samples representing workers' exposure for full shifts. 

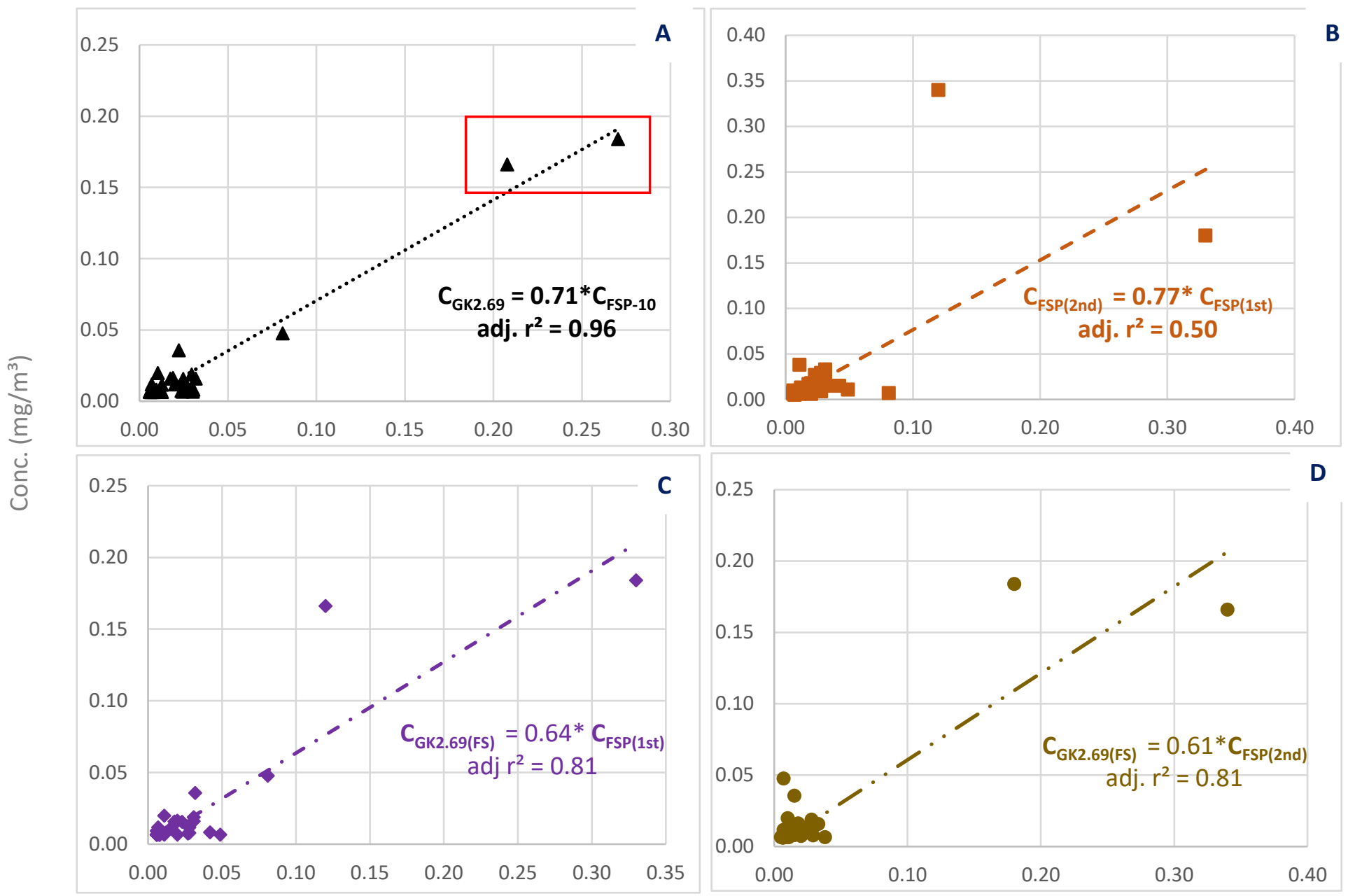

Conc. $\left(\mathrm{mg} / \mathrm{m}^{3}\right)$

Figure 3. 21. Comparison of RCS concentrations between methods: a) FSP-10 FS vs. GK2.69 FS, b) FSP-10 1stS vs. FSP-10 2ndS c) FSP-10 1stS vs. GK2.69 FS d) FSP-10 2ndS vs. GK2.69 FS

\section{AREA SAMPLING}

Respirable mass concentrations ranged from 0.007 to $0.338 \mathrm{mg} / \mathrm{m}^{3}$ for the GK2.69 (NIOSH 7500) samples with a mean (CV) of $0.101 \mathrm{mg} / \mathrm{m}^{3}(0.8), 0.013$ to $0.318 \mathrm{mg} / \mathrm{m}^{3}$ for the GK2.69 (NIOSH 7602) samples with a mean (CV) of $0.097 \mathrm{mg} / \mathrm{m}^{3}(0.8)$, and 0.008 to 0.456 $\mathrm{mg} / \mathrm{m}^{3}$ for the FSP-10 (IFA 213-582) samples with a mean (CV) of $0.154 \mathrm{mg} / \mathrm{m}^{3}$ (0.8) (Table 3.21). Overall, FSP-10 samples collected more dust than GK2.69 samples.

Interestingly, no statistical difference in respirable mass concentrations was observed between the near field and the far field samples $(p=0.1010)$. This is probably due to the open 
floor spacing of the plant, which is designed to promote the efficiency of the production process flow, where various tasks share common spaces with little to no barriers to air flow. That is, although a basket was placed in the far-field from a source emission, because of the presence of another source emission adjacent to the basket, the measured concentrations were not different compared to the one in the near-field. Statistically, the respirable mass concentrations of both sets of GK2.69 samples showed no differences ( $p=0.6095)$, while FSP10 samples showed significantly higher concentrations than GK2.69 samples.

Table 3. 21. Summary of respirable mass and RCS concentrations (Area exposure)

\begin{tabular}{|c|c|c|c|c|c|c|}
\hline \multirow{4}{*}{$\begin{array}{l}\text { Analytical } \\
\text { Methods }\end{array}$} & \multicolumn{3}{|c|}{ Respirable Mass Concentration $\left(\mathrm{mg} / \mathrm{m}^{3}\right)$} & \multicolumn{3}{|c|}{ RCS Concentration $\left(\mathrm{mg} / \mathrm{m}^{3}\right)$} \\
\hline & GK2.69 & GK2.69 & FSP-10 & GK2.69 & GK2.69 & FSP-10 \\
\hline & (NIOSH & (NIOSH & (IFA 213- & (NIOSH & (NIOSH & (IFA 213- \\
\hline & $7500)$ & $7602)$ & $582)$ & 7500) & 7602) & 582) \\
\hline Mean & 0.101 & 0.097 & 0.154 & 0.011 & 0.013 & 0.015 \\
\hline Median & 0.060 & 0.076 & 0.115 & 0.004 & 0.006 & 0.010 \\
\hline CV & 0.8 & 0.8 & 0.8 & 0.9 & 1.0 & 0.9 \\
\hline Min & 0.007 & 0.013 & 0.008 & 0.003 & 0.005 & 0.002 \\
\hline Max & 0.338 & 0.318 & 0.456 & 0.035 & 0.051 & 0.050 \\
\hline $\mathbf{N}$ & 31 & 34 & 35 & $31(20)^{1}$ & $34(17)^{1}$ & $35(8)^{1}$ \\
\hline
\end{tabular}

${ }^{1}$ Number of samples showing concentrations < LOD.

The mean RCS concentrations (CV) were $0.011 \mathrm{mg} / \mathrm{m}^{3}$ (0.9), $0.013 \mathrm{mg} / \mathrm{m}^{3}$ (1.0), and $0.015 \mathrm{mg} / \mathrm{m}^{3}$ (0.9) for the GK2.69 (NIOSH 7500) samples, GK2.69 (NIOSH 7602) samples, and FSP-10 (IFA 213-582) samples, respectively (Table 3.21). The median RCS concentrations were considerably lower than the mean values indicating RCS concentrations left-skewed. For the data analysis, the combined data of near- and far-field samples were used because of no statistical differences of RMCs were observed between near- and far-field samples. Consequently, no statistical differences were observed in the RCS concentrations between: GK2.69 (NIOSH 7602) and FSP-10 (IFA 213-582) ( $p=0.7911$ ); GK2.69 (NIOSH 7500) and FSP-10 (IFA 213-582) ( $p=0.2319) ;$ GK2.69 (NIOSH 7602) and GK2.69 (NIOSH 7500) ( $p=0.3464)$. 
Figure 3.22 shows the relationships of the RCS concentrations between methods. The slopes are $0.82\left(\operatorname{adj} . r^{2}=0.82\right), 0.73\left(\operatorname{adj} . r^{2}=0.94\right)$, and $0.84\left(\operatorname{adj} . r^{2}=0.88\right)$ for the comparison of NIOSH 7602 vs. NIOSH 7500, IFA 213-582 vs. NIOSH 7500, and IFA 213-582 vs. NIOSH 7602, respectively. Overall, RCS concentrations analyzed using XRD were higher than those analyzed using both IR methods.

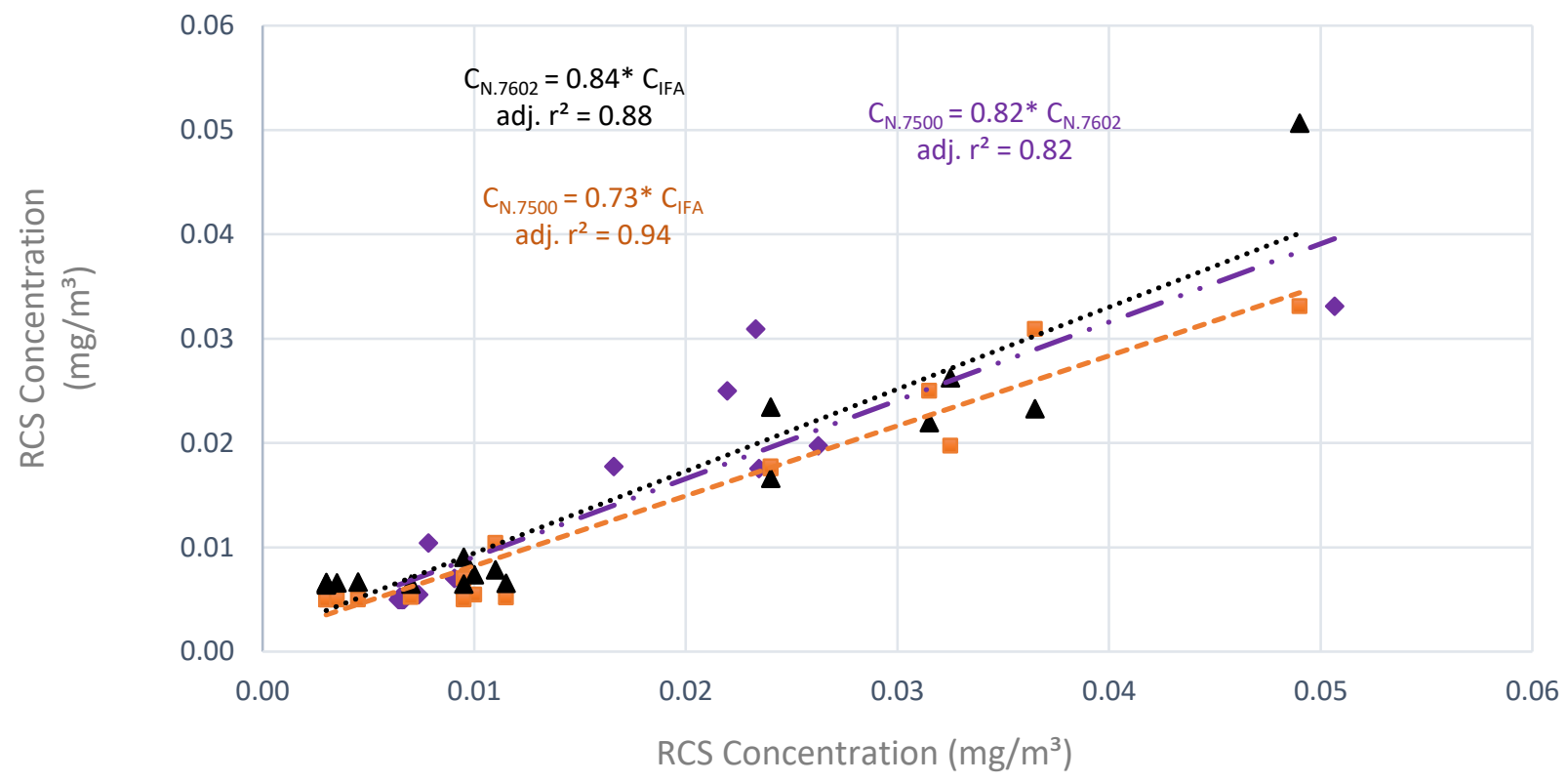

Figure 3. 22. Comparison of RCS concentrations between methods: NIOSH Method 7602 v. NIOSH Method 7500; IFA 213-582 v. NIOSH 7500; and IFA 213-582 v. NIOSH 7602

\section{COMBINED RESULTS OF PERSONAL AND AREA EXPOSURES}

An additional analysis was conducted by combining the results of personal and area samples to determine the differences of slopes compared to those calculated based on either personal or area exposure data. A summary of the combined sample results is displayed in Table 3.22. Note that the collected personal samples using sets of GK2.69 and FSP-10 were analyzed only for the IR method (i.e., NIOSH 7602 for the GK2.69 samples and IFA 213-582 for the FSP-10 samples). Thus, the comparison of exposures was limited to both IR methods. Also, for both samplers, full-shift exposure data were compared. Overall, for both RMC and RCS concentrations, FSP-10 samples showed higher concentrations than the GK2.69 samples. 
Statistical tests revealed a difference of respirable mass concentrations between the FSP-10 samples and GK2.69 samples ( $p=0.0091)$ but no difference in RCS concentrations $(p=0.3788)$.

Table 3. 22. Summary of the Combined Personal and Area exposures (full-shift exposures).

\begin{tabular}{|c|c|c|c|c|}
\hline \multirow[b]{2}{*}{$\begin{array}{l}\text { Analytical } \\
\text { Method }\end{array}$} & \multicolumn{2}{|c|}{$\begin{array}{l}\text { Respirable mass concentration } \\
\qquad\left(\mathrm{mg} / \mathrm{m}^{3}\right)\end{array}$} & \multicolumn{2}{|c|}{$\mathrm{RCS}\left(\mathrm{mg} / \mathrm{m}^{3}\right)$} \\
\hline & GK 2.69 & FSP-10 & $\begin{array}{c}\text { GK 2.691 } \\
\text { (NIOSH 7602) }\end{array}$ & $\begin{array}{c}\text { FSP-10 } \\
\text { (IFA 213-582) }\end{array}$ \\
\hline Mean & 0.151 & 0.213 & 0.017 & 0.023 \\
\hline Median & 0.092 & 0.170 & 0.008 & 0.011 \\
\hline CV & 1.3 & 1.1 & 1.8 & 1.8 \\
\hline Min & 0.013 & 0.008 & 0.005 & 0.002 \\
\hline Max & 1.019 & 1.445 & 0.184 & 0.271 \\
\hline $\mathbf{N}^{2}$ & 64 & 64 & $64(27)^{3}$ & $64(16)^{3}$ \\
\hline
\end{tabular}

${ }^{1}$ Personal samples from GK2.69 samplers analyzed according to the NIOSH 7602 (IR) method; ${ }^{2}$ Number of samples used for the regression based on the sample pairs available; ${ }^{3}$ Number of samples showing concentrations < LOD.

As shown in Figure 3.23, the regression analysis yielded a slope of 0.72 (adj. $\left.r^{2}=0.95\right)$ converting from the IFA 213-582 method to the NIOSH 7602 method. This slop is identical to the slope of 0.72 (adj. $\left.r^{2}=0.95\right)$ from the personal sample results, and similar to that of 0.79 (adj. $\left.r^{2}=0.88\right)$ from the area sample results.

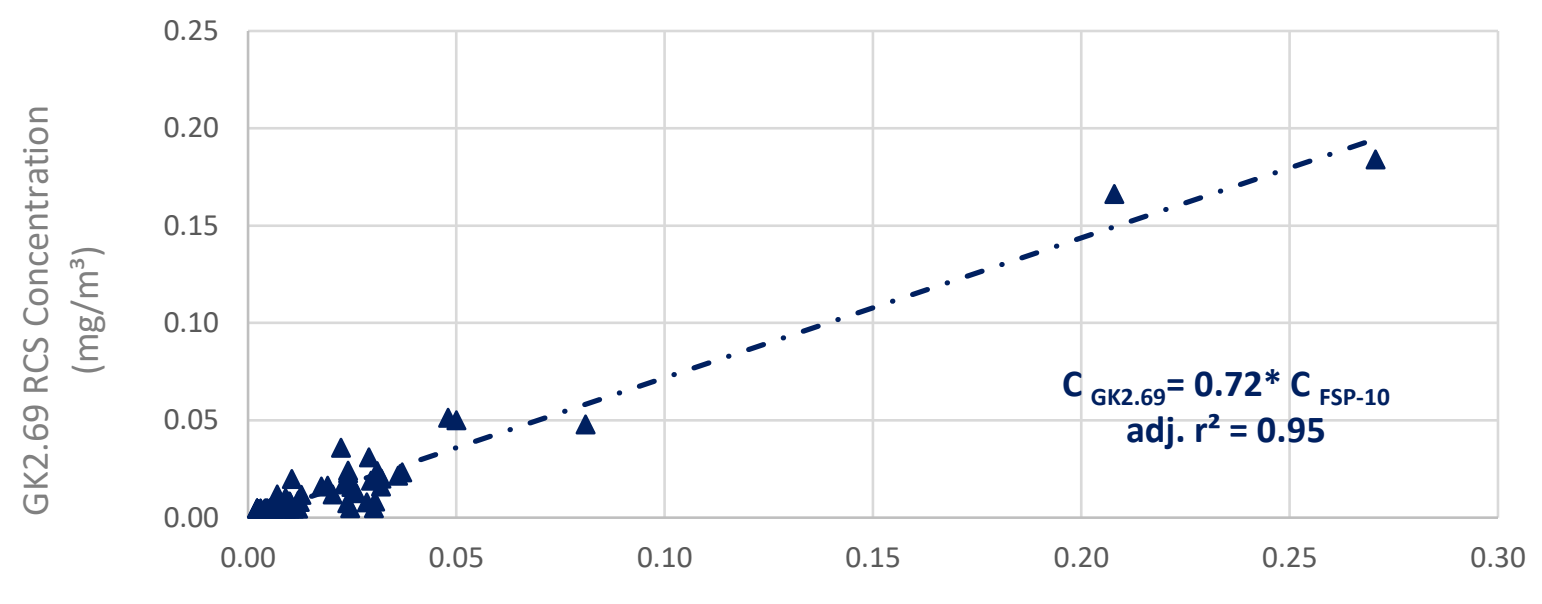

FSP-10 RCS Concentration $\left(\mathrm{mg} / \mathrm{m}^{3}\right)$

Figure 3. 23. Comparison of RCS concentrations for combined personal and area exposures 


\section{Summary}

Table 3.23 shows summary results for the field study. Overall, the IFA 213-582 method resulted in higher RCS concentrations than the NIOSH 7602 method for the personal, area, and combined data (all slopes < 1). Interestingly, NIOSH 7500 (XRD) generated lower concentrations than both IR methods. Additionally, FSP-10 samples had a smaller proportions of samples < LOD (24\%-26\%) than GK2.69 samples (35\% - 65\%). This observation has been noted in other investigations and is attributable to its high dust collection rate (Lee et al., 2011).

Table 3. 23. Summary of Field Samples

\begin{tabular}{|c|c|c|c|c|c|c|}
\hline Sample Type & Sampler & Analytical Method & $\mathrm{N}^{1}$ & $\begin{array}{c}\text { Total RCS } \\
\text { conc. range, } \\
\mathrm{mg} / \mathrm{m}^{3}\end{array}$ & Samples < LOD & $\begin{array}{l}\text { Conversion } \\
\text { Factors } \\
\text { (slopes) }\end{array}$ \\
\hline \multirow{2}{*}{$\begin{array}{l}\text { Personal } \\
\text { Samples }\end{array}$} & GK2.69 & NIOSH 7602 (y) & 31 & $0.007-0.184$ & $11(35 \%)$ & \multirow{2}{*}{0.71} \\
\hline & FSP-10 & IFA 213-582 (x) & 31 & $0.006-0.271$ & $8(26 \%)$ & \\
\hline \multirow{6}{*}{ Area Samples } & GK2.69 & NIOSH 7602 (y) & 34 & $0.005-0.051$ & $15(44 \%)$ & \multirow{2}{*}{0.84} \\
\hline & FSP-10 & IFA 213-582 (x) & 34 & $0.002-0.050$ & $8(24 \%)$ & \\
\hline & GK2.69 & NIOSH 7500 (y) & 31 & $0.003-0.035$ & $20(65 \%)$ & \multirow{2}{*}{0.73} \\
\hline & FSP-10 & IFA 213-582 (x) & 31 & $0.002-0.050$ & $8(26 \%)$ & \\
\hline & GK2.69 & NIOSH $7602(x)$ & 31 & $0.005-0.051$ & $15(48 \%)$ & \multirow{2}{*}{0.82} \\
\hline & GK2.69 & NIOSH 7500 (y) & 31 & $0.003-0.035$ & $20(65 \%)$ & \\
\hline \multirow{2}{*}{$\begin{array}{c}\text { Combined } \\
\text { Personal \& } \\
\text { Area samples }\end{array}$} & GK2.69 & NIOSH 7602 (y) & 65 & $0.006-0.184$ & $26(40 \%)$ & \multirow{2}{*}{0.71} \\
\hline & FSP-10 & IFA 213-582 (x) & 65 & $0.003-0.271$ & $16(25 \%)$ & \\
\hline
\end{tabular}

${ }^{1}$ Number of samples used for the regression analysis 


\section{CONCLUSION AND LIMITATIONS}

This study investigated the relationship between the US (NIOSH methods) and German (IFA method) sampling strategies of RCS exposure measurements in three parts, 1) spiked sample analysis to determine inter- and intra-laboratory variability of RCS analytical methods, 2) aerosol chamber study, where side-by-side samples were collected under environmentally controlled conditions to determine the variability from the use of different samplers along with different analytical methods, and 3) field study to determine variability caused from several factors including different sampling and analytical methods, workers' behavior, and uncontrolled environmental conditions. Ideally, the variability in exposure results from the field study would be higher than those from the spiked samples study and the aerosol chamber study. However, the standard errors (SES) to the slope/conversion factors did not show any consistent patterns. For example, the SE for the conversion of IFA 213-582 method to NIOSH 7602 method was lower for the combined data of personal and area samples (SE $=0.0180)$ than for the lab study using MIN-U-SIL ${ }^{\circledR} 10$ analyzed by the German lab (SE = 0.0352) (Table 3.24).

These inconsistent patterns could be the results of various factors such as within- and between-lab variations, utilization of different samplers, sample preparation using different procedures, unexpected environmental conditions, workers' behavior, etc. For example, the results from the field samples are based on the on-site environmental conditions during the dates of sample collection. The samples were collected during the summer months of July and August with high temperature and humidity. Personal fans utilized by employees to keep cool could alter the air flow from one sampler to the other. Employees habits and posture could also affect air movement across the face of the personal samplers attached to their shoulder, thus affecting the amount of aerosol aspirated into the sampler and the concentrations sampled. In this study, quantification of all individual factors could not be determined because of unexpected or uncontrollable conditions and thus, the SEs reported here provide general observations. The slope/conversion factors from IFA 213-582 method to NIOSH 7602 method are close to 1 for the spiked samples and the aerosol chamber study using ARD, while the 
chamber study using MIN-U-SIL ${ }^{\circledR} 10$ and the field study showed slopes considerably lower than 1 (see blue-highlighted color in Table 3.24).

Overall, these findings indicate no differences of sampling and analytical methods between two countries. However, the findings from the field study indicate that it is probable that unexpected environmental conditions of worksite or worker behavior influence the differences in concentrations. For the comparison between the NIOSH 7602 and NIOSH 7500 methods (green-highlighted color in Table 3.24), the spiked and aerosol chamber sample results showed slope/conversion factors greater than 1 except for the chamber results using MIN-U$\mathrm{SIL}^{\circledR} 10$ analyzed by the US (NC) lab, while the field study showed the conversion factor less than 1. From the magnitudes of those factors and SEs, it is difficult to determine the cause of those differences. Similarly, the comparison between the IFA 213-582 and NIOSH 7500 methods (yellow-highlighted color in Table 3.24) showed the same pattern as the results of the comparison between the NIOSH 7602 and NIOSH 7500 methods. One possible explanation might be that RCS concentrations collected from the pottery plant showed high proportion of samples less than LOD, although it is uncertain which direction (positive or negative) this would affect. Another explanation could be that the uncontrollable environmental conditions and worker behavior during the field survey considerably influence the workers' concentrations, leading to results going in the opposite direction of the spiked sample and chamber study.

Nevertheless, although slopes/conversion factors were developed for each part of the study, for the practical application, it is recommended to use the conversion factor from the field study $\left(\mathrm{C}_{\mathrm{GK} 2.69}=0.71^{*} \mathrm{C}_{\mathrm{FSP}-10}\right)$ if these results are to be used in epidemiological research because field sampling results are most relevant and practical for occupational epidemiology research. It should be noted that the regression was re-calculated after removing the 2 data points at the top right portion of the FSP-10 FS vs. GK2.69 FS graph to see if and how the slope and $r^{2}$ is affected when the high concentrations are removed. The new slope was $\mathrm{C}_{\mathrm{GK} 2.69}=0.58^{*}$ $C_{F S P-10}\left(\operatorname{adj} . r^{2}=0.45\right)$, indicating that the influence of the data points with high concentrations are not negligible and should be taken into account when evaluating personal sample concentration results. 
Although many samples were collected and efforts were made to sample high dust areas, many of the RCS concentration results were below the LOD, ranging from $24 \%$ to $65 \%$ for the field study. This might affect the outcome of determining the relationship between the US (NIOSH) method and the German (IFA) method. Also, this study is limited to sample collection from just one worksite. Thus, additional samples collected from various worksites might be necessary. In addition, only two labs - US (NC) lab and German IFA lab-participated in the spiked sample and aerosol chamber study. To determine the variability within- and betweenlabs, participation of other labs (e.g., at least 6 labs) is recommended.

Lastly, the findings presented in this report would not be applicable to existing (retrospective) or future (prospective) exposure data that was not or will not be generated using the NIOSH or IFA methods used in this investigation. Thus, when epidemiological studies adopting the findings of this research is used, care must be taken to ensure that the same sample collection and analytical methods are employed. For both NIOSH Methods 7500 (XRD) and 7602 (IR), GK2.69 cyclone was selected among several commercially available, respirable cyclones. Therefore, the conversion factors developed here would not be applicable to other respirable cyclones. 
Table 3. 24. Summary of Results from the Spiked Sample Analysis, Aerosol Chamber Study, and Field Study

\begin{tabular}{|c|c|c|c|c|c|c|c|}
\hline $\begin{array}{l}\text { Study } \\
\text { Phase }\end{array}$ & Quartz & $\begin{array}{c}\text { Analyzed } \\
\text { by }\end{array}$ & From & To & Slope/CF & $\mathrm{SE}^{1}$ & p-values \\
\hline \multirow{4}{*}{$\begin{array}{l}\text { Spiked } \\
\text { Samples }\end{array}$} & \multirow{4}{*}{$\begin{array}{c}\text { SRM } \\
2950 a \\
\text { respirable } \\
\text { alpha } \\
\text { quartz }\end{array}$} & \multirow{3}{*}{ US (NC) } & NIOSH 7602 & NIOSH 7500 & 1.25 & 0.0171 & $<0.0001$ \\
\hline & & & IFA 213-582 & NIOSH 7500 & 1.27 & 0.0067 & $<0.0001$ \\
\hline & & & IFA $213-582$ & NIOSH 7602 & 1.02 & 0.0129 & 0.728 \\
\hline & & $\begin{array}{c}\text { German } \\
\text { (IFA) }\end{array}$ & IFA 213-582 & NIOSH 7602 & 0.98 & 0.0025 & 0.0511 \\
\hline \multirow{9}{*}{$\begin{array}{l}\text { Aerosol } \\
\text { Test } \\
\text { Chamber } \\
\text { Analysis }\end{array}$} & \multirow{4}{*}{ ARD } & US (NC) & NIOSH 7602 & NIOSH 7500 & 1.09 & 0.0115 & 0.6429 \\
\hline & & \multirow{3}{*}{$\begin{array}{l}\text { German } \\
\text { (IFA) }\end{array}$} & NIOSH 7602 & NIOSH 7500 & 1.33 & 0.0279 & $<0.0001$ \\
\hline & & & IFA 213-582 & NIOSH 7500 & 1.31 & 0.0471 & $<0.0001$ \\
\hline & & & IFA 213-582 & NIOSH 7602 & 1.02 & 0.0358 & 0.2647 \\
\hline & \multirow{5}{*}{$\begin{array}{l}\text { MIN-U- } \\
\text { SIL }{ }^{\circledR} 10\end{array}$} & US (NC) & NIOSH 7602 & NIOSH 7500 & 0.85 & 0.015 & $<0.0001$ \\
\hline & & \multirow{4}{*}{$\begin{array}{l}\text { German } \\
\text { (IFA) }\end{array}$} & NIOSH 7602 & NIOSH 7500 & 1.39 & 0.0707 & 0.0006 \\
\hline & & & & & & & \\
\hline & & & IFA 213-582 & NIOSH 7500 & 1.02 & 0.034 & $\begin{array}{c}< \\
0.0001\end{array}$ \\
\hline & & & IFA 213-582 & NIOSH 7602 & 0.73 & 0.0352 & $\begin{array}{c}< \\
0.0001\end{array}$ \\
\hline $\begin{array}{l}\text { Personal } \\
\text { Samples }\end{array}$ & \multirow{5}{*}{$\begin{array}{l}\text { Various } \\
\text { RCS types }\end{array}$} & \multirow{5}{*}{ Both Labs } & IFA $213-582$ & NIOSH 7602 & 0.71 & 0.0226 & 0.0001 \\
\hline \multirow{3}{*}{$\begin{array}{c}\text { Area } \\
\text { Samples }\end{array}$} & & & NIOSH 7602 & NIOSH 7500 & 0.82 & 0.0557 & 0.3464 \\
\hline & & & IFA 213-582 & NIOSH 7500 & 0.73 & 0.029 & 0.2319 \\
\hline & & & IFA 213-582 & NIOSH 7602 & 0.84 & 0.0475 & 0.7911 \\
\hline $\begin{array}{l}\text { Personal } \\
\text { \& Area } \\
\text { samples }\end{array}$ & & & IFA $213-582$ & NIOSH 7602 & 0.71 & 0.018 & 0.3788 \\
\hline
\end{tabular}

${ }^{1}$ Standard error to a slope

Note that results of samples analyzed with IFA 213-582 were excluded due to potential errors caused from the sample preparations. 


\section{Chapter 4. Conclusions and Research Implication}




\section{AEROSOL SAMPLING STRATEGY I: Effect of Particle Transfer to Sampler Covers during Sample Transportation}

This is the first study investigating particle transfer to sampler covers using different inhalable and total particle samplers and transportation methods. The results presented in this report indicate that there is an important aspect of aerosol sampling strategies that warrants revisiting. Analytical methods of occupational agents such as wood dust using samplers like IOM may fall short in accurately predicting the hazard present if particle losses to the sampler covers are ignored. This would be especially true in dusty environments where overloaded filters are more susceptible to particle movement during transportation. If these particles are not accounted for during analysis, particle concentrations could be underestimated, leading to lower assessment of the overall hazard to the worker. Therefore, it is strongly recommended that in practice, occupational professionals are aware of the potential loss of particles during shipping and account for these particles in their sample analysis, such as including the sampler cover in pre- and post-weighing analysis. In the future, other aerosols with larger particles sizes (e.g., metals, wood dust, fibers) should be investigated to explore this phenomenon.

\section{AEROSOL SAMPLING STRATEGY II: Estimation of Conversion factors between US and German Sampling Strategies}

This investigation compared the US (NIOSH method) and German (IFA method) sampling and analytical methodologies in assessing RCS exposures. The findings revealed that there are notable differences in the sampling strategy utilized by both countries, which could lead to different concentration results for similar exposure groups. The calculated conversion factor was 0.71 when converting RCS concentrations with IR from the NIOSH 7602 to IFA 213-582. The results presented in this report will fill the knowledge gap associated with exposure discrepancies between both countries that are caused by using different measurement strategies. Furthermore, the outputs of this study can be used to merge RCS databases to determine long-term exposure trends and evaluate the effectiveness of existing control 
methods. Any other countries that adopt either NIOSH or IFA methods in their evaluation of RCS would also find many practical ways to apply the results presented here.

The nature of aerosol sampling is one of constant evolution and because the use of RCS remains invaluable to many industrial processes, determining the relationship of sampling strategies among different countries not covered in this study would be useful. 


\section{REFERENCES}

Beaudry C. Lavoue J. et al.: Occupational exposure to silica in construction workers: A literaturebased exposure database, J. of Occupational and Environmental Hygiene, 10:71-77 (2013).

Bello, Dhimiter, M. Abbas Virji, Andrew J. Kalil \& Susan R. Woskie (2002) Quantification of Respirable, Thoracic, and Inhalable Quartz Exposures by FT-IR in Personal Impactor Samples from Construction Sites, Applied Occupational and Environmental Hygiene, 17:8, 580-590, DOI: 10.1080/10473220290095853

Birk T, Guldner K, et al. (2010). Quantitative crystalline silica exposure assessment for a historical cohort epidemiologic study in the German porcelain industry, Journal of Occupational and Environmental Hygiene, 7:9, 516-528.

Carton B. 1995. COLCHIC chemical exposure database: Information on lead and formaldehyde. Appl Occup Environ Hyg 10:345-350.

CDC, NIOSH Science Blog. (2015). Silicosis update. Available at: https://blogs.cdc.gov/nioshscience-blog/2015/06/15/silicosis-update/. Accessed May 9, 2018.

Ceballos D, King B, Beaucham C, Brueck S. 2015. Comparison of a Wipe Method with and without a Rinse to Recover Wall Losses in Closed Face 37-mm Cassettes Used for Sampling Lead Dust Particulates, J Occup Environ Hyg. 12(10): D225-231.

Cena LG, Chen BT, Keane MJ. 2016. Evolution of Welding-Fume Aerosols with Time and Distance from the Source: A study was conducted on the spatiotemporal variability in welding-fume concentrations for the characterization of first- and second-hand exposure to welding fumes. Weld J. 95(Suppl):280s-285s.

Centers for Disease Control and Prevention. National Institute for Occupational Safety and Health (2008a). Silicosis: Number and percent of deaths by NORA industrial sector, U.S. residents age 15 and over, selected states and years, 1990-1999. Available at: https://wwwn.cdc.gov/eworld/Data/Silicosis_Number_and_percent_of_deaths_by_NO RA_industrial_sector_US_residents_age_15_and_over_selected_states_and_years_199 0-1999/128. Accessed November 4, 2017. 
Chen W, Hnizdo E, Chen JQ, Attfield MD, Gao P, Hearl F, Lu J, Wallace WE. Risk of silicosis in cohorts of Chinese tin and tungsten miners, and pottery workers (I): an epidemiological study. Am J Ind Med. 2005 Jul;48(1):1-9. doi: 10.1002/ajim.20174. PMID: 15940718.

Committee on the Carcinogenicity of Chemicals in Food (CCCF): Guidelines for the evaluation of chemicals for carcinogenicity, HMSO, London, UK (1991).

Demange M, et al.: Field comparison of 37- $\mathrm{mm}$ closed-face cassettes and IOM samplers, Applied Occupational and Environmental Hygiene, 17:3, 200-208 (2002).

Demange M, Gendre JC, Hervé-Bazin B, Carton B, Peltier A. 1990. Aerosol Evaluation Difficulties Due to Particle Deposition on Filter Holder Inner Walls, Ann Occup Hyg. 34(4): 399-403.

Deveau M., C-P Chen, G. Johanson, D. Krewski, A. Maier, K. J. Niven, S. Ripple, P. A. Schulte, J. Silk, J. H. Urbanus, D. M. Zalk \& R. W. Niemeier (2015) The Global Landscape of Occupational Exposure Limits - Implementation of Harmonization Principles to Guide Limit Selection, Journal of Occupational and Environmental Hygiene, 12:sup1, S127S144, DOI: 10.1080/15459624.2015.1060327

Dhimiter Bello, M. Abbas Virji, Andrew J. Kalil \& Susan R. Woskie (2002) Quantification of Respirable, Thoracic, and Inhalable Quartz Exposures by FT-IR in Personal Impactor Samples from Construction Sites, Applied Occupational and Environmental Hygiene, 17:8, 580-590, DOI: 10.1080/10473220290095853

Dotson G. S., A. Maier, P. D. Siegel, S. E. Anderson, B. J. Green, A. B. Stefaniak, C. D. Codispoti \& I. Kimber (2015) Setting Occupational Exposure Limits for Chemical AllergensUnderstanding the Challenges, Journal of Occupational and Environmental Hygiene, 12:sup1, S82-S98, DOI: 10.1080/15459624.2015.1072277

Esche, Curtis A., and Jensen H. Groff. "Proficiency Analytical Testing (PAT) Program August 28, 1998." American Industrial Hygiene Association Journal 60.1 (1999): 123-5. ProQuest. Web. 7 Oct. 2021.

Environmental Protection Agency: Risk assessment forum technical panel for cancer guidelines, Proposed guidelines for carcinogen risk assessment. US Office of Research and Development, Washington DC. EPA/600/P-92/003C (1996). 
Esche, Curtis A., and Jensen H. Groff. "Proficiency Analytical Testing (PAT) Program August 28, 1998." American Industrial Hygiene Association Journal 60.1 (1999): 123-5. ProQuest. Web. 7 Oct. 2021.

Esmen NA, Johnson DL. (2002) The variability of delivered dose of aerosols with the same respirable concentration but different size distributions. Ann Occup Hyg; 46: 401-7.

Filios, M. S., Mazurek, J. M., Schleiff, P. L., Reilly, M. J., Rosenman, K. D., Lumia, M. E., and Worthington, K. (2015). Summary of notifiable noninfectious conditions and disease outbreaks: Surveillance for silicosis - Michigan and New Jersey, 2003-2010. MMWR Morb Mortal Wkly Rep 62(54), 81-5, 0.15585/mmwr.mm6254a6.

Guldner K, Dahmann D, et al. (2011). Development of conversion factors for results of early gravimetric dust measurements. Gefahrstoffe Reinhaltung der Luft, May: 191-198.

Harper M, Akbar MZ, Andrew ME. 2004. Comparison of wood-dust aerosol size-distributions collected by air samplers, J Environ Monit. 6:18-22.

Harper M, Demange M. 2007. Concerning sampler wall deposits in the chemical analysis of airborne metals. J Occup Environ Hyg. 4: D81-D86.

Harper M, Pacolay B, Andrew ME. 2005. A Comparison of X-ray Fluorescence and Wet Chemical Analysis for Lead on Air Filters from Different Personal Samplers Used in a Bronze Foundry, J Environ Monitor. 7: 592-597.

Harper M, Pacolay B, Hintz P, Andrew ME. 2006. A comparison of XRF and ICP-OES for lead on air filter samples from a lead ore concentrator mill and a lead-acid battery recycler. J Environ Monitor. 8: 384-392.

Harper M, Pacolay B. 2006. A Comparison of X-ray Fluorescence and Wet Chemical Analysis for Lead on Air Filters from Different Personal Samplers Used in a Secondary Lead Smelter/Solder Manufacturer, J Environ Monitor. 8(1): 140-146.

Harper, M., Sarkisian, K., Andrew, M., 2014. Assessment of respirable crystalline silica analysis using Proficiency Analytical Testing results from 2003-2013. J. Occup. Environ. Hyg. 11 (10), D157eD163.

Hart JF, Autenrieth DA, Cauda E, Chubb L, Spear TM, Wock S, Rosenthal S. A comparison of respirable crystalline silica concentration measurements using a direct-on-filter Fourier 
transform infrared (FT-IR) transmission method vs. a traditional laboratory X-ray diffraction method. J Occup Environ Hyg. 2018 Oct;15(10):743-754. doi: 10.1080/15459624.2018.1495334. PMID: 29985762; PMCID: PMC6327839.

Hendricks W, Stones F, Lillquist D. 2009. On wiping the interior walls of 37-mm closed-face cassettes An OSHA perspective. J Occup Environ Hyg. 6:732-734.

Henn SA, Sussell AL, Li J, Shire JD, Alarcon WA, Tak S. 2011. Characterization of lead in US workplaces using data from OSHA's integrated management information system. Am J Ind Med 54:356-365.

Hetland S, Thomassen, Y. 1993. Sampling Efficiencies of the American 25-mm Personal Sampler. Poster presented at Airmon: Modern Principles of Workplace Air Monitoring, June 1216, Geilo, Norway.

Hewett P. (1991) Limitations in the use of particle size-selective sampling criteria in occupational epidemiology. Appl Occup Environ Hyg; 6: 290-300.

Heyder J., J. Gebhart, G. Rudolf, C.F. Schiller, W. Stahlhofen, Deposition of particles in the human respiratory tract in the size range $0.005-15 \mu \mathrm{m}$. Journal of Aerosol Science, Volume 17, Issue 5, 1986, Pages 811-825, ISSN 0021-8502, https://doi.org/10.1016/0021-8502(86)90035-2.

Hinds WC. 1988. Basis for particle size-selective sampling for wood dust. Appl Ind Hyg. 3:67-72. Hnizdo, E., and Vallyathan, V. (2003). Chronic obstructive pulmonary disease due to occupational exposure to silica dust: a review of epidemiological and pathological evidence. Occup Environ Med 60(4), 237-43.

Hornung RW, Reed LD. 1990. Estimation of average concentration in the presence of nondetectable values. Appl. Occup. Environ Hyg. 5:46-51.

Ichikawa Akemi, John Volpato, Gregory E O’Donnell, Martin Mazereeuw, Comparison of the Analysis of Respirable Crystalline Silica in Workplace Air by Direct-on-Filter Methods using X-ray Diffraction and Fourier Transform Infrared Spectroscopy, Annals of Work Exposures and Health, 2021; , wxab094, https://doi.org/10.1093/annweh/wxab094

IFA. 2018. Exposure database MEGA. Accessed on October 28, 2021. https://www.dguv.de/ifa/gestis/ expositionsdatenbank-mega/index-2.jsp 
Karvonen, M \& Mikheev, MI. (1986). Epidemiology of occupational health. World Health Organization. Regional Office for Europe. https://apps.who.int/iris/handle/10665/272256

Kauppinen T, Vincent R, Liukkonen T et al. (2006). Occupational exposure to inhalable wood dust in the member states of the European Union. Ann Occup Hyg, 50:549-561.

Koppisch D, Schinkel J, Gabriel S, Fransman W, Tielemans E. 2012. Use of the MEGA exposure database for the validation of the Stoffenmanager model. Ann Occup Hyg 56:426-439. Lee EG, Cena L, Kwon J, Afshari A, Park H, Casuccio G, Bunker K, Lersch T, Gall A, Pham H, Wagner A, Agarwal S, Dinu CZ, Gupta R, Friend SA, Stueckle TA. 2020. Characterization of aerosolized particles from nanoclay-enabled composites during manipulation processes. Environ Sci Nano. 7, 1539-1553.

Lee EG, Grimson P, Chisholm WP, Kashon ML, He X, L'Orange C, Volckens J. 2019. Performance evaluation of disposable inhalable aerosol sampler at a copper electrorefinery, J Occup Environ Hyg. 16:3, 250-257.

Lee T, Kim SW, Chisholm WP, Slaven J, Harper M. Performance of high flow rate samplers for respirable particle collection. Ann Occup Hyg. 2010 Aug;54(6):697-709. doi: 10.1093/annhyg/meq050. Epub 2010 Jul 21. PMID: 20660144; PMCID: PMC2918491. Lee T, Kim SW, Chisholm WP, Slaven J, Harper M. Performance of high flow rate samplers for respirable particle collection. Ann Occup Hyg. 2010 Aug;54(6):697-709. doi: 10.1093/annhyg/meq050. Epub 2010 Jul 21. PMID: 20660144; PMCID: PMC2918491. Lee T, Lee EG, Kim SW, Chisholm WP, Kashon M, Harper M. Quartz measurement in coal dust with high-flow rate samplers: laboratory study. The Annals of Occupational Hygiene, Volume 56, Issue 4, May 2012, Pages 413-425, https://doi.org/10.1093/annhyg/mer111 Louis Anthony (Tony) Cox. How accurately and consistently do laboratories measure workplace concentrations of respirable crystalline silica? Regulatory Toxicology and Pharmacology, Volume 81, 2016, Pages 268-274, ISSN 0273-2300, https://doi.org/10.1016/j.yrtph.2016.09.008.

Malit BD and TJ Lentz. "6th International Conference, Scientific Committee on Education and Training in Occupational Health." The International Communication Network, ICOH, 
Introduction to Occupational Epidemiology and Industrial Hygiene: a Web-Based Case Study on Silicosis in Sandblasters., 2002, pp. 103-104, www.cdc.gov/niosh/nioshtic2/20023236.html.

Mater G, Paris C, Lavoué J. Descriptive analysis and comparison of two French occupational exposure databases: COLCHIC and SCOLA. American Journal of Industrial Medicine. 2016 May;59(5):379-391. DOI: 10.1002/ajim.22569.

McCawley MA. (1993) Caveats in the use of particle size-selective sampling criteria. In Proceedings of the second international conference on occupational health and safety in the minerals industry, Perth, Australia, March 1993.

NIOSH 2008. Work-Related Lung Disease Surveillance System (eWoRLD). 2008-128 U.S. Department of Health and Human Services, Centers for Disease Control and Prevention, National Institute for Occupational Safety and Health, Respiratory Health Division, Morgantown, WV. Available at: <https://wwwn.cdc.gov/eWorld/Data/128> October 28, 2021.

NIOSH. 2020. Chapter AE: Factors affecting aerosol sampling. by PA Baron, NIOSH Manual of Analytical Methods. 5th Edition, Available at https://www.cdc.gov/niosh/nmam/pdf/NMAM_5thEd_EBook-508-final.pdf (accessed March 10, 2021).

NIOSH. Health Hazard Evaluations (HHEs). Available at https://www.cdc.gov/ niosh/hhe/default.html Accessed on October 28, 2021.

NIOSH. Method 0501, NIOSH Manual of Analytical Methods (NMAM). NIOSH Manual of Analytical Methods (NMAM) 5th ed., Available at https://www.cdc.gov/niosh/docs/2014-151/pdfs/methods/0501.pdf (accessed March 10, 2021).

NIOSH. Method 7302, NIOSH Manual of Analytical Methods (NMAM). NIOSH Manual of Analytical Methods (NMAM) 5th ed., Available at https://www.cdc.gov/niosh/docs/2014-151/pdfs/methods/7302.pdf (accessed March 10, 2021). 
NIOSH. Method 7303, NIOSH Manual of Analytical Methods (NMAM). NIOSH Manual of Analytical Methods (NMAM) 4th ed., Available at https://www.cdc.gov/niosh/docs/2003-154/pdfs/0500.pdf (accessed March 10, 2021).

OSHA. 2006. OSHA Analytical Methods Manual, 2nd ed.; Method ID215 (version 2): Hexavalent chromium, rev. 2006. Salt Lake City, Utah: U.S. Department of Labor; OSHA Salt Lake Technical Center.

OSHA. 2008. OSHA Sampling and Analytical Methods. Methods ID-121, ID-125g, and ID-215. Sandy, Utah: U.S. Department of Labor, Occupational Safety and Health Administration.

Peter M. Eller , H. Amy Feng, Ruiguang S. Song , Rosa J. Key-Schwartz , Curtis A. Esche \& Jensen H. Groff (1999) Proficiency Analytical Testing (PAT) Silica Variability, 1990-1998, American Industrial Hygiene Association Journal, 60:4, 533-539, DOI:10.1080/00028899908984475

Pickard KJ, Walker RF, West NG. (1985) A comparison of Xray diffraction and infrared spectrophotometric methods for the analysis of alpha quartz in airborne dust. Ann Occup Hyg; 29: 149-67.

Pisaniello DL, Connell KE, Muriale L. 1991. Wood dust exposure during furniture manufactureResults from an Australian survey and considerations for threshold limit value development. Ann Ind Hyg Assoc J. 52:485-492.

Puskar MA, Harkins JM, Moomey JD, Hecker LH. 1991. Internal wall losses of pharmaceutical dusts during closed-face, 37-mm polystyrene cassette sampling. Am Ind Hyg Assoc J. $52: 280-286$

Salathé M. Digital epidemiology: what is it, and where is it going? Life Sci Soc Policy. 2018 Jan 4;14(1):1. doi: 10.1186/s40504-017-0065-7. PMID: 29302758; PMCID: PMC5754279.

Schleiff, P. L., Mazurek, J. M., Reilly, M. J., Rosenman, K. D., Yoder, M. B., Lumia, M. E., and Worthington, K. (2016). Surveillance for silicosis - Michigan and New Jersey, 2003-2011. MMWR Morb Mortal Wkly Rep 63(55), 73-78, 10.15585/mmwr.mm6355a7.

Soutar CA, et al.: Epidemiological evidence on the carcinogenicity of silica: factors in scientific judgment, Annals of Occupational Hygiene, 44(1):3-14 (2000). 
Stacey P, Mecchia M, et al. (2013) Differences between samplers for respirable dust and the analysis of quarts - An international study, Silica and Associated Respirable Mineral Particles, STP 1565, available at www.astm.org DOI:10.1520/STP156520120188.

Stacey P, Tylee B, Bard D et al. (2003) The performance of laboratories analyzing alpha-quartz in the Workplace Analysis Scheme for Proficiency (WASP). Ann Occup Hyg; 47: 269-77.

Stamm R. 2001. MEGA-database: One million data since 1972. Appl Occup Environ Hyg 16:159163.

Steven J. Page (2003) Comparison of Coal Mine Dust Size Distributions and Calibration Standards for Crystalline Silica Analysis, AlHA Journal, 64:1, 30-39, DOI:10.1080/15428110308984781

Stewart P, Rice C. 1990. A source of exposure data for occupational epidemiology studies. Appl Occup Environ Hyg 5:359-363.

United States Department of Labor. Occupational Safety and Health Administration. OSHA's Final Rule to Protect Workers from Exposure to Respirable Crystalline Silica. Available at: https://www.osha.gov/dsg/topics/ silicacrystalline/ . Accessed November 4, 2017.

United States Department of Labor. Occupational Safety and Health Administration. Worker exposure to silica during hydraulic fracturing. Available at: https://www.osha.gov/dts/hazardalerts/hydraulic_frac_hazard_alert.html Accessed November 4, 2017.

Vincent R, Jeandel B. 2001. COLCHIC-Occupational exposure to chemical agents database: Current content and development perspectives. Appl Occup Environ Hyg 16:115-121.

Wheeler M.W., R. M. Park, A. J. Bailer \& C. Whittaker (2015) Historical Context and Recent Advances in Exposure-Response Estimation for Deriving Occupational Exposure Limits, Journal of Occupational and Environmental Hygiene, 12:sup1, S7-S17, DOI: 10.1080/15459624.2015.1076934

Whitehead LW, Freund T, Hahn LL. 1981. Suspended dust concentrations and size distributions, and qualitative analysis of inorganic particles, from woodworking operations. Am Ind Hyg Assoc J. 42:461-467. 
Yang L, Chen W, Wang Z, Sun J, Wang L, Yi G, Yang J, Li J, Mao G, Mattenklott M, Koob M, Sun Y, Bochmann F, Dahmann D. A comparative field study on dust measurements by different sampling methods with emphasis on estimating factors for recalculation from chinese 'total dust' measurements to respirable dust concentrations. Ann Occup Hyg. 2012 May;56(4):401-412. doi: 10.1093/annhyg/mer120. Epub 2012 Jan 6.

Zilaout H, Vlaanderen J, et al. (2017). 15 years of monitoring occupational exposure to respirable dust and quartz within the European industrial minerals sector, International Journal of Hygiene and Environmental Health, 220:810-819. 


\section{APPENDICES}

APPENDIX I- Raw Data for Chapter II

APPENDIX II- Detailed Research Hypotheses

APPENDIX III- Standard Operating Procedure for RCS Laboratory Study

APPENDIX IV- Sample and Analysis Plan (SAP) for Field Study

APPENDIX V- Field Study: Job Tasks and Descriptions

APPENDIX VI- Raw Data for Chapter III 


\section{APPENDIX I}

\section{RAW DATA FOR CHAPTER II}

\begin{tabular}{|c|c|c|c|c|c|c|c|}
\hline $\begin{array}{l}\text { Sampler } \\
\text { Type }\end{array}$ & $\begin{array}{c}\text { Transportation } \\
\text { Method }\end{array}$ & Run & $\begin{array}{l}\text { Sample } \\
\text { ID }\end{array}$ & \% Cap & $\begin{array}{l}\text { Mass (mg) } \\
\text { (Trad. way) }\end{array}$ & $\begin{array}{l}\text { Sampling } \\
\text { vol. (L) }\end{array}$ & $\begin{array}{c}\text { Conc. } \\
\left.\text { (mg/m } / \mathrm{m}^{3}\right) \\
\text { (trad. } \\
\text { way) }\end{array}$ \\
\hline$A C$ & Land & 1 & A-01 & 19.35 & 0.310 & 8 & 38.75 \\
\hline$A C$ & Land & 1 & A-03 & 9.38 & 0.320 & 8 & 40.00 \\
\hline$A C$ & Land & 4 & A-25 & 17.24 & 0.290 & 26 & 11.15 \\
\hline$A C$ & Land & 4 & A-27 & 11.76 & 0.340 & 26 & 13.08 \\
\hline$A C$ & Land & 1 & A-05 & 8.47 & 0.590 & 14 & 42.14 \\
\hline$A C$ & Land & 1 & A-07 & 8.62 & 0.580 & 14 & 41.43 \\
\hline$A C$ & Land & 2 & A-13 & 9.26 & 0.540 & 14 & 38.57 \\
\hline$A C$ & Land & 2 & A-15 & 27.85 & 0.790 & 14 & 56.43 \\
\hline$A C$ & Land & 3 & A-17 & 9.45 & 0.140 & 26 & 5.38 \\
\hline$A C$ & Land & 3 & A-19 & 2.84 & 1.410 & 26 & 54.23 \\
\hline$A C$ & Land & 4 & A-29 & 3.03 & 1.320 & 44 & 30.00 \\
\hline$A C$ & Land & 4 & $A-31$ & 33.33 & 2.280 & 44 & 51.82 \\
\hline$A C$ & Land & 3 & $A-21$ & 1.15 & 2.620 & 44 & 59.55 \\
\hline$A C$ & Land & 3 & A-23 & 1.35 & 2.230 & 44 & 50.68 \\
\hline DISP & Land & 2 & D-11 & 12.12 & 0.330 & 8 & 41.25 \\
\hline DISP & Land & 2 & D-09 & 17.50 & 0.400 & 8 & 50.00 \\
\hline DISP & Land & 2 & D-13 & 30.85 & 0.940 & 14 & 67.14 \\
\hline DISP & Land & 2 & D-15 & 10.39 & 0.770 & 14 & 55.00 \\
\hline DISP & Land & 1 & D-01 & 28.32 & 1.130 & 8 & 141.25 \\
\hline DISP & Land & 1 & D-03 & 30.77 & 1.300 & 8 & 162.50 \\
\hline DISP & Land & 3 & D-19 & 11.90 & 1.260 & 26 & 48.46 \\
\hline DISP & Land & 3 & D-17 & 17.33 & 1.500 & 26 & 57.69 \\
\hline DISP & Land & 4 & D-25 & 5.41 & 1.480 & 26 & 56.92 \\
\hline DISP & Land & 4 & $\mathrm{D}-27$ & 21.20 & 1.840 & 26 & 70.77 \\
\hline DISP & Land & 1 & D-07 & 18.97 & 1.950 & 14 & 139.29 \\
\hline DISP & Land & 1 & D-05 & 4.71 & 1.910 & 14 & 136.43 \\
\hline DISP & Land & 3 & $D-21$ & 0.00 & 2.230 & 44 & 50.68 \\
\hline DISP & Land & 3 & D-23 & 0.49 & 2.030 & 44 & 46.14 \\
\hline DISP & Land & 4 & D-29 & 3.66 & 2.730 & 44 & 62.05 \\
\hline DISP & Land & 4 & D-31 & 1.15 & 2.610 & 44 & 59.32 \\
\hline IOM & Land & 1 & $\mathrm{I}-01$ & 2.31 & -65.91 & 8 & -8238.75 \\
\hline IOM & Land & 1 & $1-03$ & 0.06 & 196.58 & 8 & 24572.50 \\
\hline IOM & Land & 1 & $1-05$ & 0.21 & 4.59 & 14 & 327.86 \\
\hline IOM & Land & 1 & $1-07$ & 0.62 & 4.69 & 14 & 335.00 \\
\hline IOM & Land & 2 & I-09 & 74.11 & 0.92 & 8 & 115.00 \\
\hline IOM & Land & 2 & $\mid-11$ & 86.05 & 1.79 & 8 & 223.75 \\
\hline IOM & Land & 2 & $\mid-15$ & 33.75 & 3.26 & 14 & 232.86 \\
\hline IOM & Land & 3 & $1-21$ & 97.24 & 1.28 & 44 & 29.09 \\
\hline IOM & Land & 3 & $\mid-17$ & 16.85 & 0.15 & 26 & 5.77 \\
\hline
\end{tabular}




\begin{tabular}{|c|c|c|c|c|c|c|c|}
\hline IOM & Land & 4 & $1-25$ & 32.61 & 0.11 & 26 & 4.23 \\
\hline IOM & Land & 4 & $1-27$ & 21.69 & 0.12 & 26 & 4.62 \\
\hline IOM & Land & 4 & $1-29$ & 4.64 & 0.93 & 44 & 21.14 \\
\hline IOM & Land & 4 & $\mid-31$ & 0.01 & 510.94 & 44 & 11612.27 \\
\hline $\mathrm{IOM}+\mathrm{C}$ & Land & 1 & I-01 & 2.31 & -65.75 & 8 & -8218.75 \\
\hline $\mathrm{IOM}+\mathrm{C}$ & Land & 1 & I-03 & 0.06 & 196.87 & 8 & 24608.75 \\
\hline $10 M+C$ & Land & 1 & I-05 & 0.21 & 4.99 & 14 & 356.43 \\
\hline $\mathrm{IOM}+\mathrm{C}$ & Land & 1 & I-07 & 0.62 & 5.10 & 14 & 364.29 \\
\hline $10 M+C$ & Land & 2 & I-09 & 74.11 & 3.94 & 8 & 492.50 \\
\hline $\mathrm{IOM}+\mathrm{C}$ & Land & 2 & I-11 & 86.05 & 13.60 & 8 & 1700.00 \\
\hline $\mathrm{IOM}+\mathrm{C}$ & Land & 2 & $\mid-15$ & 33.75 & 3.22 & 14 & 230.00 \\
\hline $\mathrm{IOM}+\mathrm{C}$ & Land & 3 & $\mid-21$ & 97.24 & 50.46 & 44 & 1146.82 \\
\hline $\mathrm{IOM}+\mathrm{C}$ & Land & 3 & I-17 & 16.85 & 0.46 & 26 & 17.69 \\
\hline $\mathrm{IOM}+\mathrm{C}$ & Land & 4 & $1-25$ & 32.61 & 0.56 & 26 & 21.54 \\
\hline $\mathrm{IOM}+\mathrm{C}$ & Land & 4 & $1-27$ & 21.69 & 0.57 & 26 & 21.92 \\
\hline $\mathrm{IOM}+\mathrm{C}$ & Land & 4 & $1-29$ & 4.64 & 1.81 & 44 & 41.14 \\
\hline $\mathrm{IOM}+\mathrm{C}$ & Land & 4 & $1-31$ & 0.01 & 511.30 & 44 & 11620.45 \\
\hline CFC & Land & 1 & C-01 & 5.36 & 0.187 & 8 & 23.33 \\
\hline CFC & Land & 1 & C-03 & 0.00 & 0.257 & 8 & 32.08 \\
\hline CFC & Land & 1 & C-05 & 1.82 & 1.097 & 14 & 78.33 \\
\hline CFC & Land & 1 & C-07 & 1.57 & 0.637 & 14 & 45.48 \\
\hline CFC & Land & 2 & C-09 & 0.00 & 0.337 & 8 & 42.08 \\
\hline CFC & Land & 2 & C-11 & 3.75 & 0.267 & 8 & 33.33 \\
\hline CFC & Land & 2 & $C-13$ & 3.41 & 0.587 & 14 & 41.90 \\
\hline CFC & Land & 2 & C-15 & 3.14 & 0.637 & 14 & 45.48 \\
\hline CFC & Land & 3 & C-17 & 4.01 & 0.997 & 26 & 38.33 \\
\hline CFC & Land & 3 & C-19 & 7.98 & 0.627 & 26 & 24.10 \\
\hline CFC & Land & 3 & $C-21$ & 0.53 & 3.807 & 44 & 86.52 \\
\hline CFC & Land & 3 & $C-23$ & 0.32 & 3.097 & 44 & 70.38 \\
\hline CFC & Land & 4 & $C-25$ & 5.34 & 0.937 & 26 & 36.03 \\
\hline CFC & Land & 4 & $C-27$ & 0.00 & 0.767 & 26 & 29.49 \\
\hline CFC & Land & 4 & C-29 & 3.44 & 2.617 & 44 & 59.47 \\
\hline CFC & Land & 4 & $C-31$ & 1.22 & 2.467 & 44 & 56.06 \\
\hline$A C$ & Air & 1 & A-04 & 25.71 & 0.350 & 8 & 43.75 \\
\hline$A C$ & Air & 1 & A-02 & 20.93 & 0.430 & 8 & 53.75 \\
\hline$A C$ & Air & 2 & $A-10$ & 12.20 & 0.410 & 8 & 51.25 \\
\hline$A C$ & Air & 4 & A-28 & 79.76 & 2.470 & 26 & 95.00 \\
\hline$A C$ & Air & 2 & A-14 & 14.67 & 0.750 & 14 & 53.57 \\
\hline$A C$ & Air & 1 & A-06 & 15.12 & 0.860 & 14 & 61.43 \\
\hline$A C$ & Air & 4 & A-26 & 0.00 & 0.750 & 26 & 28.85 \\
\hline$A C$ & Air & 1 & A-08 & 6.52 & 0.920 & 14 & 65.71 \\
\hline$A C$ & Air & 2 & A-16 & 3.30 & 0.910 & 14 & 65.00 \\
\hline$A C$ & Air & 3 & A-18 & 0.00 & 1.330 & 26 & 51.15 \\
\hline$A C$ & Air & 3 & $A-20$ & 0.72 & 1.390 & 26 & 53.46 \\
\hline$A C$ & Air & 4 & $A-30$ & 0.63 & 1.590 & 44 & 36.14 \\
\hline$A C$ & Air & 4 & $A-32$ & 8.21 & 1.950 & 44 & 44.32 \\
\hline$A C$ & Air & 3 & $A-22$ & 0.00 & 2.550 & 44 & 57.95 \\
\hline$A C$ & Air & 3 & A-24 & 1.09 & 2.740 & 44 & 62.27 \\
\hline
\end{tabular}




\begin{tabular}{|c|c|c|c|c|c|c|c|}
\hline DISP & Air & 2 & D-12 & -22.11 & 0.317 & 8 & 39.58 \\
\hline DISP & Air & 2 & D-10 & 12.80 & 0.547 & 8 & 68.33 \\
\hline DISP & Air & 2 & D-16 & 15.27 & 0.917 & 14 & 65.48 \\
\hline DISP & Air & 2 & D-14 & -3.86 & 0.777 & 14 & 55.48 \\
\hline DISP & Air & 1 & D-04 & 4.87 & 1.027 & 8 & 128.33 \\
\hline DISP & Air & 1 & D-02 & 0.95 & 1.057 & 8 & 132.08 \\
\hline DISP & Air & 3 & D-20 & 0.00 & 1.157 & 26 & 44.49 \\
\hline DISP & Air & 3 & D-18 & 0.84 & 1.197 & 26 & 46.03 \\
\hline DISP & Air & 4 & D-28 & 0.67 & 1.487 & 26 & 57.18 \\
\hline DISP & Air & 4 & D-26 & 0.00 & 1.517 & 26 & 58.33 \\
\hline DISP & Air & 1 & D-06 & 5.73 & 1.747 & 14 & 124.76 \\
\hline DISP & Air & 1 & D-08 & 5.30 & 2.077 & 14 & 148.33 \\
\hline DISP & Air & 3 & D-22 & 14.36 & 2.647 & 44 & 60.15 \\
\hline DISP & Air & 3 & D-24 & 1.30 & 2.307 & 44 & 52.42 \\
\hline DISP & Air & 4 & D-30 & 0.00 & 2.897 & 44 & 65.83 \\
\hline DISP & Air & 4 & D-32 & -1.85 & 2.707 & 44 & 61.52 \\
\hline IOM & Air & 1 & $1-02$ & 0.61 & 0.34 & 8 & 42.50 \\
\hline IOM & Air & 1 & I-04 & 64.76 & 0.86 & 8 & 107.50 \\
\hline IOM & Air & 1 & $1-06$ & 30.14 & 1.49 & 14 & 106.43 \\
\hline IOM & Air & 1 & I-08 & 38.33 & 2.05 & 14 & 146.43 \\
\hline IOM & Air & 2 & $\mathrm{I}-10$ & 67.51 & 0.38 & 8 & 47.50 \\
\hline IOM & Air & 2 & I-14 & 75.46 & 1.43 & 14 & 102.14 \\
\hline IOM & Air & 2 & I-16 & 83.52 & 0.86 & 14 & 61.43 \\
\hline IOM & Air & 3 & I-18 & 80.17 & 0.16 & 26 & 6.15 \\
\hline IOM & Air & 3 & $1-20$ & 100.23 & 0.32 & 26 & 12.31 \\
\hline IOM & Air & 3 & $1-22$ & 10.33 & 0.63 & 44 & 14.32 \\
\hline IOM & Air & 3 & $1-24$ & 44.38 & 0.41 & 44 & 9.32 \\
\hline IOM & Air & 4 & $1-26$ & 61.35 & 0.29 & 26 & 11.15 \\
\hline IOM & Air & 4 & $1-28$ & 63.31 & 0.25 & 26 & 9.62 \\
\hline IOM & Air & 4 & $1-30$ & 85.11 & 0.21 & 44 & 4.77 \\
\hline IOM & Air & 4 & $1-32$ & 81.95 & 0.16 & 44 & 3.64 \\
\hline $\mathrm{IOM}+\mathrm{C}$ & Air & 1 & $1-02$ & 0.61 & 1.78 & 8 & 222.50 \\
\hline $\mathrm{IOM}+\mathrm{C}$ & Air & 1 & $1-04$ & 64.76 & 2.3 & 8 & 287.50 \\
\hline $\mathrm{IOM}+\mathrm{C}$ & Air & 1 & I-06 & 30.14 & 3.68 & 14 & 262.86 \\
\hline $10 M+C$ & Air & 1 & $1-08$ & 38.33 & 3.89 & 14 & 277.86 \\
\hline $\mathrm{IOM}+\mathrm{C}$ & Air & 2 & I-10 & 67.51 & 1.01 & 8 & 126.25 \\
\hline $10 M+C$ & Air & 2 & I-14 & 75.46 & 6.88 & 14 & 491.43 \\
\hline $\mathrm{IOM}+\mathrm{C}$ & Air & 2 & I-16 & 83.52 & 4.82 & 14 & 344.29 \\
\hline $\mathrm{IOM}+\mathrm{C}$ & Air & 3 & I-18 & 80.17 & 0.49 & 26 & 18.85 \\
\hline $10 M+C$ & Air & 3 & $1-20$ & 100.23 & 4.62 & 26 & 177.69 \\
\hline $\mathrm{IOM}+\mathrm{C}$ & Air & 3 & $1-22$ & 10.33 & 0.7 & 44 & 15.91 \\
\hline $\mathrm{IOM}+\mathrm{C}$ & Air & 3 & $1-24$ & 44.38 & 0.68 & 44 & 15.45 \\
\hline $\mathrm{IOM}+\mathrm{C}$ & Air & 4 & I-26 & 61.35 & 0.63 & 26 & 24.23 \\
\hline $\mathrm{IOM}+\mathrm{C}$ & Air & 4 & $1-28$ & 63.31 & 0.55 & 26 & 21.15 \\
\hline $\mathrm{IOM}+\mathrm{C}$ & Air & 4 & $1-30$ & 85.11 & 0.96 & 44 & 21.82 \\
\hline $\mathrm{IOM}+\mathrm{C}$ & Air & 4 & $1-32$ & 81.95 & 0.53 & 44 & 12.05 \\
\hline CFC & Air & 1 & C-02 & 17.65 & 0.113 & 8 & 14.17 \\
\hline CFC & Air & 1 & C-04 & 15.52 & 0.193 & 8 & 24.17 \\
\hline
\end{tabular}




\begin{tabular}{llllllll}
\hline CFC & Air & 1 & C-06 & 10.17 & 0.393 & 14 & 28.10 \\
\hline CFC & Air & 1 & C-08 & -4.72 & 0.423 & 14 & 30.24 \\
\hline CFC & Air & 2 & C-10 & 13.95 & 0.143 & 8 & 17.92 \\
\hline CFC & Air & 2 & C-12 & 19.74 & 0.253 & 8 & 31.67 \\
\hline CFC & Air & 2 & C-14 & 10.43 & 0.383 & 14 & 27.38 \\
\hline CFC & Air & 2 & C-16 & 11.32 & 0.353 & 14 & 25.24 \\
\hline CFC & Air & 3 & C-18 & 2.91 & 0.343 & 26 & 13.21 \\
\hline CFC & Air & 3 & C-20 & 22.88 & 0.393 & 26 & 15.13 \\
\hline CFC & Air & 3 & C-22 & 2.53 & 3.553 & 44 & 80.76 \\
\hline CFC & Air & 3 & C-24 & 3.72 & 2.153 & 44 & 48.94 \\
\hline CFC & Air & 4 & C-26 & 62.73 & 0.733 & 26 & 28.21 \\
\hline CFC & Air & 4 & C-28 & 9.68 & 0.413 & 26 & 15.90 \\
\hline CFC & Air & 4 & C-30 & 9.68 & 0.723 & 44 & 16.44 \\
\hline CFC & Air & 4 & C-32 & 3.66 & 1.093 & 44 & 24.85 \\
\hline
\end{tabular}




\section{APPENDIX II}

\section{DETAILED RESEARCH HYPOTHESES}

For this project, the overall research question of interest is:

"Is there a relationship between the US (NIOSH) and German (IFA) sampling methodologies for respirable crystalline silica for which conversion factors can be generated?"

The question will be explored using sampling data collected from both controlled lab conditions and uncontrolled environmental conditions in an industrial setting. The overall null and alternative hypotheses are:

Table 1: Overall null and alternative hypotheses for RSC sampling strategy

$\boldsymbol{H}_{0}$ : There are no statistical differences between results from US sampling strategy (NIOSH) and German sampling strategy (IFA) for respirable crystalline silica (RCS). $\boldsymbol{\mu}_{\boldsymbol{N I O S H}}=\boldsymbol{\mu}_{\text {IFA }}$

$\boldsymbol{H}_{\boldsymbol{a}}$ : There are statistical differences between results from US sampling strategy (NIOSH) and German sampling strategy (IFA) for respirable crystalline silica (RCS). $\boldsymbol{\mu}_{\boldsymbol{N I O S H}} \neq \boldsymbol{\mu}_{\text {IFA }}$

A few intermediate hypotheses will be explored.

SPIKED SAMPLES: to determine the effect of analytical methods

For samples analyzed in US Iab

1. $\mathrm{H}_{\mathrm{o}}$ : There are no statistical differences in mass $(\mu \mathrm{g})$ between NIOSH 7602 (US method \#1) and IFA 213-582 (German method) for NIST RCS reference samples. $\boldsymbol{\mu}_{\text {NIOSH 7602 }}=\boldsymbol{\mu}_{\text {IFA 213-582 }}$

$\mathrm{H}_{\mathrm{a}}$ : There are statistical differences in mass $(\mu \mathrm{g})$ between NIOSH 7602 (US method \#1) and IFA 213582 (German method) for NIST RCS reference samples. $\mu_{\text {NIOSH 7602 }} \neq \mu_{\text {IFA 213-582 }}$

2. $H_{0}$ : There are no statistical differences in mass $(\mu \mathrm{g})$ between NIOSH 7500 (US method \#2) and IFA 213-582 (German method) for NIST RCS reference samples. $\boldsymbol{\mu}_{\text {NIOSH 7500 }}=\boldsymbol{\mu}_{\text {IFA 213-582 }}$ $\mathrm{H}_{\mathrm{a}}$ : There are statistical differences in mass $(\mu \mathrm{g})$ between NIOSH 7500 (US method \#2) and IFA 213582 (German method) for NIST RCS reference samples. $\boldsymbol{\mu}_{\text {NIOSH }} \mathbf{7 5 0 0} \neq \boldsymbol{\mu}_{\text {IFA 213-582 }}$

3. $\mathrm{H}_{\mathrm{o}}$ : There are no statistical differences in mass $(\mu \mathrm{g})$ between NIOSH 7602 (US method \#1) and NIOSH 7500 (US method \#2) for NIST RCS reference samples. $\boldsymbol{\mu}_{\text {NIOSH } 7602}=\boldsymbol{\mu}_{\text {NIOSH }} 7500$ $\mathrm{H}_{\mathrm{a}}$ : There are statistical differences in mass $(\mu \mathrm{g})$ between NIOSH 7602 (US method \#1) and NIOSH 7500 (US method \#2) for NIST RCS reference samples. $\boldsymbol{\mu}_{\text {NIOSH } 7602} \neq \boldsymbol{\mu}_{\text {NIOSH } 7500}$ 


\section{For samples analyzed in IFA lab}

4. $H_{0}$ : There are no statistical differences in mass $(\mu \mathrm{g})$ between NIOSH 7602 (US method \#1) and IFA 213-582 (German method) for NIST RCS reference samples. $\boldsymbol{\mu}_{\text {NIOSH 7602 }}=\boldsymbol{\mu}_{\text {IFA 213-582 }}$ $\mathrm{H}_{\mathrm{a}}$ : There are statistical differences in mass $(\mu \mathrm{g})$ between NIOSH 7602 (US method \#1) and IFA 213582 (German method) for NIST RCS reference samples. $\boldsymbol{\mu}_{\text {NIOSH }} \mathbf{7 6 0 2} \neq \boldsymbol{\mu}_{\text {IFA 213-582 }}$

\section{SPIKED SAMPLES: to determine the difference between labs}

5. $H_{0}$ : There are no statistical differences in mass $(\mu \mathrm{g})$ of NIST RCS reference samples between US (NIOSH) and German (IFA) labs using NIOSH Method 7602 (US method \#1). $\boldsymbol{\mu}_{\boldsymbol{U S ~ L a b}}=\boldsymbol{\mu}_{\text {IFA Lab }}$ $\mathrm{H}_{\mathrm{a}}$ : There are statistical differences in mass $(\mu \mathrm{g})$ of NIST RCS reference samples between US (NIOSH) and German (IFA) labs using NIOSH Method 7602 (US method \#1). $\boldsymbol{\mu}_{U S \text { Lab }} \neq \boldsymbol{\mu}_{I F A \text { Lab }}$

6. $H_{0}$ : There are no statistical differences in mass $(\mu \mathrm{g})$ of NIST RCS reference samples between US (NIOSH) and German (IFA) labs using IFA 213-582 (German method). $\boldsymbol{\mu}_{\text {US Lab }}=\boldsymbol{\mu}_{\text {IFA Lab }}$ $\mathrm{H}_{\mathrm{a}}$ : There are statistical differences in mass $(\mu \mathrm{g})$ of NIST RCS reference samples between US (NIOSH) and German (IFA) labs using IFA 213-582 (German method). $\boldsymbol{\mu}_{\boldsymbol{U S} \text { Lab }} \neq \boldsymbol{\mu}_{\text {IFA L Lab }}$

\section{AEROSOL CHAMBER: to determine the effect of (sampler + analytical method)}

\section{ARIZONA ROAD DUST and MIN-U-SIL ${ }^{\circledR} 10$}

\section{For samples analyzed in US lab}

7. $\mathrm{H}_{\mathrm{o}}$ : There are no statistical differences in RCS concentrations between GK2.69 samples (NIOSH 7602) \& FSP-10 samples (IFA 213-582). $\boldsymbol{\mu}_{G K 2.69 \text { (N.7602) }}=\boldsymbol{\mu}_{F S P-10 \text { (IFA 213-582) }}$ $\mathrm{H}_{\mathrm{a}}$ : There are statistical differences in RCS concentrations between GK2.69 samples (NIOSH 7602) \& FSP-10 samples (IFA 213-582). $\boldsymbol{\mu}_{\boldsymbol{G K 2 . 6 9} \text { (N.7602) }} \neq \boldsymbol{\mu}_{\boldsymbol{F S P}-10 \text { (IFA 213-582) }}$

8. $\mathrm{H}_{\mathrm{o}}$ : There are no statistical differences in RCS concentrations between GK2.69 samples (NIOSH 7500) \& FSP-10 samples (IFA 213-582). $\boldsymbol{\mu}_{G K 2.69(N .7500)}=\boldsymbol{\mu}_{\text {FSP-10 (IFA 213-582) }}$ $\mathrm{H}_{\mathrm{a}}$ : There are statistical differences in RCS concentrations between GK2.69 samples (NIOSH 7500) \& FSP-10 samples (IFA 213-582). $\boldsymbol{\mu}_{\boldsymbol{G K} \text { 2.69 (N.7500) }} \neq \boldsymbol{\mu}_{\boldsymbol{F S P}-10 \text { (IFA 213-582) }}$

9. $\mathrm{H}_{\mathrm{o}}$ : There are no statistical differences in RCS concentrations between GK2.69 samples (NIOSH 7602) \& GK2.69 samples (NIOSH 7500). $\boldsymbol{\mu}_{G K 2.69(N .7602)}=\boldsymbol{\mu}_{G K 2.69(N .7500)}$ $\mathrm{H}_{\mathrm{a}}$ : There are statistical differences in RCS concentrations between GK2.69 samples (NIOSH 7602) \& GK2.69 samples (NIOSH 7500)). $\boldsymbol{\mu}_{G K 2.69(N .7602)} \neq \boldsymbol{\mu}_{G K 2.69(N .7500)}$

\section{For samples analyzed in IFA lab}

10. $H_{0}$ : There are no statistical differences in RCS concentrations between GK2.69 samples (NIOSH 7602) \& FSP-10 samples (IFA 213-582). $\boldsymbol{\mu}_{G K 2.69(\text { N.7602) }}=\boldsymbol{\mu}_{\text {FSP-10 (IFA 213-582) }}$ 
$\mathrm{H}_{\mathrm{a}}$ : There are statistical differences in RCS concentrations between GK2.69 samples (NIOSH 7602) \& FSP-10 samples (IFA 213-582). $\boldsymbol{\mu}_{G K 2.69}$ (N.7602) $\neq \boldsymbol{\mu}_{\text {FSP-10 (IFA 213-582) }}$

11. $\mathrm{H}_{\mathrm{o}}$ : There are no statistical differences in RCS concentrations between GK2.69 samples (NIOSH 7500) \& FSP-10 samples (IFA 213-582). $\boldsymbol{\mu}_{G K 2.69(N .7500)}=\boldsymbol{\mu}_{F S P-10(\text { IFA 213-582) }}$

$\mathrm{H}_{\mathrm{a}}$ : There are statistical differences in RCS concentrations between GK2.69 samples (NIOSH 7500) \& FSP-10 samples (IFA 213-582). $\boldsymbol{\mu}_{G K 2.69(N .7500)} \neq \boldsymbol{\mu}_{\text {FSP-10 (IFA 213-582) }}$

12. $H_{0}$ : There are no statistical differences in RCS concentrations between GK2.69 samples (NIOSH 7602) \& GK2.69 samples (NIOSH 7500). $\boldsymbol{\mu}_{G K 2.69(N .7602)}=\boldsymbol{\mu}_{G K 2.69(N .7500)}$

$\mathrm{H}_{\mathrm{a}}$ : There are statistical differences in RCS concentrations between GK2.69 samples (NIOSH 7602) \& GK2.69 samples (NIOSH 7500)). $\boldsymbol{\mu}_{G K 2.69(N .7602)} \neq \boldsymbol{\mu}_{G K 2.69(N .7500)}$

\section{To determine the difference between labs}

13. $\mathrm{H}_{\mathrm{o}}$ : There are no statistical differences in RCS concentrations between US (NIOSH) and German (IFA) labs using NIOSH Method 7602 (US method \#1). $\mu_{U S \text { Lab }}=\boldsymbol{\mu}_{\text {IFA Lab }}$ $\mathrm{H}_{\mathrm{a}}$ : There are statistical differences in RCS concentrations between US (NIOSH) and German (IFA) labs using NIOSH Method 7602 (US method \#1). $\boldsymbol{\mu}_{U S \text { Lab }} \neq \boldsymbol{\mu}_{\text {IFA Lab }}$

14. $\mathrm{H}_{\mathrm{o}}$ : There are no statistical differences in RCS concentrations between US (NIOSH) and German (IFA) labs using NIOSH Method 7500 (US method \#2). $\boldsymbol{\mu}_{U \boldsymbol{U} \text { Lab }}=\boldsymbol{\mu}_{\text {IFA Lab }}$ $\mathrm{H}_{\mathrm{a}}$ : There are statistical differences in RCS concentrations between US (NIOSH) and German (IFA) labs using NIOSH Method 7500 (US method \#2). $\boldsymbol{\mu}_{\text {US Lab }} \neq \boldsymbol{\mu}_{\text {IFA Lab }}$

15. $\mathrm{H}_{\mathrm{o}}$ : There are no statistical differences in RCS concentrations between US (NIOSH) and German (IFA) labs using IFA 213-582 (German method). $\boldsymbol{\mu}_{U S \text { Lab }}=\boldsymbol{\mu}_{I F A \text { Lab }}$. $\mathrm{H}_{\mathrm{a}}$ : There are statistical differences in RCS concentrations between US (NIOSH) and German (IFA) labs using IFA 213-582 (German method). $\boldsymbol{\mu}_{U \boldsymbol{S} \text { Lab }} \neq \boldsymbol{\mu}_{\text {IFA L Lab }}$

\section{FIELD STUDY: To determine the effect of (sampler + analytical method + worker/workplace} characteristics)

\section{PERSONAL SAMPLES}

16. $\mathrm{H}_{\mathrm{o}}$ : There are no statistical differences in RCS concentrations between GK2.69 (NIOSH 7602) and FSP-10 (IFA 213-582) samples in an industrial setting. $\boldsymbol{\mu}_{G K 2.69}$ (N.7602) $=\boldsymbol{\mu}_{\text {FSP }(\text { IFA 213-582) }}$

$\mathrm{H}_{\mathrm{a}}$ : There are statistical differences in RCS concentrations between GK2.69 (NIOSH 7602) and FSP-10 (IFA 213-582) samples in an industrial setting. $\boldsymbol{\mu}_{G K 2.69(\text { N.7602) }} \neq \boldsymbol{\mu}_{\text {FSP (IFA 213-582) }}$ 


\section{AREA SAMPLES}

17. $\mathrm{H}_{0}$ : There are no statistical differences in RCS concentrations between GK2.69 samples (NIOSH 7602)

\& FSP-10 samples (IFA 213-582). $\boldsymbol{\mu}_{G K 2.69(\text { N.7602) }}=\boldsymbol{\mu}_{\text {FSP-10 (IFA 213-582) }}$

$\mathrm{H}_{\mathrm{a}}$ : There are statistical differences in RCS concentrations between GK2.69 samples (NIOSH 7602) \& FSP-10 samples (IFA 213-582). $\boldsymbol{\mu}_{\boldsymbol{G K 2 . 6 9}}$ (N.7602) $\neq \boldsymbol{\mu}_{\boldsymbol{F S P}-10}$ (IFA 213-582)

18. $H_{o}$ : There are no statistical differences in RCS concentrations between GK2.69 samples (NIOSH 7500)

\& FSP-10 samples (IFA 213-582). $\boldsymbol{\mu}_{G K 2.69(N .7500)}=\boldsymbol{\mu}_{\text {FSP-10 (IFA 213-582) }}$

$\mathrm{H}_{\mathrm{a}}$ : There are statistical differences in RCS concentrations between GK2.69 samples (NIOSH 7500) \& FSP-10 samples (IFA 213-582). $\boldsymbol{\mu}_{\boldsymbol{G K} \text { 2.69 (N.7500) }} \neq \boldsymbol{\mu}_{\boldsymbol{F S P}-10 \text { (IFA 213-582) }}$

19. $H_{0}$ : There are no statistical differences in RCS concentrations between GK2.69 samples (NIOSH 7602)

\& GK2.69 samples (NIOSH 7500). $\mu_{G K 2.69(N .7602)}=\mu_{G K 2.69(N .7500)}$

$\mathrm{H}_{\mathrm{a}}$ : There are statistical differences in RCS concentrations between GK2.69 samples (NIOSH 7602) \& GK2.69 samples (NIOSH 7500)). $\boldsymbol{\mu}_{G K 2.69(\text { N.7602) }} \neq \boldsymbol{\mu}_{G K 2.69(N .7500)}$

\section{COMBINED PERSONAL AND AREA SAMPLES}

20. $\mathrm{H}_{\mathrm{o}}$ : There are no statistical differences in RCS concentrations between GK2.69 (NIOSH 7602) and FSP-10 (IFA 213-582) results. $\mu_{G K 2.69(N .7602)}=\mu_{F S P(I F A ~ 213-582)}$

$H_{a}$ : There are statistical differences in RCS concentrations between GK2.69 (NIOSH 7602) and FSP-10 (IFA 213-582) results. $\mu_{G K 2.69(N .7602)} \neq \mu_{\text {FSP (IFA 213-582) }}$ 


\section{APPENDIX III}

\section{SOP for the sample preparation for laboratory evaluation using an exposure chamber in PMRD (RCS)}

\section{Purpose:}

This sampling activity is part of a HELD research project, entitled "Comparison of sampling strategy between the United States and Germany". The objective of the project is to determine the relationship between exposure measurements using the U.S. measurement strategy and the German strategy, and to develop conversion factors (or equations) to adjust for differences, if applicable. This project has 3 phases: laboratory evaluation with spiked samples, laboratory evaluation with samples collected using side-by-side sample sets in environmentally controlled chambers, and field evaluation using different measurement strategies at various worksites. Table 1 shows a summary of sampling/analytical methods for respirable crystalline silica (RCS).

This SOP is prepared to provide a general procedural guideline for the collection of aerosol samples (RCS) in the environmentally controlled chamber built in the Office of Mine Safety Health Research (OMSHR)/NIOSH, Pittsburgh, PA, USA.

Table 1. Sampling and analytical methods for RCS

\begin{tabular}{|c|c|c|c|c|}
\hline \multirow[b]{2}{*}{ Chemical } & \multicolumn{2}{|l|}{ NIOSH method } & \multicolumn{2}{|l|}{ IFA method } \\
\hline & Principle of the method & $\begin{array}{c}\text { Method } \\
\text { No }\end{array}$ & & $\begin{array}{c}\text { Method } \\
\text { No }\end{array}$ \\
\hline \multirow{11}{*}{ RCS } & Cyclone with PVC filter (GK2.69 cyclone at 4.2 & & & \multirow{11}{*}{$\begin{array}{c}\text { IFA 213- } \\
582 \\
\text { Method 1 }\end{array}$} \\
\hline & $\mathrm{L} / \mathrm{min}$ ) with conductive filter holder; Filter ash & & FSP-10 cyclone with & \\
\hline & in muffle furnace ; Mixing the sample with $\mathrm{KBr}$ & & nitrocellulose filter (pore & \\
\hline & and pressing into a pellet; Analysis by IR at & $\mathrm{NIOSH}$ & size $8.0 \mu \mathrm{m}$ ) at $10 \mathrm{~L} / \mathrm{min}$; & \\
\hline & wavelength $800 \mathrm{~cm}^{-1}\left(915 \mathrm{~cm}^{-1}\right.$, if the sample & 7602 & Filter ash in furnace (low & \\
\hline & was ashed at low temperature) - Personal and & & or high temperature); & \\
\hline & area samples & & Mixing the sample with & \\
\hline & & & $\mathrm{KBr}$ and pressing into a & \\
\hline & Cyclone with PVC filter (GK 2.69 cyclone at 4.2 & & pellet; Analysis by FTIR at & \\
\hline & L/min); Filter ash in muffle furnace ; & $\mathrm{NIOSH}$ & two wavelengths $798 \mathrm{~cm}^{-}$ & \\
\hline & Redeposition on Ag membrane filter; analysis & 7500 & ${ }^{1}$ and $779 \mathrm{~cm}^{-1}$ & \\
\hline
\end{tabular}




\section{Methodology:}

Sample collection using side-by-side samples will be performed in an environmentally controlled aerosol test chamber in PMRD/NIOSH. Figure 1 shows the procedures of laboratory sample preparation. A full factorial design of experimental factors including 3 samplers per set, 7 sets of samplers per run, 2 particle types, and 4 concentration levels (Table 2 ) will be utilized. A preliminary test was conducted on September 19, 2019 to determine spatial variations of samplers and target concentrations to be employed. Detail information regarding the preliminary study was presented in Appendix A. Below are the factors selected based on the preliminary study results:

- 3 Samplers per set: 2 GK2.69 cyclones running at 4.2 L/min [for NIOSH 7602 and NIOSH 7500 methods] and FSP-10 cyclone running at 10 L/min [IFA 213-582]

- 7 sets of samplers per run: calculated number of sets based on power analysis to detect a difference of $25 \%$ with $>85 \%$ power. From a preliminary experiment, less than $3 \%$ variation was observed for each sampler type, when tested 7 sets of samplers per run (Appendix A for the results).

- 2 particles types: medium grade of Arizona road dust (ARD) with particle sizes between 0-80 $\mu \mathrm{m}$, known to include about 70\% crystalline silica and MIN-U-SIL ${ }^{\circledR} 10$ (CAS \# 14808-60-7, Western reserve chemical, Stow, OH, US) containing at least $98.6 \% \mathrm{SiO}_{2}$ with $97 \%$ of the silica particles having an equivalent spherical diameter $<10 \mu \mathrm{m}$ (median size of $3.4 \mu \mathrm{m}$ )

- 4 levels of dust concentrations: $0.5,1.0,3.0$ and $5.0 \mathrm{mg} / \mathrm{m}^{3}$ determined from a preliminary study Sampling flow rate should be checked before and after the sample collection and ensure that the measured flow rate is within $\pm 5 \%$ of the nominal flow rate. Also, note that each sampler has a quite good number of O-rings. When assembling samplers, make sure that you do not miss any O-rings.

The prepared samples will be analyzed by both NIOSH and IFA regardless of filter type. That is, both labs will analyze PVC filters using XRD and IR methods and nitrocellulose filters using IFA method. Table 2 indicates the number of filters required for lab samples. To make all samples, it is expected to run 16 testing conditions ( 4 concentration levels $\times 2$ particle types $\times 2$ labs). There will be no required order of test runs. Researcher(s) can conduct the test runs by convenience in terms of the test condition settings. 
Table 2. Number of filters required for lab samples

\begin{tabular}{|c|c|c|c|c|c|c|c|c|}
\hline \multirow{3}{*}{ Dust } & \multirow{3}{*}{$\begin{array}{l}\text { Analysis } \\
\text { by }\end{array}$} & \multirow{3}{*}{$\begin{array}{l}\text { Target } \\
\text { Conc. } \\
\left(\mathrm{mg} / \mathrm{m}^{3}\right)\end{array}$} & \multicolumn{6}{|c|}{ Number of filters } \\
\hline & & & \multicolumn{2}{|c|}{ NIOSH 7602} & \multicolumn{2}{|c|}{ NIOSH 7500} & \multicolumn{2}{|c|}{ IFA } \\
\hline & & & Chamber & $\begin{array}{l}\text { Media } \\
\text { blank* }\end{array}$ & Chamber & $\begin{array}{l}\text { Media } \\
\text { blank* }\end{array}$ & Chamber & $\begin{array}{l}\text { Media } \\
\text { blank* }\end{array}$ \\
\hline & & 0.5 & 7 & \multirow{4}{*}{16} & 7 & \multirow{4}{*}{16} & 7 & \multirow{4}{*}{16} \\
\hline & $\mathrm{NIOSH}$ & 1 & 7 & & 7 & & 7 & \\
\hline & \multirow[t]{2}{*}{ lab } & 3 & 7 & & 7 & & 7 & \\
\hline Dust 1 & & 5 & 7 & & 7 & & 7 & \\
\hline (either & \multirow{4}{*}{ IFA lab } & 0.5 & 7 & \multirow{4}{*}{16} & 7 & \multirow{4}{*}{16} & 7 & \\
\hline ARD or & & 1 & 7 & & 7 & & 7 & \\
\hline MIN-U- & & 3 & 7 & & 7 & & 7 & 10 \\
\hline \multirow[t]{7}{*}{ SIL) } & & 5 & 7 & & 7 & & 7 & \\
\hline & \multicolumn{2}{|l|}{ Sub-total } & 56 & 32 & 56 & 32 & 56 & 32 \\
\hline & \multicolumn{2}{|c|}{ Lab blank** } & \multicolumn{2}{|c|}{6} & \multicolumn{2}{|c|}{6} & \multicolumn{2}{|c|}{6} \\
\hline & \multicolumn{2}{|c|}{ Total (Dust 1) } & & & \multicolumn{2}{|c|}{282} & & \\
\hline & \multirow{4}{*}{$\begin{array}{l}\text { NIOSH } \\
\text { lab }\end{array}$} & 0.5 & 7 & \multirow{4}{*}{16} & 7 & \multirow{4}{*}{16} & 7 & \multirow{4}{*}{16} \\
\hline & & 1 & 7 & & 7 & & 7 & \\
\hline & & 3 & 7 & & 7 & & 7 & \\
\hline \multirow{2}{*}{$\begin{array}{l}\text { Dust } 2 \\
\text { (either }\end{array}$} & & 5 & 7 & & 7 & & 7 & \\
\hline & \multirow{4}{*}{ IFA lab } & 0.5 & 7 & \multirow{4}{*}{16} & 7 & \multirow{4}{*}{16} & 7 & \\
\hline ARD or & & 1 & 7 & & 7 & & 7 & \\
\hline MIN-U- & & 3 & 7 & & 7 & & 7 & \\
\hline \multirow[t]{4}{*}{$\mathrm{SIL})$} & & 5 & 7 & & 7 & & 7 & \\
\hline & \multicolumn{2}{|l|}{ Sub-total } & 56 & 32 & 56 & 32 & 56 & 32 \\
\hline & Lab blank & & & & & & & \\
\hline & Total (Du & t 2) & & & & & & \\
\hline Grand Tc & (Dust 1 ar & d Dust 2) & & $4(n=376$ & PVC filters & 188 for $r$ & cellulose filt & \\
\hline
\end{tabular}




\section{a) Filter Pre-weighing}

Prior to collecting samples in the chamber, PVC filters ( $5 \mu \mathrm{m}$ pore size) will be weighed in the weighing room built in NIOSH/PMRD. The weighing room should always maintain a temperature (20 \pm $3^{\circ} \mathrm{C}$ ) and humidity ( $50 \pm 5 \%$ Relative Humidity) control. Prior to weighing, all filters must be equilibrated in the weighing room for at least 24 hours. In all cases, tare the calibrated 5-figure balance before placing a filter on the balance and wait exactly 60 seconds (use stopwatch) before taking the reading to ensure the balance has come to stability. After weighing, all PVC filters will be placed in 3-piece cassettes (with support pads). The nitrocellulose filters will be placed in 2-piece cassettes (with support pads), which later will be placed into FSP-10 cyclones. No weighing analysis will be performed for the media blanks. Lab blanks, approximately $10 \%$ of the number of lab samples, will be weighed but no analytical methods (XRD or IR) will be applied.

\section{b) Chamber study}

Once all sampling trains (i.e., sampler with a sampling medium and pump connected by a tubing) are ready, conduct sample collection by following these procedures:

1) Place all 7 sets of sampling trains in the marple chamber by hanging samplers' side-by-side.

2) Turn on the fluidized bed aerosol generator where particles are put and monitor the chamber mass concentrations using Thermo TEOM (model 1400, Thermo Fisher Scientific, Franklin, MA). In addition, collect particle size distributions by mass/number using Aerodynamic Particle Sizer ${ }^{\circledR}$ (APS) spectrometer (model 3321, TSI Inc.).

3) Once the mass concentrations were stabilized and reached at one of target concentrations (0.5, $1.0,3.0$ and $5.0 \mathrm{mg} / \mathrm{m}^{3}$ ), turn on all pumps to start sample collection.

4) Conduct sample collection for one hour and turn off all sampling pumps and the aerosol generator.

5) Provide dilution air into the chamber and monitor concentrations with TEOM to ensure almost zero concentration.

6) Remove all samplers from the chamber, clean the exterior of samplers with wipes, and check the flow rate of each sample train.

7) Remove filters from the samplers and carefully transport to the weighing room for stabilization of the filters.

8) Clean all samplers using compress air.

9) Repeat the previous steps for another target concentration. After completing all target concentrations with one material type, clean the chamber thoroughly for another material to 
ensure no cross-contamination from the previous material. Also clean all samplers with tab water first, rinse with deionized water, and dry by blowing air.

\section{c) Filter Post-weighing}

After the chamber study, all samples will be delivered to the weighing room and equilibrate for at least 24 hours. Then, conduct weighing analysis the same way as described in filter pre-weighing section. The researcher can measure the filters after a few test runs or at the end of all runs of one dust material. After weighing, place the PVC filters in 3-piece 37-mm CFCs and nitrocellulose filters in 2-piece CFCs. After the post-weighing of lab samples for one dust material, NIOSH/EAB will pick up the lab samples, divide into half, and send to IFA and NIOSH contract lab for the analysis according to the methods described in Table 1.

\section{Expected Outcome}

From this laboratory evaluation study using different types of samplers, it is expected to determine the variability of concentrations caused from different sampling and analytical methods in a controlled environment. Variability of concentrations from environmental factors will be determined by field surveys.

\section{Task}

Briefly, NIOSH/PMRD with assistance of NIOSH/EAB will prepare laboratory samples (including pre- and post-weighing of filters and chamber study), as shown in Figure 1. All the generated samples will be delivered to NIOSH/EAB. A staff in NIOSH/EAB will divide the samples into half to be analyzed by IFA and NIOSH contract laboratory for RCS. Lastly, NIOSH/EAB will collect the results and perform data analysis. 


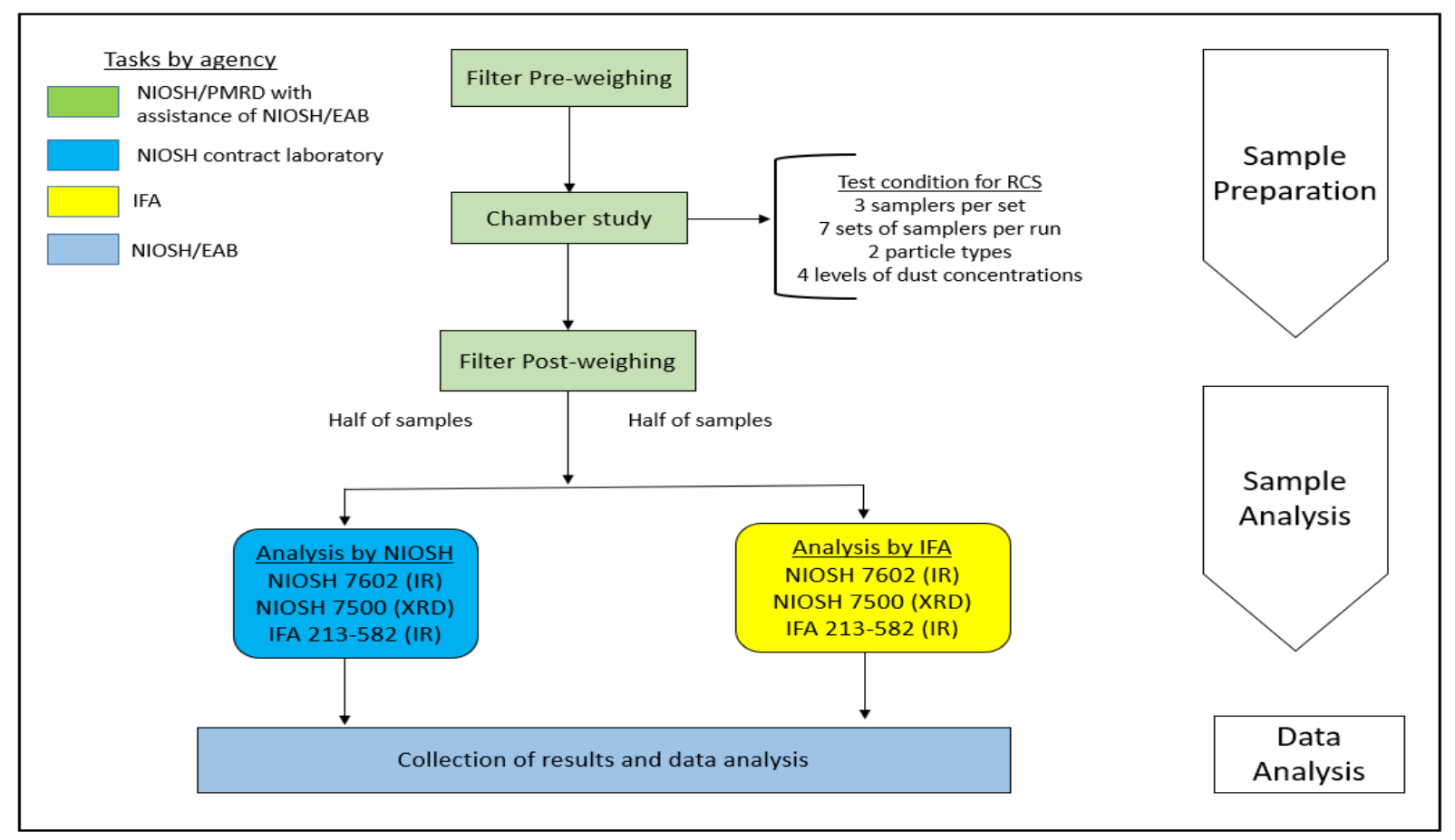

Figure 1. Procedures of laboratory sample preparation, sample analysis, and data analysis

\section{Logistics}

Table 3 shows a summary of the experimental parameters in a table format and all equipment to be used for this sampling activity and supplied agencies are listed in Table 4.

Table 3. Summary of the experimental parameters

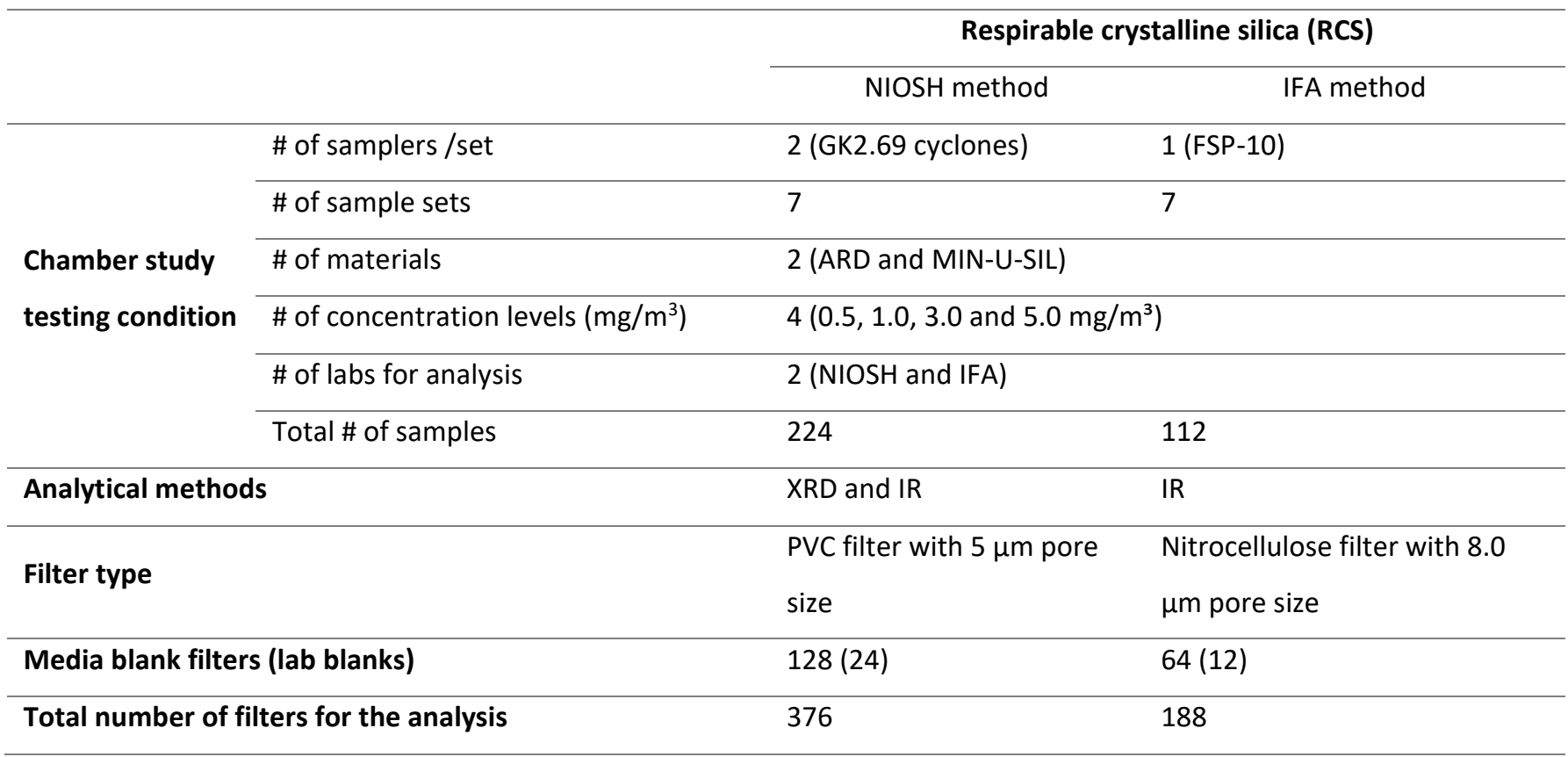


Table 4. Inventory needed for the laboratory evaluation (RCS)

\begin{tabular}{|c|c|c|c|}
\hline & Item & Number & Supplied by \\
\hline \multirow{8}{*}{$\begin{array}{l}\text { Samplers and } \\
\text { sampling media }\end{array}$} & GK2.69 cyclones & 28 (14 required) & $\mathrm{EAB}$ \\
\hline & FSP-10 cyclones & 14 (7 required) & EAB \\
\hline & PVC filters ( $5 \mu \mathrm{m}$ pore size) & 400 & $\mathrm{EAB}$ \\
\hline & Nitrocellulose filters ( $8 \mu \mathrm{m}$ pore size) & 200 & $\mathrm{EAB}$ \\
\hline & 37-mm 2-piece CFC (to place filters from FSP-10) & 150 & EAB \\
\hline & 37-mm 3-piece CFC (for GK2.69) & 250 & EAB \\
\hline & Filter keeper (37-mm) for media blanks & 200 & EAB \\
\hline & FSP-10 filter cartridges & 14 & EAB \\
\hline \multirow{2}{*}{ Pumps } & Medium volume pumps (up to $5 \mathrm{~L} / \mathrm{min}$ ) with chargers & 9 (with 2 extra) & PMRD \\
\hline & High volume (up to $15 \mathrm{~L} / \mathrm{min}$ ) with chargers & 8 (with 2 extra) & $\mathrm{EAB}$ \\
\hline \multirow{2}{*}{ Testing materials } & Arizona Road Dust & & PMRD \\
\hline & MIN-U-SIL ${ }^{\circledR} 10$ & & EAB \\
\hline \multirow{5}{*}{ Others } & Mass flow meter - Low & 1 & PMRD \\
\hline & Mass flow meter - High & 1 & PMRD \\
\hline & Tubing & - & PMRD \\
\hline & Calibrated 5-figure balance & 1 & PMRD \\
\hline & Miscellaneous for weighing & - & PMRD \\
\hline DRIs & TEOM and APS & & PMRD \\
\hline
\end{tabular}

\section{Preliminary study}

\section{Purpose}

A preliminary study was conducted to determine 1) spatial variations of cyclone samplers and 2) target concentration levels for the study. This test was conducted using a marple chamber in PMRD on September 19, 2019.

\section{Method}

After pre-weighing the PVC filters (for GK2.69) and nitrocellulose filters (for FSP-10), 7 sets of sampling trains were prepared; each set includes 2 GK2.69 cyclones (running at 4.2 LPM) and FSP-10 cyclone (running at 10 LPM). All 7 sets of samplers were placed in the marple chamber side-by-side and 
ARD particles were generated via a fluidized bed aerosol generator. Without turning on the sampling pumps, the chamber concentrations were continuously monitored with a Thermo TEOM. In addition, APS was monitored to determine size distributions of mass and number concentrations. When the mass concentrations were stabilized and reached at $\sim 5 \mathrm{mg} / \mathrm{m}^{3}$, all pumps were turned on and collected samples for one hour. We then removed a few GK2.69 samplers, weighed the filters of the samplers, placed those back to the chamber; this is to determine a spatial variation by comparing masses of the filters. The chamber concentration was then lowered to $\sim 0.5 \mathrm{mg} / \mathrm{m}^{3}$. We collected samples for another hour, waited until the chamber concentration was low enough, removed all samples, did post-check of pump flowrates and weighed all filters.

\section{Results/Conclusions}

It was determined that the chamber concentrations were able to reach at $\sim 0.5 \mathrm{mg} / \mathrm{m}^{3}$ and $\sim 5$ $\mathrm{mg} / \mathrm{m}^{3}$ when the chamber concentrations were monitored with TEOM. As shown in Table 1 and Table 2, the spatial variation was $<3.5 \%$, when tested 7 sets of samplers in the chamber.

Table 5. Summary of preliminary test (GK2.69)

\begin{tabular}{|c|c|c|c|c|c|}
\hline GK2.69 Filter \# & Pre wt (mg) & Post wt (mg) & Net (mg) & Volume(L) & Concentration $\left(\mathrm{mg} / \mathrm{m}^{3}\right)$ \\
\hline T413-1 & 16.063 & 18.03 & 1.967 & 534.3 & 3.68 \\
\hline T413-2 & 14.438 & 16.376 & 1.938 & 536.6 & 3.61 \\
\hline T413-3 & 16.164 & 18.232 & 2.068 & 524.5 & 3.94 \\
\hline T413-4 & 14.472 & 16.504 & 2.032 & 531.1 & 3.83 \\
\hline T413-5 & 16.162 & 18.215 & 2.053 & 529.3 & 3.88 \\
\hline T413-6 & 16.147 & 18.109 & 1.962 & 529.0 & 3.71 \\
\hline T413-7 & 14.041 & 16.054 & 2.013 & 531.7 & 3.79 \\
\hline T413-8 & 16.169 & 18.2 & 2.031 & 529.8 & 3.83 \\
\hline T413-9 & 14.343 & 16.439 & 2.096 & 531.6 & 3.94 \\
\hline T413-10 & 16.294 & 18.323 & 2.029 & 527.8 & 3.84 \\
\hline T413-11 & 14.245 & 16.252 & 2.007 & 525.0 & 3.82 \\
\hline T413-12 & 14.5 & 16.412 & 1.912 & 535.4 & 3.57 \\
\hline T413-13 & 16.178 & 18.236 & 2.058 & 530.1 & 3.88 \\
\hline \multirow[t]{4}{*}{ T2543-133 } & 12.134 & 14.067 & 1.933 & 534.2 & 3.62 \\
\hline & & & & Average & 3.78 \\
\hline & & & & SD & 0.12 \\
\hline & & & & RSD (\%) & 3.25 \\
\hline
\end{tabular}


Table 6. Summary of preliminary test (FSP-10)

\begin{tabular}{cccccc}
\hline FSP-10 Filter \# & $\begin{array}{c}\text { Pre wt } \\
(\mathbf{m g})\end{array}$ & $\begin{array}{c}\text { Post wt } \\
(\mathbf{m g})\end{array}$ & Net $(\mathbf{m g})$ & Volume(L) & Concentration $\left(\mathbf{m g}^{\prime} \mathbf{m}^{\mathbf{3}}\right)$ \\
\hline T414-5 & 41.214 & 47.127 & 5.913 & 1245.5 & 4.75 \\
\hline T414-8 & 41.138 & 47.176 & 6.038 & 1266.3 & 4.77 \\
\hline T414-9 & 41.066 & 46.945 & 5.879 & 1253.7 & 4.69 \\
\hline T414-10 & 40.942 & 46.995 & 6.053 & 1262.5 & 4.79 \\
\hline T414-11 & 41.226 & 47.13 & 5.904 & 1243.6 & 4.75 \\
\hline T414-12 & 41.183 & 47.106 & 5.923 & 1260.0 & 4.70 \\
\hline T414-13 & 41.305 & 47.417 & 6.112 & 1269.5 & 4.81 \\
\hline & & & Average & 4.75 \\
\cline { 4 - 5 } & & & SD & 0.05 \\
\hline
\end{tabular}

In addition, the nitrocellulose filters showed noticeable changes of masses, when few media blanks were measured.

\begin{tabular}{ccccc}
\hline FSP-10 Filter \# & Pre wt $(\mathbf{m g})$ & Post wt $(\mathbf{m g})$ & Net $(\mathbf{m g})$ & \\
\hline T414-1 & 41.186 & 41.203 & 0.017 & Blank \\
\hline T414-2 & 41.257 & 41.297 & 0.04 & Blank \\
\hline T414-3 & 41.123 & 41.164 & 0.041 & Blank \\
\hline T414-4 & 40.857 & 40.884 & 0.027 & Blank \\
\hline T414-6 & 41.201 & 41.209 & 0.008 & Blank \\
\hline T414-7 & 41.015 & 40.996 & -0.019 & Blank \\
\hline
\end{tabular}

Below are items consented by the group from the preliminary test.

- Target concentration levels: $0.5,1,3$, and $5 \mathrm{mg} / \mathrm{m}^{3}$

- Number of sampling sets per run: 7

- Sampling time: 1 hour

- Acceptable variation of samples: $15 \%$ of target concentration

- A researcher will complete test runs using one material type and conduct all weighing analysis prior to moving to a next material. If there is a high variation (unexpectedly), he will redo some runs. 


\section{APPENDIX IV}

\section{SAMPLE AND ANALYSIS PLAN (SAP)}

\section{PURPOSE}

This Sampling and Analysis Plan (SAP) provides a general procedural guideline for the collection of air samples of employees exposed to occupationally hazardous aerosols as well as the general work area, using standard sampling techniques (a calibrated air pump attached to a sampler, which contains an appropriate filter medium). The collected samples will be sent to an IH laboratory for further analysis.

The objective of air sampling is to produce data such that reflects a reasonably accurate representation of the levels of aerosols to which employees are exposed to during normal working hours and activities.

\section{GENERAL REMINDERS}

\section{Personnel/Location Selection}

Personnel and locations to be sampled will be selected in conjunction with the person responsible for the company's Safety and Health program. A walk-through survey will obtain the following information

- Department layout showing potential source locations, air inlet/exhaust locations

- Room volume of each department (If a department is connected to another department without doors, please provide the whole room volume and volume of the department)

- Size of Company (number of employees)

- Exposure pattern (Duration and frequency per shift and week) Employees who are reasonably expected to be exposed to the aerosols under study above the

Action Level (AL) will be evaluated, given consideration to the following criteria:

- Shift

- Job Classification

- Work Area

- Previous Sampling Data 
The above information will be used to determine similar exposure groups (SEGs). Observation of the tasks as well as a review of any available past exposure data from previous monitoring campaigns will then determine the job tasks to be sampled. Representative sampling can used when it is expected that employees engaged in similar work will have similar exposure.

\section{Schedule}

Sample collection activities are planned for June through December of 2019. The schedule is based on the arrival of all sampling equipment, approval from the company's S\&H team and availability of participants for sample collection. It is anticipated that sampling activities will occur within 2-3 days of a single week with multiple shifts per day.

Laboratory analysis of the collected samples are usually completed within 2 months of sample collection and data analysis will commence shortly thereafter.

\section{PRE-SAMPLING}

\section{Equipment}

- Environmentally controlled weighing room

- $\quad$ Filter (37 mm, 5-um pore PVC filter \& 37-mm Nitro-cellulose)

- Calibrated 5-figure balance

- Sampling pumps
- Sampling train for flow rate calibration (for GK2.69 \& FSP10)

- FSP-10 calibrator

- Tubing

- Mass flow meter

\section{Preparation of Sampling Media}

The sampling media should be prepared in a designated weighing room. The weighing room should always maintain a temperature $\left(20 \pm 2^{\circ} \mathrm{C}\right)$ and humidity $(50 \pm 5 \%$ Relative Humidity) control to allow for the best weighing accuracy with an analytical balance.

- Prior to weighing, all filters must be equilibrated in the environmentally controlled weighing room or equilibration chamber for at least 24 hours.

- In all cases, tare the calibrated 5-figure balance before placing the item on the balance and wait exactly 180 seconds (use stopwatch) before taking a weight reading to ensure the balance has come to stability. 
- Remove the filter from the packet and pass it through the static eliminator before taking the weight. Record the pre-weight reading of the filter and load the filter into the sampler. Place the assembled sampler into a container until it's ready for use.

\section{Flowrate Adjustment of Sampling Pumps}

Prepare a sampler to be used for flowrate adjustment of sampling pumps (prior to sample collection) and post-check of flowrate of pumps. Examine the O-rings in the sampler (if any) and replace if in poor condition.

- Use a clean location (office room). Attach a length of rigid tubing $(\sim 90 \mathrm{~cm}$ ) to the inlet of the pump and connect to the outlet of a sampler.

- Connect the outlet end of a certified mass flow meter via another length of rigid tubing (e.g., tygon) to the inlet of the sampler. Note that FSP-10 cyclones require a special kit to be attached to the sampler.

a. For 37-mm cassette, directly connect the inlet of the sampler to the calibrator.

b. For GSP-10 and FSP-10 cyclones, connect the hose-barb connector on the inlet cone of the sampler to the calibrator.

- Switch on both pump and mass flow meter and allow to warm up for a minimum of 15 minutes.

- Adjust pump flow if necessary, to obtain a required nominal reading $\pm 5 \%$ (GK2.69 - 4.2 LPM, FSP-10 - 10LPM, CFC- 2 LPM)

- Record the average flowrate.

\section{SAMPLING}

Select a sampling pump that has been adjusted to the required flowrate $(+/-5 \%)$ and attach a length of tubing $(\sim 90 \mathrm{~cm}$ ) to the inlet of the pump and connect the other end of the tubing to the outlet of a sampler. Make sure all connections are free of leaks by closing off the filter inlet. On the sampling data sheet, record the label of the sampling media alongside that of the sample pump.

\section{For Personal Sampling:}

- Attach the sampling head to a person's breathing zone and collect samples according to the method.

- When two samplers are being worn by a worker at the same time, one is deployed on the left side and one on the right. The sides are "randomized" to the extent that no 
sampler is significantly weighted to one side over the other. The side (left or right) is recorded for each sampler deployed.

- Ensure the worker has signed a consent form.

- For each source location, check the direction of source emission and record if the worker is present at downstream (D), upstream (U), or neither (N) from the source emission.

\section{For Area Sampling:}

- A stationary sampling basket will be used to allow side-by-side comparison of the samplers

- For each source emission, at least two area samples should be collected, one in a near-field (i.e., within a 2-meter distance) and the other one in a far-field (i.e., beyond a 2-meter distance).

- For the near-field location, two sets of paired-samplers should be placed as close as to the source at a breathing zone height. For the far-field location, two sets of paired-samplers should be placed at a height between 0.5 and 1.5 meter.

- For each source location, check the direction of source emission and record a wind direction on a drawing. If allowed measure velocity near each source emission and record it.

- Record the distance between the source emission and sampler location and height from the ground (A map showing locations is recommended along with pictures).

- Initiate sampling by turning the pump on and record the flow rate and the time.

- The required sampling time should be determined based on the information written in each country's standard method so as not to overload the filter.

- Periodically check the pump whether the pump functions properly. If a noticeable change of the flow rate is visually observed due to bending or blockage of tubing, turn off the pump and reset the flow rate. If unable to reset the flow rate to the original setting, terminate sampling and note the reason for termination.

- Note that depending on sample load, consecutive samples over the shift may be required. Sampling times shorter than a full shift are permitted if the pressure drop across the filter exceeds the pump's capabilities; that is, the filter becomes clogged.

- Using an appropriate instrument, measure the temperature, humidity, and pressure during the sampling period.

- During the sampling, observe the tasks of each worker participating in the field survey and record whether the worker's exposure represents normal task or unusual situation (e.g., maintenance, use of wrong tools) in a sampling log. Also, fill a worker's observation form. 
- For all samplers, when sampling is completed, check the flowrate and turn off the pumps and record the time each one is switched off. Remove the sampling train(s) from the sampling location and return them to a clean area for disassembly.

- Disassemble the sampling train and place collected samples in a container. If necessary, wipe the exterior of the sampling header with a wetted tissue.

\section{POST SAMPLING}

\section{Storage/Transportation}

All samples must be clearly marked on the exterior surface with the appropriate label. It is preferable that the investigator personally transports the samples back to the laboratory rather than to use a shipping service. However, if shipping services must be used, sample packages must be placed inside larger boxes, and cushioned with packing materials, with the packaging exteriors legibly marked "Fragile".

- For 37 mm CFC: Samplers must be completely capped, placed in a suitable container, and arranged upright and tightly packed in boxes. The sampler must not be inverted at any time.

- For FSP samplers: Filter holders removed from the GSP/FSP bodies are matched with the transport covers bearing the original label, placed in a container, and arranged upright and tightly packed in boxes. Use the containers provided by IFA. 


\section{APPENDIX V}

\section{FIELD STUDY: JOB TASKS \& DESCRIPTIONS}

1. WAREDRESSER: Selects imperfect ware and performs any final de-burring of the ware bottom with a hand tool after its emergence from the AEM machine. The hand tool is used to smooth out the surface.

Potential Hazard: Dust from the ware becomes airborne and saturates the worker breathing zone due to poor

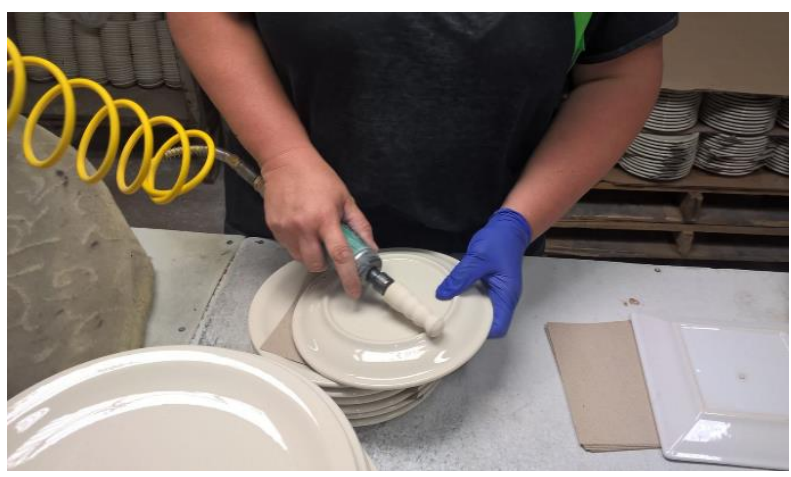
ventilation.

2. PLASTER MACHINE OPERATOR (Mold Shop): Dump bags of powder plaster into plaster bin for mixing with water. After mixing, the plaster mix is poured into a casing. This is used to make the mold for different ware vessels. The operator removes the mold from the casing and trims the edges.

Potential Hazard: Powder plaster becomes airborne during transfer from bag to bin.
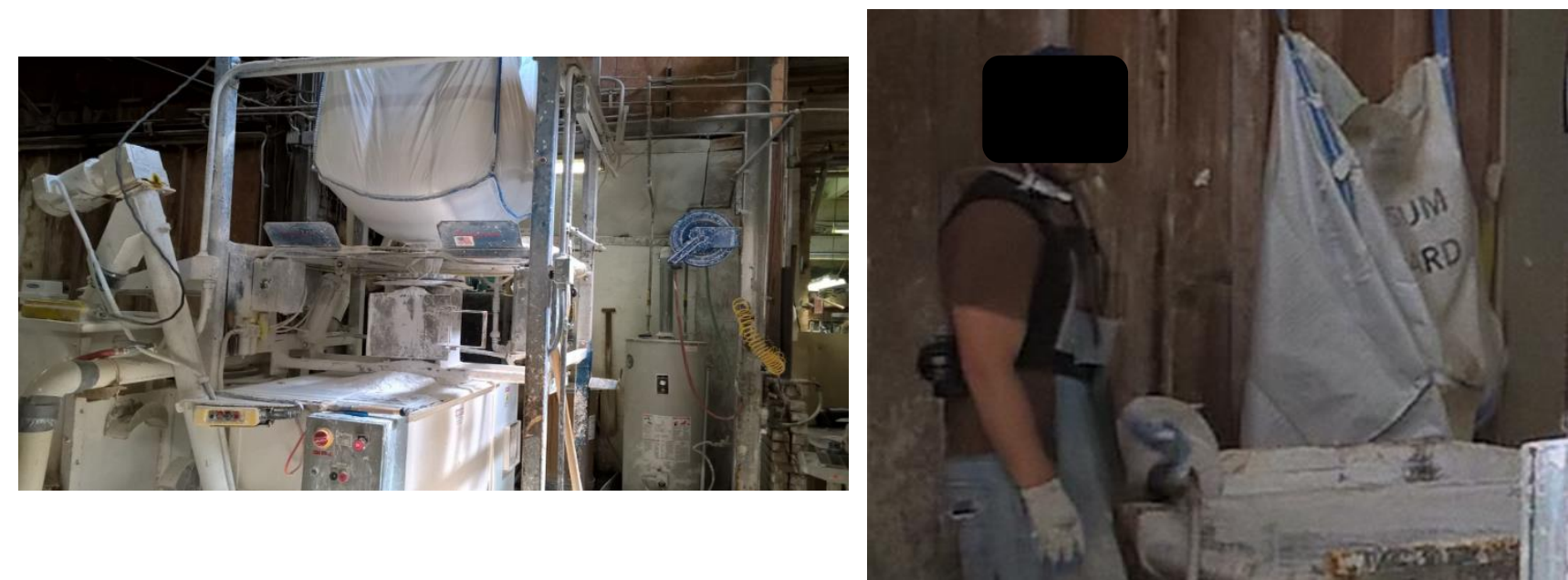
3. PRESSURE CASTER: Liquid slip goes inside a cast and pressurized to make solid ware. A robotic arm takes processes the ware. At the final stage, the pressure caster takes the ware and vacuums and loose edges from the bottom.

Potential Hazard: Vacuuming the bottom of the ware generates air borne dust in and around the area.
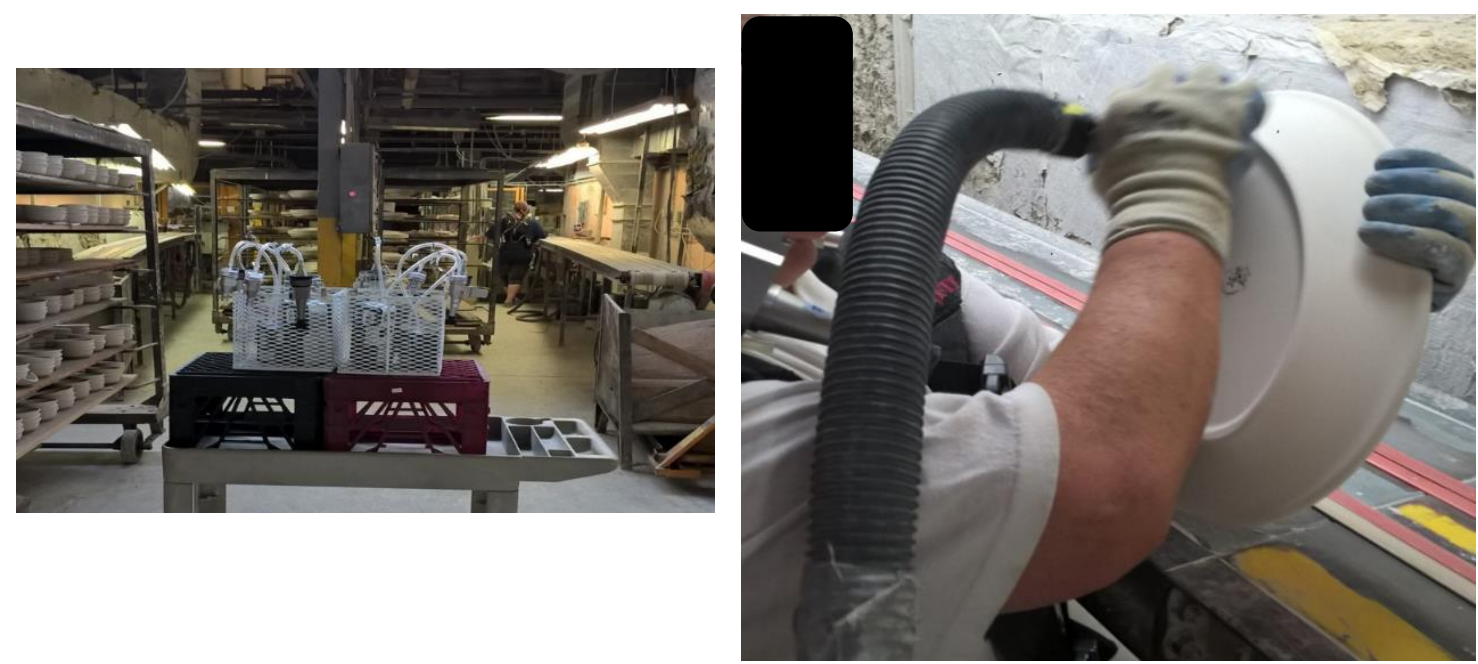

4. Stripper: Selects good ware from the line and discards bad (cracked) ware into the large suction bin.

Potential Hazard: The dust collection system for the suction bin is not routinely serviced. Thus, dust from broken ware emerges from the bin into the area where strippers are stationed.
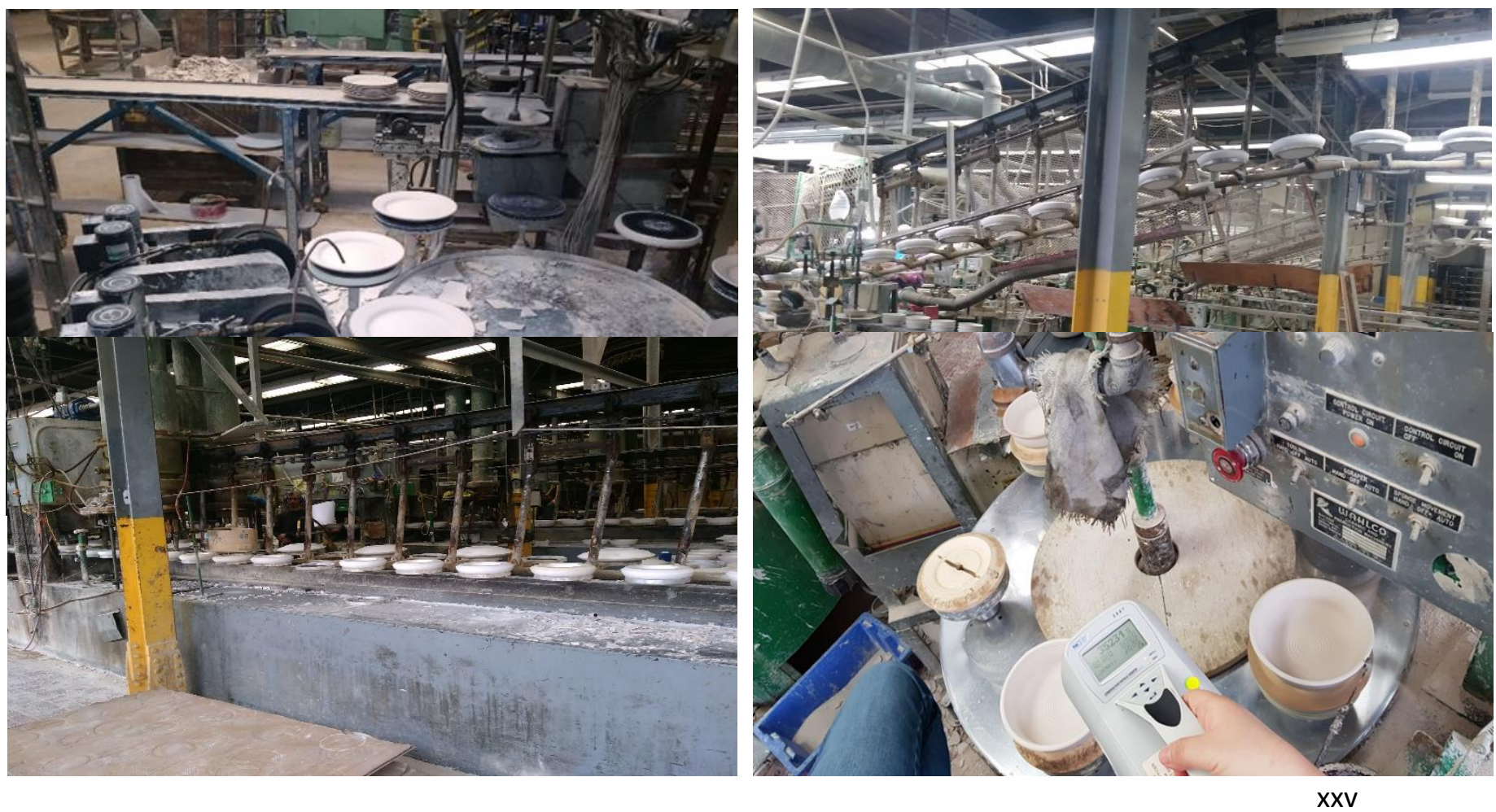
5. FINISHER (Rams Press): De-burr rough edges off the bottom of ware coming from RAMS Press. Uses a brusher and sometimes a hand tool. The RM Finisher is stationed in front of a dust collector to collect dust particle from the ware being worked on.

Potential Hazard: The dust collector is not routinely serviced and might have low suction. The RM Finisher is stationed along a main corridor. Forklifts transporting material around the warehouse creates airborne dust due to poor housekeeping.
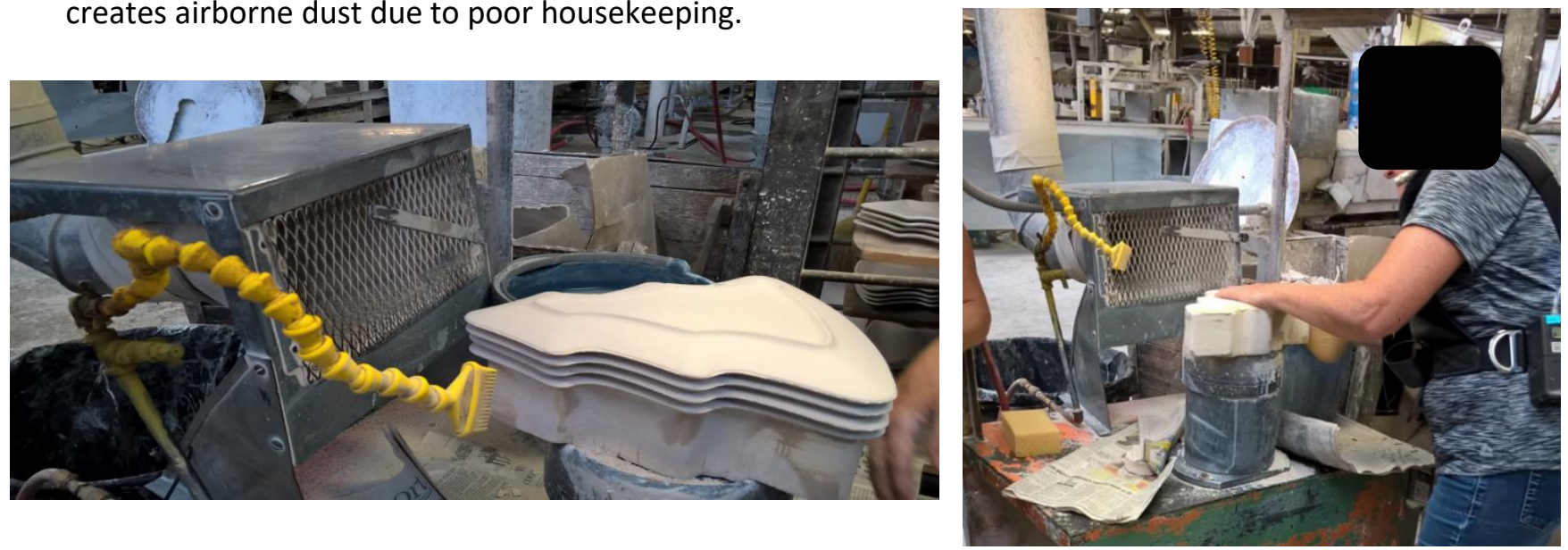

6. GLOST PROCESSOR (GP): Does final QC check. The GP selects and sorts the ware after kilning. Uses a hand-tool to deburr rough edges off the bottom of the ware.

Potential Hazard: Dust from the ware becomes airborne and saturates the worker breathing zone due to poor ventilation.
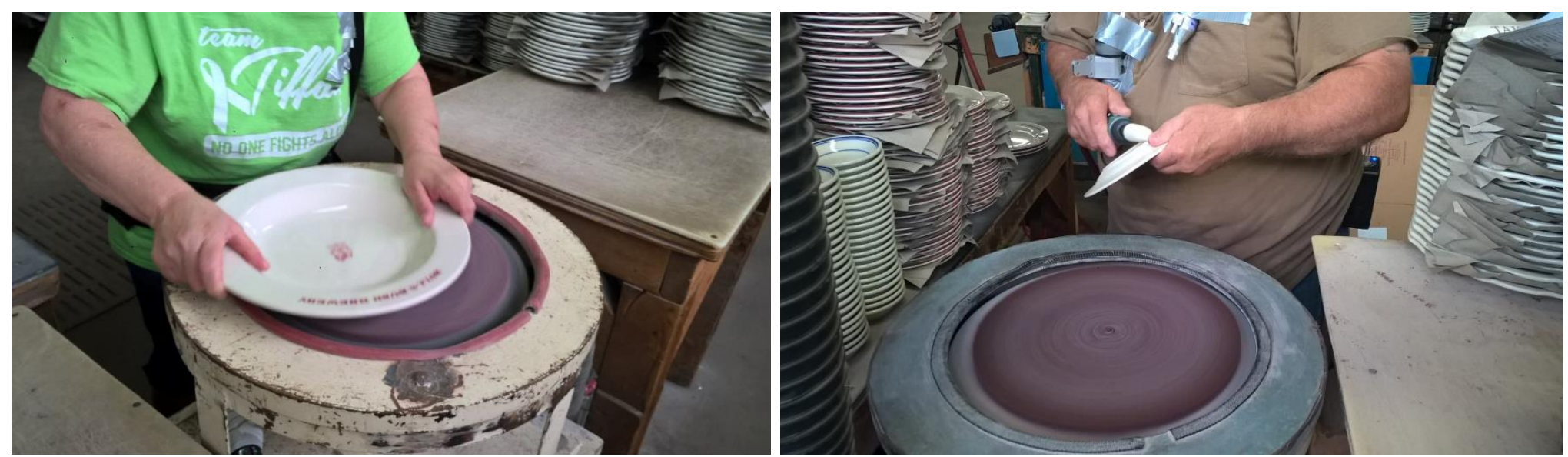
7. GLAZE MAKERS: Manual dumping of the powered glaze raw material in the mill to make the liquid glaze for the ware. If more stain (color) is needed, the GM's will dump more powder (color) in the mixer with the glaze.

Potential Hazard: Dust from the powdered material becomes airborne and saturates the worker breathing zone due to poor dust collection and ventilation.
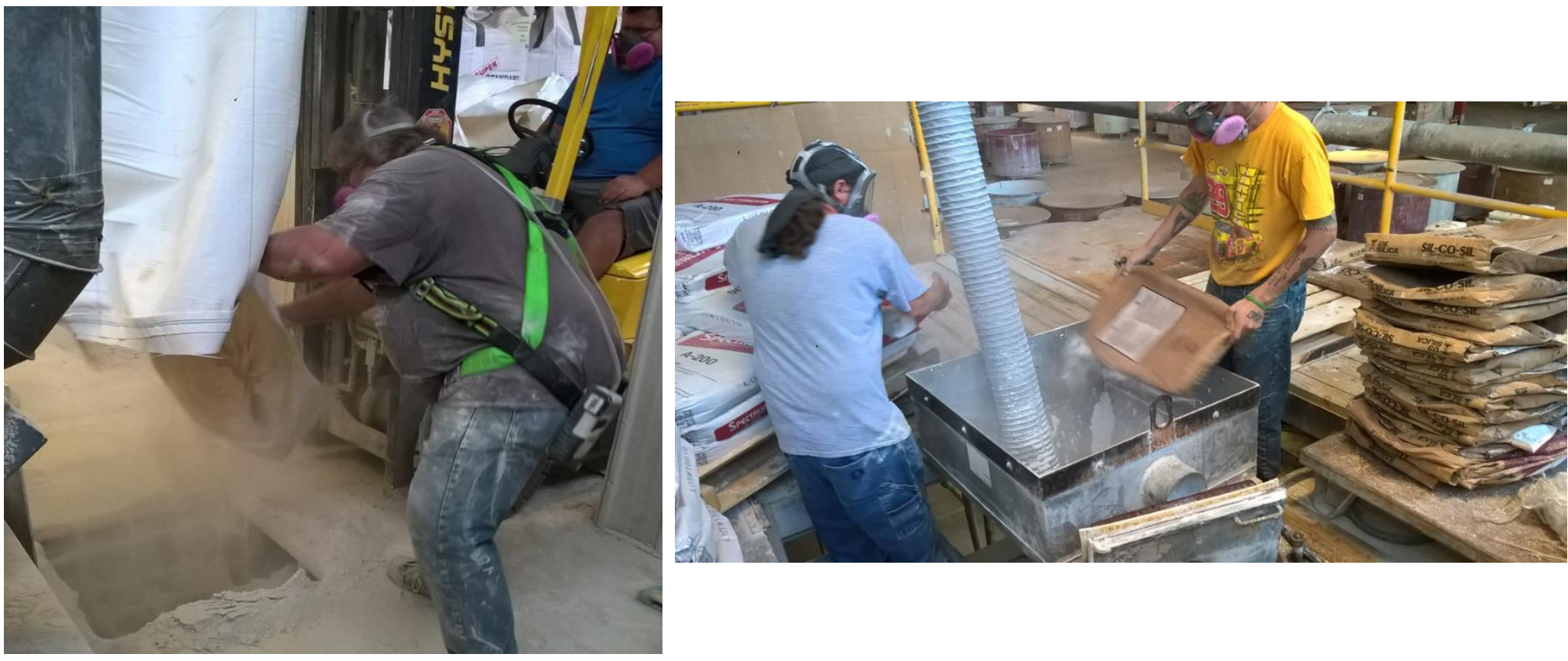

8. \#8 SYSTEM OPERATOR: Oversees operation of SKK machines and makes adjustment as needed. The SKK machine is an system that automates the process of ware making from start to finish. The system operator intervenes as necessary to removes broken ware from bad batches or cleans part of the machines for better operation.

Potential Hazard: Dust from the ware becomes airborne while cleaning. Little to no dust collection or ventilation in some areas. 

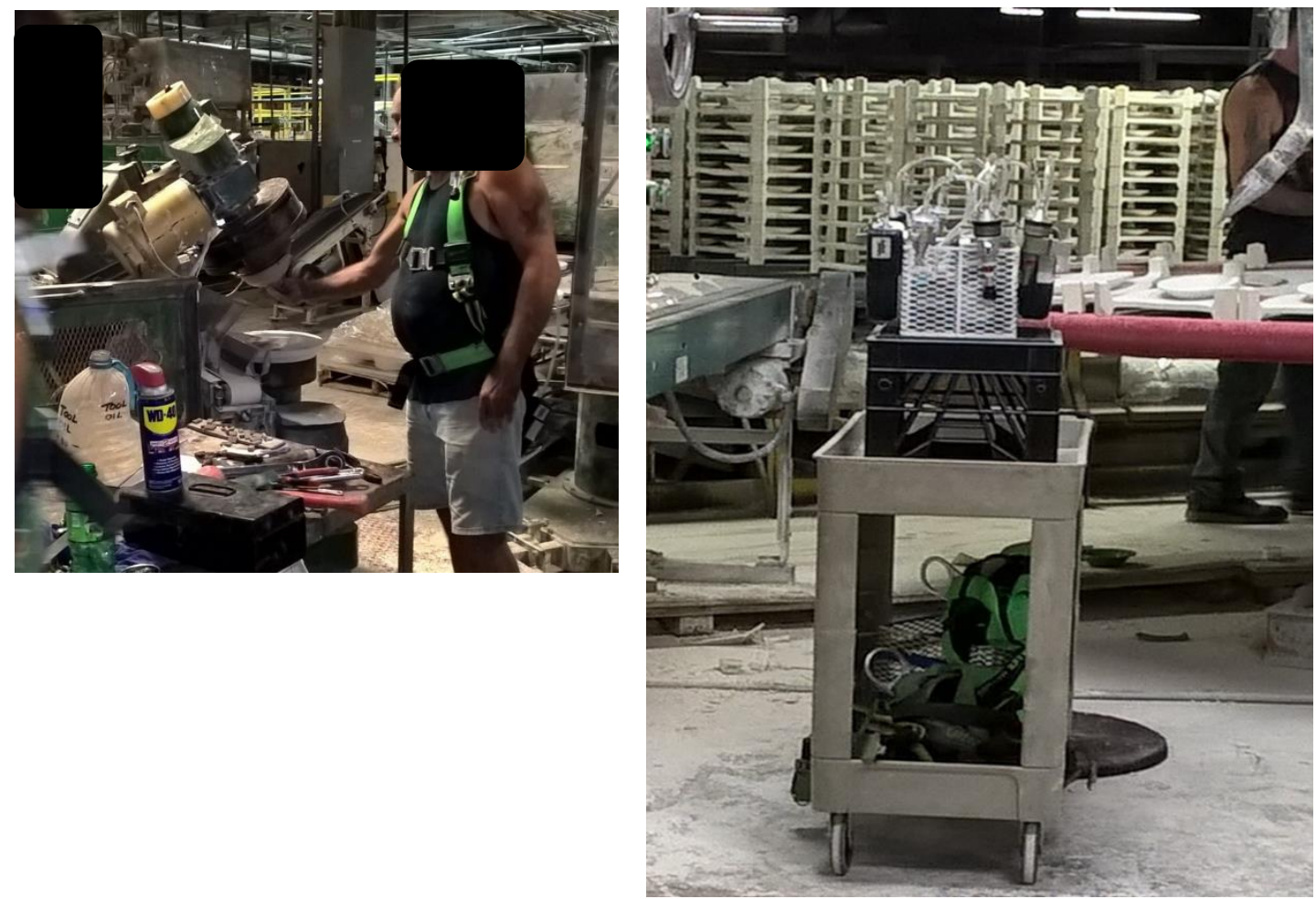

9. SILO Crew: The SC maintains the silo house. Unloads clay from the rails. In some cases, manually dumps powered clay into the vessel to make slip for the main factory.

Potential Hazard: Dust becomes airborne during unloading, even though the station is outdoors. Small leaks for the pipes create a haze of respirable dust inside the silo house.
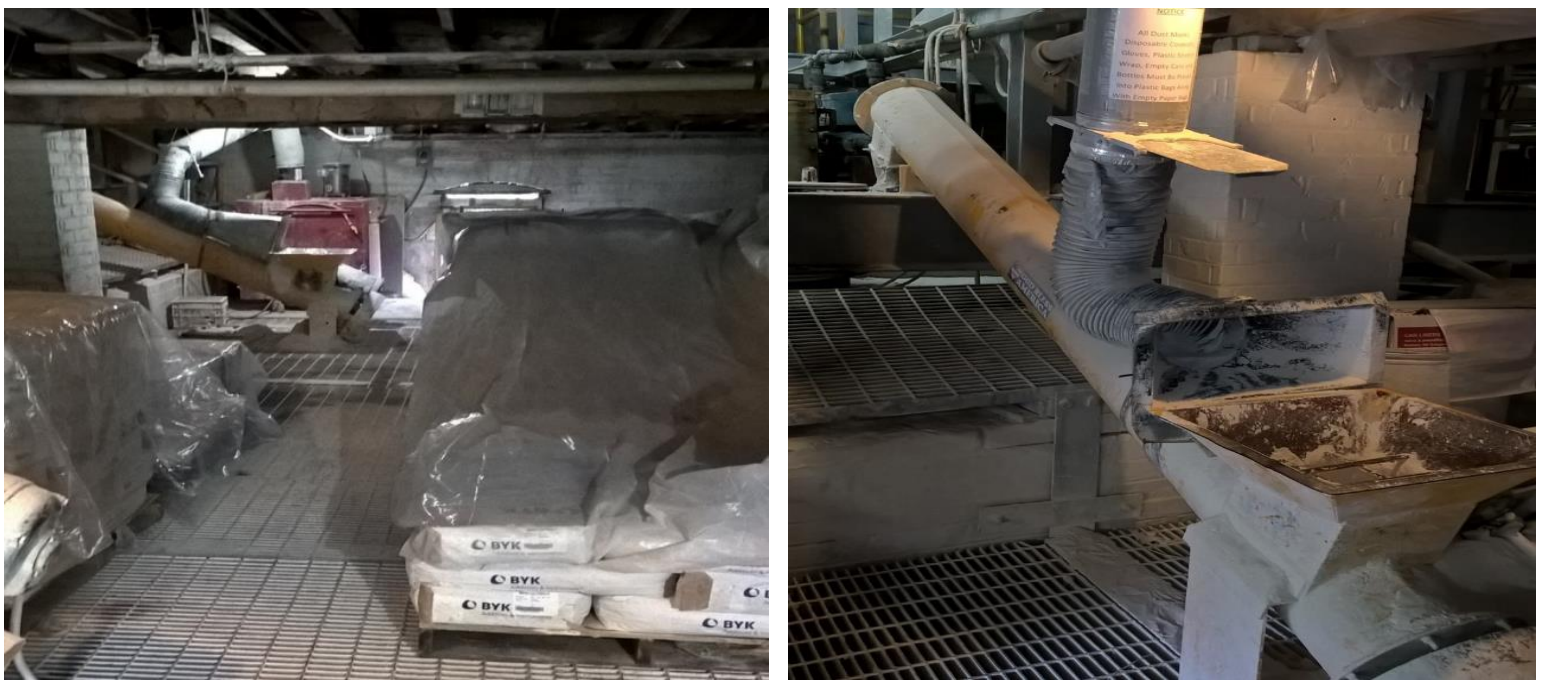
10. CASTING: Casters pour slip (liquid clay) into casings to make molds for the different wares. The molds dry in the casting room are rough edges as well as excess clay is removed.

Potential Hazard: Improper housekeeping (Sweeping) can create air borne dust from dry powdered material from waste.
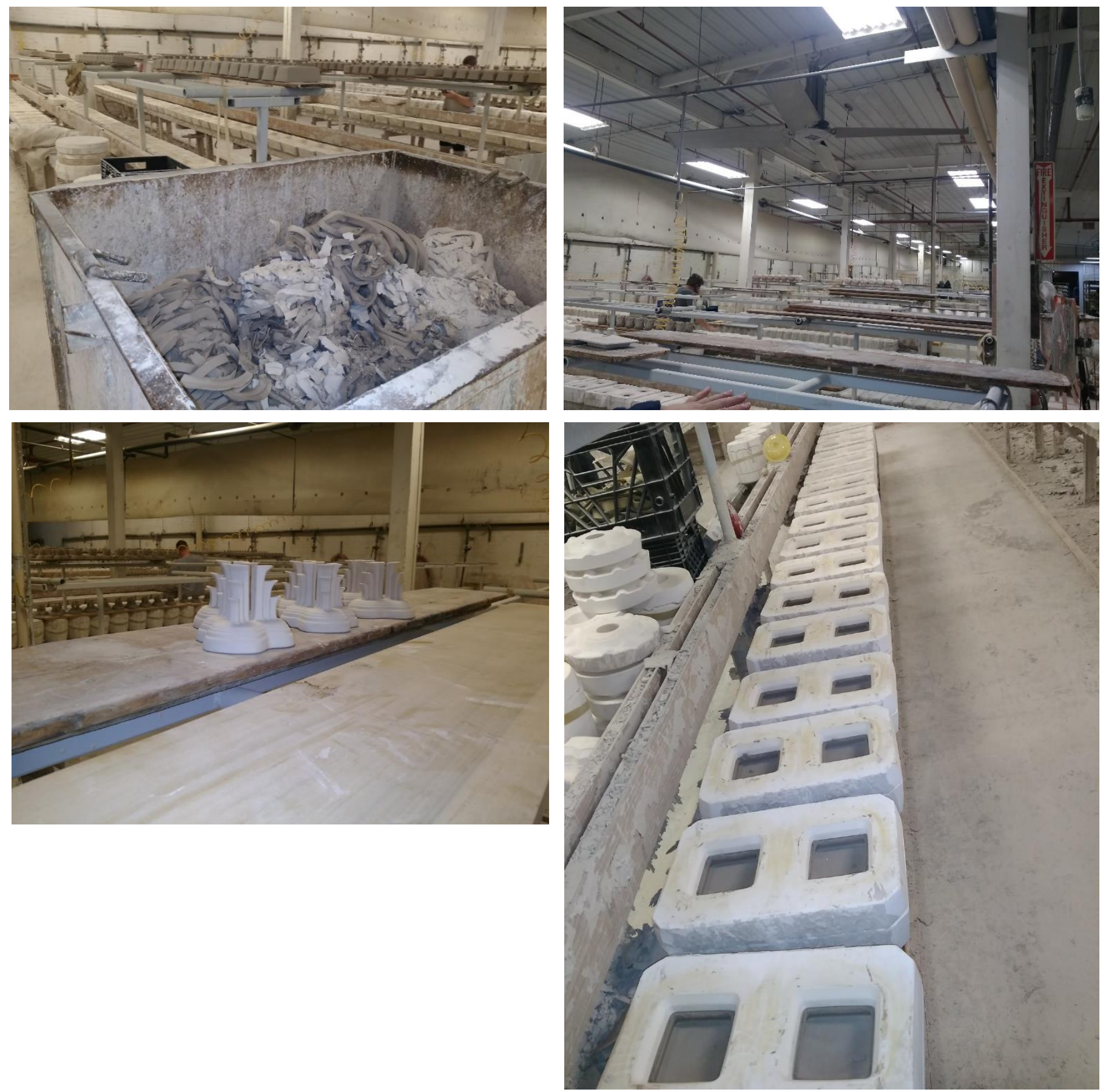


\section{APPENDIX VII}

RAW DATA: SPIKED SAMPLES STUDY

\begin{tabular}{|c|c|c|c|c|c|}
\hline & US Lab & & & IFA Lab & \\
\hline $\begin{array}{l}\text { Weight } \\
\text { (Filter, } \mu \mathrm{g} \text { ) }\end{array}$ & $\begin{array}{l}\text { IFA 213-582 (IR), } \\
\mu \mathrm{g}\end{array}$ & $\begin{array}{l}\text { NIOSH } 7602 \text { (IR), } \\
\mu \mathrm{g}\end{array}$ & $\begin{array}{l}\text { NIOSH } 7500 \\
\text { (XRD), } \mu \mathrm{g}\end{array}$ & $\begin{array}{l}\text { IFA 213-582 (IR), } \\
\mu \mathrm{g}\end{array}$ & $\begin{array}{l}\text { NIOSH } 7602 \text { (IR), } \\
\mu \mathrm{g}\end{array}$ \\
\hline \multirow[t]{3}{*}{$5 \mu \mathrm{g}$} & $<10.0$ & $<10.0$ & ND & $<5$ & $<5$ \\
\hline & $<10.0$ & $<10.0$ & ND & $<5$ & $<5$ \\
\hline & $<10.0$ & $<10.0$ & 6.71 & $<5$ & $<5$ \\
\hline \multirow[t]{5}{*}{$10 \mu g$} & $<10.0$ & $<10.0$ & 12.1 & 6.93 & 8.53 \\
\hline & $<10.0$ & $<10.0$ & 11.5 & 6.27 & 7.93 \\
\hline & $<10.0$ & $<10.0$ & 13 & 7.45 & 7.74 \\
\hline & $<10.0$ & $<10.0$ & 12 & 6.28 & 6.27 \\
\hline & $<10.0$ & $<10.0$ & 12.4 & $<5$ & $<5$ \\
\hline \multirow[t]{5}{*}{$20 \mu \mathrm{g}$} & 13 & 10.1 & 22.5 & 16.03 & 18.29 \\
\hline & 14.9 & 15.1 & 21.4 & 13.70 & 15.68 \\
\hline & 14.7 & $<10.0$ & 22.7 & 8.18 & 9.18 \\
\hline & 13 & 16.9 & 21.6 & 12.94 & 13.29 \\
\hline & 16.1 & 17.9 & 19.4 & 7.63 & 7.85 \\
\hline \multirow[t]{5}{*}{$50 \mu \mathrm{g}$} & 36.2 & 45.3 & 56.5 & 43.93 & 45.02 \\
\hline & 45.2 & 45.1 & 60.7 & 45.78 & 46.82 \\
\hline & 47.5 & 39.3 & 60.7 & 28.64 & 28.47 \\
\hline & 48.3 & 39.1 & 57.4 & 39.88 & 37.17 \\
\hline & 47.3 & 38.7 & 58.2 & 26.59 & 26.90 \\
\hline \multirow[t]{5}{*}{$100 \mu \mathrm{g}$} & 99.2 & 76.9 & 95.1 & 93.34 & 95.15 \\
\hline & 95.1 & 94.7 & 114 & 95.91 & 95.49 \\
\hline & 94 & 104 & 116 & 78.61 & 79.50 \\
\hline & 87.7 & 102 & 102 & 84.30 & 81.62 \\
\hline & 74.2 & 96.8 & 118 & 80.49 & 80.05 \\
\hline \multirow[t]{5}{*}{$250 \mu \mathrm{g}$} & 217 & 235 & 255 & 243.06 & 229.32 \\
\hline & 199 & 198 & 286 & 269.09 & 259.47 \\
\hline & 195 & 220 & 276 & 220.13 & 218.66 \\
\hline & 218 & 244 & 289 & 222.31 & 220.83 \\
\hline & 243 & 249 & 270 & 225.15 & 223.49 \\
\hline \multirow[t]{5}{*}{$500 \mu \mathrm{g}$} & 469 & 489 & 639 & 449.40 & 443.34 \\
\hline & 496 & 480 & 630 & 418.53 & 417.82 \\
\hline & 509 & 464 & 585 & 432.05 & 420.39 \\
\hline & 376 & 454 & 543 & 446.98 & 433.28 \\
\hline & 486 & 461 & 576 & 439.80 & 415.09 \\
\hline
\end{tabular}


RAW DATA: AEROSOL CHAMBER STUDY (ARD)

\begin{tabular}{|c|c|c|c|c|c|c|c|c|}
\hline Lab & $\begin{array}{l}\text { Quartz } \\
\text { Type }\end{array}$ & $\begin{array}{l}\text { Target } \\
\text { RD Conc. }\end{array}$ & RD_GK_XRD & RD_GK_IR & RD_FSP_IR & Q_GK_XRD & Q_GK_IR & Q_FSP_IR \\
\hline US (NIOSH) & ARD & 0.800 & 0.701 & 0.658 & 0.848 & 0.150 & 0.146 & 0.026 \\
\hline US (NIOSH) & ARD & 0.800 & 0.697 & 0.656 & 0.905 & 0.145 & 0.136 & 0.024 \\
\hline US (NIOSH) & ARD & 0.800 & 0.406 & 0.704 & 0.847 & 0.099 & 0.165 & 0.033 \\
\hline US (NIOSH) & ARD & 0.800 & 0.750 & 0.710 & 0.789 & 0.165 & 0.155 & 0.033 \\
\hline US (NIOSH) & ARD & 0.800 & 0.510 & 0.713 & 0.782 & 0.115 & 0.147 & 0.022 \\
\hline US (NIOSH) & ARD & 0.800 & 0.688 & 0.682 & 0.746 & 0.095 & 0.146 & 0.031 \\
\hline US (NIOSH) & ARD & 0.800 & 0.710 & 0.715 & 0.792 & 0.171 & 0.164 & 0.038 \\
\hline US (NIOSH) & ARD & 1.300 & 1.071 & 1.053 & 1.101 & 0.247 & 0.196 & 0.057 \\
\hline US (NIOSH) & ARD & 1.300 & 1.020 & 1.069 & 1.178 & 0.236 & 0.233 & 0.061 \\
\hline US (NIOSH) & ARD & 1.300 & 0.992 & 0.997 & 1.178 & 0.230 & 0.227 & 0.045 \\
\hline US (NIOSH) & ARD & 1.300 & 1.031 & 1.082 & 1.373 & 0.213 & 0.237 & 0.091 \\
\hline US (NIOSH) & ARD & 1.300 & 1.040 & 1.001 & 1.176 & 0.254 & 0.234 & 0.062 \\
\hline US (NIOSH) & ARD & 1.300 & 1.026 & 1.050 & 1.019 & 0.257 & 0.240 & 0.041 \\
\hline US (NIOSH) & ARD & 1.300 & 1.060 & 1.014 & 1.165 & 0.261 & 0.247 & 0.063 \\
\hline US (NIOSH) & ARD & 5.000 & 4.426 & 4.230 & 4.596 & 1.030 & 0.935 & 0.346 \\
\hline US (NIOSH) & ARD & 5.000 & 4.503 & 4.267 & 5.362 & 1.023 & 0.929 & 0.350 \\
\hline US (NIOSH) & ARD & 5.000 & 4.448 & 4.431 & 5.347 & 0.995 & 0.967 & 0.292 \\
\hline US (NIOSH) & ARD & 5.000 & 4.568 & 4.613 & 4.813 & 1.181 & 1.011 & 0.430 \\
\hline US (NIOSH) & ARD & 5.000 & 4.399 & 4.561 & 5.409 & 1.101 & 1.006 & 0.318 \\
\hline US (NIOSH) & ARD & 5.000 & 4.403 & 4.632 & 5.023 & 1.024 & 1.006 & 0.279 \\
\hline US (NIOSH) & ARD & 5.000 & 4.433 & 4.560 & 5.547 & 1.027 & 1.004 & 0.241 \\
\hline US (NIOSH) & ARD & 8.000 & 7.517 & 7.062 & 9.236 & 1.780 & 1.359 & 0.861 \\
\hline US (NIOSH) & ARD & 8.000 & 7.361 & 7.275 & 8.656 & 1.779 & 1.550 & 0.675 \\
\hline US (NIOSH) & ARD & 8.000 & 7.144 & 7.318 & 9.114 & 1.624 & 1.582 & 0.559 \\
\hline US (NIOSH) & ARD & 8.000 & 7.394 & 7.037 & 9.780 & 1.582 & 1.437 & 0.771 \\
\hline US (NIOSH) & ARD & 8.000 & 7.218 & 7.459 & 8.339 & 1.582 & 1.601 & 0.708 \\
\hline US (NIOSH) & ARD & 8.000 & 6.905 & 7.586 & 7.811 & 1.657 & 1.561 & 0.455 \\
\hline US (NIOSH) & ARD & 8.000 & 7.159 & 7.443 & 9.575 & 1.620 & 1.501 & 0.890 \\
\hline German (IFA) & ARD & 0.800 & 0.813 & 0.816 & 0.916 & 0.270 & 0.179 & 0.190 \\
\hline German (IFA) & ARD & 0.800 & 0.835 & 0.809 & 0.976 & 0.270 & 0.174 & 0.190 \\
\hline German (IFA) & ARD & 0.800 & 0.801 & 0.695 & 0.971 & 0.220 & 0.165 & 0.180 \\
\hline German (IFA) & ARD & 0.800 & 0.857 & 0.917 & 0.873 & 0.280 & 0.183 & 0.170 \\
\hline German (IFA) & ARD & 0.800 & 0.848 & 0.911 & 0.948 & 0.280 & 0.182 & 0.180 \\
\hline German (IFA) & ARD & 0.800 & 0.820 & 0.895 & 0.884 & 0.260 & 0.179 & 0.190 \\
\hline German (IFA) & ARD & 0.800 & 0.844 & 0.816 & 0.959 & 0.290 & 0.164 & 0.180 \\
\hline German (IFA) & ARD & 1.300 & 1.490 & 1.354 & 1.778 & 0.520 & 0.301 & 0.300 \\
\hline German (IFA) & ARD & 1.300 & 1.443 & 1.365 & 1.734 & 0.480 & 0.288 & 0.300 \\
\hline German (IFA) & ARD & 1.300 & 1.437 & 1.398 & 1.778 & 0.490 & 0.321 & 0.320 \\
\hline German (IFA) & ARD & 1.300 & 1.473 & 1.459 & 1.567 & 0.460 & 0.326 & 0.300 \\
\hline German (IFA) & ARD & 1.300 & 1.441 & 1.478 & 1.696 & 0.530 & 0.315 & 0.300 \\
\hline German (IFA) & ARD & 1.300 & 1.408 & 1.508 & 1.607 & 0.480 & 0.338 & 0.310 \\
\hline German (IFA) & ARD & 1.300 & 1.421 & 1.509 & 1.673 & 0.480 & 0.322 & 0.340 \\
\hline German (IFA) & ARD & 5.000 & 4.977 & 4.602 & 6.000 & 1.400 & 0.881 & 0.990 \\
\hline German (IFA) & ARD & 5.000 & 4.936 & 4.655 & 5.825 & 1.200 & 0.874 & 1.000 \\
\hline German (IFA) & ARD & 5.000 & 4.720 & 4.792 & 6.022 & 1.200 & 0.881 & 1.100 \\
\hline German (IFA) & ARD & 5.000 & 4.958 & 4.890 & 5.697 & 1.200 & 0.945 & 0.930 \\
\hline German (IFA) & ARD & 5.000 & 4.786 & 4.914 & 5.826 & 1.200 & 0.951 & 1.000 \\
\hline
\end{tabular}




\begin{tabular}{lllllllll}
\hline German (IFA) & ARD & 5.000 & 4.722 & 4.927 & 5.707 & 1.200 & 0.917 & 1.000 \\
\hline German (IFA) & ARD & 5.000 & 4.855 & 4.864 & 6.073 & 1.200 & 0.923 & 1.100 \\
\hline German (IFA) & ARD & 8.000 & 7.775 & 7.448 & 9.657 & 1.800 & 1.416 & 1.500 \\
\hline German (IFA) & ARD & 8.000 & 7.692 & 7.435 & 9.216 & 2.000 & 1.449 & 1.300 \\
\hline German (IFA) & ARD & 8.000 & 7.390 & 7.635 & 9.234 & 1.900 & 1.454 & 1.400 \\
\hline German (IFA) & ARD & 8.000 & 7.861 & 7.823 & 9.369 & 1.900 & 1.464 & 1.400 \\
\hline German (IFA) & ARD & 8.000 & 7.564 & 7.672 & 9.737 & 2.000 & 1.457 & 1.400 \\
\hline German (IFA) & ARD & 8.000 & 7.464 & 7.764 & 6.122 & 1.900 & 1.523 & 1.000 \\
\hline German (IFA) & ARD & 8.000 & 7.680 & 7.680 & 9.553 & 1.800 & 1.363 & 1.900 \\
\hline
\end{tabular}

RAW DATA: AEROSOL CHAMBER STUDY (ARD)

\begin{tabular}{|c|c|c|c|c|c|c|c|c|}
\hline Lab & $\begin{array}{l}\text { Quartz } \\
\text { Type }\end{array}$ & $\begin{array}{l}\text { Targe } \\
\text { t RD } \\
\text { Conc. }\end{array}$ & $\begin{array}{l}\text { RD_GK_XR } \\
\text { D }\end{array}$ & $\begin{array}{l}\text { RD_GK_I } \\
\text { R }\end{array}$ & $\begin{array}{l}\text { RD_FSP_I } \\
R\end{array}$ & $\begin{array}{l}\text { Q_GK_XR } \\
\text { D }\end{array}$ & $\begin{array}{l}\text { Q_GK_I } \\
R\end{array}$ & $\underset{R}{Q_{R} F S P_{-} I}$ \\
\hline US (NIOSH) & Min 10 & 0.800 & 0.765 & 0.784 & 0.903 & 0.552 & 0.788 & 0.208 \\
\hline US (NIOSH) & Min 10 & 0.800 & 0.772 & 0.788 & 0.631 & 0.594 & 0.863 & 0.082 \\
\hline US (NIOSH) & Min 10 & 0.800 & 0.753 & 0.830 & 0.841 & 0.516 & 0.834 & 0.071 \\
\hline US (NIOSH) & Min 10 & 0.800 & 0.783 & 0.800 & 0.904 & 0.554 & 0.856 & 0.080 \\
\hline US (NIOSH) & Min 10 & 0.800 & 0.804 & 0.795 & 0.964 & 0.634 & 0.855 & 0.120 \\
\hline US (NIOSH) & Min 10 & 0.800 & 0.771 & 0.793 & 0.816 & 0.590 & 0.516 & 0.095 \\
\hline US (NIOSH) & Min 10 & 0.800 & 0.761 & 0.788 & 0.866 & 0.555 & 0.824 & 0.138 \\
\hline US (NIOSH) & Min 10 & 1.820 & 1.739 & 1.683 & 1.880 & 1.469 & 1.778 & 0.452 \\
\hline US (NIOSH) & Min 10 & 1.820 & 1.731 & 1.715 & 1.396 & 1.472 & 1.933 & 0.163 \\
\hline US (NIOSH) & Min 10 & 1.820 & 1.705 & 1.784 & 1.862 & 1.352 & 1.796 & 0.297 \\
\hline US (NIOSH) & Min 10 & 1.820 & 1.732 & 1.762 & 1.872 & 1.466 & 1.774 & 0.238 \\
\hline US (NIOSH) & Min 10 & 1.820 & 1.708 & 1.715 & 2.180 & 1.311 & 1.766 & 0.374 \\
\hline US (NIOSH) & Min 10 & 1.820 & 1.690 & 1.699 & 2.045 & 1.352 & 1.822 & 0.406 \\
\hline US (NIOSH) & Min 10 & 1.820 & 1.727 & 1.726 & 1.924 & 1.505 & 1.769 & 0.340 \\
\hline US (NIOSH) & Min 10 & 5.900 & 6.004 & 5.791 & 6.840 & 5.148 & 5.574 & 1.358 \\
\hline US (NIOSH) & Min 10 & 5.900 & 5.993 & 5.755 & 5.781 & 5.143 & 3.076 & 1.365 \\
\hline US (NIOSH) & Min 10 & 5.900 & 5.784 & 5.714 & 7.080 & 4.364 & 5.691 & 2.035 \\
\hline US (NIOSH) & Min 10 & 5.900 & 6.060 & 6.900 & 6.584 & 4.749 & 5.988 & 1.526 \\
\hline US (NIOSH) & Min 10 & 5.900 & 6.019 & 4.934 & 7.294 & 5.162 & 6.028 & 2.231 \\
\hline US (NIOSH) & Min 10 & 5.900 & 5.959 & 5.976 & 7.005 & 4.774 & 6.225 & 2.461 \\
\hline US (NIOSH) & Min 10 & 5.900 & 6.100 & 6.054 & 7.024 & 5.153 & 6.328 & 1.532 \\
\hline US (NIOSH) & Min 10 & 8.700 & 8.621 & 8.212 & 10.455 & 7.541 & 8.610 & 3.734 \\
\hline US (NIOSH) & Min 10 & 8.700 & 8.514 & 8.316 & 7.500 & 7.954 & 8.301 & 1.898 \\
\hline US (NIOSH) & Min 10 & 8.700 & 8.334 & 8.303 & 10.105 & 7.591 & 8.295 & 2.657 \\
\hline US (NIOSH) & Min 10 & 8.700 & 8.712 & 8.506 & 9.766 & 6.782 & 9.587 & 1.335 \\
\hline US (NIOSH) & Min 10 & 8.700 & 8.447 & 8.517 & 10.756 & 7.151 & 9.003 & 2.554 \\
\hline
\end{tabular}




\begin{tabular}{|c|c|c|c|c|c|c|c|c|}
\hline US (NIOSH) & Min 10 & 8.700 & 8.308 & 8.422 & 10.711 & 6.790 & 8.418 & 2.211 \\
\hline US (NIOSH) & Min 10 & 8.700 & 8.467 & 8.684 & 9.924 & 7.546 & 9.145 & 2.756 \\
\hline German (IFA) & Min 10 & 0.800 & 0.781 & 0.799 & 0.925 & 0.830 & 0.570 & 0.380 \\
\hline German (IFA) & Min 10 & 0.800 & 0.755 & 0.799 & 0.581 & 0.840 & 0.629 & 0.200 \\
\hline German (IFA) & Min 10 & 0.800 & 0.740 & 0.777 & 0.883 & 0.820 & 0.617 & 0.370 \\
\hline German (IFA) & Min 10 & 0.800 & 0.760 & 0.762 & 0.809 & 0.840 & 0.580 & 0.340 \\
\hline German (IFA) & Min 10 & 0.800 & 0.722 & 0.804 & 0.826 & 0.730 & 0.628 & 0.440 \\
\hline German (IFA) & Min 10 & 0.800 & 0.731 & 0.752 & 1.002 & 0.870 & 0.632 & 0.610 \\
\hline German (IFA) & Min 10 & 0.800 & 0.779 & 0.789 & 0.910 & 0.770 & 0.611 & 0.460 \\
\hline German (IFA) & Min 10 & 1.820 & 1.842 & 1.819 & 2.045 & 2.000 & 1.729 & 1.800 \\
\hline German (IFA) & Min 10 & 1.820 & 1.865 & 1.849 & 1.675 & 1.800 & 1.697 & 1.400 \\
\hline German (IFA) & Min 10 & 1.820 & 1.854 & 1.820 & 2.004 & 2.000 & 1.665 & 1.600 \\
\hline German (IFA) & Min 10 & 1.820 & 1.872 & 1.850 & 1.966 & 2.000 & 1.697 & 1.600 \\
\hline German (IFA) & Min 10 & 1.820 & 1.817 & 1.799 & 2.190 & 2.000 & 1.660 & 2.000 \\
\hline German (IFA) & Min 10 & 1.820 & 1.135 & 1.854 & 2.103 & 1.200 & 1.639 & 1.600 \\
\hline German (IFA) & Min 10 & 1.820 & 1.828 & 1.879 & 2.026 & 2.000 & 1.650 & 1.800 \\
\hline German (IFA) & Min 10 & 5.900 & 5.649 & 5.312 & 6.553 & 5.500 & 4.847 & 6.500 \\
\hline German (IFA) & Min 10 & 5.900 & 5.622 & 5.367 & 4.934 & 6.000 & 4.643 & 4.500 \\
\hline German (IFA) & Min 10 & 5.900 & 5.404 & 5.376 & 6.334 & 5.700 & 4.656 & 6.200 \\
\hline German (IFA) & Min 10 & 5.900 & 5.673 & 5.499 & 6.275 & 6.000 & 4.948 & 5.800 \\
\hline German (IFA) & Min 10 & 5.900 & 5.422 & 2.565 & 6.665 & 5.700 & 2.550 & 6.300 \\
\hline German (IFA) & Min 10 & 5.900 & 5.350 & 5.486 & 6.497 & 5.700 & 4.965 & 6.200 \\
\hline German (IFA) & Min 10 & 5.900 & 4.779 & 4.619 & 6.131 & 4.800 & 4.433 & 5.700 \\
\hline German (IFA) & Min 10 & 8.700 & 8.051 & 7.917 & 9.633 & 7.900 & 6.159 & 7.300 \\
\hline German (IFA) & Min 10 & 8.700 & 7.942 & 8.065 & 7.869 & 8.300 & 6.098 & 6.200 \\
\hline German (IFA) & Min 10 & 8.700 & 7.711 & 8.007 & 9.629 & 8.100 & 5.994 & 8.900 \\
\hline German (IFA) & Min 10 & 8.700 & 8.126 & 8.164 & 9.618 & 8.400 & 7.321 & 8.800 \\
\hline German (IFA) & Min 10 & 8.700 & 7.942 & 8.085 & 10.552 & 8.300 & 6.193 & 9.000 \\
\hline German (IFA) & Min 10 & 8.700 & 7.831 & 8.071 & 9.790 & 8.500 & 6.098 & 6.900 \\
\hline German (IFA) & Min 10 & 8.700 & 8.227 & & 9.421 & 8.500 & & 8.600 \\
\hline
\end{tabular}


RAW DATA: FIELD STUDY

\begin{tabular}{|c|c|c|c|c|}
\hline ID & Task Personal & Sampler & RD & Quartz (LOD) \\
\hline 1 & \multirow{20}{*}{ Casting } & GK2.69_FS & 0.053 & 0.00657 \\
\hline 2 & & FSP_FS & 0.102 & 0.00848 \\
\hline 3 & & FSP_1st & 0.144 & 0.01100 \\
\hline 4 & & FSP_2nd & 0.060 & 0.00600 \\
\hline 5 & & GK2.69_FS & 0.053 & 0.00745 \\
\hline 6 & & FSP_FS & 0.245 & 0.02376 \\
\hline 7 & & FSP_1st & 0.279 & 0.02700 \\
\hline 8 & & FSP_2nd & 0.205 & 0.02000 \\
\hline 9 & & GK2.69_FS & 0.086 & 0.00785 \\
\hline 10 & & FSP_FS & 0.250 & 0.02844 \\
\hline 11 & & FSP_1st & 0.292 & 0.02800 \\
\hline 12 & & FSP_2nd & 0.197 & 0.02900 \\
\hline 13 & & GK2.69_FS & 0.092 & 0.00820 \\
\hline 14 & & FSP_FS & 0.275 & 0.03049 \\
\hline 15 & & FSP_1st & 0.334 & 0.04200 \\
\hline 16 & & FSP_2nd & 0.195 & 0.01500 \\
\hline 17 & & GK2.69_FS & 0.469 & 0.01170 \\
\hline 18 & & FSP_FS & 0.162 & 0.01276 \\
\hline 19 & & FSP_1st & 0.174 & 0.01600 \\
\hline 20 & & FSP_2nd & 0.145 & 0.00800 \\
\hline 21 & \multirow{12}{*}{ Glost Processing } & GK2.69_FS & 0.040 & 0.00667 \\
\hline 22 & & FSP_FS & 0.072 & 0.00650 \\
\hline 23 & & FSP_1st & 0.072 & 0.00600 \\
\hline 24 & & FSP_2nd & 0.073 & 0.00700 \\
\hline 25 & & GK2.69_FS & 0.120 & 0.00668 \\
\hline 26 & & FSP_FS & 0.025 & 0.00587 \\
\hline 27 & & FSP_1st & 0.032 & 0.00700 \\
\hline 28 & & FSP_2nd & 0.019 & 0.00500 \\
\hline 29 & & GK2.69_FS & 1.019 & 0.03580 \\
\hline 30 & & FSP_FS & 0.229 & 0.02230 \\
\hline 31 & & FSP_1st & 0.330 & 0.03200 \\
\hline 32 & & FSP_2nd & 0.153 & 0.01500 \\
\hline 33 & \multirow{2}{*}{ Glaze Making } & GK2.69_FS & 0.179 & 0.01180 \\
\hline 34 & & FSP_FS & 0.224 & 0.02025 \\
\hline
\end{tabular}




\begin{tabular}{|c|c|c|c|c|}
\hline 35 & & FSP_1st & 0.295 & 0.02800 \\
\hline 36 & & FSP_2nd & 0.1222 & 0.00900 \\
\hline 37 & & GK2.69_FS & 0.564 & 0.0478 \\
\hline 38 & & FSP_FS & 0.656 & 0.0810 \\
\hline 39 & & FSP_1st & 1.121 & 0.08100 \\
\hline 40 & & FSP_2nd & 0.136 & 0.00700 \\
\hline 41 & & GK2.69_FS & 0.853 & 0.184 \\
\hline 42 & & FSP_FS & 1.445 & 0.271 \\
\hline 43 & & FSP_1st & 1.622 & 0.33000 \\
\hline 44 & & FSP_2nd & 1.175 & 0.18000 \\
\hline 45 & & GK2.69_FS & 0.868 & 0.166 \\
\hline 46 & & FSP_FS & 1.077 & 0.208 \\
\hline 47 & & FSP_1st & 0.704 & 0.12000 \\
\hline 48 & & FSP_2nd & 1.637 & 0.34000 \\
\hline 49 & \multirow{4}{*}{ Mold Shop } & GK2.69_FS & 0.106 & 0.00662 \\
\hline 50 & & FSP_FS & 0.187 & 0.00647 \\
\hline 51 & & FSP_1st & 0.253 & 0.00600 \\
\hline 52 & & FSP_2nd & 0.112 & 0.00700 \\
\hline 53 & \multirow{12}{*}{ Plant \#8 (SKK \& WD) } & GK2.69_FS & 0.164 & 0.00655 \\
\hline 54 & & FSP_FS & 0.196 & 0.00749 \\
\hline 55 & & FSP_1st & 0.249 & 0.00800 \\
\hline 56 & & FSP_2nd & 0.144 & 0.00700 \\
\hline 57 & & GK2.69_FS & 0.066 & 0.00657 \\
\hline 58 & & FSP_FS & 0.171 & 0.01285 \\
\hline 59 & & FSP_1st & 0.261 & 0.02000 \\
\hline 60 & & FSP_2nd & 0.085 & 0.00600 \\
\hline 61 & & GK2.69_FS & 0.073 & 0.00660 \\
\hline 62 & & FSP_FS & 0.114 & 0.00647 \\
\hline 63 & & FSP_1st & 0.110 & 0.00600 \\
\hline 64 & & FSP_2nd & 0.119 & 0.00700 \\
\hline 65 & \multirow{8}{*}{ Pressure Caster } & GK2.69_FS & 0.072 & 0.00657 \\
\hline 66 & & FSP_FS & 0.074 & 0.00600 \\
\hline 67 & & FSP_1st & 0.066 & 0.00600 \\
\hline 68 & & FSP_2nd & 0.083 & 0.00600 \\
\hline 69 & & GK2.69_FS & 0.118 & 0.00925 \\
\hline 70 & & FSP_FS & 0.143 & 0.00685 \\
\hline 71 & & FSP_1st & 0.126 & 0.00600 \\
\hline 72 & & FSP_2nd & 0.165 & 0.00800 \\
\hline
\end{tabular}




\begin{tabular}{|c|c|c|c|c|}
\hline 73 & & GK2.69_FS & 0.085 & 0.01250 \\
\hline 74 & & FSP_FS & 0.248 & 0.02599 \\
\hline 75 & & FSP_1st & 0.260 & 0.02700 \\
\hline 76 & & FSP_2nd & 0.235 & 0.02500 \\
\hline 77 & \multirow{8}{*}{ RAM Finishing } & GK2.69_FS & 0.154 & 0.01590 \\
\hline 78 & & FSP_FS & 0.260 & 0.01758 \\
\hline 79 & & FSP_1st & 0.265 & 0.01800 \\
\hline 80 & & FSP_2nd & 0.252 & 0.01700 \\
\hline 81 & & GK2.69_FS & 0.194 & 0.01640 \\
\hline 82 & & FSP_FS & 0.269 & 0.01911 \\
\hline 83 & & FSP_1st & 0.304 & 0.02000 \\
\hline 84 & & FSP_2nd & 0.225 & 0.01800 \\
\hline 85 & \multirow{8}{*}{ Silo } & GK2.69_FS & 0.073 & 0.01180 \\
\hline 86 & & FSP_FS & 0.116 & 0.00700 \\
\hline 87 & & FSP_1st & 0.142 & 0.00700 \\
\hline 88 & & FSP_2nd & 0.089 & 0.00700 \\
\hline 89 & & GK2.69_FS & 0.158 & 0.01990 \\
\hline 90 & & FSP_FS & 0.211 & 0.01051 \\
\hline 91 & & FSP_1st & 0.293 & 0.01100 \\
\hline 92 & & FSP_2nd & 0.126 & 0.01000 \\
\hline 93 & \multirow{12}{*}{ Stripping } & GK2.69_FS & 0.054 & 0.00671 \\
\hline 94 & & FSP_FS & 0.086 & 0.00728 \\
\hline 95 & & FSP_1st & 0.102 & 0.00600 \\
\hline 96 & & FSP_2nd & 0.052 & 0.01000 \\
\hline 97 & & GK2.69_FS & 0.098 & 0.00807 \\
\hline 98 & & FSP_FS & 0.148 & 0.01234 \\
\hline 99 & & FSP_1st & 0.154 & 0.01200 \\
\hline 100 & & FSP_2nd & 0.135 & 0.01300 \\
\hline 101 & & GK2.69_FS & 0.142 & 0.00818 \\
\hline 102 & & FSP_FS & 0.224 & 0.00966 \\
\hline 103 & & FSP_1st & 0.233 & 0.01000 \\
\hline 104 & & FSP_2nd & 0.207 & 0.00900 \\
\hline 105 & \multirow{6}{*}{ Ware dressing } & GK2.69_FS & 0.047 & 0.00675 \\
\hline 106 & & FSP_FS & 0.183 & 0.03019 \\
\hline 107 & & FSP_1st & 0.201 & 0.04900 \\
\hline 108 & & FSP_2nd & 0.165 & 0.01100 \\
\hline 109 & & GK2.69_FS & 0.095 & 0.00677 \\
\hline 110 & & FSP_FS & 0.173 & 0.02444 \\
\hline
\end{tabular}




\begin{tabular}{|c|c|c|c|}
\hline 111 & FSP_1st & 0.200 & 0.01100 \\
\hline 112 & FSP_2nd & 0.146 & 0.03800 \\
\hline 113 & GK2.69_FS & 0.090 & 0.01570 \\
\hline 114 & FSP_FS & 0.332 & 0.02476 \\
\hline 115 & FSP_1st & 0.327 & 0.02300 \\
\hline 116 & FSP_2nd & 0.338 & 0.02700 \\
\hline 117 & GK2.69_FS & 0.170 & 0.01600 \\
\hline 118 & FSP_FS & 0.390 & 0.03189 \\
\hline 119 & FSP_1st & 0.379 & 0.03100 \\
\hline 120 & FSP_2nd & 0.403 & 0.03300 \\
\hline 121 & GK2.69_FS & 0.167 & 0.01890 \\
\hline 122 & FSP_FS & 0.392 & 0.02950 \\
\hline 123 & FSP_1st & 0.411 & 0.03100 \\
\hline 124 & FSP_2nd & 0.373 & 0.02800 \\
\hline
\end{tabular}




\begin{tabular}{|c|c|c|c|c|c|c|}
\hline Task_Area & Field & Sampler & $\begin{array}{l}\text { Sample } \\
\text { ID }\end{array}$ & Method & RD & Quartz (LOD) \\
\hline \multirow[t]{12}{*}{ Casting } & $\mathrm{NF}$ & GK2.69 & $\mathrm{C} 01$ & NIOSH_XRD & 0.0526 & 0.0043 \\
\hline & $\mathrm{NF}$ & GK2.69 & $\mathrm{CO} 2$ & NIOSH_XRD & 0.0460 & 0.0066 \\
\hline & NF & GK2.69 & $\mathrm{CO3}$ & NIOSH_IR & 0.0327 & 0.0065 \\
\hline & NF & GK2.69 & CO4 & NIOSH_IR & 0.0729 & 0.0082 \\
\hline & $\mathrm{NF}$ & FSP & $\mathrm{CO5}$ & IFA_IR & 0.1145 & 0.0100 \\
\hline & $\mathrm{NF}$ & FSP & C06 & IFA_IR & 0.1130 & 0.0100 \\
\hline & $\mathrm{FF}$ & GK2.69 & $\mathrm{CO1}$ & NIOSH_XRD & 0.0197 & 0.0056 \\
\hline & $\mathrm{FF}$ & GK2.69 & $\mathrm{CO} 2$ & NIOSH_XRD & 0.0131 & 0.0048 \\
\hline & $\mathrm{FF}$ & GK2.69 & $\mathrm{CO3}$ & NIOSH_IR & 0.0328 & 0.0066 \\
\hline & $\mathrm{FF}$ & GK2.69 & $\mathrm{CO4}$ & NIOSH_IR & 0.0920 & 0.0066 \\
\hline & $\mathrm{FF}$ & FSP & $\mathrm{CO5}$ & IFA_IR & 0.1175 & 0.0120 \\
\hline & $\mathrm{FF}$ & FSP & $\mathrm{C06}$ & IFA_IR & 0.1186 & 0.0110 \\
\hline \multirow[t]{11}{*}{ Glaze/Sliphouse } & NF & GK2.69 & GSO1 & NIOSH_XRD & 0.1398 & 0.0216 \\
\hline & NF & GK2.69 & GSO2 & NIOSH_XRD & 0.1598 & 0.0179 \\
\hline & $\mathrm{NF}$ & GK2.69 & GSO3 & NIOSH_IR & 0.1917 & 0.0310 \\
\hline & NF & GK2.69 & GSO4 & NIOSH_IR & 0.1525 & 0.0215 \\
\hline & NF & FSP & GS05 & IFA_IR & 0.1724 & 0.0290 \\
\hline & $\mathrm{NF}$ & FSP & GS06 & IFA_IR & 0.1902 & 0.0360 \\
\hline & $\mathrm{FF}$ & GK2.69 & GSO1 & NIOSH_XRD & 0.0325 & 0.0104 \\
\hline & $\mathrm{FF}$ & GK2.69 & GSO2 & NIOSH_IR & 0.0913 & 0.0087 \\
\hline & $\mathrm{FF}$ & GK2.69 & GSO3 & NIOSH_IR & 0.0904 & 0.0069 \\
\hline & $\mathrm{FF}$ & FSP & GSO4 & IFA_IR & 0.0998 & 0.0120 \\
\hline & $\mathrm{FF}$ & FSP & GS05 & IFA_IR & 0.1356 & 0.0100 \\
\hline \multirow[t]{8}{*}{ Glost Processing } & $\mathrm{NF}$ & GK2.69 & GP01 & NIOSH_XRD & 0.0330 & 0.0050 \\
\hline & $\mathrm{NF}$ & GK2.69 & GP02 & NIOSH_IR & 0.0000 & 0.0065 \\
\hline & NF & FSP & GP03 & IFA_IR & 0.0281 & 0.01 \\
\hline & NF & FSP & GP04 & IFA_IR & 0.0111 & 0.009 \\
\hline & $\mathrm{FF}$ & GK2.69 & GP01 & NIOSH_XRD & 0.0449 & 0.0050 \\
\hline & $\mathrm{FF}$ & GK2.69 & GP02 & NIOSH_IR & 0.0128 & 0.0064 \\
\hline & $\mathrm{FF}$ & GK2.69 & GP03 & NIOSH_IR & 0.0257 & 0.0064 \\
\hline & $\mathrm{FF}$ & FSP & GP04 & IFA_IR & 0.0083 & 0.0030 \\
\hline \multirow[t]{12}{*}{ Mold Shop/RAM } & NF & GK2.69 & MS01 & NIOSH_XRD & 0.0391 & 0.0050 \\
\hline & $\mathrm{NF}$ & GK2.69 & MSO2 & NIOSH_XRD & 0.0259 & 0.0050 \\
\hline & $\mathrm{NF}$ & GK2.69 & MSO3 & NIOSH_IR & 0.0584 & 0.0065 \\
\hline & NF & GK2.69 & MSO4 & NIOSH_IR & 0.0452 & 0.0065 \\
\hline & NF & FSP & MS05 & IFA_IR & 0.0743 & 0.0030 \\
\hline & NF & FSP & MS06 & IFA_IR & 0.0471 & 0.0030 \\
\hline & $\mathrm{FF}$ & GK2.69 & MS01 & NIOSH_XRD & 0.0066 & 0.0050 \\
\hline & $\mathrm{FF}$ & GK2.69 & MSO2 & NIOSH_XRD & 0.0133 & 0.0050 \\
\hline & $\mathrm{FF}$ & GK2.69 & MSO3 & NIOSH_IR & 0.0198 & 0.0066 \\
\hline & $\mathrm{FF}$ & GK2.69 & MSO4 & NIOSH_IR & 0.0398 & 0.0066 \\
\hline & $\mathrm{FF}$ & FSP & MSO5 & IFA_IR & 0.0610 & 0.0030 \\
\hline & $\mathrm{FF}$ & FSP & MS06 & IFA_IR & 0.0529 & 0.0030 \\
\hline \multirow[t]{7}{*}{ Pressure Caster } & NF & GK2.69 & PC01 & NIOSH_XRD & 0.0328 & 0.0050 \\
\hline & NF & GK2.69 & $\mathrm{PCO2}$ & NIOSH_XRD & 0.0589 & 0.0050 \\
\hline & $\mathrm{NF}$ & GK2.69 & $\mathrm{PCO3}$ & NIOSH_IR & 0.0262 & 0.0066 \\
\hline & NF & GK2.69 & PCO4 & NIOSH_IR & 0.0393 & 0.0066 \\
\hline & NF & FSP & PC05 & IFA_IR & 0.0668 & 0.0030 \\
\hline & $\mathrm{NF}$ & FSP & PC06 & IFA_IR & 0.0528 & 0.0030 \\
\hline & $\mathrm{FF}$ & GK2.69 & PC01 & NIOSH_XRD & 0.1812 & 0.0239 \\
\hline
\end{tabular}




\begin{tabular}{|c|c|c|c|c|c|c|}
\hline & $\mathrm{FF}$ & GK2.69 & PCO2 & NIOSH_XRD & 0.2019 & 0.0261 \\
\hline & $\mathrm{FF}$ & GK2.69 & PCO3 & NIOSH IR & 0.1957 & 0.0239 \\
\hline & FF & GK2.69 & PCO4 & NIOSH_IR & 0.1829 & 0.0200 \\
\hline & FF & FSP & PC05 & IFA_IR & 0.2484 & 0.0310 \\
\hline & $\mathrm{FF}$ & FSP & PC06 & IFA_IR & 0.2845 & 0.0320 \\
\hline \multirow[t]{12}{*}{ Silo } & NF & GK2.69 & S01 & NIOSH_XRD & 0.3384 & 0.0345 \\
\hline & $\mathrm{NF}$ & GK2.69 & SO2 & NIOSH_XRD & 0.2710 & 0.0317 \\
\hline & NF & GK2.69 & S03 & NIOSH IR & 0.3063 & 0.0500 \\
\hline & NF & GK2.69 & SO4 & NIOSH_IR & 0.3179 & 0.0513 \\
\hline & NF & FSP & S05 & IFA_IR & 0.4562 & 0.0500 \\
\hline & NF & FSP & S06 & IFA IR & 0.3615 & 0.0480 \\
\hline & FF & GK2.69 & S01 & NIOSH_XRD & 0.1653 & 0.0172 \\
\hline & FF & GK2.69 & SO2 & NIOSH_XRD & 0.1722 & 0.0179 \\
\hline & FF & GK2.69 & $\mathrm{SO3}$ & NIOSH_IR & 0.0796 & 0.0229 \\
\hline & $\mathrm{FF}$ & GK2.69 & SO4 & NIOSH_IR & 0.1514 & 0.0240 \\
\hline & $\mathrm{FF}$ & FSP & S05 & IFA_IR & 0.2390 & 0.0240 \\
\hline & $\mathrm{FF}$ & FSP & S06 & IFA IR & 0.2193 & 0.0240 \\
\hline \multirow[t]{12}{*}{ SKK (\#8) } & NF & GK2.69 & SKK01 & NIOSH_XRD & 0.0703 & 0.0083 \\
\hline & $\mathrm{NF}$ & GK2.69 & SKKO2 & NIOSH_XRD & 0.1282 & 0.0058 \\
\hline & $\mathrm{NF}$ & GK2.69 & SKKO3 & NIOSH_IR & 0.1346 & 0.0101 \\
\hline & NF & GK2.69 & SKK04 & NIOSH_IR & 0.0448 & 0.0080 \\
\hline & NF & FSP & SKK05 & IFA_IR & 0.1460 & 0.0090 \\
\hline & NF & FSP & SKK06 & IFA_IR & 0.1698 & 0.0100 \\
\hline & $\mathrm{FF}$ & GK2.69 & SKK01 & NIOSH_XRD & 0.0527 & 0.0050 \\
\hline & $\mathrm{FF}$ & GK2.69 & SKKO2 & NIOSH_XRD & 0.0391 & 0.0050 \\
\hline & $\mathrm{FF}$ & GK2.69 & SKKO3 & NIOSH_IR & 0.0728 & 0.0066 \\
\hline & FF & GK2.69 & SKKO4 & NIOSH_IR & 0.0528 & 0.0066 \\
\hline & $\mathrm{FF}$ & FSP & SKK05 & IFA_IR & 0.0634 & 0.0030 \\
\hline & $\mathrm{FF}$ & FSP & SKK06 & IFA_IR & 0.0719 & 0.0040 \\
\hline \multirow[t]{11}{*}{ Stripper/Flat Auto } & NF & GK2.69 & SF01 & NIOSH_XRD & 0.1306 & 0.0048 \\
\hline & NF & GK2.69 & SF02 & NIOSH_XRD & 0.1101 & 0.0057 \\
\hline & NF & GK2.69 & SF03 & NIOSH_IIR & 0.1041 & 0.0065 \\
\hline & NF & GK2.69 & SF04 & NIOSH_IR & 0.0970 & 0.0065 \\
\hline & NF & FSP & SF05 & IFA_IR & 0.1108 & 0.0080 \\
\hline & $\mathrm{NF}$ & FSP & SF06 & IFA_IR & 0.0925 & 0.0060 \\
\hline & $\mathrm{FF}$ & GK2.69 & SF01 & NIOSH_XRD & 0.0602 & 0.0050 \\
\hline & FF & GK2.69 & SF02 & NIOSH_IR & 0.0400 & 0.0067 \\
\hline & $\mathrm{FF}$ & GK2.69 & SF03 & NIOSH_IR & 0.0599 & 0.0067 \\
\hline & FF & FSP & SF04 & IFA_IR & 0.0534 & 0.0030 \\
\hline & $\mathrm{FF}$ & FSP & SF05 & IFA_IR & 0.0701 & 0.0060 \\
\hline \multirow[t]{11}{*}{ Ware dresser } & NF & GK2.69 & W01 & NIOSH_XRD & 0.1511 & 0.0171 \\
\hline & NF & GK2.69 & W02 & NIOSH_XRD & 0.1382 & 0.0184 \\
\hline & $\mathrm{NF}$ & GK2.69 & W03 & NIOSH_IR & 0.1114 & 0.0162 \\
\hline & NF & GK2.69 & W04 & NIOSH_IR & 0.1124 & 0.0170 \\
\hline & NF & FSP & W05 & IFA_IR & 0.3294 & 0.0250 \\
\hline & NF & FSP & W06 & IFA_IR & 0.2802 & 0.0230 \\
\hline & $\mathrm{FF}$ & GK2.69 & W01 & NIOSH_XRD & 0.1908 & 0.0309 \\
\hline & $\mathrm{FF}$ & GK2.69 & W02 & NIOSH__IR & 0.0594 & 0.0233 \\
\hline & FF & GK2.70 & W03 & NIOSH_IR & 0.1491 & 0.0186 \\
\hline & FF & FSP & W04 & IFA_IR & 0.3715 & 0.0370 \\
\hline & FF & FSP & W05 & IFA_IR & 0.3589 & 0.0360 \\
\hline
\end{tabular}


